\title{
Constraining Natural and Anthropogenic Disturbances in the Delivery of Coastal Ecosystem Services
}

\author{
by \\ Sheron You-Xian Luk \\ B.A., Barnard College of Columbia University (2015) \\ Submitted to the Department of Earth, Atmospheric, and Planetary Sciences \\ in partial fulfillment of the requirements for the degree of \\ Doctor of Philosophy \\ at the

\begin{abstract}
MASSACHUSETTS INSTITUTE OF TECHNOLOGY
\end{abstract} \\ and the \\ WOODS HOLE OCEANOGRAPHIC INSTITUTION
}

February 2022

(C2022 Sheron Y. Luk. All rights reserved.

The author hereby grants to MIT and WHOI permission to reproduce and to distribute publicly paper and electronic copies of this thesis document in whole or in part in any medium now known or hereafter created.

Author.

Joint Program in Oceanography/Applied Ocean Science \& Engineering Massachusetts Institute of Technology \& Woods Hole Oceanographic Institution

Certified by

January 7, 2022

Dr. Amanda C. Spivak and Dr. Matthew A. Charette University of Georgia and Woods Hole Oceanographic Institution

Thesis Supervisors

Accepted by

Dr. Colleen Hansel

Senior Scientist in Marine Chemistry \& Geochemistry

Woods Hole Oceanographic Institution

Chair, Joint Committee for Chemical Oceanography 


\title{
Constraining Natural and Anthropogenic Disturbances in the Delivery of Coastal Ecosystem Services
}

\author{
by \\ Sheron You-Xian Luk \\ Submitted to the Department of Earth, Atmospheric, and Planetary Sciences on January 7, 2022, \\ in Partial Fulfilment of the Requirements for the Degree of Doctor of Philosophy in Chemical \\ Oceanography.
}

\begin{abstract}
Coastal ecosystems provide key services that benefit human wellbeing yet are undergoing rapid degradation due to natural and anthropogenic pressures. This thesis seeks to understand how disturbances impact salt marsh and estuarine ecosystem functioning in order to refine their role in coastal ecosystem service delivery and predict future resilience. Salt marsh survival relative to sealevel rise increasingly relies on the accumulation and preservation of soil organic carbon (SOC). Firstly, I characterized SOC development and turnover in a New England salt marsh and found that salt marsh soils typically store marsh grass-derived compounds that are reworked over centuries-to-millennia. Next, I assessed how two common marsh disturbances - natural ponding and anthropogenic mosquito ditching - affect salt marsh carbon cycling and storage. Salt marsh ponds deepen through soil erosion and decomposition of long-buried marsh peat. Further, the SOC lost during pond development is not fully recouped once drained ponds are revegetated and virtually indistinguishable from the surrounding marsh. Mosquito ditches, which were installed in $\sim 90 \%$ of New England salt marshes during the Great Depression, did not significantly alter marsh carbon storage. In Buzzards Bay, Massachusetts, a US National Estuary, we tested relationships among measures of estuarine water quality, recreational activity, and local socioeconomic conditions to understand how the benefits of cultural ecosystem services are affected by shifts in water quality associated with global change and anthropogenic activity. Over a 24-year period, water quality degradation coinciding with increases in Chlorophyll $a$ is associated with declines in fishery abundance and cultural ecosystem service values (\$0.08 - 0.67 million USD). In combination, incorporation of both anthropogenic and natural disturbances to coastal ecosystem functioning and service delivery can produce improved estimates of ecosystem service valuation for effective resource decision-making under future climate scenarios.
\end{abstract}

Thesis Supervisors: Dr. Amanda C. Spivak and Dr. Matthew A. Charette

Title: Associate Professor (University of Georgia) and Senior Scientist (Woods Hole Oceanographic Institution) 


\section{ACKNOWLEDGEMENTS}

It took a literal village to become the scientist that I am today. This thesis encompasses nearly six years of support and cheerleading from so many people who taught me how to be the best researcher I could be.

I would like to first thank the people who opened my eyes to the possibility that I could even pursue a $\mathrm{PhD}$ in Oceanography. Lalith Munasinghe was my Microeconomics professor who first showed me how to pull information from large datasets using modeling techniques that could be applied in almost any field of research. Bob Anderson and Jerry McManus taught me the fundamentals of oceanography and have been sources of incredible inspiration and encouragement.

I am very fortunate to have been advised by so many remarkable scientists. Scott Doney patiently helped me incorporate the field of economics into my early years of research. I am very thankful for my advisor, Amanda Spivak, who taught me how to be a wet lab chemist and patiently explained to me the complexities of salt marsh biogeochemistry. Matthew Charette has always provided support and reassurance during my time in the Joint Program. I will forever be grateful to these advisors for the time and energy they spent to guide and mentor me throughout this process.

My thesis committee miraculously made my committee meetings a stress-free supportive learning environment. Porter Hoagland, Taylor Perron, and Jonathan Sanderman opened my eyes to different aspects of my research that allowed me to step back from the complexities of the geochemical techniques to see the larger-scale impacts of my research.

To my fellow EAPS, MIT-WHOI JP, Chemical Oceanography starfish cohort... I could not and would not want to imagine a world in which I would've done this $\mathrm{PhD}$ without you. Craig McLean, Jennifer Kenyon, Jule Middleton, Lydia Babcock-Adams, and Mallory Ringham: you helped me survive this.

Last but not least, my loving friends and family were always there to hear the complaints about slow thesis writing and a finicky RPO as well as the small wins (accompanied with a small dance party). This thesis is dedicated to all of you.

\section{Financial Support}

Funding for this work was provided by John D. and Catherine T. MacArthur Foundation (Grant no. 14-106159-000CFP), National Science Foundation (OCE1233678), National Oceanic and Atmospheric Administration, National Oceanic and Atmospheric Administration - National Estuaries Research Reserve Collaborative (NA14OAR4170104 and NA- 14NOS4190145), Woods Hole Sea Grant (NA14OAR4170104), MIT Sea Grant (subaward number 5710004045), Ocean Ventures Fund, the Marine Policy Center Johnson Endowment, and Woods Hole Oceanographic Institution. 


\section{TABLE OF CONTENTS}

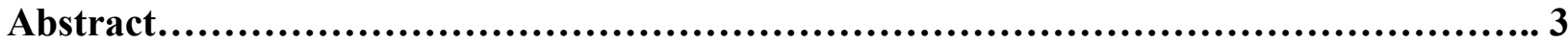

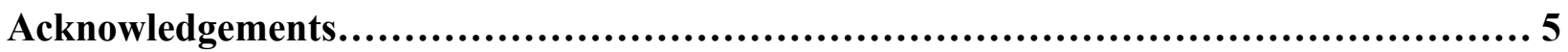

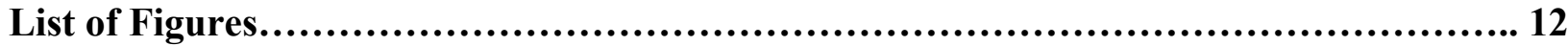

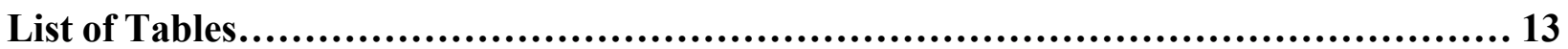

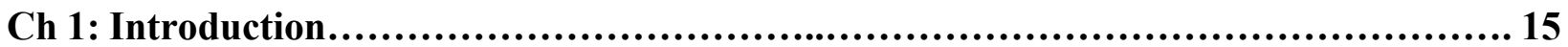

Ch 2: Soil organic carbon development and turnover in natural and disturbed salt marsh

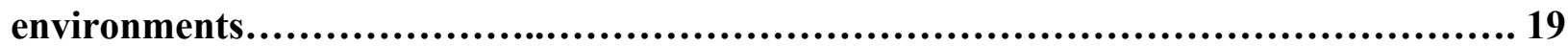

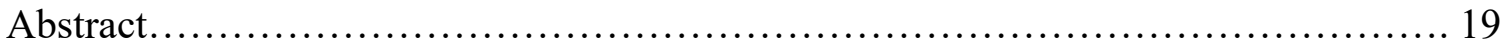

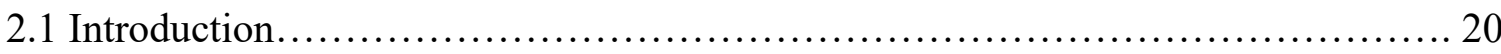

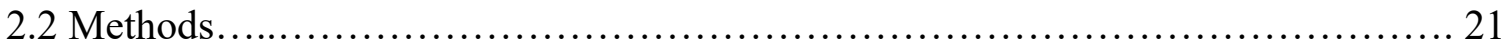

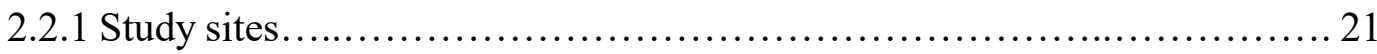

2.2.2 Bulk soil properties..................................................... 21

2.2 .3 Bulk soil data analysis............................................ 21

2.2.4 Thermal reactivity and carbon isotope measurements..................... 22

2.2.5 Thermal reactivity and isotope data analysis........................... 22

2.2 .6 Age models............................................................ 22

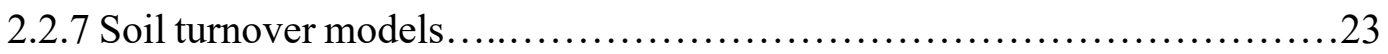

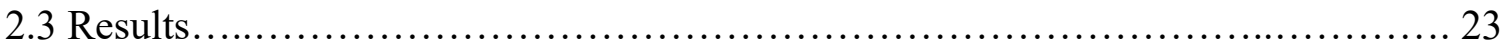

2.3.1 Bulk soil properties................................................. 23

2.3.2 SOC reactivity .......................................................... 24

2.3.4 Soil age models......................................................... 24

2.3.5 Marsh SOC turnover models........................................... 24

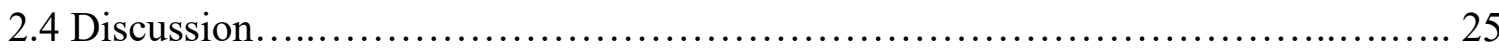

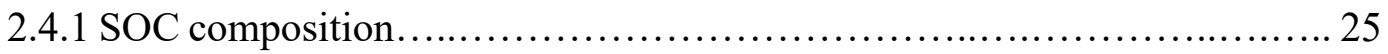

2.4.2 SOC turnover under natural conditions................................ 26

2.4.3 Disturbances alter SOC reactivity .................................... 26

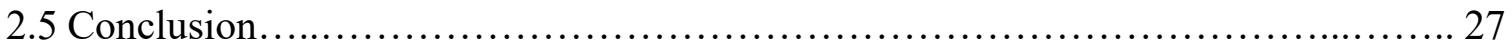

Data Availability Statement............................................................ 27

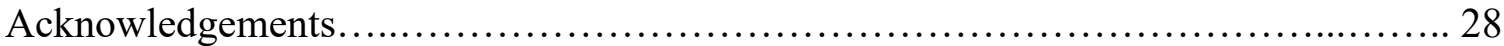

Ch 3: The inclusion of ponds in the lateral and vertical variability of marsh carbon

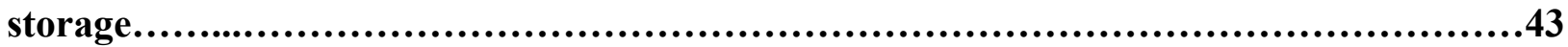

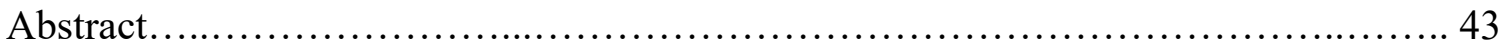

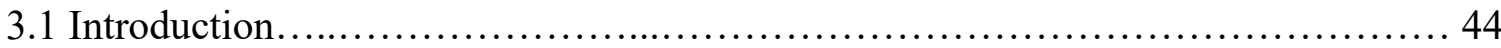

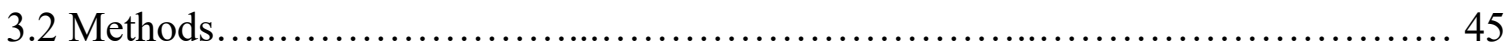

3.2.1 Study location and sample collections............................... 45 
3.2.2 Bulk soil properties and elemental composition........................ 46

3.2.3 Lipid biomarkers...............................................47

3.2.4 Thermal reactivity.................................................47

3.2.5 Radiometric dating and accretion rates...............................47

3.2.6 Pond erosion estimates.............................................48

3.2.7 Data analysis.................................................... 48

3.3 Results............................................................. 49

3.3.1 Bulk soil properties.............................................. 49

3.3.2 SOM sources and reactivity ...................................... 49

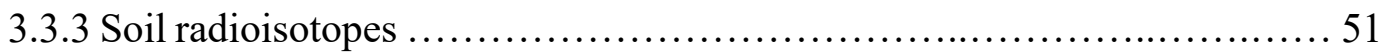

3.3.4 Estimating pond erosion........................................... 51

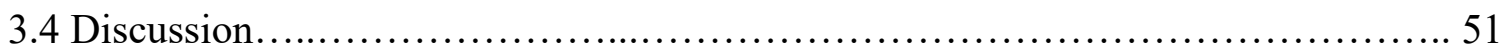

3.4.1 Ponding effects on soil processes are localized........................ 52

3.4.2 Pond soils reflect changing organic matter inputs and decomposition....... 52

3.4.3 The fate of carbon during pond deepening............................ 54

3.4.4 Incorporating ponds into ecosystem carbon budgets.................... 56

3.5 Conclusion ................................................................ 56

Acknowledgements..................................................... 57

Ch 4: Decades of marsh pond infilling results in spatial heterogeneity within salt marsh carbon budgets................................................................................72

Abstract...................................................................... 72

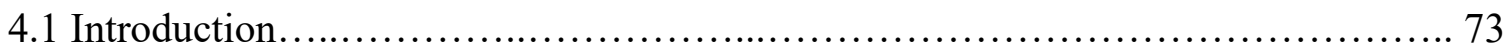

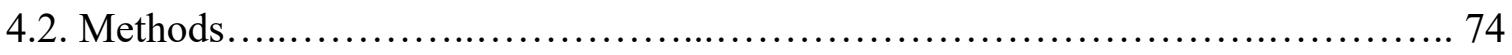

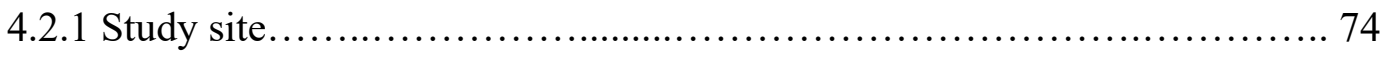

4.2.2 Plant characteristics.......................................... 75

4.2.3 Bulk soil properties............................................. 75

4.2.4 Soil age models.................................................. 75

4.2.5 SOC reactivity, sources, and age .................................. 75

4.2.6 Data analysis ................................................... 76

4.3 Results.............................................................. 77

4.3.1 Elevation and plant communities................................... 77

4.3.2 Bulk soil properties............................................. 77

4.3 .3 Accretion rates......................................................... 77

4.3.4 SOC reactivity, sources, and ages................................. 78

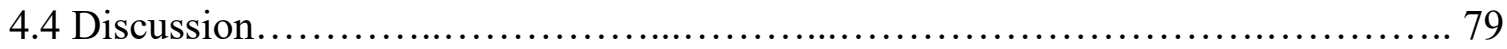

4.4.1 Biophysical drivers of pond elevation recovery...................... 79

4.4.2 Infilling salt marsh ponds contribute to persistent soil spatial heterogeneity. 80

4.4.3 Age differences in infilling salt marsh soil organic carbon................. 81 
4.4.4 Future ponding can impact marsh carbon storage estimates.............. 83

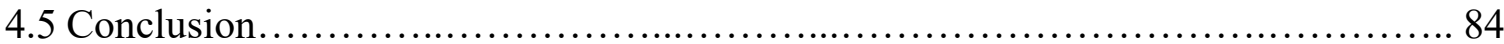

Acknowledgements.......................................................... 84

Ch 5: Impacts of mosquito ditches on salt marsh carbon stocks and future sustainability...99

Abstract.................................................................. 99

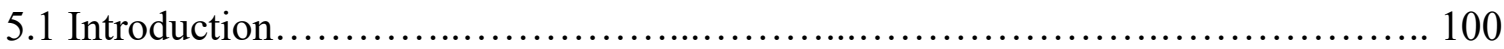

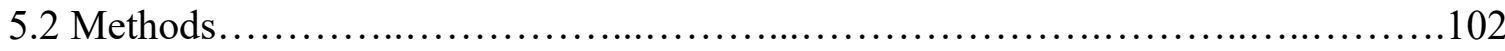

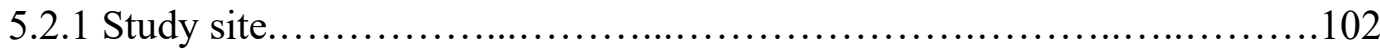

5.2.2 Plant characteristics............................................. 102

5.2.3 Bulk soil properties.................................................. 102

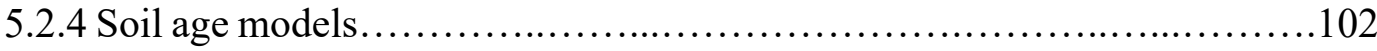

5.2.5 Thermal reactivity and carbon isotope measurements......................103

5.2.6 Tidal creek total suspended sediments............................... 103

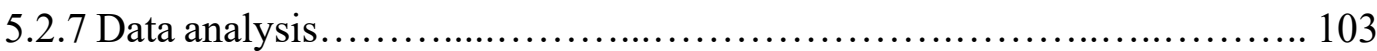

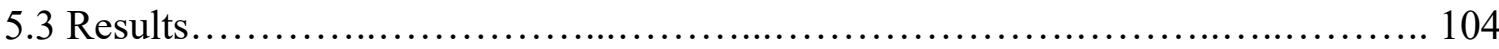

5.3.1 Marsh elevations and accretion rates................................. 104

5.3.2 Plant characteristics................................................ 104

5.3 .3 Bulk soil properties............................................ 104

5.3.4 SOC thermal reactivity, sources, and age............................. 105

5.3.5 Incorporation of mosquito ditches into the marsh carbon budget......... 106

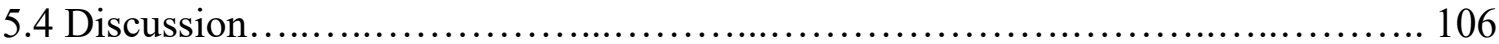

5.4.1 Factors contributing to subsidence of the ditched marsh................. 107

5.4.2 Biogeomorphic responses to lower elevations in the tidal frame.......... 107

5.4.3 The role of the tidal channel and ditches in marsh ecosystem functioning.. 108

5.4.4 Recycled marsh material contribute to marsh carbon stocks.............. 108

5.4.5 Inclusion of resource management strategies in marsh ecosystem accounting

5.5 Conclusion................................................................... 111

Acknowledgements......................................................... 111

Ch 6: Modeling the effect of water quality on the recreational shellfishing cultural ecosystem service of Buzzards Bay, Massachusetts..............................................124

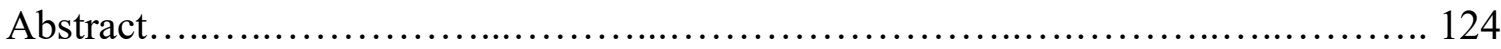

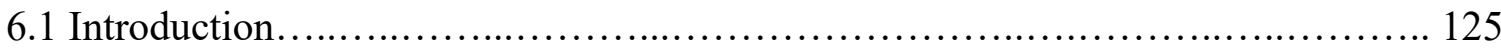

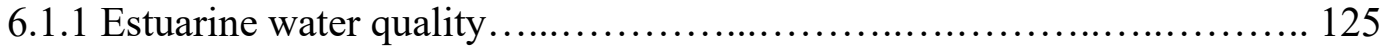

6.1.2 Linkage between water quality and recreational shellfishing............. 126

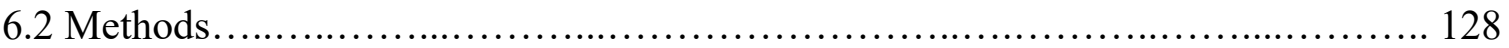

6.2 .1 Water quality monitoring...................................... 128 
6.2.2 Recreational shellfishing permits.............................. 128

6.2.3 Benefits transfer............................................... 128

6.2 .4 Auxiliary data................................................... 129

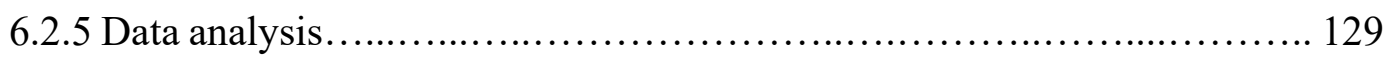

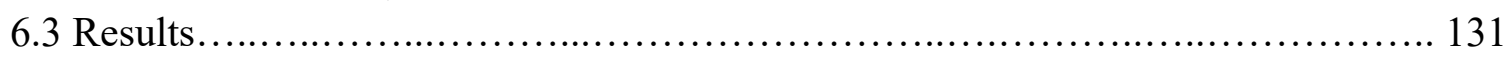

6.3 .1 Summary statistics.............................................. 131

6.3 .2 Year trend analysis................................................ 131

6.3.3 Permit sales, shellfish landings, and water quality..................... 132

6.4 Discussion.................................................................. 132

6.4.1 Indirect impacts of water quality on permit sales....................... 133

6.4.2 Direct impacts of water quality on recreational permit sales............... 133

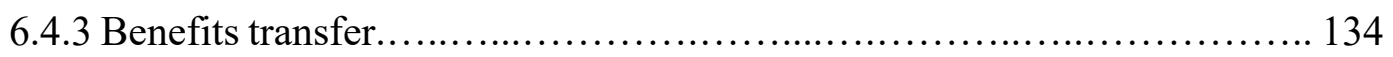

6.5 Conclusions................................................................. 135

Acknowledgements........................................................ 136

Ch 7: Conclusions...................................................................... 146

References............................................................................ 150 


\section{LIST OF FIGURES}

\section{Chapter 1:}

1. Study site map............................................................ 18

\section{Chapter 2:}

2. Marsh and pond soil bulk soil properties........................................29

3. Marsh and pond thermograms and thermal reactivity indices......................... 30

4. Thermal properties, sources, and age of marsh and pond SOC ........................ 31

5. Turnover times estimated by one-, two-, and five-pool models for marsh SOC..........32

\section{Chapter 3:}

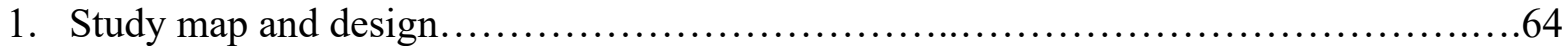

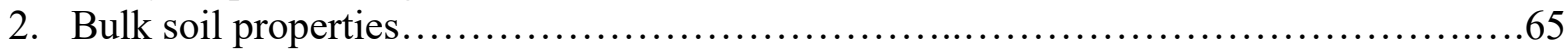

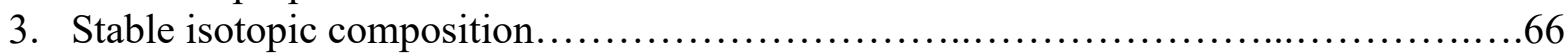

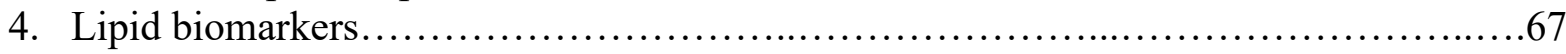

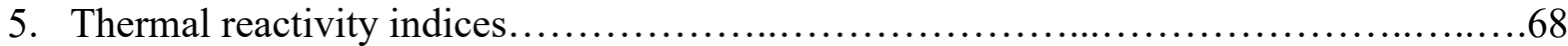

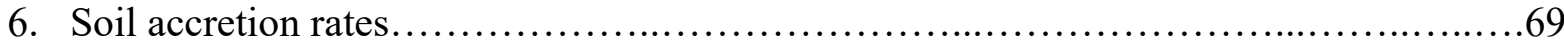

\section{Chapter 4:}

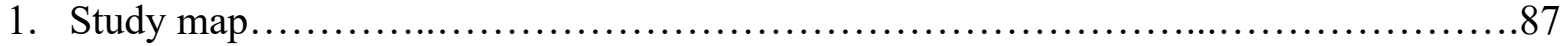

2. Elevation, accretion rates, and plant characteristics............................. 88

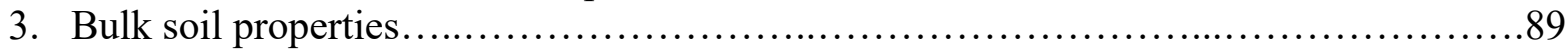

4. Isotopic and thermal properties.............................................. 90

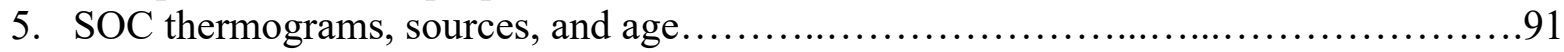

\section{Chapter 5:}

1. Study map and experimental design........................................... 116

2. Unditched and ditched elevations................................................ 117

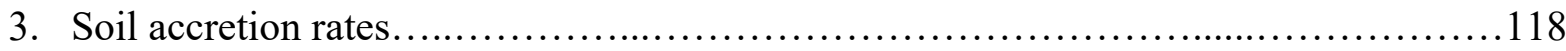

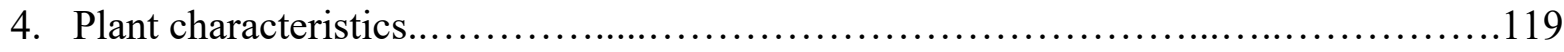

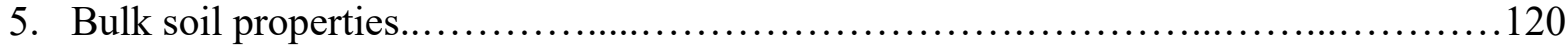

6. Isotopic composition and thermal properties...................................... 121

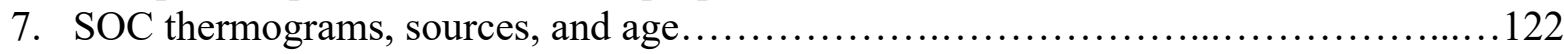

\section{Chapter 6:}

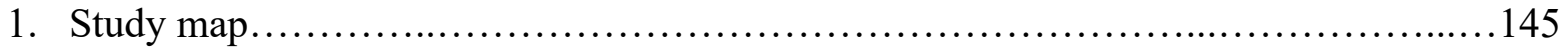




\section{LIST OF TABLES}

\section{Chapter 3}

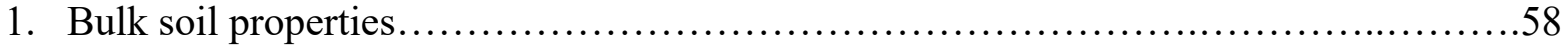

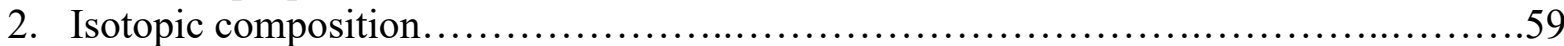

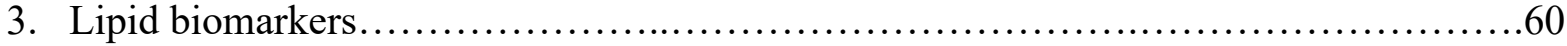

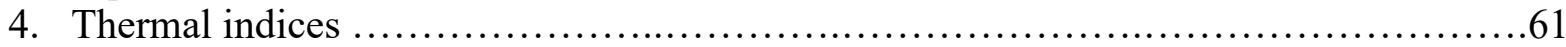

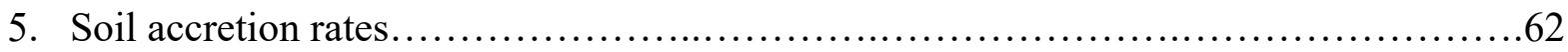

6. Constraining pond decomposition............................................63

\section{Chapter 4}

1. Six infilling pond characteristics................................................ 85

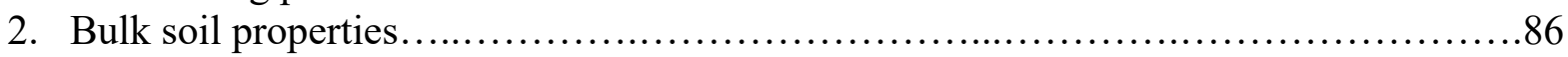

\section{Chapter 5}

1. Marsh elevations and plant characteristics........................................112

2. Bulk soil properties of ditched and unditched marsh.............................. 113

3. Bulk soil properties of near-channel and marsh interior locations.....................114

4. Incorporating mosquito ditches into marsh carbon budget....................... 115

\section{Chapter 6}

1. Shellfish landings by species............................................. 137

2. Willingness-to-pay and willingness-to-accept total value estimates..................138

3. Summary statistics of regression variables..........................................139

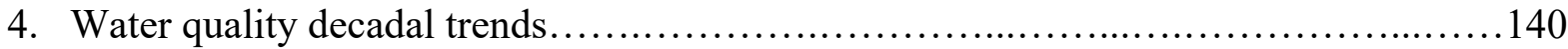

5. Socioeconomic decadal trends......................................................

6. First stage PLS regression results.............................................. 142

7. Second stage PLS regression results............................................... 143

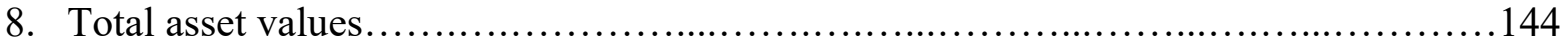

\section{Chapter 7}

1. Summary table of thesis findings............................................ 149 


\section{Chapter 1: Introduction}

Coastal ecosystems provide crucial ecosystem goods and services, yielding economic benefits and protecting human communities from the impacts of global change (Costanza et al., 1997; Barbier et al., 2011). Natural and anthropogenic perturbations to these systems can result in shifts in ecosystem functioning, interrupting the flow of services and diminishing the welfare of local communities. Particularly, global change processes associated with rising sea-levels and warming temperatures can correspond with declining carbon storage in salt marshes and decreased water quality within coastal estuarine ecosystems that subsequently reduce ecosystem service values. Resource management is a necessary step to protect these environments from current and future disturbances and loss. To aid effective management of these valuable environments, my thesis quantifies the alterations in coastal ecosystem biogeochemical functioning associated with natural and anthropogenic disturbances and elucidates the subsequent impact on the delivery of ecosystem goods and services.

The need to build connections between coastal ecosystem functioning and ecosystem service delivery is becoming increasingly clear for resource managers and coastal biogeochemists alike. The full gamut of ecosystem services provided by these environments hinges upon biogeochemical processes such as nutrient uptake by plant productivity, tidal inundation and sediment delivery, and soil accretion balanced by organic matter decomposition, among others (Gedan et al., 2009; Barbier et al., 2011; Tobias and Neubauer, 2019). Perturbations of ecosystem functioning can result in catastrophic steady state shifts resulting in an entirely different set of ecosystem functions and services (Marani et al., 2010; Moffett et al., 2015); for example, a vegetated salt marsh platform can undergo shifts to an unvegetated mudflat resulting in decreased storm-surge buffering capacity and lowered carbon storage rates (Marani et al., 2007; Wang and Temmerman, 2013). Yet, a barrier to making the connection between ecosystem functioning and services to human populations is the dearth in long-term spatiotemporal environmental and socioeconomic datasets and analysis that can demonstrate a directionality of ecosystem metrics to human wellbeing over time. The expansion of these datasets and their interpretation can aid resource decision-making and public communication of the importance in protecting and enhancing these environments.

Salt marshes are located in coastal estuarine settings, representing a transition zone between terrestrial and marine environments. Many of these ecosystems have been degraded or lost due to human alterations (Caçador et al., 2016). Yet, these ecosystems remain highly productive environments (Gedan et al., 2009; Barbier, 2015). Salt marshes have some of the highest aerial rates of carbon storage, due to high marsh grass productivity and slow decomposition within anoxic soils, allowing these systems to maintain elevation relative to sea-level rise (Chmura et al., 2003; Ouyang and Lee, 2014). Characterizing in situ long-term natural decomposition within salt marshes will be key to understanding and comparing how marsh disturbances impact SOC decomposition, subsequent carbon storage, and marsh elevation maintenance.

Increasing sea-level rise rates and changes in hydrological management strategies can catalyze the conversion of vegetated marsh interior habitats into open water environments through 
shallow pond development (Wilson et al., 2014a; Watson et al., 2017). However, it is unclear how pond expansion processes alter the fate of long-buried carbon vital to marsh carbon storage services. Ponds can have a dynamic life cycle whereby they form, deepen, drain, become revegetated, and rapidly accrete soils, eventually returning to an elevation similar to the surrounding marsh. However, it is unknown whether pond infilling to the elevation of the surrounding marsh constitutes a full recovery of marsh ecosystem functioning (i.e. similar rates of carbon accumulation and storage). The installation and maintenance of mosquito ditches in New England has been largely successful in reducing permanently ponded areas on the marsh platform (Kennish, 2001; Adamowicz and Roman, 2005; Riepe, 2010). Yet, management decisions often involve a tradeoff between one set of ecosystem services and another set; the long-term net impacts of ditches on marsh ecosystem functioning (e.g. plant productivity) and ecosystem service delivery (e.g. carbon storage) remain unclear. A valuable tool for assessing the long-term changes in ecosystem functioning and subsequent ecosystem service delivery is the salt marsh soil record that captures decades to centuries of soil organic carbon burial and preservation. To this end, understanding how disturbances - particularly salt marsh ponds and mosquito ditching - impact salt marsh biogeochemical functioning is critical for refining their roles in coastal carbon budgets and predicting future resilience.

Chapter 2, published in Geophysical Research Letters (Luk et al., 2021), characterizes soil organic carbon within natural and disturbed marsh environments in Plum Island Ecosystems Long Term Ecological Reserve to understand the transformations in soil composition due to natural and accelerated decomposition (Fig. 1a). The goals of this chapter were to:

1. Constrain decomposition rates in natural marsh settings and the resulting impact on the composition of buried soil organic carbon (SOC).

2. Evaluate the role of decomposition during pond expansion and associated shifts in SOC stability.

Chapter 3 aims to understand how ponds impact marsh carbon dynamics by constraining the processes associated with pond expansion on the marsh platform. This chapter expands on geochemical analysis conducted in Chapter 2 and benefits from the addition of soil cores to quantify pond expansion processes and the implications on the fate of marsh carbon. The goals of this chapter were to:

1. Assess the fate of carbon due to pond soil erosion and decomposition.

2. Quantify the overall impact of ponding disturbance to salt marsh carbon budgets.

Chapter 4 addresses the impact of the full pond life-cycle on marsh carbon cycling and carbon storage ecosystem services. This chapter uses historical aerial photographs in Great Barnstable Marsh, MA to identify infilling ponds on the marsh platform that offers insight into the changes in carbon storage associated with pond recovery (Fig. 1b). The goals of this chapter were to:

1. Evaluate changes in SOC composition, sources, and reactivity associated with pond infilling and recovery on the marsh platform.

2. Quantify the overall impact of the pond life-cycle on marsh carbon accounting. 
Chapter 5 determines the net effect of mosquito ditching on marsh ecosystem functioning (e.g. plant productivity, carbon burial), ecosystem services (long-term carbon storage), and future survival. This study compares marsh ecosystem functioning and carbon storage services within the ditched (60\%) and unditched (40\%) portions of Great Barnstable Marsh, MA (Fig. 1b). The goals of this chapter were to:

1. Determine the short- and long-term impacts that ditching has on the spatial heterogeneity of the marsh landscape (e.g. elevation, ponds) and soil composition (e.g. source, age, thermal reactivity).

2. Quantify the net effect of mosquito ditching, with the inclusion of ponds and the presence of ditches, on marsh carbon storage services.

Globally, coastal estuaries have experienced increases in coastal populations and rapid development, making them especially susceptible to water quality degradation. Human activity in the United States has led to an estimated six-fold increase in nutrient fluxes to coastal waters, resulting in the moderate to severe degradation of two-thirds of the nation's coastal waters (Howarth and Marino, 2006). Further, alterations in ecosystem functioning within one type of coastal ecosystem - such as salt marsh vegetation loss and reduced nutrient uptake capacity - can propagate to adjacent coastal estuarine systems (e.g. increased eutrophication). Eutrophication within estuarine systems can lead to acute hypoxia (low oxygen), reduced carbon sequestration, increased mortality of shellfish, and losses in the economic value of ecosystem services. Through long-term coastal water monitoring efforts, a deeper understanding of the historical relationship between water quality and the supply of cultural ecosystem services can better equip policymakers and resource managers with the capacity to design and implement effective strategies that could enhance the overall sustainability of coastal systems (Halpern et al., 2012).

Chapter 6, published in Marine Pollution Bulletin (Luk et al., 2019), uses a long-term water quality dataset with high spatial resolution to quantify changes in estuarine water quality and the associated shifts in cultural ecosystem service benefits received by local communities (Fig. 1c). Here, an economic benefits transfer framework was utilized to estimate changes in recreational ecosystem service asset values associated with increasing water quality degradation. This chapter was guided by the following research questions:

1. What are the long-term water quality and socioeconomic trends in Buzzards, MA?

2. Are there relationships between water quality trends and recreational permit sales and cultural ecosystem service values?

Chapter 7 presents a summary of the results within this thesis. Decision-making informed by an understanding of complex coastal biogeochemical processes based on long-term environmental and socioeconomic datasets can help to demonstrate how changing environmental factors can impact human wellbeing on local and global scales. This research encompasses the fieldwork, lab analysis, and modelling necessary to measure in-situ coastal biogeochemical processes that can be extrapolated to shifts in ecosystem functioning and service delivery. 

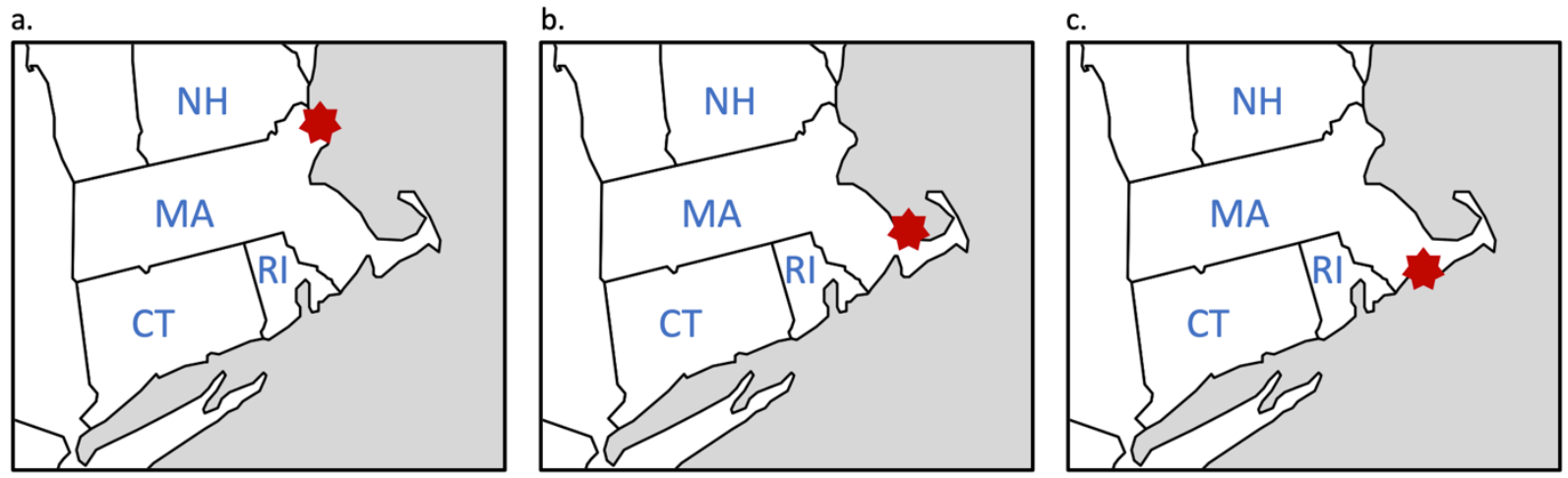

Figure 1. a) Location of Plum Island Ecosystem - Long Term Ecological Reserve (Chapter 2 and 3), MA b) Great Barnstable Marsh, MA (Chapter 4 and 5), and c) Buzzards Bay Estuary, MA (Chapter 6). 


\title{
Chapter 2: Soil organic carbon development and turnover in natural and disturbed salt marsh environments
}

\begin{abstract}
Salt marsh survival with sea-level rise (SLR) increasingly relies on soil organic carbon (SOC) accumulation and preservation. Using a novel combination of geochemical approaches, we characterized fine SOC $(\leq 1 \mathrm{~mm})$ supporting marsh elevation maintenance. Overlaying thermal reactivity, source $\left(\delta^{13} \mathrm{C}\right)$, and age $\left(\mathrm{F}^{14} \mathrm{C}\right)$ information demonstrates several processes contributing to soil development: marsh grass production, redeposition of eroded material, and microbial reworking. Redeposition of old carbon, likely from creekbanks, represented $\sim 9 \%-17 \%$ of shallow SOC $(\leq 26 \mathrm{~cm})$. Soils stored marsh grass-derived compounds with a range of reactivities that were reworked over centuries-to-millennia. Decomposition decreases SOC thermal reactivity throughout the soil column while the decades-long disturbance of ponding accelerated this shift in surface horizons. Empirically derived estimates of SOC turnover based on geochemical composition spanned a wide range (640-9,951 years) and have the potential to inform predictions of marsh ecosystem evolution.
\end{abstract}

This chapter was originally published in Geophysical Research Letters by American Geophysical Union in 2021 and is reproduced here with permission.

Luk, S. Y., Todd-Brown, K., Eagle, M., McNichol, A. P., Sanderman, J., Gosselin, K., \& Spivak, A. C. (2021). Soil organic carbon development and turnover in natural and disturbed salt marsh environments. Geophysical Research Letters, 48, e2020GL090287.

https://doi.org/10.1029/2020GL090287 


\subsection{INTRODUCTION}

Salt marshes maintain elevation in the tidal frame through rapid vertical accretion supported by efficient burial of minerals and organic matter. Soil accumulation and preservation support valuable ecosystem services (Barbier et al., 2011) and are critical to salt marsh survival with increasing sea-level rise (SLR; Morris et al., 2002, 2016). Declining mineral inputs to certain marshes (Weston, 2014) place additional importance on soil organic carbon (SOC) preservation. Global climate change-induced disturbances are expected to increase SOC vulnerability to decomposition, potentially leading to marsh subsidence (Pendleton et al., 2012; Spivak et al., 2019). Characterizing SOC composition and reactivity and how those properties are changed by decomposition is key to predicting future marsh sustainability and carbon storage. Efficient SOC burial and preservation largely reflect high rates of primary production and slow decomposition. Under anoxic conditions of marsh soils, decomposition is often conceptualized as modified decay functions with labile and refractory compounds turning over on time scales of months-to-years and centuries-to-millennia, respectively (Kirwan \& Mudd, 2012). Slow-cycling SOC is the critical component supporting carbon storage and elevation maintenance. It is often estimated at $10 \%-20 \%$ of annual organic matter production and composed of macromolecules such as lignin (Kirwan \& Mudd, 2012; Morris \& Bowden, 1986; Schile et al., 2014). Recent evidence that environmental constraints on microbial communities limit decomposition rather than intrinsic molecular recalcitrance (Lehmann et al., 2020; Marín-Spiotta et al., 2014) suggests that marsh soils likely preserve a broad mixture of compounds with differing reactivities. Assessing how decomposition changes the composition and reactivity of slow-cycling SOC can provide insight into controls on preservation as well as potential for loss following disturbances.

Rapid SLR and certain hydrological management practices have contributed to the expansion of shallow ponds in many salt marshes (Adamowicz \& Roman, 2005; Watson et al., 2017). While permanently inundated ponds are natural features that can exist for decades before draining and recovering (Mariotti et al., 2020), runaway expansion has been described as a transitional state between healthy and drowning marshes (Kirwan \& Murray, 2007; Ortiz et al., 2017). Ponds typically form following disturbances that cause marsh vegetation dieback (e.g., waterlogging) and deepen through decomposition of underlying peat (Johnston et al., 2003; Spivak et al., 2018). Ponds therefore offer a natural, decadal-scale experiment for evaluating how disturbances that accelerate decomposition alter slow-cycling SOC.

We assessed how slow-cycling SOC composition and reactivity changes over decades-tomillennia and in response to the disturbance of ponding in a temperate salt marsh. We hypothesized that marshes bury a range of compounds with differing reactivities that derive from local production but long-term decomposition results in a progressive homogenization and decrease in SOC reactivity. Further, we predicted that the disturbance of ponding accelerates decompositiondriven changes in SOC composition and reactivity. SOC reactivity, sources, and age were characterized by overlaying thermal properties and isotopic composition $\left(\delta^{13} \mathrm{C}, \mathrm{F}^{14} \mathrm{C}\right)$. We 
estimated the turnover times of slow-cycling SOC by modeling changes in composition against geochronologies developed from radioisotope-based age models and SLR reconstructions.

\subsection{METHODS}

\subsubsection{Study Sites}

We collected soil cores from three sites within the Plum Island Ecosystems - Long Term Ecological Research (PIE-LTER) domain (MA, USA; $42.74^{\circ} \mathrm{N},-70.85^{\circ} \mathrm{W}$; Figure S1). The sites are within marshes that formed prior to European settlement (Kirwan et al., 2011) and had similar elevations (1.41-1.51 m North American Vertical Datum of 1988 [NAVD88]) and high marsh plant communities, dominated by Spartina alterniflora, S. patens, and Distichlis spicata, that are typical of New England marshes (Redfield, 1972). Permanently inundated ponds within each site had comparable depths $(0.24-0.30 \mathrm{~m})$ but varied in size $\left(643-7,149 \mathrm{~m}^{2}\right)$ and age $(40-53$ years; Spivak et al., 2017, 2018). Paired soil cores were collected from the marsh platform (100 cm) and a pond $(50 \mathrm{~cm})$ within each site; differences in core length reflected lower surface elevations in the ponds relative to the marsh.

\subsubsection{Bulk Soil Properties}

Soil cores were sectioned at 1, 2, or $5 \mathrm{~cm}$ intervals, with higher resolution in the top $30 \mathrm{~cm}$. Soil water content $(\%)$ and bulk density $\left(\mathrm{g} \mathrm{cm}^{-3}\right)$ were determined gravimetrically. Samples were sieved $(1 \mathrm{~mm})$ to remove large roots. We focused on particles $(\leq 1 \mathrm{~mm})$ passed through the sieve that are consistent with functional definitions of slow-cycling fine SOC (Bruun et al., 2010; Hemminga et al., 1988; Williams \& Rosenheim, 2015). Samples were ball milled and $~ 90 \%$ were fumed with hydrochloric acid and analyzed for bulk elemental (total organic carbon [TOC ( $\%, \mathrm{~kg}$ $\left.\left.\mathrm{m}^{-3}\right)\right]$ ) and isotopic $\left(\delta^{13} \mathrm{C}, \% \mathrm{o}\right)$ composition. Carbon content of the remaining $10 \%$ was estimated from a diffuse reflectance Fourier Transform Mid-infrared (FTIR) spectroscopy partial least squares regression model (Janik et al., 2007). Partial least squares regression (PLSR) tests were conducted using the plsregress package in MATLAB with 5 components and 20-fold cross validation to use FTIR to estimate TOC content (Janik et al., 2007). Using PLSR to estimate TOC content using FTIR absorbance data resulted in an $\mathrm{R}^{2}$ of 0.97 and RMSE of 0.85 .

\subsubsection{Bulk Soil Data Analysis}

We compared bulk soil and elemental properties across three depths: (i) shallow marsh rooting zone $(0-30 \mathrm{~cm})$, (ii) intermediate marsh horizons $(30-54 \mathrm{~cm})$ that overlapped with pond surface horizons $(0-24 \mathrm{~cm})$, and (iii) deep marsh $(54-77 \mathrm{~cm})$ and pond $(24-50 \mathrm{~cm})$ horizons. Means and standard errors (SE) of soil properties were calculated in $6 \mathrm{~cm}$ increments. Based on results from the Kolmogorov-Smirnov goodness-of-fit hypothesis test, water content, dry bulk density, and TOC were log-transformed prior to statistical analyses to meet assumptions of normality. Marsh and pond cores across the three sites were used as independent replicates to conduct one-way analysis of variance tests, which were used to detect differences within the three 
depth zones of marsh and pond soils separately, and between marsh and pond downcore profiles at corresponding $6 \mathrm{~cm}$ increments based on elevation.

\subsubsection{Thermal Reactivity and Carbon Isotope Measurements}

SOC thermal properties and reactivity indices were characterized through ramped pyrolysis oxidation (RPO) for horizons representing key parts of the soil profiles, including the marsh and pond surface, base of the marsh rooting zone, and deeper horizons representing carbon buried for more than 100 years. Homogenized samples $(\sim 6 \mathrm{mg})$ were heated to $1,000^{\circ} \mathrm{C}$ at a rate of $20^{\circ} \mathrm{C}$ $\min ^{-1}$ (Rosenheim et al., 2008) and the evolved carbon dioxide $\left(\mathrm{CO}_{2}\right)$ was measured by a flowthrough infrared gas analyzer. Thermograms were constructed by plotting $\mathrm{CO}_{2}$ concentrations versus temperature. Samples were not acidified as inorganic carbon content was $<0.04 \%$ of TOC. Analyses were conducted at the National Ocean Sciences Accelerator Mass Spectrometry Facility (MA, USA).

We further analyzed $\mathrm{CO} 2$ evolved via RPO for $\delta^{13} \mathrm{C}$ and $\mathrm{F}^{14} \mathrm{C}$ composition (McNichol et al., 1994; Reimer et al., 2004) from one representative marsh and pond site. The $\mathrm{CO}_{2}$ fractions were collected over five temperature intervals; there were three low $\left(200^{\circ} \mathrm{C}-465^{\circ} \mathrm{C}\right)$ and two high $\left(465^{\circ} \mathrm{C}-650^{\circ} \mathrm{C}\right)$ temperature $\mathrm{CO}_{2}$ fractions. The isotopic composition of evolved $\mathrm{CO} 2$ was analyzed for at least three of the five fractions, capturing $\sim 70 \%$ of TOC within a soil horizon.

\subsubsection{Thermal Reactivity and Isotope Data Analysis}

We evaluated SOC thermal reactivity within and between marsh and pond environments by calculating ratios of $\mathrm{CO} 2$ evolved at low versus high temperatures (hereafter, peak ratio) and thermal activation energies (supporting information 2.5). Peak ratios were determined by normalizing the area under the low $\left(200^{\circ} \mathrm{C}-465^{\circ} \mathrm{C}\right)$ versus high $\left(465^{\circ} \mathrm{C}-650^{\circ} \mathrm{C}\right)$ temperature peaks of the thermograms. The theoretical activation energy $\left(E a \mathrm{~kJ} \mathrm{~mol}^{-1}\right)$ and blank contamination correction were calculated using the Python package rampedpyrox (Hemingway et al., 2017a, 2017b). The mean and SE of peak ratios and $E a$ were calculated across $25 \mathrm{~cm}$ increments based on elevation.

\subsubsection{Age Models}

Soil horizon ages across all sites were constrained with several inputs in order to conservatively model turnover times. Post-1900 accretion rates were calculated using ${ }^{210} \mathrm{~Pb}$ constant initial concentration (CIC) and continuous rate of supply (CRS) models with radioisotope activities measured on planar-type gamma counters (Canberra Inc., USA). Contemporary rates of SLR, from a local tide gauge (Boston $8443870,2.83 \pm 0.15 \mathrm{~mm} \mathrm{year}^{-1}$ ), provided an age constraint for the past century based on the assumption that the marsh kept pace with SLR (Appleby \& Oldfield, 1978; Pennington et al., 1976). For pre-1900 horizons, we extended CIC ${ }^{210} \mathrm{~Pb}$-based accretion rates deeper in the soil profile, while upper age limits were constrained with lateHolocene SLR $\left(0.6 \pm 0.1 \mathrm{~mm}_{\text {year }}{ }^{-1}\right.$ and $0.9 \pm 0.2 \mathrm{~mm}_{\text {year }}{ }^{-1}$; Engelhart et al., 2009; Gonneea et al., 2019), and glacial isostatic adjustment (1.2 $\mathrm{mm}_{\text {year }}{ }^{-1}$; Peltier et al., 2015). Age models were 
not developed for the ponds due to the violation of steady-state assumptions as ${ }^{210} \mathrm{~Pb}$ inventories suggested erosion (supporting information 2.6).

\subsubsection{Soil Turnover Models}

We estimated turnover times of fine SOC in the marsh platform using a depth-for-time substitution where downcore changes in carbon concentration were modeled against geochronology. First, across all marsh sites, a one-pool model captured changes in total fine SOC concentrations and a two-pool model was developed from persistent low-temperature and hightemperature thermogram peaks. We expanded to a five-pool model based on thermal and isotopic data at one site suggesting at least five compositionally distinct SOC pools. For the two-pool and five-pool models, carbon concentrations within each consecutive pool were defined as the amount of $\mathrm{CO} 2$ evolved over discrete increasing temperature intervals within the thermogram.

$$
\begin{gathered}
U_{i}(t)=U_{\text {initial, } \mathrm{i}}-\frac{U_{\text {initial }, \mathrm{i}}}{t_{\text {root }}} \times t \text { if } t<t_{\text {root }} \\
\text { for } i=1: \frac{\mathrm{d} x_{i}(t)}{\mathrm{d} t}=U_{i}(t)-\frac{1}{\tau_{i}} \times x_{i}(t) \\
\text { for } i>1: \quad \frac{\mathrm{d} x_{i}(t)}{\mathrm{d} t}=U_{i}(t)+\left(r_{i-1}\right) \times \frac{1}{\tau_{i-1}} \times x_{i-1}(t)-\frac{1}{\tau_{i}} \times x_{i}(t)
\end{gathered}
$$

Turnover in the first pool $(i=1)$ is described as first-order kinetics dictated by the carbon concentration of the pool $(x)$ at a given time obtained from the age models $(t)$, linear input $(U)$ during the time within the rooting zone (troot), and turnover time ( $\tau$; Equations 1 and 2; Manzoni et al., 2009). Subsequent pools $(i>1)$ are a linear series, where a fraction $\left(r_{i-1}\right)$ of decomposed material from the previous pool is transferred to the next pool (Equation 3).

Parameterization of turnover rate $\left(\tau_{i}\right)$, fraction transferred $\left(r_{i}\right)$, initial input $\left(U_{\text {initial }, i}\right)$, and initial pool masses $\left(x_{0, i}\right)$ with associated uncertainties were determined by sequentially fitting each pool to a uniformly sampled Latin Hypercube (https://github.com/sheronyl/SOCDecayModel). Carbon input $(U)$ is described as an initial input $\left(U_{\text {initial }}\right)$ at $\mathrm{t}=0$, which decreases linearly to zero with time within the rooting zone $\left(t_{\text {root }}\right)$ defined as 80 years (i.e., $25 \mathrm{~cm}$ rooting zone; Eq. 1). Model fits were defined by minimizing root mean squared error (RMSE) and the linear fit incorporating age uncertainty between observed and modelled pool masses $(x)$. Based on the fit criteria, a random sampling of 100 parameter sets from the previous pool was run in combination with the subsequent pool. The best fit model was determined with the mean age of each soil horizon and minimizing RMSE across pools (SI Table S6).

\subsection{RESULTS}

\subsubsection{Bulk Soil Properties}

Bulk soil properties changed with depth and differed between the marsh and ponds. In the marsh, water and TOC content $\left(\%\right.$ and $\left.\mathrm{kg} \mathrm{m}^{-3}\right)$ decreased while bulk density increased with depth 
(Figure 1). Pond soil properties were less variable across depths, with the exception of TOC (\%) which decreased slightly. Marsh soils were generally drier and had higher bulk densities than the ponds (Figures 1a and 1b, Table S1). Marsh and pond soils had similar TOC densities $\left(\mathrm{kg} \mathrm{m}^{-3}\right)$, except in pond surface horizons where lower concentrations reflected lower bulk densities (Figure 1d, Table S1). Bulk TOC content informed the one-pool turnover model.

\subsubsection{SOC Reactivity}

There was a bimodal distribution of $\mathrm{CO} 2$ evolved during RPO with low $\left(371^{\circ} \mathrm{C} \pm 4^{\circ} \mathrm{C}\right)$ and high $\left(530^{\circ} \mathrm{C} \pm 4^{\circ} \mathrm{C}\right)$ temperature peaks separated by a minimum at $465.5^{\circ} \mathrm{C} \pm 2.4^{\circ} \mathrm{C}$ (Figures $2 \mathrm{a}-$ $2 \mathrm{~g}$ ). Peak ratios decreased while $E a$ increased with depth in marsh soils (Figures $2 \mathrm{~h}$ and $2 \mathrm{i}$ ), indicating a shift toward lower thermal reactivity. Pond surface horizons had lower peak ratios and higher Ea values than the marsh ( $\sim 1.2 \mathrm{~m}$ NAVD88), but the reactivity indices converged toward similar values in both environments at $\sim 1 \mathrm{~m}$ elevation (Figures $2 \mathrm{~h}$ and $2 \mathrm{i}$, Table $\mathrm{S} 2$ ). The bimodal thermogram distribution across soil depths suggests the presence of at least two distinct fine SOC pools and was the basis of the two-pool turnover model.

\subsubsection{SOC Sources and Ages}

The $\delta^{13} \mathrm{C}-\mathrm{CO}_{2}$ values associated with different temperature intervals spanned a wider range than bulk SOC (Figure 3). The $\delta^{13} \mathrm{C}-\mathrm{CO}_{2}$ of the low-temperature peak $(-15.5 \pm 0.2 \%$ ) was similar to bulk soils $(-15.0 \pm 0.3 \%$ ), while the high-temperature peak was more enriched $(-13.8 \pm 0.2 \%$ ). These data are consistent with emergent grasses as the main carbon source to marsh and pond soils (Spivak \& Ossolinski, 2016) with variation between peaks suggesting differences in molecular composition (Benner et al., 1987).

Radiocarbon $\left(\mathrm{F}^{14} \mathrm{C}\right)$ values were highest in $\mathrm{CO}_{2}$ fractions evolved at lower temperatures, reflecting more modern inputs, and decreased with higher temperatures (Figure 3, Table S5). This trend was clearest within the marsh $(0-26 \mathrm{~cm})$ and pond surface horizons $(0-2 \mathrm{~cm})$, where modern values were expected. These data indicate that old, marsh derived, and thermally stable carbon represent substantial components $(9 \%-17 \%)$ of shallow horizons. Overlaid thermal reactivity, source, and age data point to at least five compositionally distinct fine SOC pools and were the basis of the five-pool turnover model.

\subsubsection{Soil Age Models}

Mean soil accretion rates from the CRS and CIC models for contemporary (post-1900s) deposition were $4.64 \pm 0.38 \mathrm{~mm}_{\text {year }}^{-1}$ and $2.47 \pm 0.39 \mathrm{~mm}^{\text {year }}{ }^{-1}$, respectively (Luk et al., 2020; Table S3). Horizons deeper than $28 \mathrm{~cm}$ reached the limitation of ${ }^{210} \mathrm{~Pb}$ dating (pre-1900s). Conservative age estimates for the deepest horizon $(80 \mathrm{~cm})$ ranged from 219 years to 1,194 years (Table S4).

\subsubsection{Marsh SOC Turnover Models}


The one-pool model, based on TOC content, yielded a best fit turnover time of 750 years (Figure 4a). This was similar to rates calculated from the two-pool model, which was based on the low-temperature and high-temperature peaks in the RPO thermograms (640 and 1,251, respectively; Figure 4b, Table S6). The five-pool model, based on geochemical composition (Figure 3), captured a broader distribution of turnover times, ranging from 1,011 years to 9,951 years, with generally faster rates for the first and second pools (Figure 4c, Table S6). Fitting onepool and two-pool models across the three marsh sites resulted in similar goodness-of-fit statistics, which were higher than the five-pool model at the one marsh site; this was due, in part, to lower data densities (Table S6). These results highlight the continuum of fine SOC turnover times.

\subsection{DISCUSSION}

\subsubsection{SOC Composition}

Soils in this New England salt marsh buried compounds with a range of thermal properties and $\delta^{13} \mathrm{C}$ values indicating that they derived from marsh grasses (Figures 2 and 3; Spivak \& Ossolinski, 2016). The wider range of $\delta^{13} \mathrm{C}-\mathrm{CO}_{2}$ measured across the thermograms, compared to bulk soils, likely reflects differences in the isotopic composition of compounds synthesized by marsh grasses (Figure 3). For instance, S. alterniflora is rich in cellulose and hemicellulose ( $\sim 70 \%$, $-11.5 \%$ ) with lower levels of lignin $(4 \%-9 \%,-17.4 \%$ ) and other compounds, such as lipids, carbohydrates, and amino acids ( 22\%, $-16.2 \%$; Figures 2 and 3; Benner et al., 1987). Compounds in this latter group are likely decomposed rapidly, with contributions attenuating with depth. The $\delta^{13} \mathrm{C}_{-} \mathrm{CO}_{2}$ values suggest that there was not a clear separation between compound classes across temperature intervals, potentially reflecting overlapping thermal properties as well as microbial reworking and aggregate formation (Figure 3; Bruun et al., 2010). Work in terrestrial soils consistently shows an enrichment in $\delta^{13} \mathrm{C}$ of $2 \%{ }^{-4} \%$ along gradients of increasing decomposition (Sollins et al., 2006) and thermal stability (Sanderman \& Grandy, 2020). It is unlikely that measured $\delta^{13} \mathrm{C}-\mathrm{CO}_{2}$ values are methodological artifacts, as they spanned a greater range than predicted by kinetic fractionation and enrichment did not increase monotonically with temperature (Figure 3; Hemingway et al., 2017b). This result highlights that thermal properties provide an index of reactivity that may not reflect bioavailability, which depends on environmental conditions, among other factors (Bulseco et al., 2019, 2020; Lehmann et al., 2020).

Although salt marshes are efficient carbon sinks, SOC stocks are spatially heterogeneous (Ouyang \& Lee, 2014). Compared to this New England marsh, thermogram complexity, TOC\%, and $E a$ were lower in a Gulf of Mexico marsh with similar grass communities (Williams \& Rosenheim, 2015). Factors contributing to these differences are unclear but applying thermal and isotopic characterization approaches more broadly may provide insight into controls on marsh SOC preservation (Lehmann et al., 2020).

The $\mathrm{F}^{14} \mathrm{C}$ values within and across depth horizons reveal multiple processes contributing to marsh soil development (Figures 3a-3e). In shallow horizons $(0-26 \mathrm{~cm})$, new production was an important component of lower temperature $\mathrm{CO} 2$ fractions while $\mathrm{F}^{14} \mathrm{C}$ values of $<1$ at higher temperatures suggest either redeposition of eroded creekbank carbon or microbial recycling 
(Figures $3 \mathrm{a}$ and $3 \mathrm{~b}$ ). The effects of microbial reworking on $\mathrm{F}^{14} \mathrm{C}$ are likely minor in surface horizons, due to rapid vertical accretion (Table S3). This relatively old, thermally stable fraction represents $\sim 9 \%$ of surface $(0-2 \mathrm{~cm})$ and $17 \%$ of deeper $(24-26 \mathrm{~cm})$ SOC, which is consistent with previous estimates based on creekbank erosion in this system (Figures $3 \mathrm{a}$ and 3b; Hopkinson et al., 2018). Since redistribution of previously buried soils contributes to accretion, current SOC storage estimates are likely upwardly biased. Redeposition of eroded soils may become increasingly important in maintaining marsh elevation with SLR (Hughes et al., 2009) and accounting for spatial recycling of carbon will be key for refining carbon budgets.

\subsubsection{SOC Turnover Under Natural Conditions}

Marsh soil profiles are consistent with long-term alteration due to decomposition, rather than changes in autochthonous versus allochthonous inputs. Increasing bulk densities and decreasing water and TOC content below the rooting zone $(0-28 \mathrm{~cm})$ suggest loss of organic matter, compaction, and dewatering (Figure 1). Decreasing thermal reactivity with depth (Figures $2 \mathrm{~h}$ and 2i) coincided with a small $\delta^{13} \mathrm{C}-\mathrm{CO}_{2}$ enrichment across $\mathrm{CO}_{2}$ fractions (Figures $3 \mathrm{a}-3 \mathrm{e}$ ). It is difficult to ascertain whether the preferential loss of specific compounds (i.e., Benner et al., 1987) or microbial reworking and development of microbial derived residues contributes to $\delta^{13} \mathrm{C}-\mathrm{CO}_{2}$ enrichment and homogenization of $\mathrm{F}^{14} \mathrm{C}$ values with increasing soil depth (Figure 3, Gleixner et al., 2002; Trumbore, 1997, 2009). Transitions in dominant vegetation associated with ecosystem evolution (Kirwan et al., 2011) would have a small effect on our results since $S$. alterniflora, $S$. patens, and D. spicata have similar biochemical compositions (Cristina et al., 2018; Haddad \& Martens, 1987; Wilson et al., 1986). Thus, the anoxic environment of marsh soils enhances preservation but does not completely inhibit microbial alteration of SOC.

Quantifying SOC loss alongside geochronometers can constrain turnover times that are difficult to measure experimentally. The best fit rates from the one-pool, two-pool, and five-pool models span a broader range (640-9,951 years; Figure 4, Table S6) than applied by some marsh evolution models (200-1,000 years; Day et al., 1999; Kirwan \& Mudd, 2012). Our one-pool model describes continuous loss of SOC, while the five- pool model predicts accumulation of the more thermally stable SOC, due to slower turnover and increased transfer $\left(r_{i-1}\right)$ over time (Figure 4, Table S6). The five-pool model therefore describes important mechanisms contributing to SOC preservation and marsh elevation gain that are not captured by the one-pool model. The two-pool model offers a compromise between the simple and more complex model, as it captures a thermally stable pool, which turns over $49 \%$ slower than the more reactive pool and $40 \%$ slower than the one-pool model (Table S6). Expanding ecosystem evolution models to include different turnover rates of fine SOC pools has the potential to improve predictions of marsh persistence, in the absence of disturbances.

\subsubsection{Disturbances Alter SOC Reactivity}

Decades following emergent grass dieback and submergence led to pond surface soils with different characteristics than the adjacent marsh. Collapse of marsh grass roots and water infilling 
of pore spaces contributed to higher water content, lower bulk densities, and initial subsidence (Figure 1, Chambers et al., 2019). Pond surface soils characterized with $\mathrm{F}^{14} \mathrm{C}<1$ and $\delta^{13} \mathrm{C}$ values similar to marsh soils at the same elevation $(1.17 \mathrm{~m}$; Figures $3 \mathrm{~b}$ and $3 \mathrm{f})$ are consistent with limited accumulation of recent production from submerged plant and algal communities and imply that ponds do not trap exported detritus (Figure 3; Spivak et al., 2017). Moreover, the convergence in marsh and pond SOC reactivity at depth $(<1 \mathrm{~m}$ NAVD88) (Figure 2) supports our comparative approach.

Over time, decomposition becomes an increasingly important mechanism driving pond deepening, as microbes assimilate buried peat and high respiration accounts for SOC loss (Spivak et al., 2017, 2018, 2020). Oxic surface waters during the day and benthic microalgal exudates may prime degradation of older, complex macromolecules (Fontaine et al., 2007; Spivak et al., 2017). Conditions favoring decomposition are confined to surface horizons due to limited gas diffusion and inhibition of bioturbating fauna by nighttime hypoxia (Spivak et al., 2017). Accordingly, $E a$ was greater in pond surface horizons than in deeper layers, and compared to the marsh at similar elevations (Figure 2i), but converged at depth $(<1 \mathrm{~m} \mathrm{NAVD88)}$ with the surrounding marsh. Progressive $\delta^{13} \mathrm{C}_{-}-\mathrm{CO}_{2}$ enrichment with depth suggests that microbial reworking still occurs under less favorable, waterlogged conditions, but with limited effects on thermal reactivity (Figures 1a, $2 \mathrm{~h}, 2 \mathrm{i}$, and $3 \mathrm{f}-3 \mathrm{i}$ ). Disturbances leading to pond formation therefore facilitated loss and shifts toward lower thermal reactivity of surface SOC, which could potentially slow progressive deepening.

\subsection{CONCLUSION}

We identified at least five geochemically distinct fine SOC pools (Figure 3), suggesting that slow-cycling marsh organic matter is more complex than typically conceptualized. By modeling downcore changes in fine SOC against soil geochronometers, we generated some of the first empirical estimates of turnover times (Figure 4). Carbon reactivity, source, and age described multiple processes contributing to soil development: new production, erosion and redeposition, and microbial reworking. Long-term decomposition and disturbances that accelerate decomposition (e.g., ponding) result in an accumulation of SOC with lower thermal reactivity. Further characterization of molecular composition within abiotic (e.g., redox) and biotic (e.g., microbial communities and carbon use efficiency) contexts may improve understanding of controls on decomposition and spatial variability in marsh SOC storage (Spivak et al., 2019). Broader application of these geochemical approaches has potential to enhance understanding of preservation under different environmental settings and inform marsh ecosystem evolution models and service valuation.

\section{DATA AVAILABILITY STATEMENT}

Data are archived at BCO-DMO.org (Spivak, 2020a, 2020b, 2020c, 2020d) and sciencebase.gov (Luk et al., 2020). 


\section{ACKNOWLEDGEMENTS}

We thank M. Charette for discussions; K. Gosselin, M. Fendrock, and M. Otter for field and lab measurements; and M. Lardie, J. Hemingway, and V. Galy for assisting with RPO and rampedpyrox. This work was supported by NSF (OCE1233678) and NOAA (NA14OAR4170104 and NA- 14NOS4190145) grants to ACS, USGS Coastal \& Marine Geology Program, and PIELTER (NSF OCE1238212 and OCE1637630). 
(a)
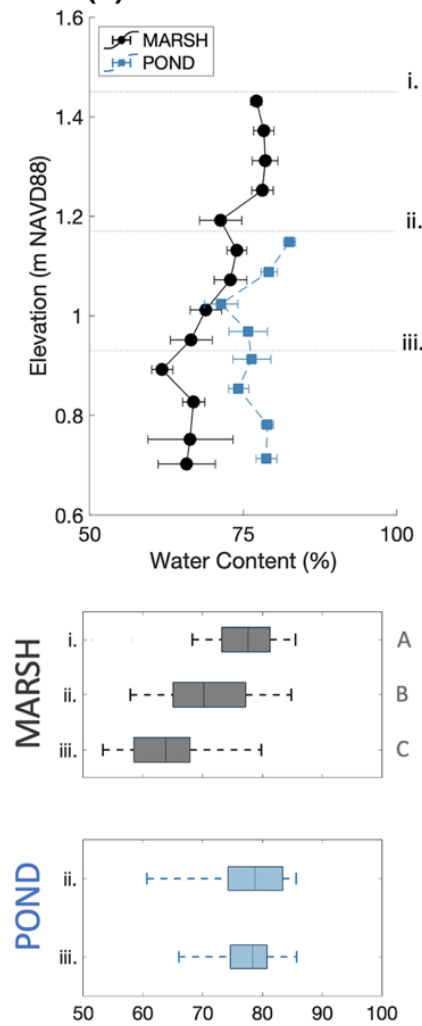

(b)
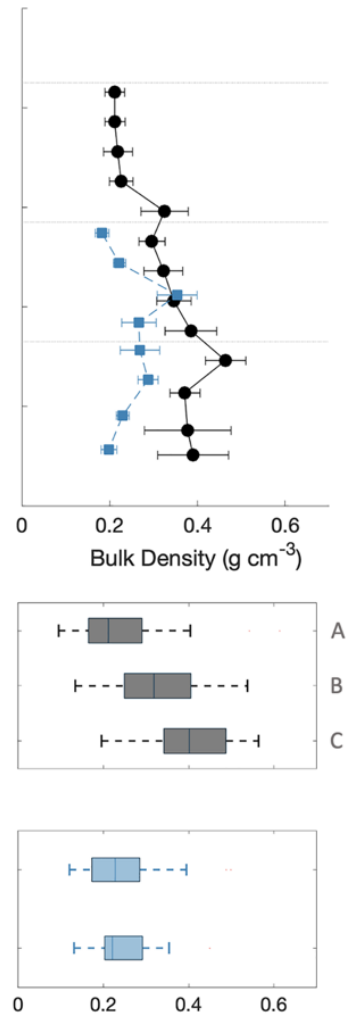

(c)

(d)
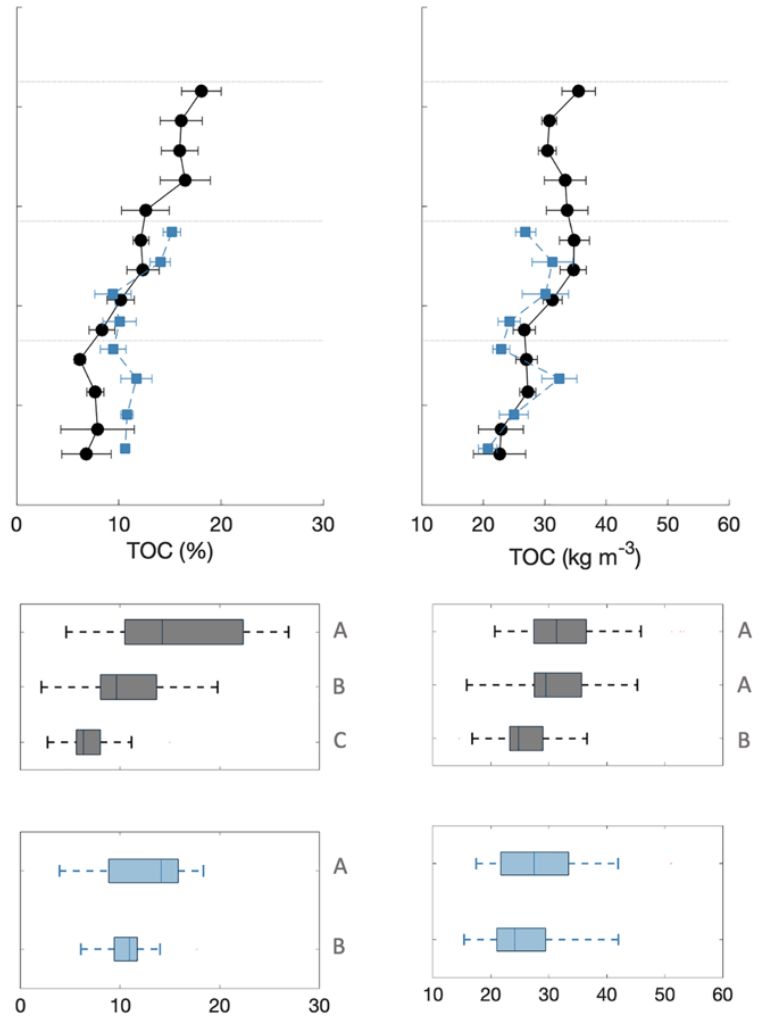
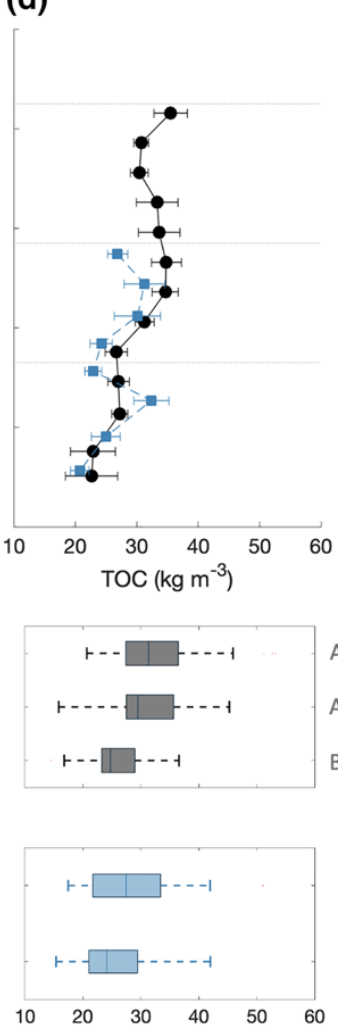

Figure 1: (Top) Marsh and pond soil (a) water content, (b) bulk density, and (c and d) TOC content at $6 \mathrm{~cm}$ increments and (bottom) within pooled depth zones: (i) shallow marsh (0-30 $\mathrm{cm})$, (ii) intermediate marsh (30-54 cm) and shallow pond (0-24 cm), and (iii) deep marsh (54$77 \mathrm{~cm})$ and pond $(24-50 \mathrm{~cm})$. Data represent means and SE; uppercase letters indicate zones are significantly different $(p<0.05)$ within marsh and pond soils, separately (supporting information 2.3). TOC, total organic carbon; SE, standard error. 

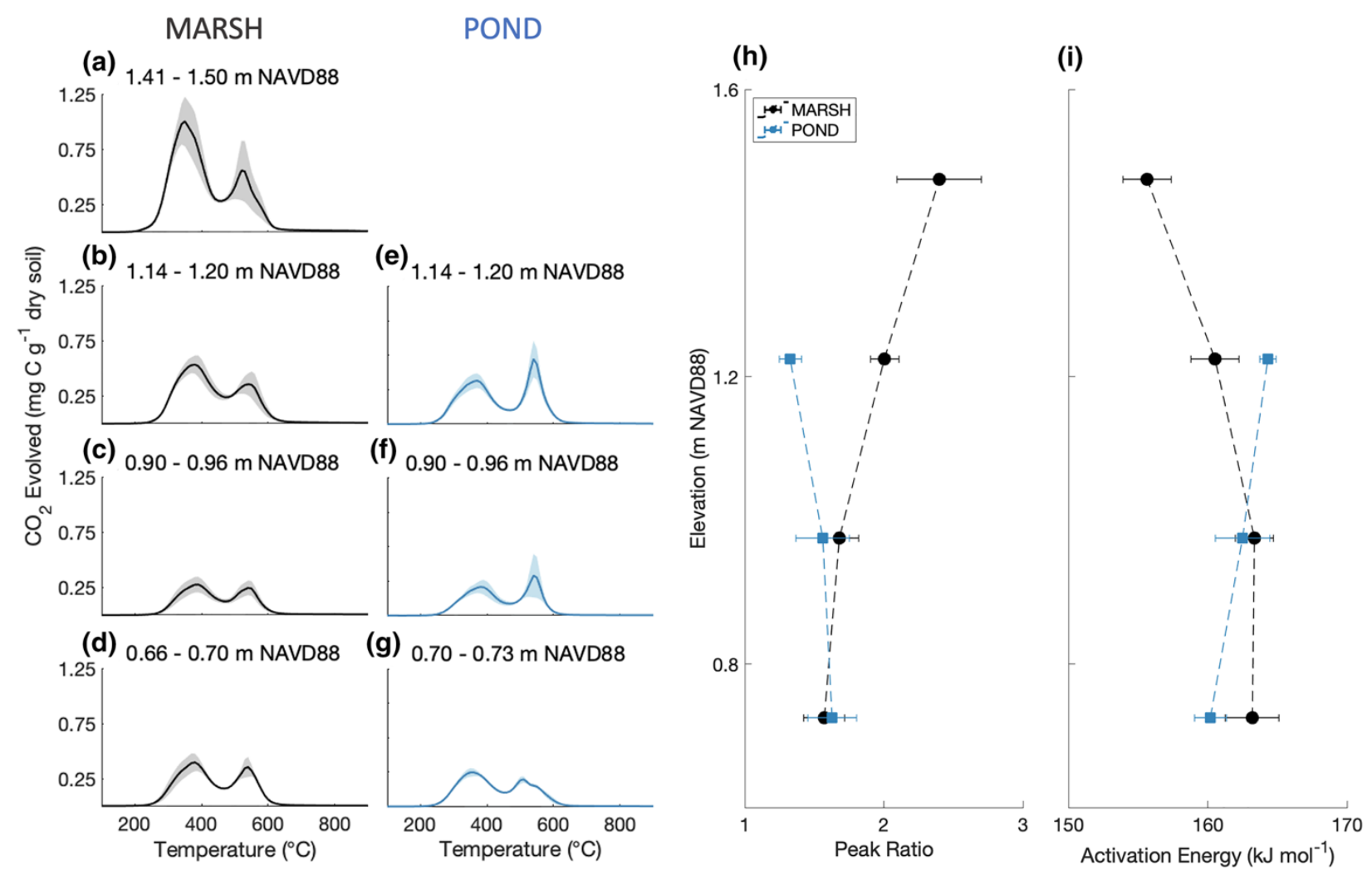

Figure 2: Thermograms of the mean and $\mathrm{SE}$ of $\mathrm{CO} 2$ evolved from marsh and pond horizons at similar elevations $(\mathrm{a}-\mathrm{g})$ were used to calculate two thermal reactivity indices, low-temperature versus high-temperature peak ratios (h) and activation energy required to combust SOC (i). SE, standard error; SOC, soil organic carbon. 

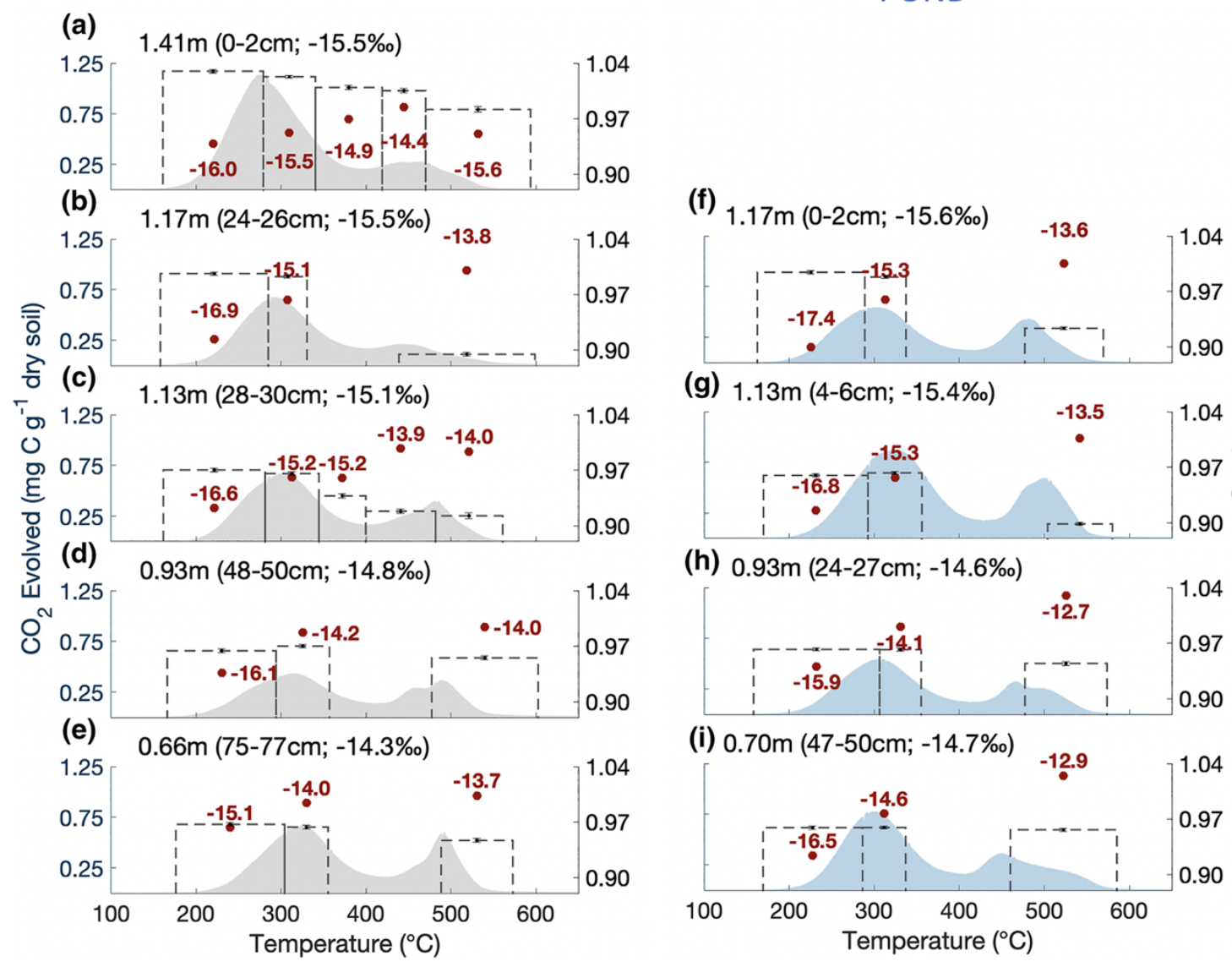

(g) $1.13 \mathrm{~m}(4-6 \mathrm{~cm} ;-15.4 \%)$

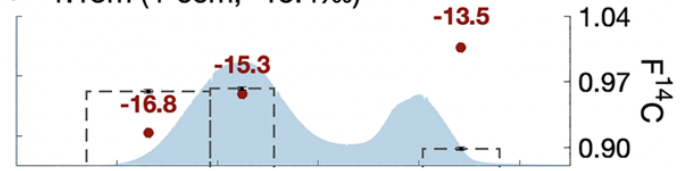

(h) $0.93 \mathrm{~m}(24-27 \mathrm{~cm} ;-14.6 \%)$

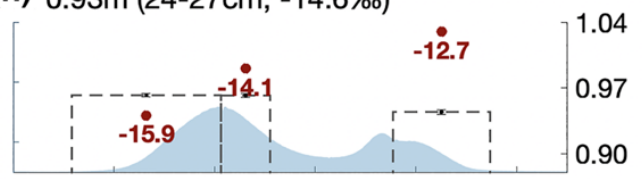

(i) $0.70 \mathrm{~m}(47-50 \mathrm{~cm} ;-14.7 \%)$

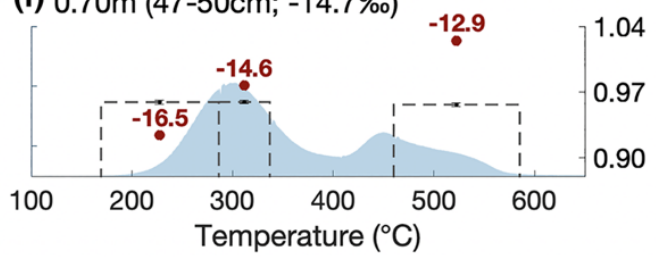

Figure 3. Thermal properties, sources $\left(\delta^{13} \mathrm{C}\right)$, and ages $\left(\mathrm{F}^{14} \mathrm{C}\right)$ of marsh $(\mathrm{a}-\mathrm{e})$ and pond $(\mathrm{f}-\mathrm{i}) \mathrm{SOC}$ at one site. Dotted bars are $\mathrm{F}^{14} \mathrm{C}$ values for $\mathrm{CO}_{2}$ fractions collected over a temperature interval (bar width) with associated analytical error. The $\delta^{13} \mathrm{C}-\mathrm{CO}_{2}$ from fractions are indicated in red. Pond and marsh horizons were paired by elevation (NAVD88, m); soil depth and bulk soil $\delta^{13} \mathrm{C}$ are in parentheses. NAVD88, North American Vertical Datum of 1988. 



Figure 4. Turnover times estimated by (a) one-pool and (b) two-pool models for all marsh sites and (c) a five-pool model for one marsh site. Measured $\mathrm{CO} 2$ concentrations (dots) from compositionally distinct fine $\mathrm{SOC} \mathrm{CO}_{2}$ fractions were modeled against soil age estimates in years. Dashed lines are modeled turnover times. Inset lists the best fit rate and range for each modeled pool (Table S6). SOC, soil organic carbon. 


\section{SUPPLEMENTARY TABLES AND FIGURES}

Table S1: Marsh and pond soil properties. Mean values are listed followed by the SE in parenthesis. Differences between marsh and pond properties within an elevation (m NAVD88) horizon were detected with one-way ANOVAs; significant differences are denoted by bolded text $(\mathrm{p}<0.05)$. Data are presented in Fig. 1.

\begin{tabular}{|c|c|c|c|c|c|c|c|c|}
\hline \multirow[b]{2}{*}{ Elevation } & \multicolumn{2}{|c|}{$\begin{array}{c}\text { Water } \\
\text { content } \\
(\%) \\
\end{array}$} & \multicolumn{2}{|c|}{$\begin{array}{l}\text { Bulk density } \\
\qquad\left(\mathrm{g} \mathrm{cm}^{-3}\right)\end{array}$} & \multicolumn{2}{|c|}{$\begin{array}{r}\text { TOC } \\
(\%)\end{array}$} & \multicolumn{2}{|c|}{$\begin{array}{c}\text { TOC } \\
\left(\mathrm{kg} \mathrm{m}^{-3}\right)\end{array}$} \\
\hline & Marsh & Pond & Marsh & Pond & Marsh & Pond & Marsh & Pond \\
\hline $1.13-1.15$ & $\begin{array}{l}74.0 \\
(1.6)\end{array}$ & $\begin{array}{l}82.5 \\
(0.9)\end{array}$ & $\begin{array}{c}0.30 \\
(\mathbf{0 . 0 3})\end{array}$ & $\begin{array}{c}0.18 \\
(0.02)\end{array}$ & $\begin{array}{l}12.1 \\
(0.8)\end{array}$ & $\begin{array}{l}15.2 \\
(0.9)\end{array}$ & $\begin{array}{l}34.8 \\
(2.4)\end{array}$ & $\begin{array}{l}26.9 \\
(1.6)\end{array}$ \\
\hline $1.07-1.09$ & $\begin{array}{l}72.9 \\
(2.6)\end{array}$ & $\begin{array}{l}79.2 \\
(1.3)\end{array}$ & $\begin{array}{c}0.32 \\
(0.04)\end{array}$ & $\begin{array}{c}0.22 \\
(0.01)\end{array}$ & $\begin{array}{l}12.4 \\
(1.6)\end{array}$ & $\begin{array}{l}14.1 \\
(1.0)\end{array}$ & $\begin{array}{l}34.7 \\
(2.1)\end{array}$ & $\begin{array}{l}31.2 \\
(3.3)\end{array}$ \\
\hline $1.01-1.02$ & $\begin{array}{l}68.9 \\
(2.6)\end{array}$ & $\begin{array}{l}71.4 \\
(2.7)\end{array}$ & $\begin{array}{c}0.35 \\
(0.04)\end{array}$ & $\begin{array}{c}0.35 \\
(0.05)\end{array}$ & $\begin{array}{l}10.2 \\
(1.4)\end{array}$ & $\begin{array}{c}9.4 \\
(1.8)\end{array}$ & $\begin{array}{l}31.2 \\
(1.6)\end{array}$ & $\begin{array}{l}30.1 \\
(3.8)\end{array}$ \\
\hline $0.95-0.97$ & $\begin{array}{l}66.5 \\
(3.4)\end{array}$ & $\begin{array}{l}75.8 \\
(3.1)\end{array}$ & $\begin{array}{c}0.39 \\
(0.06)\end{array}$ & $\begin{array}{c}0.27 \\
(0.04)\end{array}$ & $\begin{array}{c}8.3 \\
(1.3)\end{array}$ & $\begin{array}{l}10.1 \\
(1.6)\end{array}$ & $\begin{array}{l}26.7 \\
(1.8)\end{array}$ & $\begin{array}{l}24.2 \\
(1.8)\end{array}$ \\
\hline $0.89-0.91$ & $\begin{array}{l}61.8 \\
(1.7)\end{array}$ & $\begin{array}{l}76.4 \\
(3.1)\end{array}$ & $\begin{array}{c}0.46 \\
(0.05)\end{array}$ & $\begin{array}{c}0.27 \\
(0.04)\end{array}$ & $\begin{array}{c}6.2 \\
(0.5)\end{array}$ & $\begin{array}{c}9.4 \\
(1.3)\end{array}$ & $\begin{array}{c}27 \\
(1.7)\end{array}$ & $\begin{array}{l}22.9 \\
(1.4)\end{array}$ \\
\hline $0.83-0.85$ & $\begin{array}{l}66.9 \\
(1.8)\end{array}$ & $\begin{array}{l}74.2 \\
(1.7)\end{array}$ & $\begin{array}{c}0.37 \\
(0.03)\end{array}$ & $\begin{array}{c}0.29 \\
(0.02)\end{array}$ & $\begin{array}{c}7.7 \\
(0.8)\end{array}$ & $\begin{array}{l}11.7 \\
(1.5)\end{array}$ & $\begin{array}{l}27.3 \\
(1.3)\end{array}$ & $\begin{array}{l}32.4 \\
(2.8)\end{array}$ \\
\hline $0.75-0.78$ & $\begin{array}{l}66.4 \\
(6.9)\end{array}$ & $\begin{array}{l}78.9 \\
(0.9)\end{array}$ & $\begin{array}{c}0.38 \\
(0.10)\end{array}$ & $\begin{array}{c}0.23 \\
(0.01)\end{array}$ & $\begin{array}{c}7.9 \\
(3.6)\end{array}$ & $\begin{array}{l}10.8 \\
(0.6)\end{array}$ & $\begin{array}{l}22.9 \\
(3.6)\end{array}$ & $\begin{array}{l}25.0 \\
(2.4)\end{array}$ \\
\hline $0.70-0.71$ & $\begin{array}{l}65.8 \\
(4.7)\end{array}$ & $\begin{array}{l}78.8 \\
(1.7)\end{array}$ & $\begin{array}{c}0.39 \\
(0.08)\end{array}$ & $\begin{array}{c}0.20 \\
(0.02)\end{array}$ & $\begin{array}{c}6.8 \\
(2.4)\end{array}$ & $\begin{array}{l}10.6 \\
(0.4)\end{array}$ & $\begin{array}{l}22.7 \\
(4.2)\end{array}$ & $\begin{array}{l}20.7 \\
(1.5)\end{array}$ \\
\hline
\end{tabular}


Table S2. Low : high temperature peak ratios for the three marsh and pond sites. Values are the mean and SE in parentheses; significant differences within an elevation (m NAVD88) horizon are denoted by bolded text $(\mathrm{p}<0.05)$ based on one-way ANOVAs.

\begin{tabular}{c|cc}
\hline & \multicolumn{2}{|c}{ Peak ratio } \\
\hline Elevation & Marsh & Pond \\
\hline 1.48 & $2.40(0.30)$ & \\
1.23 & $\mathbf{2 . 0 0 ( \mathbf { 0 . 1 0 } )}$ & $\mathbf{1 . 3 3 ( \mathbf { 0 . 0 8 } )}$ \\
0.98 & $1.68(0.14)$ & $1.56(0.19)$ \\
0.73 & $1.57(0.15)$ & $1.63(0.18)$ \\
\hline
\end{tabular}


Table S3: Mean and SE vertical accretion rates (AR; $\mathrm{mm} \mathrm{yr}^{-1}$ ) for the three marsh platform sites using the CRS and CIC models.

\begin{tabular}{c|cc}
\hline Site & CRS & CIC \\
\hline 1 & $4.06(0.48)$ & $1.90(0.49)$ \\
2 & $3.47(0.52)$ & $2.61(0.91)$ \\
3 & $6.40(0.90)$ & $2.91(0.56)$ \\
\hline Average & $4.64(0.38)$ & $2.47(0.39)$ \\
\hline
\end{tabular}


Table S4: Conservative age ranges for soil depths analyzed by RPO for the three marsh sites. Minimum and maximum ages for horizons prior to 1900 were obtained from the extended CIC model, RSLR, and GIA rates. Ranges for 1900 onward were selected from the CIC and CRS ${ }^{210} \mathrm{~Pb}$ age models and relative sea-level rise from the Boston tide gauge. Missing values (NaN) for Site 1 and 2 are due to the higher resolution of RPO horizons for carbon isotopic analysis at Site 3.

\begin{tabular}{c|ccc}
\hline & \multicolumn{3}{|c}{ Site } \\
\hline Depth (cm) & $\mathbf{1}$ & $\mathbf{2}$ & $\mathbf{3}$ \\
\hline $0-2$ & $3-5$ & $3-8$ & $3-6$ \\
$24-26$ & $\mathrm{NaN}$ & $\mathrm{NaN}$ & $59-105$ \\
$28-30$ & $\mathrm{NaN}$ & $\mathrm{NaN}$ & $69-122$ \\
$30-34$ & $129-294$ & $88-180$ & $101-153$ \\
$48-54$ & $229-774$ & $156-614$ & $141-433$ \\
$75-80$ & $317-1,194$ & $230-1,134$ & $219-973$ \\
\hline
\end{tabular}


Table S5: Soil horizon ages based on carbon isotopes $\left(\mathrm{F}^{14} \mathrm{C}\right.$ and ${ }^{14} \mathrm{C}$ Age $)$ and reconstructions from ${ }^{210} \mathrm{~Pb}$ and RLSR models. Results are presented for marsh and pond cores selected for further isotopic analysis and are the basis for the five-pool model. Marsh and pond horizons ordered by elevation and temperature fractions $(\mathrm{F})$.

\begin{tabular}{|c|c|c|c|c|c|}
\hline & & $\mathbf{F}$ & $\begin{array}{c}{ }^{14} C \\
\left(F^{14} C\right)\end{array}$ & ${ }^{14} \mathrm{C}$ Age & $\begin{array}{c}\text { Soil Age } \\
\text { Reconstruction }\end{array}$ \\
\hline \multirow{19}{*}{$\frac{\sigma}{\sum_{0}^{\infty}}$} & \multirow{5}{*}{$\begin{array}{c}1.41 \mathrm{~m} \\
(0-2 \mathrm{~cm})\end{array}$} & 1 & 1.03 & $>$ Modern & $3-6$ \\
\hline & & 2 & 1.02 & $>$ Modern & $3-6$ \\
\hline & & 3 & 1.01 & $>$ Modern & $3-6$ \\
\hline & & 4 & 1.01 & $>$ Modern & $3-6$ \\
\hline & & 5 & 0.98 & $175 \pm 30$ & $3-6$ \\
\hline & \multirow{3}{*}{$\begin{array}{c}1.17 \mathrm{~m} \\
(24- \\
26 \mathrm{~cm})\end{array}$} & 1 & 1.00 & $40 \pm 15$ & $59-105$ \\
\hline & & 2 & 0.99 & $65 \pm 15$ & $59-105$ \\
\hline & & 5 & 0.89 & $915 \pm 20$ & $59-105$ \\
\hline & \multirow{5}{*}{$\begin{array}{c}1.13 \mathrm{~m} \\
(28- \\
30 \mathrm{~cm})\end{array}$} & 1 & 0.97 & $255 \pm 15$ & $69-122$ \\
\hline & & 2 & 0.97 & $285 \pm 15$ & $69-122$ \\
\hline & & 3 & 0.94 & $530 \pm 20$ & $69-122$ \\
\hline & & 4 & 0.92 & $695 \pm 25$ & $69-122$ \\
\hline & & 5 & 0.91 & $750 \pm 30$ & $69-122$ \\
\hline & \multirow{3}{*}{$\begin{array}{c}0.93 \mathrm{~m} \\
(48- \\
50 \mathrm{~cm})\end{array}$} & 1 & 0.96 & $315 \pm 20$ & $141-433$ \\
\hline & & 2 & 0.97 & $250 \pm 15$ & $141-433$ \\
\hline & & 5 & 0.96 & $390 \pm 20$ & $141-433$ \\
\hline & \multirow{3}{*}{$\begin{array}{c}0.66 \mathrm{~m} \\
(75- \\
77 \mathrm{~cm})\end{array}$} & 1 & 0.97 & $285 \pm 15$ & $219-973$ \\
\hline & & 2 & 0.96 & $305 \pm 20$ & $219-973$ \\
\hline & & 5 & 0.95 & $455 \pm 20$ & $219-973$ \\
\hline
\end{tabular}




\begin{tabular}{|c|c|c|c|c|}
\hline \multirow{3}{*}{$\begin{array}{c}1.17 \mathrm{~m} \\
(0-2 \mathrm{~cm})\end{array}$} & 1 & 0.99 & $55 \pm 15$ & $59-105$ \\
\hline & 2 & 0.99 & $100 \pm 15$ & $59-105$ \\
\hline & 5 & 0.92 & $650 \pm 15$ & $59-105$ \\
\hline \multirow{3}{*}{$\begin{array}{c}1.13 \mathrm{~m} \\
(4-6 \mathrm{~cm})\end{array}$} & 1 & 0.96 & $340 \pm 15$ & $69-122$ \\
\hline & 2 & 0.96 & $310 \pm 15$ & $69-122$ \\
\hline & 5 & 0.90 & $870 \pm 15$ & $69-122$ \\
\hline \multirow{3}{*}{$\begin{array}{c}0.93 \mathrm{~m} \\
(24- \\
26 \mathrm{~cm})\end{array}$} & 1 & 0.96 & $320 \pm 15$ & $141-433$ \\
\hline & 2 & 0.96 & $320 \pm 15$ & $141-433$ \\
\hline & 5 & 0.94 & $475 \pm 20$ & $141-433$ \\
\hline \multirow{3}{*}{$\begin{array}{c}0.70 \mathrm{~m} \\
(47- \\
50 \mathrm{~cm})\end{array}$} & 1 & 0.96 & $350 \pm 15$ & $219-973$ \\
\hline & 2 & 0.96 & $340 \pm 15$ & $219-973$ \\
\hline & 5 & 0.96 & $375 \pm 20$ & $219-973$ \\
\hline
\end{tabular}


Table S6. Parameter estimates for the one-, two-, and five-pool models. The best fit model parameters (best fit) and error ranges (min and max) were obtained by minimizing RMSE and accepting model parameters where the linear regression fit between observed and predicted had a slope and intercept of $1 \pm \mathrm{SE}$ and $0 \pm \mathrm{SE}$, respectively. Parameter ranges set within the model are provided (model range). Fit statistics (RMSE) of the best fit model are provided for each pool.

\begin{tabular}{ccccc}
\hline \multicolumn{5}{c}{ One Pool Model: } \\
\hline & Best fit & Min & Max & Model range \\
\hline $\mathrm{x} 01$ & 151 & 71 & 231 & $1-300$ \\
$\tau_{1}$ & 750 & 381 & 9,991 & $0.5-10,000$ \\
input1 & 0 & 0 & 2 & $0-3$ \\
\hline
\end{tabular}

\begin{tabular}{|c|c|c|c|c|}
\hline \multicolumn{2}{|c|}{ Fit Statistics } & & & \\
\hline Pool & RMSE & & & \\
\hline 1 & 41.3 & & & \\
\hline \multicolumn{5}{|c|}{ Two Pool Model: All Marsh Sites } \\
\hline & Best fit & Min & Max & Model range \\
\hline $\mathrm{x} 01$ & 102 & 85 & 104 & $75-140$ \\
\hline $\mathrm{x} 02$ & 43 & 40 & 49 & $20-50$ \\
\hline$\tau_{1}$ & 640 & 601 & 1,140 & $0.5-10,000$ \\
\hline$\tau_{2}$ & 1,251 & 350 & 2,851 & $0.5-10,000$ \\
\hline input1 & 0 & 0 & 0 & $0-3$ \\
\hline input2 & 0 & 0 & 0 & $0-3$ \\
\hline r2 & 0 & 0 & 1 & $0-1$ \\
\hline
\end{tabular}

\begin{tabular}{|c|c|}
\hline \multicolumn{2}{|c|}{ Fit Statistics } \\
\hline Pool & RMSE \\
\hline 1 & 25.8 \\
\hline 2 & 16.2 \\
\hline Total & 42.0 \\
\hline
\end{tabular}




\begin{tabular}{ccccc}
\hline \multicolumn{5}{c}{ Five Pool Model: One Marsh Site } \\
\hline & Best fit & Min & Max & Model range \\
\hline x01 & 49 & 49 & 53 & $45-55$ \\
x02 & 35 & 35 & 42 & $35-50$ \\
x03 & 19 & 19 & 20 & $19-22$ \\
x04 & 15 & 14 & 15 & $15-$ Dec \\
x05 & 14 & 13 & 14 & $13-15$ \\
$\tau_{1}$ & 1,011 & 1,011 & 2,211 & $0.5-10,000$ \\
$\tau_{2}$ & 5,351 & 600 & 5,950 & $0.5-10,000$ \\
$\tau_{3}$ & 2,201 & 1,301 & 9,850 & $0.5-10,000$ \\
$\tau_{4}$ & 3,401 & 1,701 & 9,800 & $0.5-10,000$ \\
$\tau_{5}$ & 9,951 & 2,351 & 9,951 & $0.5-10,000$ \\
input1 & 0 & 0 & 0 & $0-3$ \\
input2 & 0 & 0 & 0 & $0-3$ \\
input3 & 0 & 0 & 0 & $0-3$ \\
input4 & 0 & 0 & 0 & $0-3$ \\
input5 & 0 & 0 & 0 & $0-3$ \\
r2 & 0 & 0 & 1 & $0-1$ \\
r3 & 1 & 0 & 1 & $0-1$ \\
r4 & 1 & 0.5 & 1 & $0-1$ \\
r5 & 1 & 0.5 & 1 & $0-1$ \\
\hline
\end{tabular}

Fit Statistics

\begin{tabular}{cc}
\hline Pool & RMSE \\
\hline 1 & 14.9 \\
2 & 8.6 \\
3 & 4.7 \\
4 & 3.2 \\
5 & 1.8 \\
\hline Total & 33.3 \\
\hline
\end{tabular}


Figure S1: Map of the three sites $\left(42.738139^{\circ},-70.847129^{\circ}\right)$ and paired ponds (blue dots) within PIE-LTER (Spivak et al., 2018).

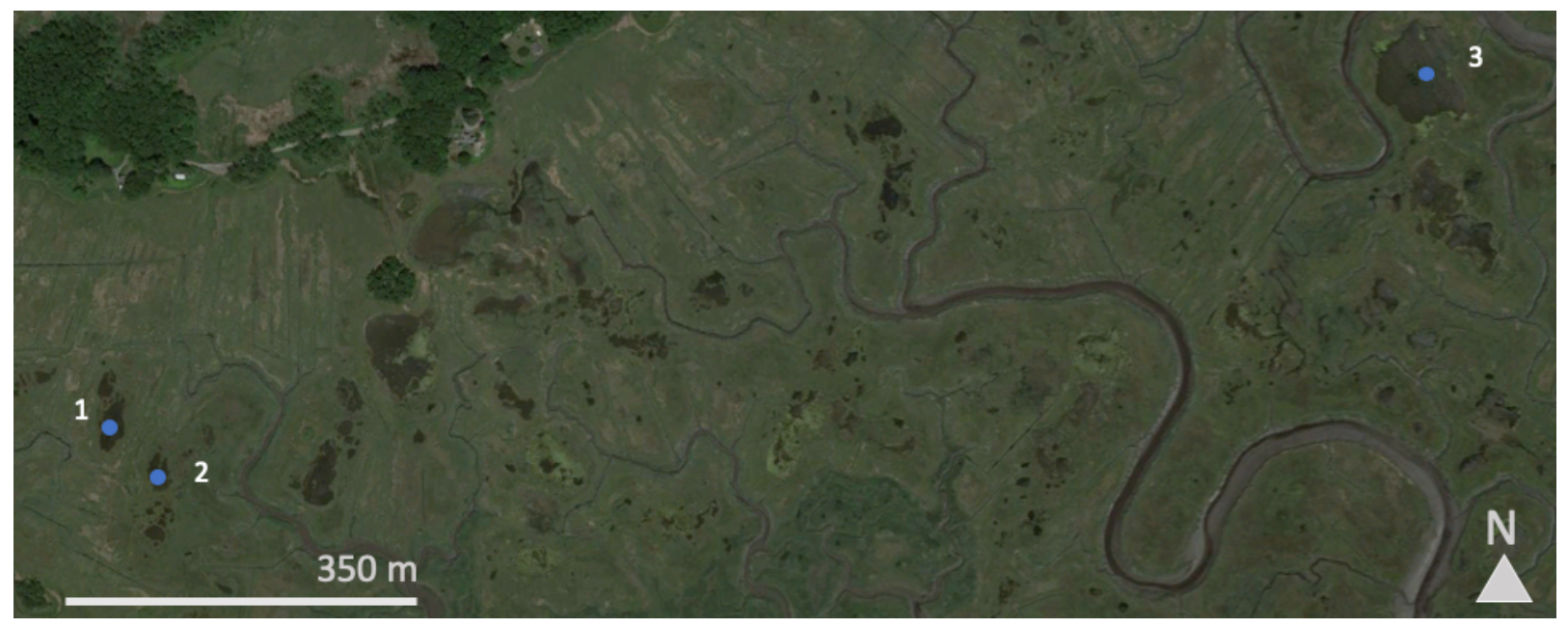




\title{
Chapter 3: The inclusion of ponds in the lateral and vertical variability of marsh carbon storage
}

\begin{abstract}
Disturbances to salt marsh ecosystem functioning have the potential to contribute uncertainty in regional-to-global estimates of tidal wetland carbon stocks. The expansion of shallow ponds within salt marshes are linked with certain resource management strategies and sealevel rise. We characterized pond and marsh soil composition, sources, and reactivity in a mesotidal marsh in New England to determine how ponds affect carbon dynamics on the marsh platform. Differences in soil composition between ponds and the adjacent marsh are consistent with the shifts from emergent to submerged environment, primary producer communities, and accelerated microbial decomposition. Accumulation of more detrital organic matter, determined by hydrocarbon composition and thermal reactivity proxies, in pond surface soils compared to the marsh indicate decomposition of long-buried marsh organic carbon. We calculated the contribution of erosion ( $35-38 \%)$ and decomposition $\left(22-33 \% ; 32-132.8 \mathrm{~g} \mathrm{C} \mathrm{m}^{-2} \mathrm{yr}^{-1}\right)$ to soil carbon loss during pond deepening over the past 38- 52 years that play a role in surficial pond soil dynamics. Accounting for ponds in salt marsh carbon accounting for our study site led to a 5\% difference in carbon budget estimates. This difference increased for microtidal marshes experiencing greater ponding aerial extents, highlighting the need to include spatial heterogeneities within the marsh platform during marsh carbon accounting. Constraining the influence of pond features within the salt marsh landscape as well as processes that contribute to pond development can therefore help refine marsh soil carbon budgets and ecosystem services.
\end{abstract}




\subsection{INTRODUCTION}

Disturbances to salt marsh ecosystems have the potential to alter important ecosystem functions (e.g. primary productivity, nutrient utilization) and the subsequent delivery of valuable marsh ecosystem services to human populations (e.g. carbon storage, storm surge buffering). Increasing sea-level rise rates and changes in hydrological management strategies can catalyze the conversion of vegetated marsh interior habitats into open water environments through shallow pond development (Wilson et al., 2014a; Watson et al., 2017). However, it is unclear whether ponds impact the structure and functioning of the surrounding salt marsh and how pond expansion processes alter the fate of long-buried carbon vital to marsh carbon storage services. Through understanding how ponds have impacted historical and current marsh carbon accumulation and the fate of carbon associated with pond expansion, we can better constrain the impacts of these marsh features on ecosystem functioning and estimates of tidal wetland carbon stocks.

Salt marsh ponds expand on the marsh platform through increased waterlogging of marsh soils, loss of emergent grass species (e.g. Spartina alterniflora) that contribute to high rates of marsh carbon burial, as well as potential export of buried soil organic carbon via pond erosion and decomposition (Adamowicz and Roman, 2005; Mariotti, 2016; Luk et al., 2021). The mechanism of pond-deepening, via physical erosion or organic matter decomposition, has different implications for the fate of salt marsh carbon. Eroded salt marsh soil carbon may be redistributed within the marsh environment (Hopkinson et al., 2018; Luk et al., 2021), exported to coastal bays and oceans, or respired and lost as $\mathrm{CO}_{2}$ (g) or dissolved inorganic carbon (DIC). Alternatively, in situ decomposition of long-buried marsh soils as ponds deepen and expand results in the export of carbon as DOC, DIC lateral flux and $\mathrm{pCO}_{2}$ evasion (Childers et al., 2000; Tobias and Neubauer, 2019). These potential soil loss processes within ponds occur alongside accretion of the surrounding marsh platform that contribute further to additional pond deepening. Characterizing and quantifying the importance each process plays during pond development can aid future predictions of soil carbon dynamics within marsh evolution models.

Previous studies of salt marsh ponds focused on surficial soil dynamics and found that these features are biogeochemically distinct within the marsh environment, particularly with respect to carbon cycling (Spivak et al., 2017, 2018; Luk et al., 2021). In comparison to the surrounding marsh dominated by emergent marsh grasses, pond surface soils are characterized with submerged plants (Ruppia maritima) and active bacterial communities that decompose multiple carbon sources coinciding with a higher concentration of thermally stable soil organic carbon (SOC) (Spivak et al., 2018; Luk et al., 2021). Current estimates of pond decomposition rates (11-172 $\mathrm{g} \mathrm{C} \mathrm{m}^{-2} \mathrm{yr}^{-1}$; Spivak et al., 2018, 2020) were approximated using techniques that include seasonally-averaged soil DIC fluxes and whole-pond dissolved oxygen fluxes. These measurements come with the caveats of deriving long-term decomposition rates from short-term (months - year) water column $\mathrm{O}_{2}$ fluxes and DIC sediment profiles; decomposition via sulfate reduction would not be captured by dissolved oxygen fluxes and respiration rates based on porewater DIC profiles are a net total of sediment processes that could potentially result in underestimating decomposition (Spivak et al., 2017, 2018). 
Characterization of soil records of ponds and the adjacent marsh landscape through measurements of bulk soil composition, lipid biomarkers, and soil organic carbon thermal reactivity can provide additional insight into long-term pond decomposition process as well as potential gradients in organic matter inputs, reactivity, and decomposition in the marsh landscape (Canuel and Martens, 1993, 1996; Canuel et al., 1997). Measurements of multiple lipid biomarker classes from fatty acids to hydrocarbons - representing fresh, recently senesced to detrital material, respectively - can address finer-scale shifts in the sources and reactivity of long-buried marsh carbon associated with pond deepening (Canuel et al., 1997; Bianchi and Canuel, 2011). Thermal analyses of bulk soil organic carbon (SOC) can be utilized as a proxy of SOC reactivity to assess SOC stability and decomposition patterns (Rosenheim et al., 2008; Plante et al., 2011; Williams and Rosenheim, 2015). Differences in surface to deep soil properties within ponds (e.g. decreased carbon content, increased accumulation of thermally stable SOC and detrital material) compared to the surrounding marsh can reveal pond decomposition processes that have altered long-buried marsh soils and directly exported soil carbon out of the marsh system. If differences exist, an additional unknown is whether ponds simply represent isolated biogeochemical features or the presence of an inundated pool on the marsh platform propagates outward into adjacent marsh soils, contributing to larger-scale marsh ecosystem spatial variability. Soil records capturing potential relationships with distance from and within pond features provide characterizations of vertical pond soil properties pertinent to regional carbon stock assessments and the potential lateral influence of ponds in the upper meter of the marsh platform.

In this study, we aim to understand 1) whether ponds impact soil carbon dynamics of the surrounding marsh soils and 2) tease apart the soil processes that play a role in pond deepening and how it may alter the fate of carbon within the system. Firstly, to understand whether ponds affect the structural integrity of the surrounding marsh and how far that signal may propagate, we characterized soil characteristics that we expected to demonstrate changes in marsh integrity (e.g. elevation, bulk density, accretion rates, and carbon content) at differing distances from ponds. Secondly, we analyzed pond soil records using bulk soil properties, lipid biomarkers, and indices of thermal reactivity to understand longer-term pond soil processes associated with shifts in organic matter inputs, decomposition, and soil erosion. Finally, we used radioisotope diffusionmigration and simple wave-driven erosion models to assess the relative contributions of erosion and decomposition via pond deepening and how this balance may impact whole-ecosystem carbon budgets. We hypothesized that downcore soil properties would differ within the ponds compared to the vegetated marsh, reflecting the inundated nature of the marsh soils, shifts in marsh vegetation, and increased soil organic matter decomposition. Further, we posit that both organic matter decomposition and erosion equally contribute to pond deepening, demonstrating an additional carbon loss pathway and source of uncertainty within the overall salt marsh carbon budget.

\subsection{METHODS}

3.2.1 Study location and sample collection 
We focused on three ponds and the surrounding high marshes within the Plum Island Ecosystems - Long Term Ecological Research (PIE-LTER) project site (Fig. 1). The three ponds have similar depths $(0.24-0.30 \mathrm{~m})$ and were previously characterized for ecological and biogeochemical processes describing metabolic rates (Spivak et al. 2017, 2018, 2020). The marshes surrounding the ponds are at similar elevations $(1.41-1.51 \mathrm{~m}$ North American Vertical Datum of 1988 [NAVD88]) and dominated by S. patens, S. alterniflora, and Distichlis spicata grasses. At each of the three sites, we collected one pond soil core $(60 \mathrm{~cm})$ and two marsh soil cores $(90 \mathrm{~cm}$ ) that were 10 - $12 \mathrm{~m}$ (core M1) and 20 - $29 \mathrm{~m}$ (core M2) away. Sampling distances reflected the goal of capturing spatial gradients that reflect zones with lesser (M2) or greater (M1) pond influence (e.g., transitions from S. alterniflora to D. spicata) and were physically constrained by tidal channels and mosquito ditches. There were not significant differences in elevations between the M1 and M2 marsh environments.

Soil cores were collected in the Summer - Fall of 2014 and were kept cold until processing within 1- 2 days. Cores were split lengthwise with one half sectioned at 1-2 cm intervals (bulk properties, elemental composition, radioisotope activities) and the other half at 2-5 cm (organic matter composition), with greater resolution in surface horizons. Sampling resolutions reflected our expectation that compositional changes would be concentrated in pond surface horizons, particularly within the $R$. maritima rooting zone $(0-10 \mathrm{~cm})$, and that physical changes in the marsh platform caused by ponding would be evident in horizons that overlapped with pond surface waters (i.e., 0-30 cm). The lower resolution of organic matter characterizations also reflected the time intensive nature and costs associated with these analyses.

\subsubsection{Bulk soil properties and elemental composition}

Soil bulk density $\left(\mathrm{g} \mathrm{cm}^{-3}\right)$ was determined gravimetrically by drying to constant mass $\left(60^{\circ} \mathrm{C}\right)$. Soils were then sieved $(<1 \mathrm{~mm})$ to remove large roots to focus on the fine fraction of soils consistent with functional definitions of refractory soil organic carbon (SOC). In preparation for elemental and isotopic analysis, samples were homogenized with a Retsch Mixer Mill 200. A majority $(90 \%)$ of samples were fumed with $12 \mathrm{~N}$ hydrochloric $(\mathrm{HCl})$ acid to remove inorganic carbonates (Hedges and Stern, 1984; Lorrain et al., 2003) and analyzed for total organic carbon [TOC] and total nitrogen [TN] at the Stable Isotope Laboratory at the Marine Biological Laboratory (MBL; Woods Hole, MA). Due to time constraints, the remaining horizons ( $10 \%)$ were analyzed via Fourier transform infrared spectroscopy and partial least squares regressions to estimate TOC (Luk et al., 2021).

Stable isotope analyses $\left(\delta^{13} \mathrm{C}, \delta^{15} \mathrm{~N} ; \%\right.$ ) were conducted to determine whether organic matter sources were similar in pond and marsh soils. Soils from the far marsh cores (M2) were selected for these analyses because we expected a stronger contrast against pond soils. Marsh surface (0$30 \mathrm{~cm}$ ) soils were analyzed at a $10 \mathrm{~cm}$ resolution while overlapping marsh and pond horizons were analyzed at a 4-6 $\mathrm{cm}$ resolution. 


\subsubsection{Lipid biomarkers}

We further assessed soil organic matter sources and reactivity by characterizing source-specific biomarkers in the ponds and far marsh sites (M2). We focused on two classes of biomarkers, fatty acids and hydrocarbons, as they represent compounds associated with fresh and detrital material, respectively, and thereby provide complementary source information (Bianchi and Canuel, 2011). Lipid biomarkers were extracted using a modified Bligh and Dyer (1959) method (Spivak, 2015). Briefly, sediments were extracted using a methanol : chloroform : phosphate buffer saline mixture $(2: 1: 0.8, \mathrm{v}: \mathrm{v}: \mathrm{v})$ with a microwave-accelerated reaction system (MARS6) that heated samples to $80^{\circ} \mathrm{C}$ for 10 minutes with constant stirring. Samples were then partitioned and the organic phase removed. The total lipid extract was concentrated under nitrogen gas and elemental sulfur was removed by filtration through acid-rinsed copper. Extracts were resuspended in hexane and sequentially separated into four fractions by solid phase extraction on Discovery DSC-NH stationary phase $(1 \mathrm{~g})$ : F1 $5 \mathrm{~mL}$ hexane; F2 $8 \mathrm{~mL}$ of 4:1 hexane : methylene chloride; F3 $10 \mathrm{~mL}$ of 9: 1 methylene chloride : acetone; F4 $15 \mathrm{~mL}$ of $2 \%$ formic acid in methylene chloride (Sessions, 2006). The $\mathrm{F} 4$ fraction was methylated with acidic methanol $(95: 5$, methanol : $\mathrm{HCl})$ and heated overnight at $70{ }^{\circ} \mathrm{C}$ to form fatty acid methyl esters (FAMES). The F1 (hydrocarbons) and $\mathrm{F} 4$ (FAMEs) were analyzed with an Agilent 7890 gas chromatograph with the effluent split $~ 70: 30$ between a $5975 \mathrm{C}$ mass spectrometer and a flame ionization detector. Compounds were separated on an Agilent DB-5 column ( $60 \mathrm{~m}, 0.25 \mathrm{~mm}$ inner diameter, $0.25 \mu \mathrm{m}$ film). Hydrocarbon and FAMEs concentrations were quantified using a methyl heneicosanoate internal standard. Percent composition was calculated by normalizing to the total concentration.

\subsubsection{Thermal reactivity}

We assessed the thermal reactivity of soil organic carbon using ramped pyrolysis oxidation (RPO) at the National Ocean Sciences Accelerator Mass Spectrometry Facility (Woods Hole MA; Luk et al. 2021). Selected horizons from the $\mathrm{M} 2$ and pond cores captured the marsh surface $(0 \mathrm{~cm}$ marsh), pond surface ( $\sim 30 \mathrm{~cm}$ marsh; $0 \mathrm{~cm}$ pond), and deeper horizons ( $\sim 80 \mathrm{~cm}$ marsh; $\sim 50 \mathrm{~cm}$ pond, NAVD88 for both). Homogenized samples were placed in a reactor where temperatures ramped from ambient to $1000^{\circ} \mathrm{C}$ under a constant flow of ultra-high purity helium and oxygen to promote thermal degradation and oxidation of SOC $\left(20^{\circ} \mathrm{C} \mathrm{min}^{-1}\right.$; Rosenheim et al., 2008). The evolved carbon dioxide $\left(\mathrm{CO}_{2}\right)$ was measured using an infrared gas analyzer. We used the temperature at which $50 \%$ of $\mathrm{CO}_{2}$ evolved (t50) as a proxy of thermal reactivity.

\subsubsection{Radiometric dating and accretion rates}

Soil accretion rates were constrained by developing geochronology models based on measurements of ${ }^{137} \mathrm{Cs},{ }^{210} \mathrm{~Pb}$, and ${ }^{226} \mathrm{Ra}$ on a planar-type gamma counter (Canberra, Inc. USA; Gonneea et al., 2019). In this study, estimates of soil accretion rates obtained from ${ }^{210} \mathrm{~Pb}$ provided rates that varied with depth into the soil core with ${ }^{137} \mathrm{Cs}$ providing an additional constraint on the $\sim 1954$ soil horizon. Activities of ${ }^{226} \mathrm{Ra}$ and ${ }^{210} \mathrm{~Pb}$ were then processed with the rPlum (0.2.2) package for $\mathrm{R}$, in order to obtain Bayesian-based accretion rate estimates and $95 \%$ confidence 
intervals (Aquino-López et al., 2018a). The model was run using measured ${ }^{226} \mathrm{Ra}$ activities as individual estimates of supported ${ }^{210} \mathrm{~Pb}$ within each soil horizon. Pond accretion rates could not be obtained due to violation of steady-state assumptions (Luk et al., 2021). Total ${ }^{210} \mathrm{~Pb}$ inventories within the marsh and ponds were used to estimate rates of soil erosion described in the next section (Walling and Quine, 1994).

\subsubsection{Pond erosion estimates}

Pond erosional losses were constrained by estimating wind-driven resuspension and export and from differences in tota ${ }^{210} \mathrm{~Pb}$ inventories between the marsh and ponds. Wave driven erosion in the pond was estimated with a simplified model. We calculated significant wave height and peak period as a function of wind speed, fetch, and water depth using semi-empirical equations (Young and Verhagan, 1996). We then calculated the bed shear stresses using the linear wave theory (Wiberg and Sherwood, 2008), and the Swart (1974) formula for the friction factor, with an equivalent bed roughness of $0.3 \mathrm{~mm}$. Wind speed estimates were based on median wind speeds $\left(4.04 \mathrm{~m} \mathrm{~s}^{-1}\right)$ recorded by a meteorological tower in PIE-LTER located near one of ponds $(42.7345$, -70.8382; Giblin, 2020).

For the fetch and depth, we considered two scenarios. First, we considered waves generated within the pond, and thus selected the fetch equal to the pond diameter $(30-100 \mathrm{~m}$, Spivak et al., 2018) and the depth calculated with respect to the surrounding marsh platform (i.e., assuming the pond is completely filled with water). Second, we considered a scenario in which the marsh is inundated. In this case we considered a larger fetch (i.e., the marsh platform, 1-3 km), but a smaller depth (equal to the depth on top of the platform). In the latter case, we used the depth on top of the marsh platform to calculate the wave height, but we used the depth inside the pond to calculate the bed shear stresses in the pond. For both scenarios we identified the pond depth (with respect to the marsh platform) for which the bed shear stress is equal to the critical value, which was assumed to range from 0.1 - 0.2 Pa based on intertidal mudflats (Mitchener and Torfs, 1996). In practice, we assumed that the pond is quickly eroded by the waves until its elevation precludes further erosion takes place and the sediments eroded are exported directly from the pond.

We further constrained erosional losses by exploiting differences in ${ }^{210} \mathrm{~Pb}$ inventories between the marsh and ponds. We assumed that within-site differences in average total inventories of the marsh cores (M1, M2) and the total inventory of the nearby pond was due to physical removal of soil material (Walling and Quine, 1994).

\subsubsection{Data analysis}

To evaluate how soil properties and composition change with depth in ponds and compare across the pond and marsh sites (near M1, far M2), we pooled soil horizons based on elevation relative to the marsh upper horizons $(1.2-1.5 \mathrm{~m}$, NAVD88) that reflect (A) marsh surface soils and emergent grass rooting zone $(0-30 \mathrm{~cm}),(\mathrm{B})$ pond upper soils and $R$. maritima rooting zone $(0-$ $10 \mathrm{~cm})$ and marsh soils at corresponding elevations $(30-40 \mathrm{~cm}),(C)$ intermediate $(10-30 \mathrm{~cm}$ pond; 40-60 $\mathrm{cm}$ marsh) and (D) deeper (30-50 $\mathrm{cm}$ pond; $60-80 \mathrm{~cm}$ marsh) horizons. Zones were selected 
to capture variations that were translatable to soil core depths used in carbon stock assessments. Kolmogorov-Smirnov tests were used to evaluate normality and data were log-transformed as needed in MATLAB. Post-hoc contrasts from linear mixed models were used to test down-core changes in the marsh (M1 \& M2) and pond zones as well as to assess differences between zones across these environments. Contrast coefficients complemented with p-values provide the magnitude difference in soil composition between environments or downcore zones being tested and whether differences are significant. Linear mixed models and post-hoc contrasts were conducted in $\mathrm{R}$ (1.3.1093) utilizing the $\operatorname{lm}(4.0 .0)$ and lsmeans $(2.30 .0)$ packages.

Due to the absence of pond accretion rates based on radioisotope age models (see Section 3.2.5), statistical comparisons of marsh soil accretion rates were treated differently. To test differences in accretion rates within the marsh platform that corresponded with pond formation as well as distance from pond, we conducted post-hoc contrasts of mixed linear models to determine differences with horizons deposited before and after pond formation (Ponds 1 and 2: 1978, Pond 3: 1963; approximated by aerial photographs Spivak et al., 2018) and between marsh cores (M1 and M2).

\subsection{RESULTS}

\subsubsection{Bulk soil properties}

Downcore trends in soil bulk density and elemental content were generally similar across the ponds and marsh environments and were consistent with decomposition leading to a loss of organic matter and soil compaction. Bulk density generally increased while TN (\%) decreased with depth (Table 1a, Fig. 2). Soil carbon content (\%) and density $\left(\mathrm{kg} \mathrm{m}^{-3}\right)$ were similar across horizons but tended to decrease with depth (Table 1a-b, Fig. 2). Reflecting opposing patterns in TN (\%) and TOC (\%), C:N ratios changed little across pond and marsh soil depths (Table 1a-b, Fig. 2). Pond soils generally had lower bulk densities and were more nitrogen rich compared to the marsh (M1 and M2; Fig. 2, Table 1 b). In contrast, carbon content $\left(\%, \mathrm{~kg} \mathrm{~m}^{-3}\right)$ and $\mathrm{C}: \mathrm{N}$ ratios were similar across pond and marsh soil horizons (Table 1b, Fig. 2). Patterns in soil properties and elemental content likely reflect a combination of processes, including water infiltration in pond surface horizons that results in lower bulk density, and long-term decomposition that can contribute to nitrogen immobilization in microbial biomass, carbon loss, and compaction of deeper soils.

Soil properties were generally similar between both marsh cores (M1, M2) in the upper 30 $\mathrm{cm}$, which overlaps in elevation with pond surface waters (SI Table 1). Only C:N ratios were significantly different with the higher values in the far marsh (M2). This suggests that the effects of ponding on the marsh soil properties of bulk density and elemental content are isolated and do not propagate through the platform.

\subsubsection{SOM sources and reactivity}

We assessed SOM sources and reactivity in the ponds and far marsh soils (M2) with a combination of stable isotopes, lipid biomarkers, thermal indices to evaluate the potential shifts in organic matter inputs and signals of pond erosion and decomposition processes (Figs 2-4, Tables 
3-5). Soil $\delta^{13} \mathrm{C}$ and $\delta^{15} \mathrm{~N}$ values ranged from -17 to $-11 \%$ and $0.74-7.17 \%$, respectively, reflecting salt marsh-derived organic matter (Fig. 3, Table 2; Spivak and Ossolinski, 2016; Spivak et al., 2018). Soil $\delta^{13} \mathrm{C}$ values were similar across depths and between marsh and pond environments (Fig. 3, Table 2). In contrast, $\delta^{15} \mathrm{~N}$ values were lower in pond soils compared to the marsh (Table 2).

Two classes of lipid biomarkers, fatty acids and hydrocarbons, were used to characterize fresher and more detrital sources of organic matter. Fatty acids were primarily comprised of longchain (LCFA; $32.9 \pm 12.8 \%$ ) and short chain (SCFA; $23.4 \pm 7.1 \%$ ) saturated compounds with smaller contributions of monounsaturated (MUFA; $8.7 \pm 8.5 \%$ ), branched (BrFA; $6.3 \pm 1.5 \%$ ), polyunsaturated fatty acids (PUFA; $0.3 \pm 0.9 \%$ ), and C18:2 + C18:3 (2.7 $\pm 5.8 \%$ ) compounds. Levels of SCFA $(\Sigma(\mathrm{C} 12: 0, \mathrm{C} 14: 0, \mathrm{C} 16: 0, \mathrm{C} 18: 0))$, representing microbes, algae, and certain vascular plants, were higher in pond surface soils and decreased with depth but were relatively constant with depth in marsh soils (Fig. 4, Table 3, Bianchi and Canuel, 2011). MUFAs ( $($ C14:1, C16:1, C 17:1, C 18:1, C 19:1, C 20:1, C 22:1, C24:1), reflecting bacteria, microalgae, macroalgae, and trace inputs from S. alterniflora, followed a similar pattern, with relatively higher levels in surface compared to deeper horizons in marsh and pond soils (Fig. 4, Table 3, (Volkman et al., 1980, 1989; Kaneda, 1991; Viso and Marty, 1993; Fleurence et al., 1994; Canuel et al., 1997; Sessions, 2006). Contributions from bacteria, represented by BrFA (iso- and anteiso- $\Sigma(\mathrm{C} 13, \mathrm{C} 15$, C17, C19)), were relatively constant in pond soils, but decreased with depth in the marsh (Fig. 4, Table 3). In contrast to compounds representing microbial contributions, levels of LCFA, which derive from vascular plants, were relatively lower in pond surface horizons and increased with depth (Fig. 4. Table 3, Bianchi and Canuel, 2011). PUFAs represent microalgae and were elevated within the pond surface and declined with depth (Fig. 4; Volkman et al., 1989). C18:2 and C18:3 are produced by S. alterniflora, microalgae, and R. maritima (Volkman et al., 1989; Canuel et al., 1997) and were a significant portion of marsh surface soils FAs $(20.9 \pm 2.8 \%)$ which also declined with depth (Fig. 4). Fatty acid profiles in marsh soils were less variable compared to ponds with some evidence of decomposition in slight increases in \%LCFA and decreasing microbial contributions (\%MUFA, \%SCFA, \%PUFA) from surface to depth. In contrast, pond soils had higher contributions of algal lipids in surface horizons $(\sim 4 \%)$, reflecting colonization by benthic microalgae and macroalgae (Spivak et al. 2017, 2018), and greater evidence of decomposition in sharper shifts in \%SCFA, \%MUFA, \%PUFA, and \%LCFA with depth.

Hydrocarbons revealed patterns in vascular plant detritus accumulation in marsh and pond soils. In the marsh, levels of long-chain $n$-alkanes C27, C29, and C31, which derive from higher plants (Eglinton and Hamilton, 1967; Bianchi and Canuel, 2011), were relatively constant with depth. In contrast, contributions of long-chain $n$-alkanes were higher in pond surface soils and decreased by $\sim 10 \%$ with depth. Greater contributions in pond surface soils compared to the marsh suggest either increased deposition of plant detritus or a changing decomposition environment that facilitates an accumulation of less reactive compounds.

Soil organic carbon thermal properties provide a proxy for reactivity (Fig. 5, Table 3). Soil t50 values were higher in the pond surface compared to deeper pond depth zones as well as 
compared to corresponding far marsh environments. In combination, our data indicate that pond upper soil horizons were distinct from the surrounding marsh, with greater contributions from algae and microbes and shifts in reactivity proxies that are consistent with microbial reworking.

\subsubsection{Soil radioisotopes}

We assessed whether marsh vertical accretion rates differed with distance from the ponds or with time since pond formation. Mean vertical accretion rates at sites closer (M1) and further (M2) from the ponds ranged from 4.78 - $5.12 \mathrm{~mm} \mathrm{yr}^{-1}$ (Fig. 6), exceeding local, long-term SLR rates $\left(2.87 \pm 0.15 \mathrm{~mm} \mathrm{yr}^{-1}\right.$; NOAA station \#8443970). In the farther marsh site (M2), accretion rates accelerated after 1963 - 1978, which roughly coincides with the appearance of the ponds in aerial images (Table 5), but near (M1) and far (M2) marsh locations converged to an average rate of $5.10 \mathrm{~mm} \mathrm{yr}^{-1}$ in the early $2000 \mathrm{~s}(\sim 1.35 \mathrm{~m} \mathrm{NAVD88)}$. It is unlikely that shifts in accretion rates could be attributed to pond infilling (Wilson et al., 2014a) due to the lack of evidence in historical aerial photographs (1960s) that infilling ponds were present at the study site that would affect contemporary accretion rates. These results demonstrate that vertical accretion rates are spatially and temporally heterogeneous but that recent accelerations are likely unrelated to ponds.

Soil radioisotopic properties further informed diffusion-migration models of soil erosion. Mean ${ }^{210} \mathrm{~Pb}$ inventories at the three marsh sites was $5,576 \mathrm{~Bq} \mathrm{~m}^{-2}$, and ranged from 4,137 to 7,835 $\mathrm{Bq} \mathrm{m}^{-2}$. The ${ }^{210} \mathrm{~Pb}$ inventory in the ponds at the three sites ranged from $517-2,915 \mathrm{~Bq} \mathrm{~m}^{-2}$.

\subsubsection{Estimating pond erosion}

Pond soil erosion rates were constrained using physical and radioisotopic models of soil erosion. A diffusion-migration model (Walling and Quine, 1994) based on the total ${ }^{210} \mathrm{~Pb}$ inventory of the marsh and pond soils, yielded erosion rates ranging from 4-10 $\mathrm{cm} \mathrm{yr}^{-1}$. Simple wind-driven erosion models provided estimates of critical pond depths in which erosion and resuspension of pond soils was feasible across multiple scenarios. When fetch is limited to pond diameter, critical depths for resuspension ranged from $1.8-5.4 \mathrm{~cm}$. Conversely, when fetch was $1-3 \mathrm{~km}$ across the inundated marsh, critical depths ranged from $0.1 \mathrm{~cm}-12 \mathrm{~cm}$. Thus, it appears unlikely that soil erosion occurs when pond surface waters are deeper than $12 \mathrm{~cm}$. In combination with pond soil bulk densities, erosion rates, and depths at which pond soil erosion could occur, we estimate that $14.4-26.4 \mathrm{~kg} \mathrm{~m}^{-2}\left(2.5-3.0 \mathrm{~kg} \mathrm{C} \mathrm{m}^{-2}\right)$ of soil was eroded within pond soils contributing to current pond depths.

\subsection{DISCUSSION}

Ponds are localized and sometimes ephemeral features of salt marsh landscapes (Wilson et al., 2014a; Mariotti, 2016) but may have long-term effects on the efficiency of these ecosystems as carbon sinks. Ponding effects on the surrounding marsh are spatially confined as soil physical and organic matter properties differed between ponds and the marsh but are similar in marsh soils 10-12 $\mathrm{m}$ and 20-30 $\mathrm{m}$ away from ponds (Fig. 2, Table 1b). Variable vertical accretion rates at the near (M1) and far (M2) marsh sites demonstrate that the processes controlling soil development 
and accumulation are spatially heterogeneous but unlikely affected by the proximity of ponds (Fig. 6). Differences in soil organic matter composition between the ponds and marsh reflect both changes in the dominant primary producer communities and microbial decomposition that accompanied the transition from an emergent to submerged environment (Fig. 2-4, Table 1b - 3). When compared to the surrounding marsh platform, we estimate that erosion, decomposition, and accretion of the surrounding marsh account for $35-38 \%, 22-33 \%$, and $29-43 \%$, respectively, of the organic carbon that was either lost or not accumulated as the ponds formed and deepened over 37 - 52 years. Therefore, ponds reduce ecosystem carbon storage by preventing accumulation and enhance loss of long-buried organic matter. Accounting for these impacts can help refine marsh carbon budgets and projecting forward ecosystem service delivery.

\subsubsection{Ponding effects on soil processes are localized}

Pond expansion occurs at the expense of the surrounding vegetated marsh: grasses dieback, mudflats form, and ponds widen (DeLaune et al., 1994; Mariotti and Fagherazzi, 2013; Wilson et al., 2014a). Because of this lateral expansion we expected that ponds influence the physical structure and potentially the composition of nearby marsh soils. Instead, we found that the bulk density and elemental composition of marsh soils were similar at differing distances ( $10 \mathrm{~m}$ vs. 20 $\mathrm{m}$ ) from the ponds (Figures Table $1 \mathrm{~b}$ ). This indicates that ponding effects on the marsh are localized and, moreover, underscores the structural integrity of peaty marsh soils (Chambers et al., 2019).

Below marsh grass roots (zone A, $0-30 \mathrm{~cm}, 1.18-1.48 \mathrm{~m}$ NAVD88), soil properties were fairly constant with slight increasing trends in bulk density, with decreasing TOC (\%) and C:N ratios (Fig. 2, Table 1a). These small trends allude to slow rates of decomposition (e.g., Luk et al. 2021) contributing to organic matter loss, soil compaction, and immobilization of nitrogen into microbial biomass and necromass (Goñi and Thomas, 2000; Wang et al., 2003). The consistency in bulk density and organic matter content might suggest that the processes building soils are similar across the marsh, however, spatial and temporal variability in vertical accretion rates point to a more dynamic system (Fig. 6, Table 5). For instance, increased deposition associated with storm tides (Schuerch et al., 2012) or erosion and redeposition of creekbank soil may also have a stronger influence on accretion rates at the far sites (Hopkinson et al., 2018; Luk et al., 2021). Therefore, this variability in vertical accretion rates is likely independent of pond proximity and may reflect other factors such as patchiness in marsh grass productivity, changing species composition, and greater particle deposition near mosquito ditches and creekbank edges (Bricker-Urso et al., 1989; Friedrichs and Perry, 2001; Turner et al., 2002).

\subsubsection{Pond soils reflect changing organic matter inputs and decomposition}

Differences between overlapping marsh and pond soil properties were isolated in the upper pond horizons reflecting new inputs of organic matter and soil decomposition. Changes in ecological communities associated with a shift from emergent marsh grass vegetation to permanently inundated pond soils were associated with new inputs of fresh organic matter within 
pond soils (Fig. 2 -3). Additionally, concurring accumulation of detrital lipid biomarkers and shifts in bulk SOC towards increasing thermal stability are consistent with microbial alteration of pond surface organic matter (Canuel and Martens, 1996; Williams and Rosenheim, 2015). This shift in the surficial environment and sources of organic matter likely altered the environment of marsh decomposition, resulting in evidence of increased detrital material and thermal stability of the bulk soil organic carbon (Fig. 4 - 5, Table 3 - 4; Kuzyakov et al., 2000; Bianchi, 2011). Convergence in soil properties between the marsh and pond below the rooting zone of $R$. maritima provides additional evidence that ponds are secondary features of the marsh (Wilson et al., 2010) whose vertical influence is limited to the upper $10 \mathrm{~cm}$ of the pond soil column. Thus, pond processes that impact marsh soil composition are limited vertically and laterally within surrounding marsh soils.

Compositional differences between the upper horizons of the ponds and the surrounding marsh reflect inputs from the primary producer and microbial communities that were established following submergence. For instance, more depleted $\delta^{13} \mathrm{C}$ and $\delta^{15} \mathrm{~N}$ values, higher nitrogen content, and greater percentages of SCFA, PUFA, and MUFA in upper pond horizons compared to the marsh are consistent with organic matter deriving from benthic microalgae and microbes (Fig 3 4, Table 2 - 3.; Spivak and Ossolinski, 2016; Spivak et al., 2018). These are generally confined to the top $10 \mathrm{~cm}$ of the ponds which coincides with the rooting zone of R. maritima (Kantrud, 1991; Jovanovic et al., 2015). Moreover, the compositional shifts are consistent with the distribution of phospholipid-linked fatty acids (PLFAs), representing viable or recently viable biomass, and the outputs of mixing models demonstrating that benthic microalgae and to a lesser extent suspended particulate organic matter are the main carbon sources in the top $2 \mathrm{~cm}$ of pond soils (Spivak et al., 2018). Inputs of new organic matter from productive algae and microbes likely diluted older contributions from the marsh grasses that built the soils, as C18:2 + C18:3 (\%) was a minor component in pond soils and LCFA (\%) were lower in the upper pond horizons compared to the marsh and increased with depth below the rooting zone of $R$. maritima (Fig. 4c; Table 3 ). Consequently, changing ecological communities that accompanied submergence deposited fresh organic matter onto the surface $(0-10 \mathrm{~cm})$ and subsurface $(10-30 \mathrm{~cm})$ of pond soils.

Disturbances that cause peat collapse in organic-rich interior marsh areas can decrease soil bulk density and alter the decomposition environment (Day et al., 2011; Wilson et al., 2018; Chambers et al., 2019). Consistent with this, ponds had lower bulk densities compared to the marsh and shifts in organic matter composition and reactivity that reflect microbial reworking (Fig. 2, 45). Levels of vascular plant-derived hydrocarbons (i.e., $\Sigma(\mathrm{C} 27,29,31)$, which represent more detrital sources of organic matter compared to fatty acids, were relatively higher in the upper horizons of pond soils $(0-20 \mathrm{~cm})$ than the marsh (Fig. 4, Table 3). This suggests an accumulation of vascular plant carbon, even though R. maritima abundances are low (Spivak et al., 2017) and benthic microalgae are the main source of newer organic matter (Fig. 4, Table 3; Spivak et al., 2018). Thermal properties indicate a shift towards more stable compounds in the pond surface compared to the marsh and deeper soil horizons (Fig. 5; Luk et al., 2021). Because the thermal proxy of t50 represents the entire soil organic carbon pool, rather than the smaller fractions 
reflected in lipid biomarker classes, this suggests a shift in the continuum of SOC reactivity towards more reworked and less reactive organic matter accumulating in pond surface horizons likely due to preferential decomposition of more labile material (Williams and Rosenheim, 2015; Lehmann et al., 2020). Increased thermal stability of soil organic carbon is associated with longer turnover times, of centuries-to-millennia, and may have implications for progressive pond deepening (Luk et al., 2021). Interestingly, levels of bacterial fatty acids (\%BrFA; Fig 4, Table 3) were similar between the upper pond horizons and the marsh. However, branched fatty acids reflect bacteria-derived organic matter and other more sensitive biomarkers (e.g., PLFAs) or molecular approaches (e.g., RNA) would be better proxies of activity (Bulseco et al., 2020).

Below the upper pond horizons and rooting depth of R. maritima $(0-20 \mathrm{~cm})$, soil properties and composition were similar to the surrounding marsh, underscoring that ponds overlie salt marsh peat deposits (Fig. 2 - 5; Wilson et al., 2010). For instance, soil bulk densities, elemental content, lipid biomarker profiles, and thermal properties were similar between the ponds and the marsh below $\sim 1.1 \mathrm{~m}$ NAVD88 (Zone $\mathrm{C}-\mathrm{D}$; Figs. $2-5$, Table $1 \mathrm{~b}-4$ ). Moreover $\delta^{13} \mathrm{C}$ values converged to $-14.3 \pm 1.2 \%$ (Fig. 3; Table 2), indicating that the soils mainly derived from marsh grasses (Benner et al., 1987; Spivak and Ossolinski, 2016). The exceptions to this pattern were $\delta^{15} \mathrm{~N}$ values and bacterial organic matter contributions (BrFA) which were lower and higher, respectively, in deeper pond soils compared to the marsh (Fig 3 - 4, Table 2 - 3). This is consistent with porewater profiles of microbial respiratory products (i.e., dissolved inorganic carbon, ammonium) and electron acceptors (i.e., sulfate) demonstrating production and consumption, respectively, occurring at least $20 \mathrm{~cm}$ deep in pond soils (Spivak et al., 2018). Further porewater $\delta^{13} \mathrm{C}$-DIC composition suggest that long-buried peat supports microbial respiration (Spivak et al., 2018). These data suggest that ponding effects on structure and organic matter composition of the underlying marsh soil are largely limited to upper horizons (i.e., 0-20 cm) but effects on biogeochemical processes may extend deeper.

Disturbances to the marsh platform resulting in permanent inundation of marsh soils result in changes in marsh carbon cycling due to shifts in changing organic matter source inputs as well as decomposition processes. Changes in the hydrology and physical properties results in inputs of fresh organic matter inputs dominated by microbes, benthic microalgae, and to a certain extent $R$. maritima. Additional evidence demonstrates this shift in the biophysical environment of marsh soils coincide with microbial alterations of marsh organic matter resulting in accumulation of detrital lipid biomarkers and increased thermal stability of bulk soil organic carbon. While these effects were limited to the upper pond horizons, pond deepening is associated with SOC decomposition within pond soils and represents an additional carbon loss pathway within the overall marsh carbon budget.

\subsubsection{The fate of carbon during pond deepening}

Pond formation and expansion reduce soil carbon storage in salt marshes by preventing accretion and removing decades of long-buried organic matter (Wilson et al., 2009, 2010). Dieback of emergent grasses in the initial phase of pond formation prevents future soil building and vertical 
accretion, resulting in a pool of 'missing' carbon relative to the surrounding, healthy marsh. The study ponds first appeared in aerial images in 1978 (Ponds 1,2) and 1965 (Pond 3; Spivak et al., 2017) and, since then, the surrounding marsh platform has grown vertically $6.8-9.7 \mathrm{~cm}$ and accumulated 59.5 - 79.3 $\mathrm{g} \mathrm{C} \mathrm{m}^{-2} \mathrm{yr}^{-1}$, or $2.3-3.2 \mathrm{~kg} \mathrm{C} \mathrm{m}^{-2}$ in total carbon stock (Table 6). Vertical accumulation of the surrounding marsh complemented with multiple estimates of pond soil erosion rates provide an opportunity to constrain long-term pond soil decomposition and the overall marsh carbon budget.

The ${ }^{210} \mathrm{~Pb}$ profiles and inventories indicate that ponds are net-erosional environments. Based on the models in section 3.5, we estimate that wind-driven resuspension and erosion have exported $14.4-26.4 \mathrm{~kg} \mathrm{~m}^{-2}$ of soil, holding $2.5-3.0 \mathrm{~kg} \mathrm{C} \mathrm{m}^{-2}$ of carbon, over the early years of pond formation (Table 6). Much of this would have occurred during the first $1-3$ years of pond formation, when the systems were shallower $(0-12 \mathrm{~cm})$ and wind waves would have disturbed surface soils. These estimates demonstrate a nonlinearity in pond soil erosion and are likely an upper bound as export would also depend on high-wind resuspension events coinciding with pondchannel connectivity when tides overtop the marsh. Further, the low likelihood of erosion and export of sediment within pond soils after initial formation is supported by previous observations of the absence of tidal effects on the levels of suspended particulate organic matter within these ponds at their current dimensions and low frequency of tidal connections within these high marsh ponds (Spivak et al., 2017). Thus, export of pond soils via wind-driven erosion may be limited during periods of tidal connection on the high marsh. Further research is required to explore whether resuspension within the ponds may promote additional loss through decomposition due to transport from anoxic porewaters to the more oxygenated overlying water column.

Combined, lost accretion and erosion could account for $\sim 67-78 \%$ of soil and carbon missing from the three ponds, based on present-day pond volumes and assuming an initial bulk density of $0.12-0.22 \mathrm{~g} \mathrm{~cm}^{-3}$ (Table 6). The remaining fraction of missing carbon was likely lost via decomposition at rates of $32.7-132.9 \mathrm{~g} \mathrm{C} \mathrm{m}^{-2} \mathrm{yr}^{-1}$ in multiple scenarios of pond soil erosion (see section 3.5, Table 6). These estimates are comparable to heterotrophic respiration rates based on benthic porewater dissolved inorganic carbon profiles (11-92 $\mathrm{g} \mathrm{C} \mathrm{m}^{-2}$; Spivak et al., 2018) and whole-pond dissolved oxygen fluxes (68 - $172.2 \mathrm{~g} \mathrm{C} \mathrm{m}^{2} \mathrm{yr}^{-1}$; Spivak et al., 2017, 2020) averaged across summer and fall. Moreover, decomposition as a loss pathway is consistent with the accumulation of detrital vascular plant organic matter and more thermally stable organic carbon in pond surface soils (Figs. 4-5).

In combination, pond processes on the marsh platform result in carbon loss, redistribution, and a lost opportunity for carbon accumulation within the marsh carbon budget. Direct loss of carbon from marsh soil reservoir through decomposition accounts for at least a quarter of the carbon lost during pond deepening; the balance between erosion and redistribution of carbon versus subsequent decomposition requires additional study. If all the material lost via erosion were exported out of the marsh ecosystem or subsequently respired, this would potentially increase carbon loss from the system from a quarter to more than half of the carbon lost during pond deepening. Conversely, if eroded material were redistributed and subsequently buried within the 
marsh this would represent recycled marsh material rather than new carbon inputs, increasing errors in carbon budget calculations. These processes which will likely be augmented by future increases in the frequency of disturbances have yet to be incorporated into estimates of marsh carbon budgets as well as salt marsh evolution models.

\subsubsection{Incorporating ponds into ecosystem carbon budgets}

A first step in assessing uncertainty in marsh carbon budgets is the incorporation of ponds and the processes that contribute to pond development in marsh carbon accounting. Consider the PIE-LTER salt marshes, which encompass approximately $40 \mathrm{~km}^{2}$, with $6 \%$ of the area represented by ponds (Millette et al., 2010; Kirwan et al., 2011; Wilson et al., 2014a; Mariotti et al., 2020). We calculated ecosystem carbon storage to $1 \mathrm{~m}$ depth with and without ponds for estimation of tidal wetland carbon stocks in PIE. The difference between the two scenarios would represent a 5\% decrease in carbon storage estimates with the incorporation of ponds, which is likely an upper bound due to the potential erosion and redistribution of buried pond soils (35-38\% of total absent carbon). This is likely a factor since it is hypothesized that contributions of inorganic sediment in this system are sourced from recycled inorganic material (Cavatorta et al., 2003; Wilson et al., 2014a) due to the low sediment supply from the tidal channel (Meade, 1982). The relatively minor change in carbon storage estimates due to ponding in PIE is consistent with studies demonstrating general stability within the system over the past 70 years (Wilson et al., 2014a). Yet, pond expansion within PIE has been related to management decisions rather than increasing sea-level rise, which may be altered with future projections of global change.

Pond expansion may represent a larger portion of carbon stock uncertainty for submerging coastal marshes (Morris et al., 2002; Mariotti, 2016). For example, pond expansion within wetlands in Blackwater River, Maryland and Mississippi River Delta Plain, Louisiana are likely related to sea-level rise with ponding coverage ranging from $50-90 \%$ of the marsh platform (Penland, 2002; Schepers et al., 2017). Based on current dimensions of Maryland's Blackwater National Wildlife Refuge marshes, soil TOC content (Van Allen et al., 2021), and pond area (51\%; Schepers et al., 2017), carbon stock differences are likely closer to $15 \%$ when ponded areas are not incorporated. Thus, the impact of ponding to the uncertainty in marsh carbon storage is roughly proportional to the extent of ponding on the marsh platform; for marshes in Maryland and Mississippi Delta with ubiquitous ponding, this poses a unique type of uncertainty to carbon stock estimates through interior loss of the marsh platform (Penland, 2002; Schepers et al., 2017). Particularly with observations of marsh elevation as an important indicator for the ratio of unvegetated-vegetated marsh ratios (Ganju et al., 2017, 2020), future sea-level rise relative to marsh elevation gain will play a greater role in lateral marsh loss and uncertainty in the future maintenance of marsh carbon stocks.

\subsection{CONCLUSION}

Ponds are isolated geochemical features in the marsh landscape, but impact salt marsh carbon dynamics through soil erosion (35- 38\%), enhanced organic matter decomposition (22 - 
$33 \%$ ), and the lost opportunity of marsh carbon storage (32-42\%) that result in absent carbon $\left(7,148-8,064 \mathrm{~g} \mathrm{C} \mathrm{m}^{-2}\right)$ in three ponds in the PIE-LTER system. Investigation into pond soil composition demonstrates alterations in surficial soil carbon dynamics due to changes in dominant primary producer communities and enhanced microbial decomposition coinciding with shifts from an emergent to submerged environment. In combination, discounting ponds in marsh carbon budgets can result in errors ranging from $5-15 \%$ based on current ponding extent within New England and Maryland marshes, which will increase proportionally with future wetland loss. In light of pond expansion due to global change and changing land management strategies, it is important to incorporate marsh spatial variability in carbon accounting and landscape evolution models. Future research will need to explore how deeper pond decomposition rates impact wholeecosystem carbon cycling and assess the magnitude of pond sediment resuspension and redistribution on the marsh platform.

\section{ACKNOWLEDGEMENTS:}

Thanks to Michaela Fendrock and Marshall Otter for help in collecting and processing soil cores. M. Lardie, J. Hemingway, and V. Galy for assisting with RPO and rampedpyrox. We are also grateful for support and assistance from PIE-LTER (OCE1238212). Funding support was provided by NSF (NSF-OCE-1233678), Woods Hole Sea Grant (NA14OAR4170104), and NOAA (NA14NOS4190145) grants to ACS. Additional support was provided by the U.S. Geological Survey Coastal \& Marine Hazards and Resources Program. Any use of trade, firm or product names is for descriptive purposes only and does not imply endorsement by the U.S. Government. 
Table 1: a) Downcore contrast analyses and b) between-environment contrasts for the pond, near (M1) and far (M2) marsh environments. Contrast coefficients are presented for depth zones as described in Section 3.2.7 and Fig 1. Bolded values are significant at $p<0.05$. For example, the downcore contrast coefficient for Pond " $\mathrm{B}-\mathrm{C}$ " for bulk density demonstrates that the significant difference between (B) surface and (C) intermediate pond soil properties is $-0.15 \log _{10}\left(\mathrm{~g} \mathrm{~cm}^{-3}\right)$. Between-environment contrast coefficient of B "M1 - M2" represents the insignificant difference between the M1 and M2 soil properties at depth zone B.

\begin{tabular}{|c|c|c|c|c|c|c|}
\hline & Contrast & $\begin{array}{l}\text { Bulk Density } \\
\log _{10}\left(\mathrm{~g} \mathrm{~cm}^{-3}\right)\end{array}$ & $\begin{array}{c}\text { Total } \\
\text { Nitrogen } \\
\log _{10}(\%)\end{array}$ & $\begin{array}{c}\text { Total Organic } \\
\text { Carbon } \\
\log _{10}(\%) \\
\end{array}$ & $\mathrm{C}: \mathrm{N}$ & $\begin{array}{c}\text { Total Organic } \\
\text { Carbon } \\
\left(\mathrm{kg} \mathrm{m}^{-3}\right) \\
\end{array}$ \\
\hline \multirow{3}{*}{ 음 } & $B-C$ & -0.15 & 0.17 & 0.13 & -0.02 & 2.04 \\
\hline & $C-D$ & 0.09 & -0.04 & -0.02 & 0.33 & 2.61 \\
\hline & $B-D$ & -0.06 & 0.13 & -0.11 & 0.31 & 4.64 \\
\hline \multirow{3}{*}{$\sum^{-1}$} & $B-C$ & -0.09 & 0.08 & 0.05 & 0.16 & 0.76 \\
\hline & $C-D$ & 0.01 & 0.02 & -0.06 & 0.15 & -1.85 \\
\hline & $B-D$ & -0.08 & 0.10 & -0.01 & 0.31 & -1.08 \\
\hline \multirow{3}{*}{$\sum$} & $B-C$ & -0.14 & 0.14 & 0.11 & 2.35 & 3.98 \\
\hline & $C-D$ & 0.06 & -0.02 & 0.00 & 0.30 & 2.40 \\
\hline & $B-D$ & -0.08 & 0.11 & 0.11 & 2.64 & 6.38 \\
\hline \multirow{3}{*}{$\infty$} & M1 - M2 & -0.02 & 0.03 & -0.01 & -1.89 & -1.93 \\
\hline & M1 - POND & 0.12 & -0.12 & -0.09 & 1.20 & 1.88 \\
\hline & $\mathrm{M} 2$ - POND & 0.14 & -0.16 & -0.08 & 3.09 & 3.81 \\
\hline \multirow{3}{*}{$\cup$} & M1 - M2 & -0.07 & 0.09 & 0.11 & 0.62 & 2.82 \\
\hline & M1 - POND & 0.06 & -0.04 & 0.01 & 1.34 & 4.68 \\
\hline & M2 - POND & 0.13 & -0.13 & -0.10 & 0.72 & 1.86 \\
\hline \multirow{3}{*}{0} & M1 - M2 & -0.02 & 0.05 & 0.07 & 1.07 & 3.37 \\
\hline & M1 - POND & 0.14 & -0.09 & -0.05 & 1.83 & 5.44 \\
\hline & $\mathrm{M} 2$ - POND & 0.16 & -0.14 & -0.12 & 0.76 & 2.07 \\
\hline
\end{tabular}


Table 2: Contrast analyses of soil $\delta^{13} \mathrm{C}$ and $\delta^{15} \mathrm{~N}$ composition $\left.\mathbf{a}-\mathbf{b}\right)$ across depth zones and c) between environments. Displayed are the contrast coefficients for the pooled depth zone (see section 3.2.7). Bolded values are significant at $p<0.05$.

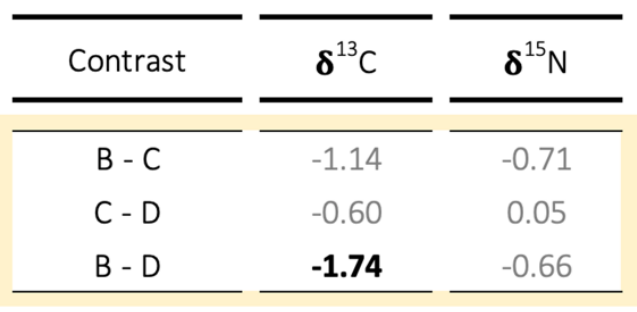

b.

\begin{tabular}{cccc} 
& B - C & 0.25 & 0.64 \\
$\Sigma$ & C - D & -0.69 & -0.50 \\
& B-D & -0.44 & 0.13 \\
\hline
\end{tabular}

c.

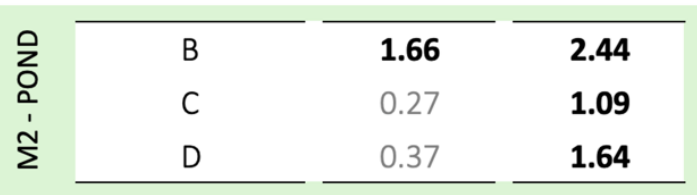


Table 3: Contrast coefficients of fatty acid and hydrocarbon compound classes between depth horizons within (a) and across (b) the ponds and the far marsh (M2) site. Significant values $(p<0.05)$ are bolded. See Fig. 4.

a.

\begin{tabular}{|c|c|c|c|c|c|c|}
\hline & Contrast & $\%$ SCFA & $\%$ MUFA & $\%$ LCFA & $\%$ BrFA & $\begin{array}{c}\% \sum(\mathrm{HC} 27, \\
29,31)\end{array}$ \\
\hline \multirow{2}{*}{ ט } & POND & 0.50 & 0.50 & -21.77 & -0.61 & 10.30 \\
\hline & M2 & 0.15 & 0.15 & -5.17 & 1.79 & 3.20 \\
\hline$\sum_{0}^{0}$ & B & -11.78 & -0.07 & 8.66 & 0.44 & -10.09 \\
\hline $\mathfrak{\Sigma}$ & C & 2.14 & 0.28 & -7.94 & -1.97 & -3.01 \\
\hline
\end{tabular}


Table 4: Contrast coefficients of thermal reactivity (t50) between depth horizons within a) and across $b)$ the pond and far marsh (M2) environment. Significant values $(p<0.05)$ are bolded. See Fig. 4.

a.

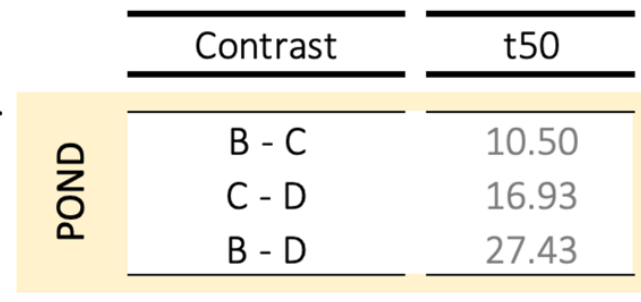

b.

\begin{tabular}{|c|c|c|}
\hline \multirow{3}{*}{$\Sigma$} & $B-C$ & -18.80 \\
\hline & $C-D$ & 5.22 \\
\hline & $B-D$ & -13.58 \\
\hline \multirow{3}{*}{$\begin{array}{l}\mathcal{z} \\
0 \\
0 \\
\Sigma \\
\Sigma\end{array}$} & B & -27.72 \\
\hline & C & 1.58 \\
\hline & D & 13.28 \\
\hline
\end{tabular}


Table 5: Contrast coefficients (bolded $\mathrm{p}<0.05)$ of accretion rates $\left(\mathrm{mm} \mathrm{yr}^{-1}\right)$ between a) the near (M1) and far (M2) marsh cores after (After pond: soil horizons deposited after 1963 - 1978) and before pond formation (Before pond; soil horizons deposited before 1963 - 1978) and b) horizons deposited before and after pond formation (Before - After) downcore within the near (M1) and far (M2) marsh cores across all three sites.

\begin{tabular}{cccc}
\hline \multicolumn{2}{c}{$\begin{array}{c}\text { Accretion Rate } \\
\text { (M1 - M2) }\end{array}$} & & \multicolumn{2}{c}{$\begin{array}{c}\text { Accretion Rate } \\
\text { (BEFORE - AFTER) }\end{array}$} \\
\cline { 1 - 2 } \cline { 4 - 4 } Contrast & Coefficient & Contrast & Coefficient \\
\hline AFTER POND & -0.08 & & -0.01 \\
BEFORE POND & $\mathbf{0 . 0 9}$ & M2 & -0.02 \\
\hline
\end{tabular}


Table 6: Estimated pond decomposition rates under scenarios where (a) erosion does or (b) does not occur and drive deepening. a) For each site, values of pond erosion rate (Pond Erosion Rate; $\mathrm{cm} \mathrm{yr}^{-1}$ ), accretion of the surrounding marsh (Marsh Accretion; $\mathrm{cm} \mathrm{yr}^{-1}$ ), calculated depths attributed to erosion and accretion Erosion + Accretion Depth; $\mathrm{cm}$ ), pond depths attributed to decomposition (Decomposition Depth; $\mathrm{cm}$ ), and decomposition rates $\left(\mathrm{g} \mathrm{C} \mathrm{m}^{-2} \mathrm{yr}^{-1}\right)$. b) Calculated pond decomposition rates when pond erosion rates were set to $0 \mathrm{~cm} \mathrm{yr}^{-1}$.

a.

\begin{tabular}{|c|c|c|c|c|c|c|}
\hline Site & Pond Age & $\begin{array}{l}\text { Pond Erosion } \\
\text { Rate }\left(\mathrm{cm} \mathrm{yr}^{-1}\right)\end{array}$ & $\begin{array}{c}\text { Marsh } \\
\text { Accretion } \\
\left(\mathrm{cm} \mathrm{yr}^{-1}\right)\end{array}$ & $\begin{array}{c}\text { Erosion + } \\
\text { Accretion Depth } \\
(\mathrm{cm})\end{array}$ & $\begin{array}{l}\text { Decomposition } \\
\text { Depth }(\mathrm{cm})\end{array}$ & $\begin{array}{c}\text { Decomposition } \\
\text { Rate } \\
\left(\mathrm{g} \mathrm{C} \mathrm{m}^{-2} \mathrm{yr}^{-1}\right)\end{array}$ \\
\hline 1 & 38 & 10 & 0.18 & 18.8 & 11.2 & 62.0 \\
\hline 2 & 38 & 7 & 0.24 & 21.1 & 7.9 & 52.7 \\
\hline 3 & 52 & 4 & 0.19 & 21.7 & 7.3 & 32.7 \\
\hline
\end{tabular}

b.

\begin{tabular}{|c|c|c|c|c|c|c|}
\hline Site & Pond Age & $\begin{array}{l}\text { Pond Erosion } \\
\text { Rate }\left(\mathrm{cm} \mathrm{yr}^{-1}\right)\end{array}$ & $\begin{array}{c}\text { Marsh } \\
\text { Accretion } \\
\left.(\mathbf{c m ~ y r})^{-1}\right)\end{array}$ & $\begin{array}{l}\text { Accretion Depth } \\
\text { (cm) }\end{array}$ & $\begin{array}{l}\text { Decomposition } \\
\text { Depth }(\mathrm{cm})\end{array}$ & $\begin{array}{c}\text { Decomposition } \\
\text { Rate } \\
\left(\mathrm{g} \mathrm{C} \mathrm{m}^{-2} \mathrm{yr}^{-1}\right)\end{array}$ \\
\hline 1 & 38 & 0 & 0.18 & 6.8 & 23.2 & 128.6 \\
\hline 2 & 38 & 0 & 0.24 & 9.1 & 19.9 & 132.9 \\
\hline 3 & 52 & 0 & 0.19 & 17.7 & 11.3 & 86.3 \\
\hline
\end{tabular}




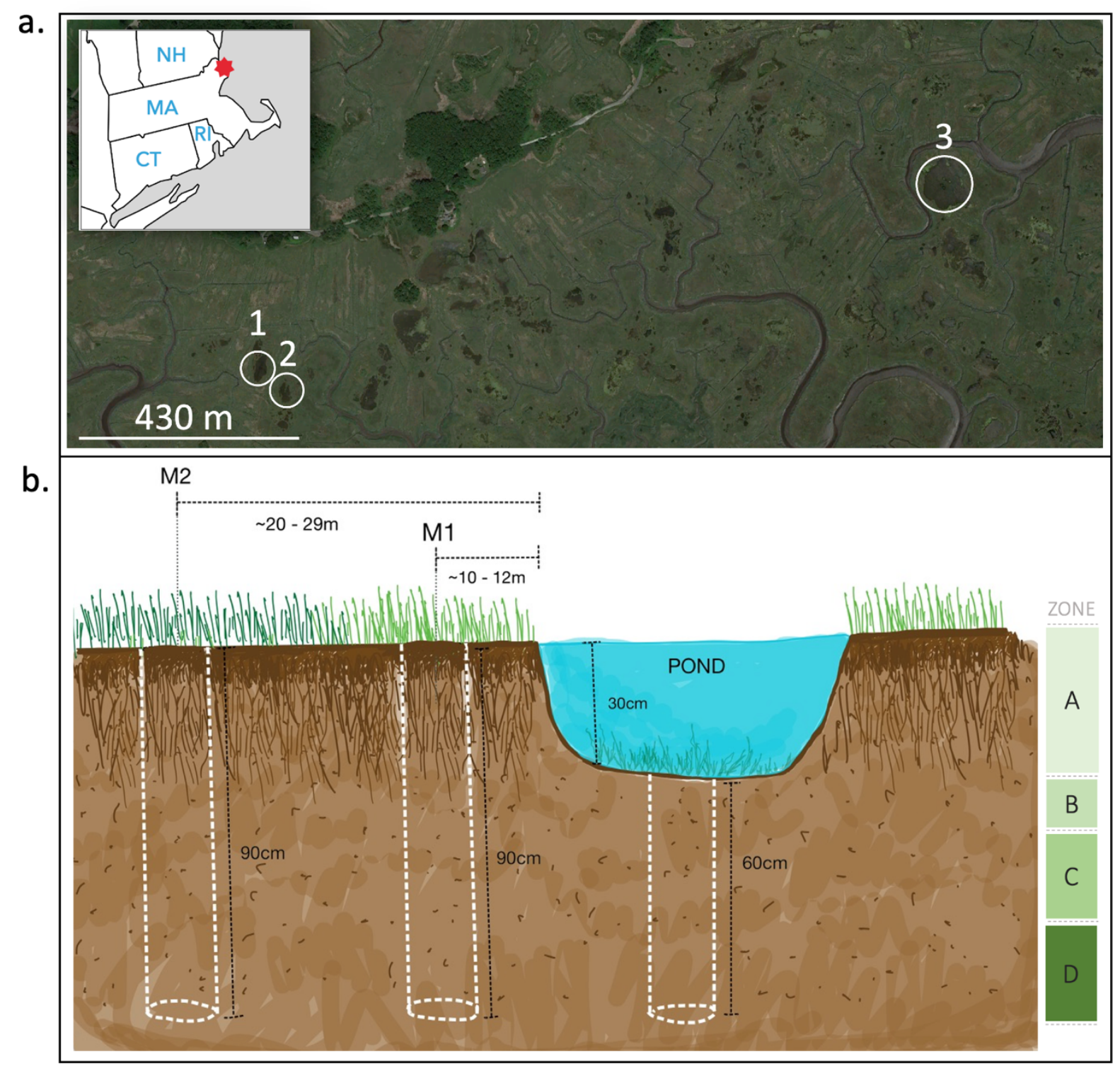

Figure 1. a) Location of the three ponds on the high marsh platform with inset map of PIE-LTER (MA, U.S.). b) Study design testing whether ponds affect the soil integrity of the surrounding marsh and whether the pond soil record reflects organic matter losses via erosion or decomposition. Soil cores were collected from ponds and nearby (M1) or farther away (M2) sites in the marsh at three locations within PIE-LTER (MA, USA). Comparisons between overlapping soil horizons between the ponds $(0-60 \mathrm{~cm})$ and marsh $(30-90 \mathrm{~cm})$ were used to evaluate the role of decomposition in contributing to pond deepening. 

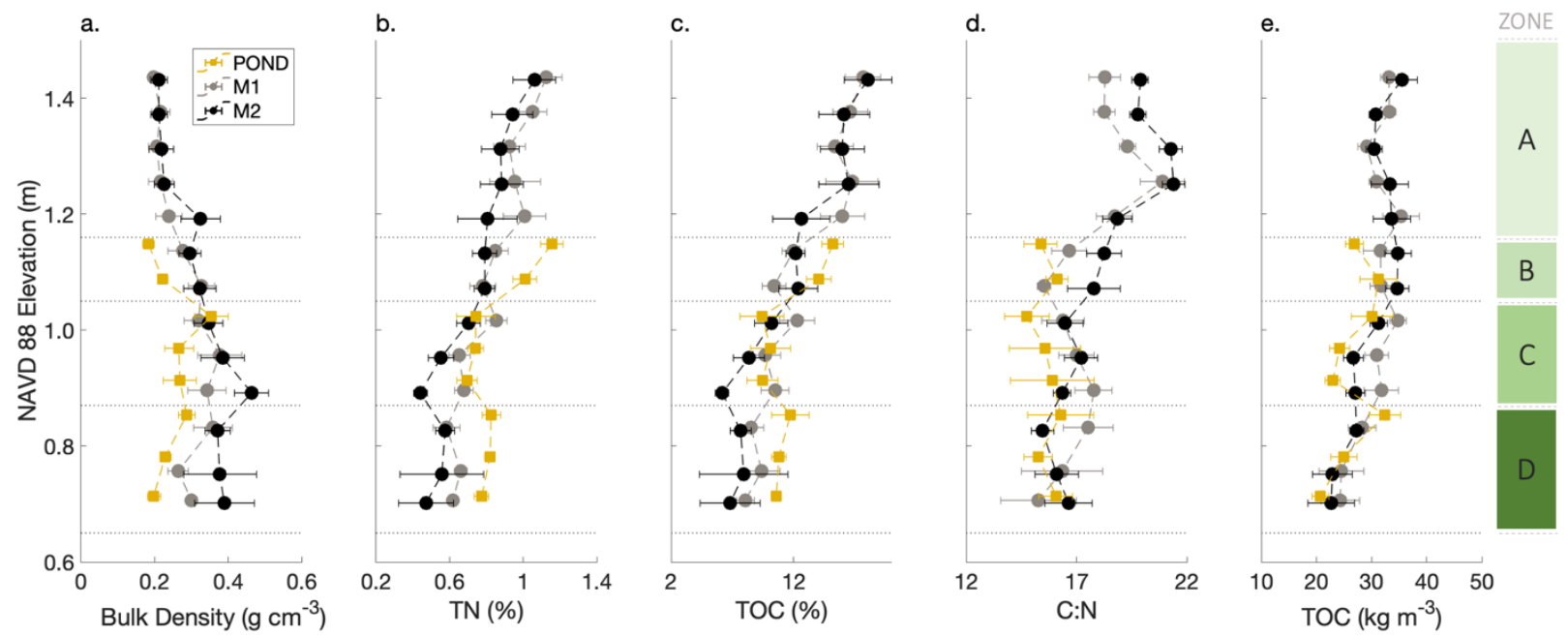

Figure 2: Pond and marsh (near: M1; far: M2) soil (a) bulk density, (b) total nitrogen content (TN \%), (c, e) total organic carbon content (TOC \% and $\mathrm{kg} \mathrm{m}^{-3}$ ), and (d) C:N (molar) by elevation and depth horizon. Data represent mean and SE of $6 \mathrm{~cm}$ horizons. See methods for descriptions of depth zones A-D and Tables 1 for contrast analyses. 

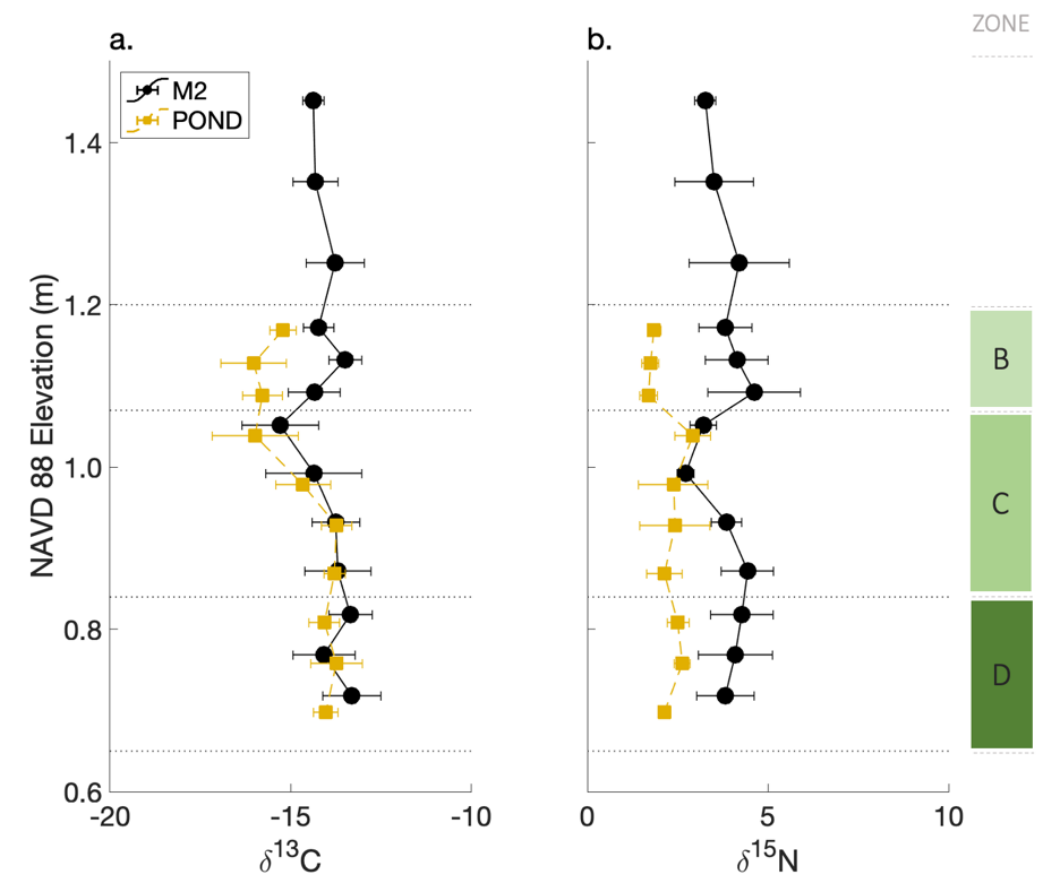

Figure 3: Stable isotope composition $\left(\delta^{13} \mathrm{C}, \delta^{15} \mathrm{~N}\right.$; \%o) of pond and marsh (M2, far) soils by elevation (NAVD88) and depth zone (B-D see section 3.2.7). Data are mean and SE of elevation adjusted marsh horizons overlapping the pond. Statistical results in Table 2. 

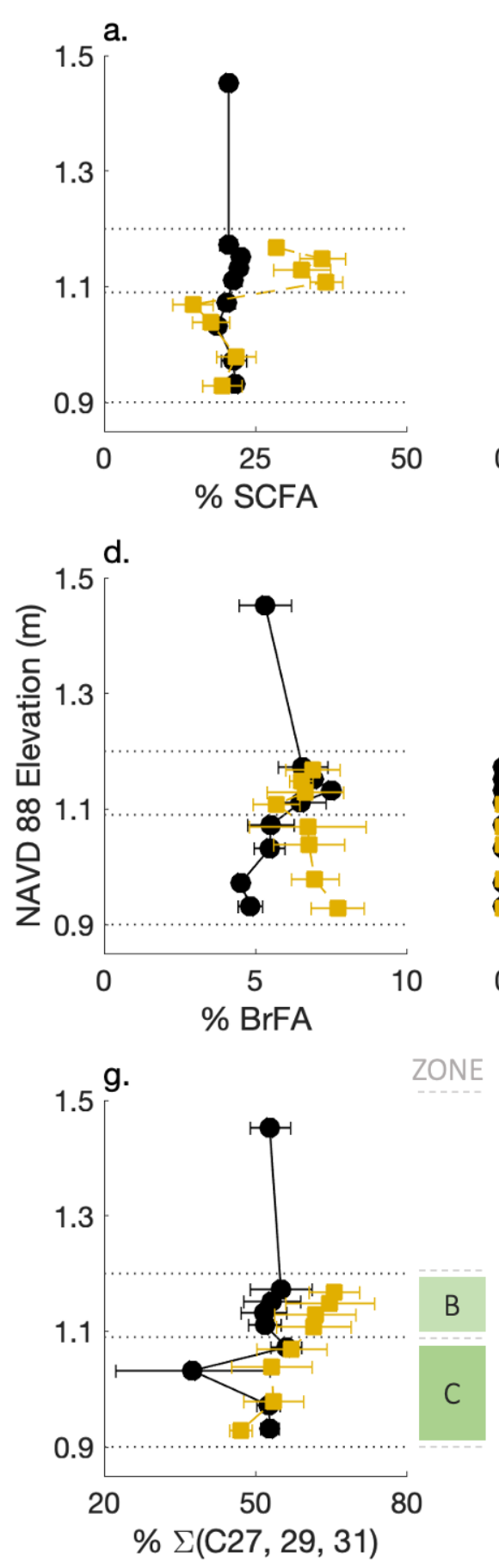

b.

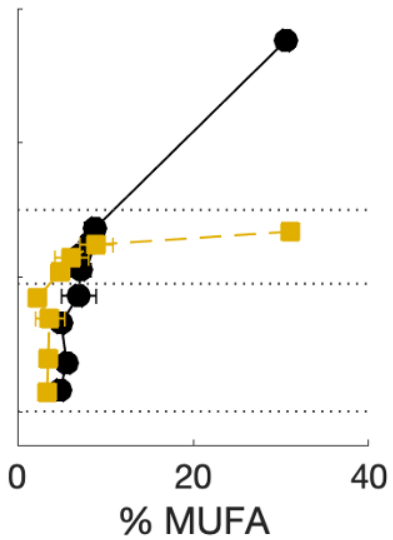

c.

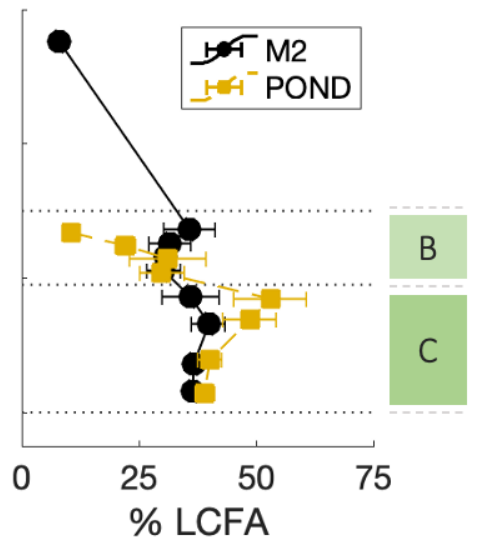

e.

f.

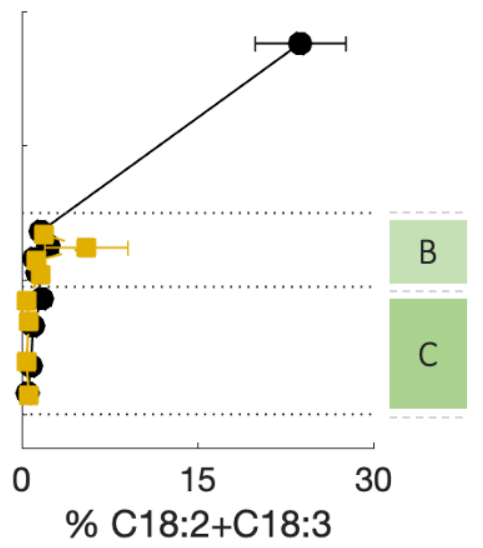

Figure 4: Abundances of lipid biomarkers in ponds and the far marsh sites (M2) representing (a) general microbes and algae (SCFA), (b) microbes (MUFA), (c) vascular plants (LCFA), (d) bacteria (BrFA), (e) microalgae (PUFA), (f) marsh grasses (C18:2 + C18:3), (g) and odd-chain hydrocarbons $\Sigma(\mathrm{HC} 27,29,31))$ representing detrital vascular plant material. Data are the mean and SE of elevation adjusted marsh horizons overlapping the pond. See Section 3.2.7 for description of soil zones and Table 3 for statistical results. 


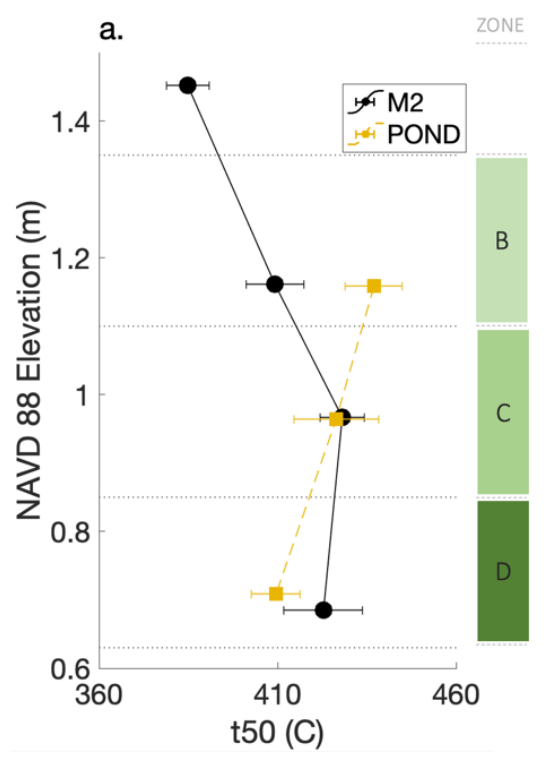

Figure 5: Thermal reactivity proxy of temperatures at which $50 \%$ of soil organic carbon is pyrolyzed. Data are mean and standard error of marsh surface, marsh horizons overlapping pond surface $(0-10 \mathrm{~cm})$, intermediate $(10-30 \mathrm{~cm})$, and deep $(30-50 \mathrm{~cm})$ soil horizons. Zones B, C, and D represent horizons used for contrast analyses in Table 4. 


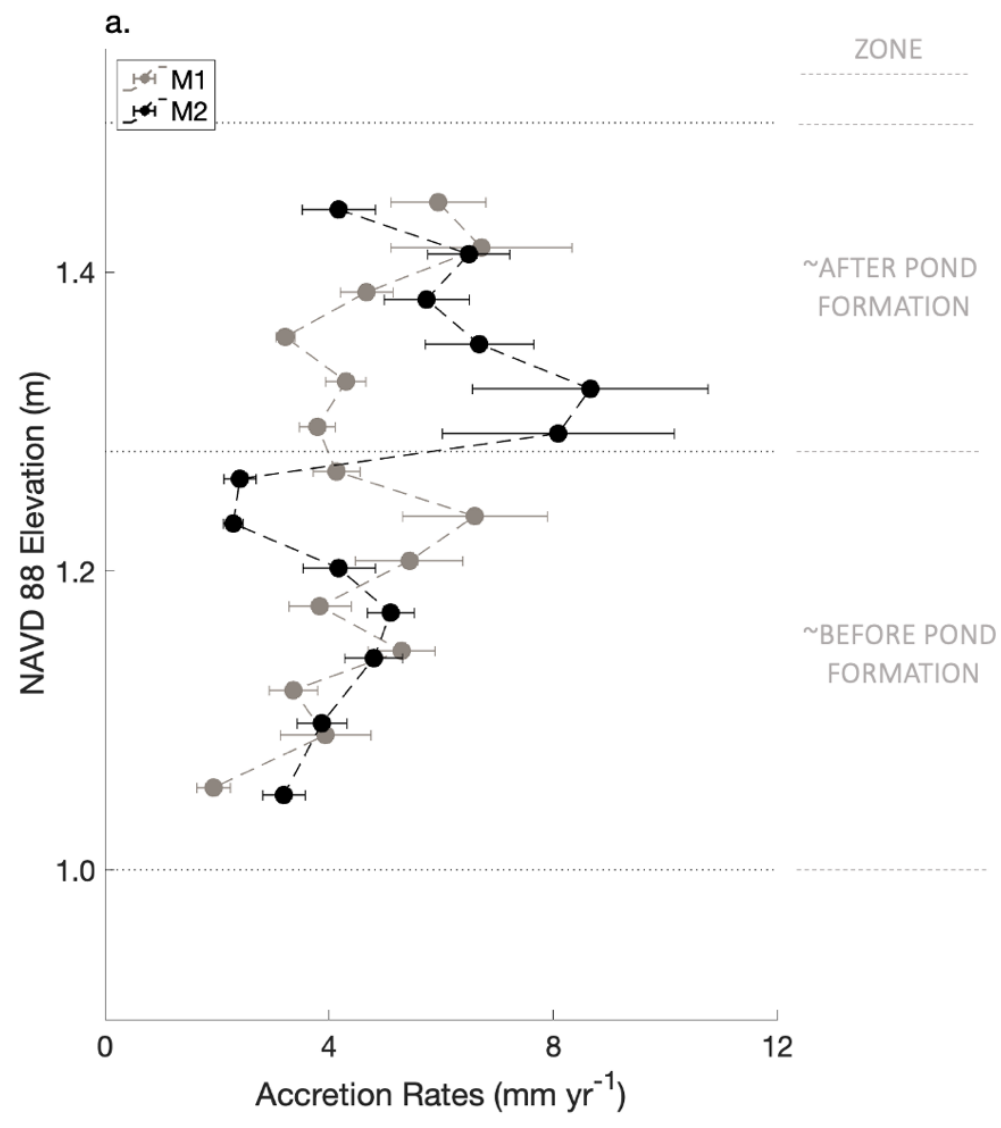

Figure 6: Mean accretion rates $\left(\mathrm{mm} \mathrm{yr}^{-1}\right)$ and SE of the near (M1) and far (M2) marsh sites based on $3 \mathrm{~cm}$ increments. Zones after and before pond formation correspond to horizons above and below the year 1978 (Pond 1 and Pond 2) and 1963 (Pond 3), respectively, which is approximately when the ponds formed ( 1.3 m NAVD88). See Table 5 for contrast analyses. 


\section{SUPPLEMENTAL TABLES AND FIGURES}

Table S1: Table of post-hoc contrasts for the near (M1) and far (M2) marsh bulk and elemental soil properties: bulk density $\left(\mathrm{g} \mathrm{cm}^{-3}\right)$, total nitrogen (TN\%), total organic carbon (TOC\%), C:N, and total organic carbon density $\left(\mathrm{kg} \mathrm{m}^{-3}\right)$. Displayed are the contrast coefficients and $\mathrm{p}$-values comparing the near and far marsh (M1 - M2) for the (A) marsh surface (0-30 cm marsh) overlapping inundated pond waters. Highlighted values are significant $(p<0.05)$.

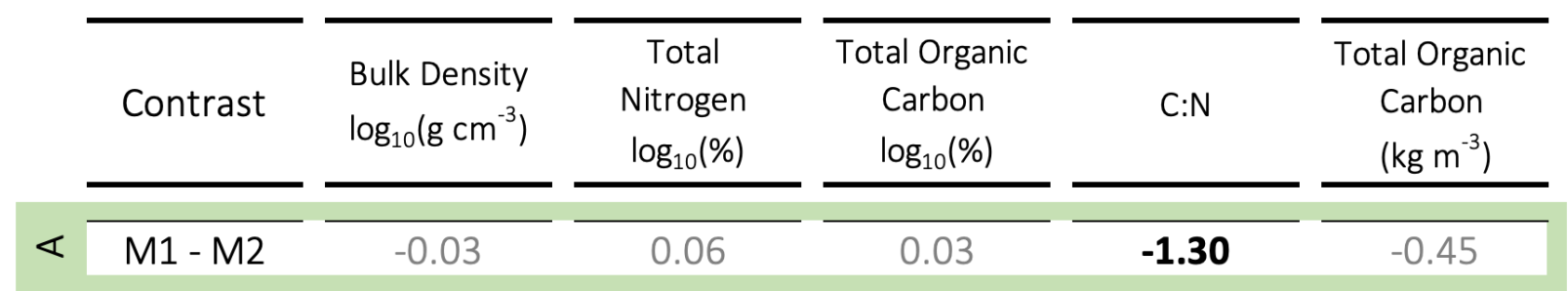



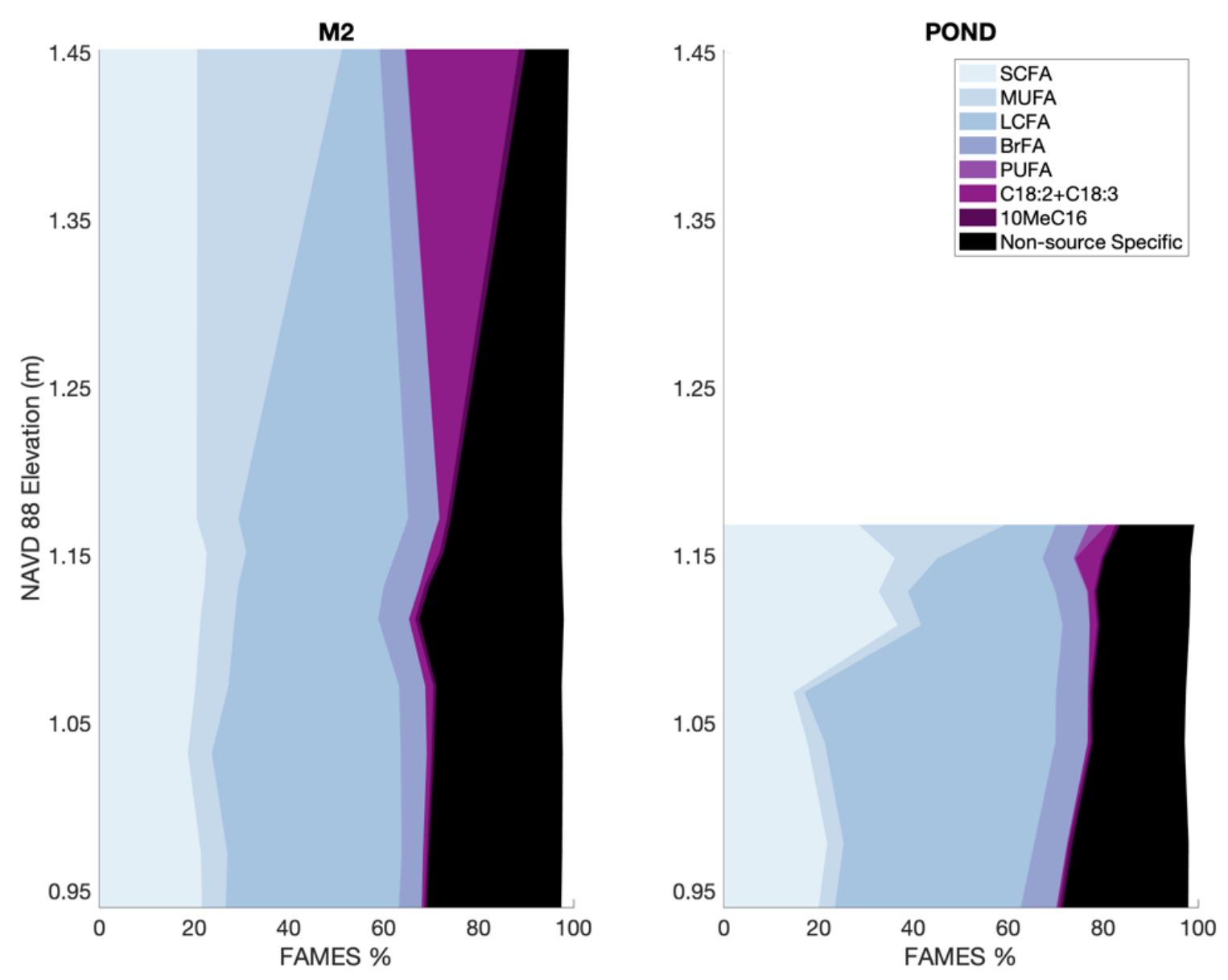

Figure S1: Mean distribution of FAMES lipid compounds by percent with elevation within the marsh (M2) and pond core across the three sites. Displayed are FAMES compounds associated with short-chain fatty acids (SCFA), mono-unsaturated fatty acids (MUFA), long-chain fatty acids (LCFA), branched fatty acids (BrFA \%), polyunsaturated fatty acids (PUFA), C18:2 + C18:3, 10methyl C16 (10MeC16), and non-source specific FAMES compounds (Non-source Specific). 


\title{
Chapter 4: Decades of marsh pond infilling results in spatial heterogeneity within salt marsh carbon budgets
}

\begin{abstract}
Salt marshes play a critical role in human wellbeing through the delivery of valuable ecosystem services (e.g. carbon storage), yet are becoming increasingly threatened by disturbance through global change (e.g. sea-level rise, increased storm intensities). In one New England salt marsh (Great Barnstable Marsh, MA), resource managers have employed anthropogenic ditching since the 1920 s in an effort to return permanently submerged marsh features (e.g. ponds) to a vegetated marsh habitat. The purpose of this hydrological management strategy was to provide employment opportunities and reduce areas in which mosquito populations breed. To understand how pond recovery impacts overall marsh ecosystem functioning and services, we analyzed the spatial variability in soil accretion rates, organic carbon composition, source, age, and reactivity with respect to anthropogenic ditches, the tidal channel, and marsh environments that have experienced historical ponding. After nearly a century of ditching, ponds that previously existed in the 1920s have now nearly recovered in elevation to the surrounding marsh platform through drainage, revegetation, and rapid soil accumulation $\left(4.8-10.9 \mathrm{~mm} \mathrm{yr}^{-1}\right)$. While we observed tidal creek inorganic contributions to soil accretion within both the infilling ponds and paired adjacent marsh environments, we find that accretion via marsh grass productivity, characterized by greater plant heights and biomass, dominates pond infilling processes. Infilling pond environments continue to contribute to soil heterogeneity within the marsh environment through lower bulk densities, total organic carbon content and soil carbon age. Thus, incorporating the full pond life cycle into estimates of salt marsh carbon budgets and turnover is key to informing ditch management decisions and refining marsh carbon budgets.
\end{abstract}




\subsection{INTRODUCTION}

The installation and maintenance of parallel grid ditches in New England to reduce ponded areas on the marsh platform has largely been successful (Kennish, 2001; Adamowicz and Roman, 2005; Riepe, 2010). By instigating pond drainage, revegetation of emergent marsh grasses, and subsequent infilling, the footprint of the former pond becomes level with the surrounding marsh resulting in a virtually indistinguishable vegetated marsh landscape (Wilson et al., 2014b). However, it is unknown whether pond infilling to the elevation of the surrounding marsh constitutes a full recovery of marsh ecosystem functions that contribute to rapid soil building and carbon storage. Thus, constraining processes that contribute to pond recovery and the resulting impacts on the spatial distribution of carbon storage will be key for natural resource managers who must make decisions that balance the long-term effects of past decisions as well as the provisioning of ecosystem services in the future.

Whereas pond expansion represents net losses of salt marsh productivity, soil, and elevation capital (Mariotti, 2016; Spivak et al., 2018; Luk et al., 2021), pond infilling potentially compensates through revegetation, rapid accretion, and elevation gain (Wilson et al., 2014b). Processes associated with pond recovery may reflect the natural resilience and biogeomorphic feedbacks that allow the marsh platform to keep pace with sea-level rise; typically vegetated marsh platforms at lower elevations are characterized with longer hydroperiods that allow for vegetation to accumulate suspended sediment from the tidal channel and enhanced aboveground and belowground plant production coinciding with increased organic matter accumulation and accretion (Morris et al., 2002; Mudd et al., 2009; Wilson et al., 2014b). Exploring the primary processes driving pond infilling can give insight into the nature of marsh recovery and what future marsh elevation maintenance may look like after ponding disturbance on the marsh platform. For example, recovering ponds in Plum Island Estuary were dominated by rapid inorganic sediment deposition due to increased hydroperiod and tidal exchange (Wilson et al., 2014). If tidal channel sediment supply is a critical factor in pond infilling, then low suspended sediment environments and future reductions in sediment sources (e.g. due to hydrological dams) may inhibit processes that allow for elevation recovery within ponded marsh habitats. Alternatively, rapid vertical accretion can occur through organic matter accumulation during enhanced plant production in response to lower elevations (Nyman et al., 2006), providing a pathway for pond recovery in sediment deficient marshes. Therefore, characterizing the continuum of processes associated with pond recovery can give insight into conceptualization of marsh biogeomorphic feedbacks and the efficacy of future resource management decisions.

The composition of soils infilling ponds is a key component in assessing the controls on pond recovery and whether this results in a full compensation of the soil carbon lost due to pond expansion through soil erosion and organic matter decomposition (Spivak et al., 2018; Luk et al., 2021). The delivery of inorganic sediments to salt marsh ponds from allochthonous sources could play an important role in pond recovery and reduce the carbon storage capacity of these recovering features (Wilson et al., 2014). Further complexity is added when we consider the sources of organic carbon that are buried within the infilling ponds; infilling ponds may bury reactive carbon 
that originates from new production (e.g., recolonized emergent grasses), allochthonous (marine, terrestrial), or more stable recycled autochthonous carbon (e.g. old marsh material eroded from the creekbanks) (Peterson and Howarth, 1987; Deegan and Garritt, 1997; Hopkinson et al., 2018; Luk et al., 2021). If pond recovery relies on the burial of recycled old material within the marsh platform, this would represent an additional loss to the long-term carbon storage within the marsh platform. Yet, the increased contribution of more structurally complex and stable soil organic carbon with longer turnover times may be more resistant to future decomposition processes (Luk et al., 2021). Therefore, by identifying the composition, source, reactivity, and age of the organic material contributing to pond infilling, we can understand whether infilling ponds represent a recovery of marsh ecosystem functioning that recoups the initial carbon lost due to pond expansion on the marsh platform.

To understand the processes linked with pond recovery and the subsequent impact on marsh carbon storage, we compared proximal marsh areas that have and have not exhibited historical ponding based on historical aerial photographs (USGS). Sites were selected at varying distance (but within 100m) of the tidal channel to evaluate potential controls on pond recovery. At each site, we measured marsh platform elevation and aboveground plant characteristics, complemented with soil accretion rates, composition, source, and reactivity of soils contributing to pond infilling and recovery. We hypothesize that inorganic sediments will be an important contributor to rapid pond soil accretion that will decrease with distance from tidal channel. As a result, infilling ponds will be characterized with lower soil carbon densities resulting in the loss of stored carbon associated with the pond lifecycle. Further, we expect that lower elevations within infilling ponds may enhance trapping of recycled marsh material that would serve as an additional loss term within marsh carbon accounting. This will allow us to gain insight into processes linked with marsh elevation recovery and whether infilling ponds represent a return to the original vegetated marsh state with comparable ecosystem functions and ecosystem service delivery.

\subsection{METHODS}

\subsubsection{Study site}

Great Barnstable Marsh, MA, USA $\left(41.729007^{\circ},-70.376137^{\circ}\right)$ is a macrotidal system (mean tidal range $\sim 3 \mathrm{~m}$ ) with an extensive high marsh platform $\left(\sim 10 \mathrm{~km}^{2}\right.$; Redfield, 1972; Fig. 1). Ditches were installed in $\sim 60 \%$ of the marsh in the 1930 s and have been continuously maintained by the Cape Cod Mosquito Control Project. Using publicly available historical aerial images from US Geological Survey and Google Earth, we selected six pairs of sites that include areas that were ponded in the 1920s and transitioned to vegetated marsh following ditch installation (i.e., infilling ponds) and nearby areas that have been continuously vegetated by marsh grasses ( 8 - 30m away to avoid ponding impacts of the marsh) (Luk et al., in prep). Criteria for selecting the six ponds was informed by 1938 photographs indicating the area was ponded when ditches were installed; Paired sites were varying distances $(33-94 \mathrm{~m})$ from the tidal channel, in order to assess whether proximity affects the composition of infilling material or soil accretion rates (Table 1). At each of the paired sites we measured elevation (North American Vertical Datum of 1988 [NAVD88 m]), 
and plant community characteristics, and collected soil cores $(\sim 1 \mathrm{~m})$ to characterize soil organic carbon (SOC) composition and reactivity, and soil accretion rates. Study site elevations and locations were measured using a real time kinematic unit. Fieldwork was conducted in the Summer - Fall of 2018.

\subsubsection{Plant characteristics}

Plant community characteristics were determined through species-specific percent cover, plant canopy eight, and biomass. We established duplicate $1 \mathrm{~m}^{2}$ quadrats in infilling ponds and single quadrats in the marsh; the difference in sampling resolution reflected the expectation of greater heterogeneity in the former pond. Percent cover was determined through visual estimates and canopy height by measuring the five tallest plants. Aboveground biomass was collected from a sub-quadrat of $0.0625 \mathrm{~m}^{2}$, to minimize disturbance, and then dried $\left(60{ }^{\circ} \mathrm{C}\right)$ to constant mass.

\subsubsection{Bulk soil properties}

Soil cores $(10 \mathrm{~cm}$ diameter $\mathrm{x} 60 \mathrm{~cm}$ long) collected from paired pond and marsh sites were split laterally and sectioned into $1-2 \mathrm{~cm}$ horizons, with a finer resolution in the top $45 \mathrm{~cm}$ horizon (root zone). Samples were freeze dried and soil water content (\%) and bulk density $\left(\mathrm{g} \mathrm{cm}^{-3}\right)$ were determined gravimetrically. For subsequent elemental analysis, samples at $3 \mathrm{~cm}$ increments were sieved to remove roots $(1 \mathrm{~mm})$, ball milled and analyzed for elemental (total organic carbon [TOC], total nitrogen [TN], and total sulfur [TS]). Measurements for TOC and TN were fumed with $12 \mathrm{~N}$ $\mathrm{HCl}$ prior to analysis (Lorrain et al., 2003).

Additional soil cores (10 cm diameter x $30 \mathrm{~cm}$ long) were collected at each site to increase replication of soil properties within the rooting zone, where we expected greater heterogeneity. We focused on grain size, elemental composition, and organic matter content in aggregated upper $(0-10 \mathrm{~cm})$ and lower $(10-30 \mathrm{~cm})$ regions of the rooting zone. Elemental analyses were prepared as described above. We also measured organic matter content (\%)using loss on ignition (LOI \%) where soils were sieved $(<1 \mathrm{~mm})$ and combusted $\left(550^{\circ} \mathrm{C}\right.$ for $\left.5.5 \mathrm{hrs}\right)$ to obtain loss of organic material weight on ignition (Dean, 1974). This methodology provided relationships between TOC (\%), organic, and inorganic content that could be extrapolated for the $60 \mathrm{~cm}$ soil core horizons (Morris et al., 2016).

\subsubsection{Soil age models}

Soil accretion rates and age models were developed through measurements of ${ }^{137} \mathrm{Cs},{ }^{210} \mathrm{~Pb}$, and ${ }^{226} \mathrm{Ra}$ on a planar-type gamma counter (Canberra, Inc. USA; Gonneea et al., 2019). Measured activities of ${ }^{210} \mathrm{~Pb}$ were then processed using the constant initial concentration (CIC) ${ }^{210} \mathrm{~Pb}$ models to estimate rates of soil accretion (Appleby and Oldfield, 1978).

\subsubsection{SOC reactivity, sources, and age}

Soil organic carbon composition was characterized through ramped pyrolysis oxidation (RPO) coupled to isotope measurements to evaluate the thermal reactivity, source, and age of 
marsh and infilling pond soils. To determine how marsh soils changed over time since ditching and whether infilling ponds are compositionally similar to the adjacent marsh, we selected marsh horizons deposited between 1850 to 2018 as they represented periods pre- and post-ditching. With the marsh soils as a reliable chronometer for the time period of ditch implementation, we analyzed infilling pond horizons that corresponded in elevation with the selected marsh soil horizons. Ball milled and homogenized samples $(\sim 20-40 \mathrm{mg})$ were placed within a reactor where temperatures ramped at $5{ }^{\circ} \mathrm{C} \mathrm{min}^{-1}$ to $1000{ }^{\circ} \mathrm{C}$ (; Rosenheim et al., 2008). The evolved carbon dioxide $\left(\mathrm{CO}_{2}\right)$ was measured by a flow-through infrared gas analyzer and thermograms were constructed by plotting $\mathrm{CO}_{2}$ concentrations versus temperature. To facilitate comparisons across horizons, we normalized the thermogram to unit area.

We subsequently analyzed the evolved $\mathrm{CO}_{2}$ for ${ }^{13} \mathrm{C}\left(\delta^{13} \mathrm{C}, \% 0\right)$ and ${ }^{14} \mathrm{C}\left(\mathrm{F}^{14} \mathrm{C}\right)$ composition (McNichol et al., 1994b; Reimer et al., 2004; Luk et al. 2021). The $\mathrm{CO}_{2}$ gas was collected during five discrete ramping temperature intervals; there were three low $\left(200-465^{\circ} \mathrm{C}\right)$ and two high $(465$ $-650^{\circ} \mathrm{C}$ ) temperature fractions. The isotopic composition of evolved $\mathrm{CO}_{2}$ was analyzed for all five fractions for the $2018(0-2 \mathrm{~cm})$ horizons and two of the five fractions capturing the full range of thermal reactivity were analyzed for the four deeper horizons spanning $1850-1980$.

We evaluated SOC thermal reactivity by calculating temperatures at which $50 \%$ of $\mathrm{CO}_{2}$ was evolved (t50) and thermal activation energies. The theoretical activation energy ( $\left.E a \mathrm{~kJ} \mathrm{~mol}^{-1}\right)$ and blank contamination correction were calculated using the Python package rampedpyrox (Hemingway et al., 2017a, 2017b)

\subsubsection{Data Analysis}

We pooled soil horizons based on depths that reflect (1) the surface and rooting zone (0 $30 \mathrm{~cm})$, (2) just below the rooting zone $(30-45 \mathrm{~cm})$, and (3) deeper layers $(45-60 \mathrm{~cm})$. Based on Kolmogorov-Smirnov goodness-of-fit hypothesis tests, bulk density and TOC (\%) were logtransformed prior to statistical analysis to meet assumptions of normality. Post-hoc contrasts from mixed linear models testing bulk soil relationships with pooled soil zones and infilling vs. marsh environments were then used to evaluate differences with soil depth and between marsh environments.

Multiple linear regressions were employed to predict plant and bulk soil characteristics using variables capturing distance from marsh landscape features (e.g distance from tidal creek and nearest ditch) and based on pooled soil zones. Univariate regressions were used to assess potential relationships between accretion rate and distance from tidal creek, as well as between soil bulk density and TOC (\%), S (\%), and C:S. Further to estimate organic content (\%) using TOC (\%) for soils analyzed in the $60 \mathrm{~cm}$ soil cores, we used a linear regression to establish the relationship between organic content (\%) and TOC (\%) measured in the $30 \mathrm{~cm}$ soil cores. This range of modeling techniques provided assessment of shifts in plant and soil properties based on differences in the marsh landscape (e.g. marsh vs. infilling pond, soil zone, distance from tidal creek and ditch, marsh platform elevations) as well as relationships between individual soil parameters (e.g. TOC (\%) and organic content). 


\subsection{RESULTS}

\subsubsection{Elevation and plant communities}

Elevations of the infilling ponds and adjacent marsh ranged from 1.31 - 1.46 (m NAVD88) and 1.41-1.48 (m NAVD88), respectively (Fig. 2a). Despite this overlap, marsh platform elevations were consistently higher than the infilling ponds with greater differences at increasing distances from the tidal channel. Elevations of infilling ponds decreased with increasing distance from tidal creek $(\mathrm{p}<0.05)$ while nearby marsh sites did not follow a similar trend. Fractional elevations were calculated for the infilling ponds and marsh, $1.07-1.11$ and $1.08-1.13$, respectively, demonstrating that marsh platform resides near mean higher high water (Burns et al., 2021).

Infilling ponds and the surrounding marsh were populated by the grasses Spartina patens, S. alterniflora, and Distichlis spicata. The dominant plant species in both the infilling ponds and adjacent marshes was $S$. alterniflora $(80-90 \%)$ with minor contributions of D. spicata and $S$. patens. Plant canopy height and biomass were greater in the infilling ponds compared to the marsh (Fig. 2 c-d), which demonstrates distinct infilling pond plant characteristics coinciding with the lower position in the tidal frame relative to the marsh. However, plant characteristics (plant height, biomass) did not vary with elevation or distance from the tidal channel (SI Table 1).

\subsubsection{Bulk soil properties}

Soil properties reflected both ponding history and distance from the tidal channel. Marsh soils generally had higher bulk densities and TOC content $\left(\%\right.$ and $\left.\mathrm{kg} \mathrm{m}^{-3}\right)$ than the infilling ponds (Fig. 3; Table 2). Soil C:N ratios and sulfur content were also higher in the marsh, but only in the rooting zone $(\mathrm{A}, 0-30 \mathrm{~cm})$. Increasing distances from tidal channel correlated with lower bulk densities and inorganic content and higher TOC\% in both marsh and infilling pond soils (SI Table 2). Similarly, bulk density was lower in infilling ponds that were at greater distances from mosquito ditches (SI Table 2). Overall, infilling pond soils displayed lower bulk density and TOC content relative to the marsh as well as gradients with distance from the tidal creek.

Relationships between soil properties reveal strong patterns with bulk density and inorganic contents (SI Fig. 3 - 4). Increasing bulk density significantly coincided with decreasing TOC (\%), sulfur content (\%), and C:S for the infilling pond and the marsh to a lesser extent (Fig. S3). Further, a significant relationship $(\mathrm{p}<0.05)$ between TOC $(\%)$ and LOI $(\%)$ provided an equation to convert TOC content to organic and inorganic content within infilling pond and marsh soils (Eq.1-2, Fig. S4).

$$
\begin{array}{cc}
\text { TOC }(\%)=-1.03+0.45(L O I \%) & E q(1) \\
\text { Inorganic }(\%)=100-\text { LOI }(\%) & E q(2)
\end{array}
$$

\subsubsection{Accretion rates}


Soil accretion rates were determined using the CIC model (Appleby and Oldfield, 1978). Mean CIC accretion rates for the marsh were $3.16 \pm 0.44 \mathrm{~mm} \mathrm{yr}^{-1}$, demonstrating that the marsh is keeping pace with local sea level rise rates based on the nearest long-term tide gauge in Boston (Fig. $2 b ; 2.86 \pm 0.15 \mathrm{~mm} \mathrm{yr}^{-1}$; NOAA station \#8443970).

Excess ${ }^{210} \mathrm{~Pb}$ did not reach secular equilibrium for four of the six infilling ponds, preventing development of constant rate of supply models (Appleby and Oldfield, 1978; SI Fig. 2). Therefore, we focused on CIC rates to compare accretion between infilling ponds and the marsh (Fig. 2b). Accretion rates for the infilling ponds ranged from $4.8-10.9 \mathrm{~mm} \mathrm{yr}^{-1}$; the lower end is due to slower rates $\left(4.82 \mathrm{~mm} \mathrm{yr}^{-1}\right)$ in Pond 2 where the excess ${ }^{210} \mathrm{~Pb}$ activity reached secular equilibrium. There were no relationships between accretion rates and distance from the tidal channel; infilling pond accretion rates were generally similar $\left(9.0-10.9 \mathrm{~mm} \mathrm{yr}^{-1}\right)$ despite varying in distance from creek $(33-94 \mathrm{~m})$ (SI Fig. 1). Mean infilling pond accretion rates $\left(8.78 \pm 0.84 \mathrm{~mm} \mathrm{yr}^{-1}\right)$ were threefold greater than the marsh and local sea-level rise.

\subsubsection{SOC reactivity, source, and age}

Infilling pond and marsh soil carbon derived from autochthonous production and had similar thermal properties (Fig. 4 - 5). Bulk soil $\delta^{13} \mathrm{C}$ values ranged from -15.6 to $-14.2 \%$ which is more consistent with salt marsh grass production (e.g., S. alterniflora; -14.2 to $-10.3 \%$; Spivak et al., 2018), than imported organic matter from terrestrial (-24 to - 18\%) or marine sources (-30 to $-26 \%$ ) (Fig. 4; Bianchi and Canuel, 2011).

Marsh and infilling pond soil organic carbon had similar thermal decomposition patterns, with a bimodal distribution encompassing pyrolysis of SOC pools at low and high temperatures (Fig. 5). The $\delta^{13} \mathrm{C}$ values of $\mathrm{CO}_{2}$ evolved from SOC within a horizon generally became more enriched ( 1-2\%) with increasing temperatures; this trend persisted across depth horizons in both the marsh and infilling ponds (Fig. 5). One infilling pond (Pond \#3) had an additional and replicable peak at high temperatures $\left(600-700^{\circ} \mathrm{C}\right)$ in the surface $(0-2 \mathrm{~cm})$ horizon that was not present in deeper layers (Fig. 5f), with $\mathrm{Fm}>1$ and $\delta^{13} \mathrm{C} \mathrm{(-2 \% )}$ ) that were enriched relative to marsh, marine, and terrestrial organic matter. The origin of this anomalous $\mathrm{CO}_{2}$ peak is uncertain and requires further investigation. We used thermograms to calculate two thermal indices, t50 and thermal activation energies $\left(\mathrm{kJ} \mathrm{mol}^{-1}\right)$ (Fig. $\left.4 \mathrm{~b}-\mathrm{c}\right)$. In the marsh, both indices generally increased with depth, indicating a shift towards greater thermal stability (Fig. 4, SI Table 3). In contrast, infilling pond soils had generally similar thermal properties with depth and in comparison to the marsh at corresponding elevations (Fig. 4; SI Table 3).

Radiocarbon $\left(\mathrm{F}^{14} \mathrm{C}\right)$ values generally decreased from low to high temperature fractions reflecting a continuum of SOC age inputs (Fig. 5). In both the marsh and infilling pond surface, low temperature fractions exhibited greater than modern $\mathrm{F}^{14} \mathrm{C}$ values while the two highest temperature fractions, which captured $\sim 25 \%$ of the total $\mathrm{CO}_{2}$ evolved had less than modern $\mathrm{F}^{14} \mathrm{C}$ values (Fig. 5). Marsh horizons deposited between 1960-1980, based on CIC age models, had greater than modern $\mathrm{F}^{14} \mathrm{C}$ values, which suggests incorporation of radiocarbon from nuclear bomb testing $\left(\mathrm{F}^{14} \mathrm{C}>1\right)$. Radiocarbon values of pond horizons at similar elevations did not mirror the 
those in the marsh (Fig. $5 g-h)$. Instead, we observed elevated $\mathrm{F}^{14} \mathrm{C}$ values $\left(\mathrm{F}^{14} \mathrm{C}\right)$ for deeper pond horizons (Fig. 5i-j) compared to the marsh at similar elevations that were deposited in 1850-1920 (Fig. 5d-e). Differences in soil ages at similar elevations as a result of pond infilling provides additional complexity with regard to estimates of soil organic carbon turnover within the salt marsh.

\subsection{DISCUSSION}

Marsh recovery in the form of pond drainage and subsequent infilling occurs on decadal scales. Since ditch installation in the 1920s, ponds drained and became recolonized with emergent marsh grasses yet continue to reside at a lower elevation relative to the adjacent marsh particularly within the marsh interior (100m away) (Fig. 2a, Table 1) Further, we observed distinct plant characteristics (e.g. greater plant height and biomass) within the infilling ponds that coincided with three-fold accretion rates within the infilling pond soils relative to the adjacent marsh and local sea level rise rates (Fig. $2 b-d$ ). The soil composition of the rapidly infilling material - capturing distinctions between the marsh rooting zone and deeper horizons - demonstrated that the infilling ponds had lower bulk densities, TOC content $\left(\%\right.$ and $\left.\mathrm{kg} \mathrm{m}^{-3}\right), \mathrm{C}: \mathrm{N}$, and sulfur content than the surrounding marsh (Fig. 3, Table 2). The sources of organic carbon for both environments were autochthonous marsh material with similar thermal reactivities, yet radiocarbon dating revealed distinctly different ages for soils deposited at the same elevation within the marsh that contributes to further soil heterogeneity within the marsh environment (Fig. 4-5).

\subsubsection{Biophysical drivers of pond elevation recovery}

Infilling ponds remain at lower elevations compared to the surrounding marsh after nearly a century of ditching, particularly at greater distances $(\sim 100 \mathrm{~m})$ from the tidal creek (Fig. 2a). The significant decrease in infilling pond elevations - and to a lesser extent the surrounding marsh with distance from creek highlights the role of the tidal creek and its supply of inorganic material to marsh soil accretion and elevation gain (Fig. 2a, SI Table 2; Pethick, 1981; Kirwan and Guntenspergen, 2010; Wilson et al., 2014). Both the infilling pond and marsh demonstrated significant trends of greater bulk density and inorganic contents closer to the tidal creek and, to a lesser extent, ditches, highlighting the proximal role of tidal creek high density inorganics to marsh elevation gain (SI Table 2; Reed et al., 1999).

Yet, inorganic material from the tidal creek does not appear to play a larger role in pond soil elevation gain in comparison to the surrounding marsh. Both TOC (\%) and bulk densities were lower in the infilling ponds compared to the adjacent marsh and the magnitude in the increase of TOC (\%) with increasing distance from tidal creek was similar for the adjacent marsh and infilling ponds (Fig. 3; Table 2c, SI Table 2). Further, conversions of TOC (\%) to inorganic soil contributions demonstrated that the infilling ponds and adjacent marsh had generally similar inorganic sediment contents, ranging from $60-70 \%$, which overlap infilling ponds within Plum Island Estuary, MA (Wilson et al., 2014b). While infilling ponds indeed had lower TOC (\%) and correspondingly higher inorganic contents, we would expect the infilling ponds to have higher bulk densities (estimated increase by $0.05 \%$; Morris et al., 2016) and differing trends with distance 
from the tidal creek compared to the surrounding marsh. Therefore, although the supply of inorganics from the tidal creek may not be the primary driver in pond recovery, these marsh hydrological features contribute to proximal marsh elevation gain in both infilling pond and adjacent marsh environments.

Another aspect to pond recovery is the feedback between marsh grass production and platform elevation relative to the tidal frame within the marsh environment (Fig. 2 c-d; Redfield, 1972; Morris et al., 2002; Nyman et al., 2006). The ability of S. alterniflora to respond in production (e.g. plant height and biomass) due to the initial elevation differences within the drained ponds relative to the surrounding marsh may derive from elevations within GBM (1.3 - $1.5 \mathrm{~m}$ NAVD88) that reside within the stable portion of the marsh equilibrium curve that allow for revegetation and recovery within this marsh (Morris et al., 2002; Wilson et al., 2014). Once elevations reach that of the surrounding marsh, plant productivity will respond by decreasing biomass and plant heights, in turn reducing accretion rates (Allen, 2000). Mirroring the conceptualization of the marsh equilibrium model, we found that the dominant marsh grass species (S. alterniflora) plant heights and biomass were greater within the infilling ponds relative to the surrounding marsh residing at a higher elevation (Fig. $2 \mathrm{c}-$ d, SI Table 1; Wilson et al., 2014; Morris et al., 2002). Interestingly, we did not see significant differences in plant characteristics within the infilling ponds relative to surface elevation or distances from the creek (SI Table 1). This suggests that current infilling pond plant characteristics may be a response to original pond elevations relative to the marsh, that have not yet adjusted to current gradients in surface elevation that exist within the infilling ponds (Fig. 2a). This reflects the general equilibrium between the marsh platform vegetation and elevation relative to the tidal frame that is an important driver of salt marsh pond recovery in this marsh environment.

The combination of shifting plant characteristics and deposition of inorganic material from the nearby tidal creek and ditches contribute to the rapid soil accretion rates within the infilling ponds that represented a threefold increase from the surrounding marsh platform and local SLR (Fig. 2b). Studies in Maine and Massachusetts that measured accretion rates of infilling ponds found a similar or near tripling of accretion rates $\left(\sim 2-5 \mathrm{~mm} \mathrm{yr}^{-1}\right)$ relative to the high marsh platform $\left(\sim 2 \mathrm{~mm} \mathrm{yr}^{-1}\right)$ that were hypothesized to be a result of inorganic sediment deposition from the tidal channel due to the large (60-70\%) contribution of inorganics within pond soils (Wilson et al., 2010, 2014b). In this study, the range of recovery accretion rates were less variable $(9.0-$ $10.9 \mathrm{~mm} \mathrm{yr}^{-1}$ ) for five of the six ponds, despite varying distances from both the tidal creek (33 $94 \mathrm{~m})$ and ditch $(6-15 \mathrm{~m})$ (SI Fig. 1). In certain marshes, soil accretion appears to be driven by plant productivity where accretion rates varied with organic matter accumulation rather than mineral sedimentation, even in environments where inorganic material contributed up to $80 \%$ of marsh soils (Mccaffrey and Thomson, 1980; Callaway et al., 1997; Nyman et al., 2006). In combination, our findings demonstrate that the plant productivity response to elevation differences is an important driver in rapid soil accretion rates within infilling ponds.

4.4.2 Infilling salt marsh ponds contribute to persistent spatial heterogeneity of soils 
Salt marsh ponds contribute to soil heterogeneity (Spivak et al., 2018; Luk et al., in prep), which persists after decades of pond recovery. Studies of existing ponds in Plum Island Ecosystem - Long Term Ecological research site (MA, USA) demonstrated that salt marsh ponds, particularly at the surface horizons, have lower bulk density, TOC content, and C:N relative to the marsh at similar elevations (Luk et al., in prep). The subsequent drainage and reestablishment of emergent marsh grasses have resulted in revegetation and near recovery of elevation, yet differences in soil characteristics such as bulk density, TOC content, and C:N endure (Fig. 3; Table 2c). Persistent soil heterogeneity despite pond infilling may be a result of rapidly accumulating plant material, reduced compaction of soils, and altered soil redox environment (Fig. 2b - Fig. 3). Overall, we observe persistent spatial heterogeneity associated with infilling ponds indicating differences in ecosystem functioning after close to a century of recovery.

Soil sulfur content can provide insight into the soil redox environment. Lower sulfur contents within the rooting horizon of infilling pond soils may indicate changes in sulfur cycling relative to the surrounding marsh platform, either from decreased sulfate reduction, increased oxidation rates of reduced sulfur compounds, or shifts in the communities of chemolithoautotrophic bacteria (Fig. 3 and Table 2; (Howarth, 1984; Gardner, 1990; Tobias and Neubauer, 2019). Importantly, this change in $\mathrm{S} \%$ may reveal changes in the redox environment of infilling soils; more oxic conditions may reduce soil sulfur content and promote aerobic decomposition of buried organic carbon (Luther and Church, 1988). Strong trends between bulk soil properties particularly within the infilled ponds are consistent with removal of TOC content corresponding with the accumulation of higher bulk densities from inorganic material. This coincides with lower sulfur content and decreased preservation of carbon relative to sulfur $(\mathrm{C}: \mathrm{S})$ (SI Fig. 3). At the same time, more oxic soil conditions within infilling ponds could promote plant growth and soil accumulation (Fig. 2; Linthurst, 1979; Mendelssohn et al., 1981) due to the oxidation of toxic sulfur compounds (e.g. $\mathrm{H}_{2} \mathrm{~S}$; King et al., 1982; Giblin and Howarth, 1984). Relationships between soil sulfur content and plant height were tested but resulted in a weak relationship $(\mathrm{p}<0.10)$ between decreasing soil sulfur corresponding with increased plant heights. Therefore, lower TOC $\left(\mathrm{kg} \mathrm{m}^{-3}\right)$ within the infilling ponds relative to the marsh can be a result of processes associated with increased aerobic decomposition within infilling pond soils as well as differences in the initial composition of buried marsh material (Table 2).

Rapidly infilling material that coincides with pond recovery on the marsh platform results in distinctly different soil composition than that of the surrounding marsh. Particularly in the case of ecosystem-wide marsh carbon storage, lower TOC content combined with potentially more favorable conditions for aerobic organic matter decomposition, indicate that carbon storage services continue to be altered and reduced within both existing and infilling ponds. After decades of recovery, infilling ponds have not returned to the original vegetated marsh state with a similar set of ecosystem functions.

4.4.3 Age differences in salt marsh soil organic carbon contributing to pond infilling 
Despite the heterogeneity in soil composition and carbon content in infilling ponds, the overall sources of the soil organic carbon demonstrate that within this system, autochthonous marsh material contributes to pond recovery (Fig. 5). The similarity in $\delta^{13} \mathrm{C}(-15.6$ to $-14.2 \%$; Fig. 5) falling within the typical range of marsh organic matter (-14 to $-10.3 \%$; Spivak and Ossolinski, 2016; Spivak et al., 2018) across horizons overlapping the adjacent marsh soils indicate that infilling ponds do not appear to significantly trap terrestrial (-30 to $-26 \%$ ) or marine material ( -24 to $-18 \%$ ) during tidal inundation relative to the surrounding marsh (Bianchi and Canuel, 2011). Differences in soil composition and carbon content therefore reflect potentially differing contributions of marsh sources (e.g. benthic microalgae, S. alterniflora), plant composition and structure, or rates of organic matter decomposition (Spivak et al., 2018; Wang et al., 2003; Windham, 2001).

While it is difficult to link thermal properties to bioavailability, previous studies found that increased decomposition coincided with increased thermal stability and enrichment in bulk $\delta^{13} \mathrm{C}$ in salt marsh environments associated with the loss of thermally reactive SOC and $\delta^{13} \mathrm{C}$ depleted compounds such as lipids and carbohydrates (Williams and Rosenheim, 2015; Sanderman and Grandy, 2019; Luk et al., 2021). Here, we observe similar trends of enrichment in $\delta^{13} \mathrm{C}$ and increase in thermal stability with depth in the marsh and to a lesser extent the infilling ponds that are consistent with microbial reworking of salt marsh organic matter (Fig. 4 - 5). The similarities in paired infilling pond and adjacent marsh horizon thermal properties, bulk $\delta^{13} \mathrm{C}$, and $\delta^{13} \mathrm{C}-\mathrm{CO}_{2}$ of the evolved RPO fractions suggest that the rapid rate of fresh marsh material infilling the ponds (Fig. 2b; Fig. 5) and favorable redox environment for soil organic matter decomposition (Fig. 3e) result in comparable thermal reactivity profiles. Thus, the waterlogged environment of soils on an ecosystem-wide scale is efficient at SOC preservation with compounds capturing a range of thermal reactivities within the infilling pond and marsh environments.

Interestingly, we find a consistent contribution of older more thermally stable material (Fm $<1)$ with $\delta^{13} \mathrm{C}$ reflecting contributions of autochthonous marsh material within both the infilling pond and adjacent marsh environments (Fig. 5a, f). Conceptualizations of salt marsh carbon burial hinge on the assumption that new primary production is the sole contributor to carbon burial and elevation gain on the marsh platform (Chmura et al., 2003; Ouyang and Lee, 2014). Yet, we find that older marsh material contributes to surface $(0-2 \mathrm{~cm})$ soil organic carbon $(\sim 25 \%)$ that is likely recycled from the nearby eroding creekbanks or ditches (Hopkinson et al., 2018; Luk et al., 2021). Further, contributions of this older material were consistent across infilling pond surface SOC despite varying distances from channels $(8-14 \mathrm{~m})$ or ditches $(6-13 \mathrm{~m})$ (Table 1). While this suggests that carbon storage estimates are currently upwardly skewed by $\sim 25 \%$ due to the inclusion of this recycled material at the surface of the marsh and lower carbon contents due to ponding, infilling ponds do not contribute to further errors in carbon storage by enhancing the entrapment and burial of older recycled marsh material.

Extending below the surface horizon of the infilling ponds and marsh, we find differences in the radiocarbon age of the SOC pools associated with a range of thermal reactivities (Fig. 5 be, g-i). While soil horizons from the surrounding marsh exhibited bomb radiocarbon incorporation 
corresponding to the year of deposition in the 1960s-1980s (Fig. 5 b-c), the radiocarbon spike within infilling pond soils occurred at deeper soil horizons that were paired in elevation to the surrounding marsh deposited around the 1850s (Fig. 5i). This provides an additional chronometer to pond infilling since by the 1960s the ponds had not yet caught up in elevation to the surrounding marsh with an $\sim 30 \mathrm{~cm}$ deficit in elevation relative to the adjacent marsh. Assuming the $0.83-$ $0.85 \mathrm{~m}$ NAVD88 infilling pond captured radiocarbon atmospheric conditions in the 1960s, to achieve current day elevations of $1.39-1.46 \mathrm{~m}$ NAVD88 would require an accretion rate of $\sim 10$ $\mathrm{mm} \mathrm{yr}^{-1}$, which is consistent with infilling pond ${ }^{210} \mathrm{~Pb}$ CIC accretion rates $\left(4.8-10.9 \mathrm{~mm} \mathrm{yr}^{-1}\right)$. This is a first order calculation since the radiocarbon signature of soil organic carbon records new production within both above- and below-ground biomass (Trumbore, 1997, 2009). Therefore, this estimated elevation differential around the 1960s is likely high since it does not include potential incorporation of bomb carbon in the marsh rhizosphere, but demonstrates expected differences in soil organic carbon ages associated with pond recovery.

Marsh soils dominated by autochthonous organic matter inputs deposited from 1850-2018 demonstrate incorporation of bomb radiocarbon particularly during the years 1960 and 1980 (Fig. $5 b-c)$ suggesting that soil incorporation and turnover within the marsh occurs on decadal timescales, capturing the shift in radiocarbon within the atmospheric reservoir (Torn et al., 2009; Trumbore, 2009). Importantly, the differences in soil organic carbon ages are a necessary consideration when employing techniques such as bomb carbon modeling that exploits the intrusion of ${ }^{14} \mathrm{C}$ enriched $\mathrm{CO}_{2}$ into plant material to estimate carbon inputs and turnover times (Trumbore, 2009). Particularly, the time horizon in which carbon turnover would be calculated is considerably different within the infilling pond and adjacent marsh; the latter would span more than a century of carbon turnover while the former, a few decades. This is a critical component for carbon modeling exercises that aim to capture longer term soil decomposition relevant for future climate scenarios (Day et al., 1999; Kirwan and Mudd, 2012); characterizing SOC decomposition on shorter timescales within infilling ponds can result in more rapid decomposition rates that do not encompass the decay of slow-cycling SOC (Trumbore, 1997; Choi and Wang, 2004). Therefore, the spatial heterogeneity in soil organic carbon age across a range of thermal reactivities serves as an additional facet to be considered when estimating carbon turnover and resulting carbon persistence in marsh ecosystems.

\subsubsection{Future ponding can impact marsh carbon storage estimates}

Habitat heterogeneity can impact ecosystem-scale estimates of carbon storage and impede restoration efforts by wetland managers balancing human health aspects and marsh ecosystem service delivery. The goals of resource managers that continue to maintain the ditches in GBM have since expanded from mosquito population management to also include preserving and enhancing salt marsh ecosystem service delivery such as carbon storage (G. Sakolsky pers comm.). We find that carbon content in an infilling pond reveals that the full life cycle of a pond - from formation to infilling - represents a net loss of carbon on the order of $14.9-17.2 \mathrm{~kg} \mathrm{~m}^{-3}$, based on differences in whole core TOC content between the marsh and infilling pond, when calculating 
carbon storage in the upper meter of the soil column (Table 2c). Factoring in both differences in carbon content and elevation, and assuming the percent of infilling pond area is $13 \%$ (based on current ponding rate in GBM), carbon budget estimates would be $7 \%$ higher if the marsh was assumed to be a homogeneous vegetated marsh environment. This has important implications for a future of global change in which internal marsh loss through ponding is expected to increase, augmenting future uncertainty in carbon storage estimates and ecosystem service valuation (Kirwan et al., 2008; Mariotti, 2016).

\subsection{CONCLUSION}

Salt marsh managers are tasked with employing management strategies that must balance historical management actions, human health, and the continued delivery of vital salt marsh ecosystem services. Crucial to this effort is the evaluation of the impacts of these management strategies with these targets in mind; after nearly a century of ditch maintenance in Great Barnstable Marsh, we observe that ditches promote the recovery of ponds through rapid soil accretion rates, although soil composition characteristics (e.g. carbon and sulfur content) within infilling ponds continue to contribute to spatial heterogeneity in salt marsh ecosystem services. While the sources of organic matter appear to be a similar mixture of new and old autochthonous marsh material within these infilling features, the age of the carbon and time window of soil burial can impede efforts to accurately constrain global carbon burial and turnover times. With predicted future expansion of ponds and marsh interior loss associated with increasing sea-level rise, we find that this stable marsh system can recover in elevation through accretion via plant productivity, providing insight to salt marsh managers of potential recovery processes for similar marshes experiencing significant vegetation disturbances (Schepers et al., 2017; Penland et al., 2002). These findings are applicable to relatively healthy salt marsh environments that have experienced historical ditching; future exploration is required to determine whether natural pond infilling processes in marshes lower in the tidal frame proceed in a similar fashion to ditch-induced pond infilling. To fully incorporate the impacts of anthropogenic ditches on ecosystem service delivery, further exploration is needed to quantify the spatial extent of ditches and existing ponds and the incorporation of these features into carbon management in a future with global change.

\section{ACKNOWLEDGEMENTS:}

Thanks to Adrian Mann, Jennifer O'Keefe Suttles, and Marshall Otter for help in collecting and processing soil cores. M. Lardie, J. Hemingway, and V. Galy for assisting with RPO and rampedpyrox. Funding support was provided by Woods Hole Sea Grant (NA14OAR4170104), and NOAA (NA14NOS4190145) grants to ACS. 
Table 1: Six infilling ponds with measured elevations (m NAVD88) in the field. Distances from paired adjacent marsh site $(\mathrm{m})$, tidal channel $(\mathrm{m})$, and nearest ditch $(\mathrm{m})$ were measured using soil core coordinates in Google Earth.

\begin{tabular}{ccccc}
\hline Pond & $\begin{array}{c}\text { Elevation } \\
(\mathrm{m} \text { NAVD88) }\end{array}$ & $\begin{array}{c}\text { Distance from } \\
\text { Pair }(\mathrm{m})\end{array}$ & $\begin{array}{c}\text { Distance from } \\
\text { channel }(\mathrm{m})\end{array}$ & $\begin{array}{c}\text { Distance from } \\
\text { ditch }(\mathrm{m})\end{array}$ \\
\hline 1 & 1.35 & 17 & 88 & 8 \\
2 & 1.36 & 13 & 94 & 15 \\
3 & 1.44 & 10 & 49 & 6 \\
4 & 1.46 & 8 & 33 & 13 \\
5 & 1.40 & 14 & 41 & 9 \\
6 & 1.31 & 30 & 76 & 9 \\
\hline
\end{tabular}


Table 2: Downcore comparisons of the a) infilling pond and b) marsh environments and c) between environment contrast analysis. Contrasts are presented within soil zones (A-C), described in the methods section. Contrast coefficients provide the magnitude difference in soil zones (e.g. $\mathrm{A}-\mathrm{B}$ ) and between infilling pond and marsh environments at corresponding soil zones (e.g. MARSH - POND: A). Bolded values are significant at $\mathrm{p}<0.05$.
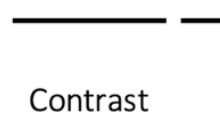

a.

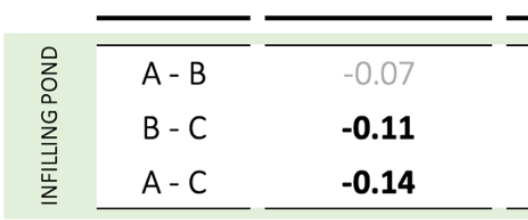

b.

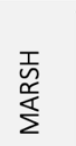

A-

$-0.07$
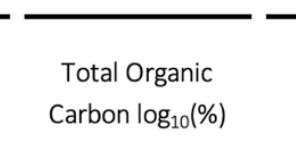

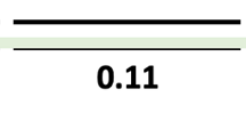

$A-C$

$-0.10$

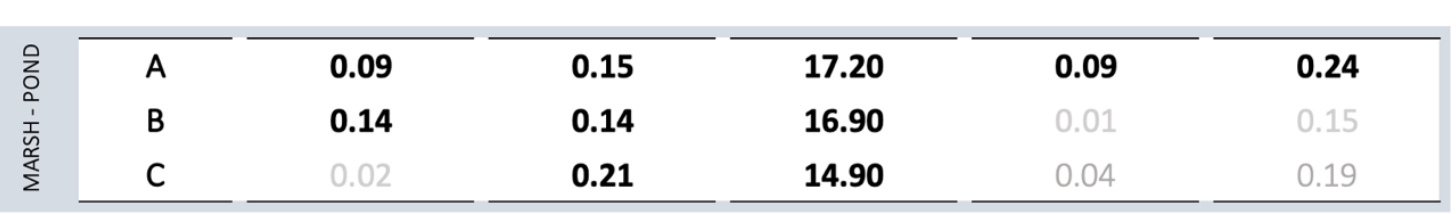

\begin{tabular}{|c|c|c|c|c|c|}
\hline$A$ & 0.09 & 0.15 & 17.20 & 0.09 & 0.24 \\
\hline B & 0.14 & 0.14 & 16.90 & 0.01 & 0.15 \\
\hline C & 0.02 & 0.21 & 14.90 & 0.04 & 0.19 \\
\hline
\end{tabular}
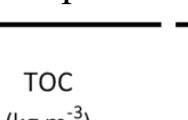

$\left(\mathrm{kg} \mathrm{m}^{-3}\right)$

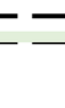

0.06

0.17

0.12

$-0.01$

0.11

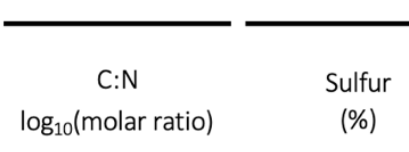

4.71

$-3.01$

1.70

4.99

$-1.02$

3.97

0.15

0.14

0.21
17.20

16.90

14.90
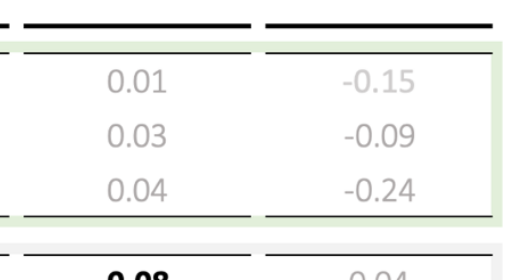

0.08

0.00

0.08

$-0.13$

$-0.09$

c. 


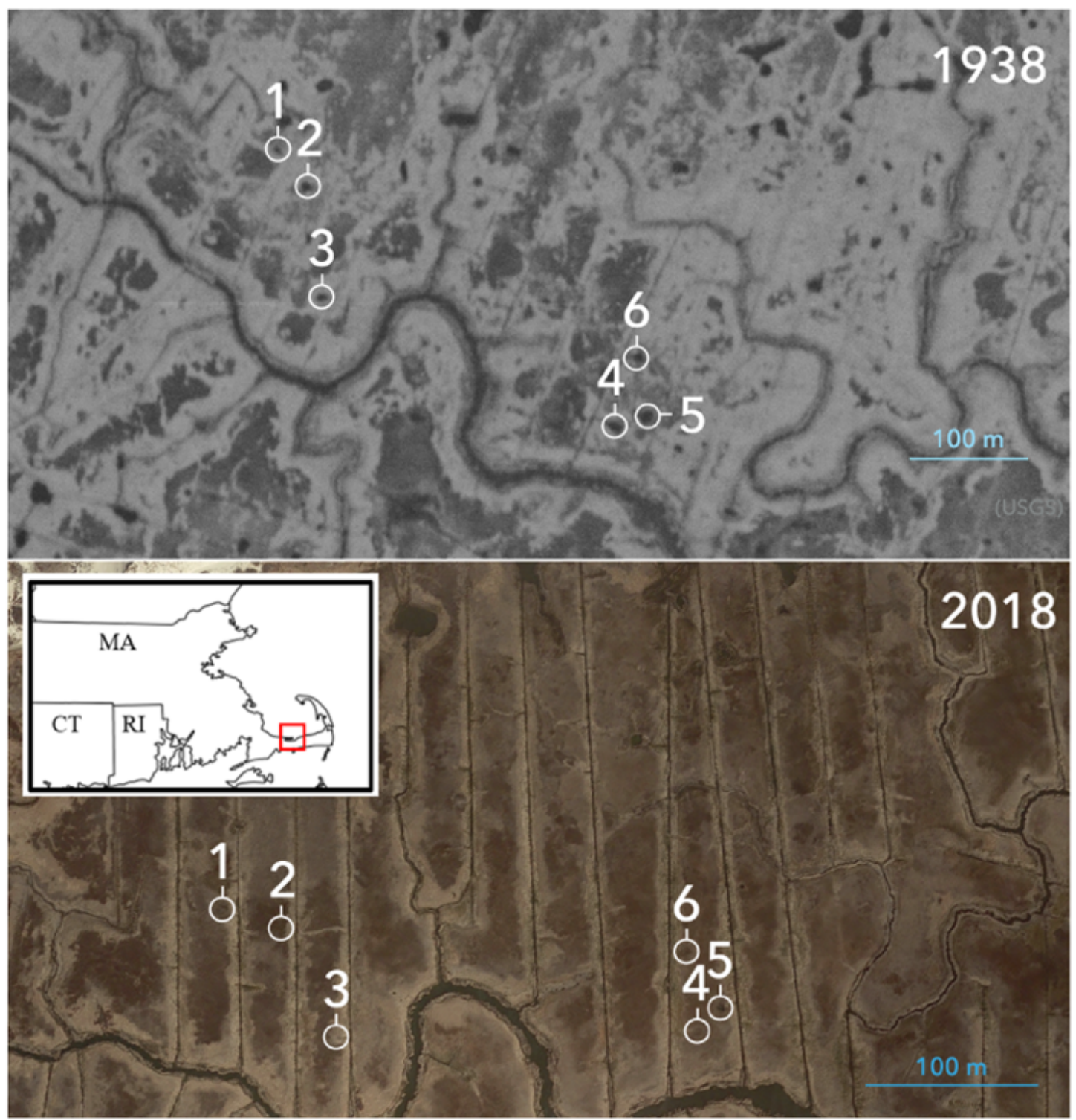

Figure 1: Great Barnstable Marsh, MA, USA (inset map of marsh location within MA) and photographs from 1938 (US Geological Survey) of the 6 infilling ponds focused in this study (Google Earth). 

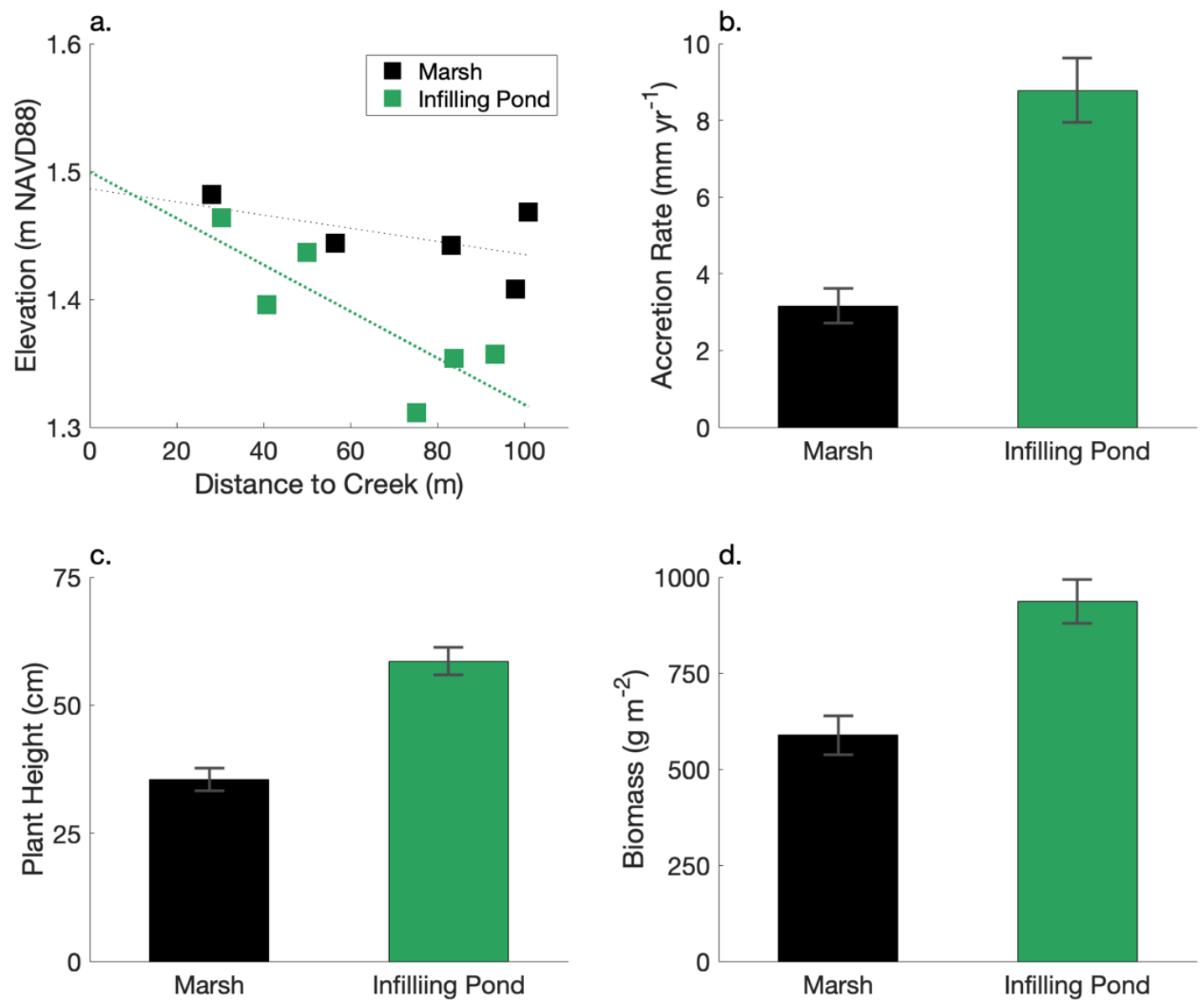

Figure 2: Infilling pond and adjacent marsh (a) elevations (m, NAVD88) relative to distance from creek (m), (b) accretion rates, $\left(\mathrm{mm} \mathrm{yr}^{-1}\right)$ and (c) S. alterniflora plant height $(\mathrm{cm})$ and (d) biomass $\left(\mathrm{g} \mathrm{m}^{-2}\right)$. A linear regression was used to determine whether elevation varied with distance from tidal creek (Fig. 2a); bolded regression lines indicate significance at $\mathrm{p}<0.05$. Bar plot data are means and standard error. 

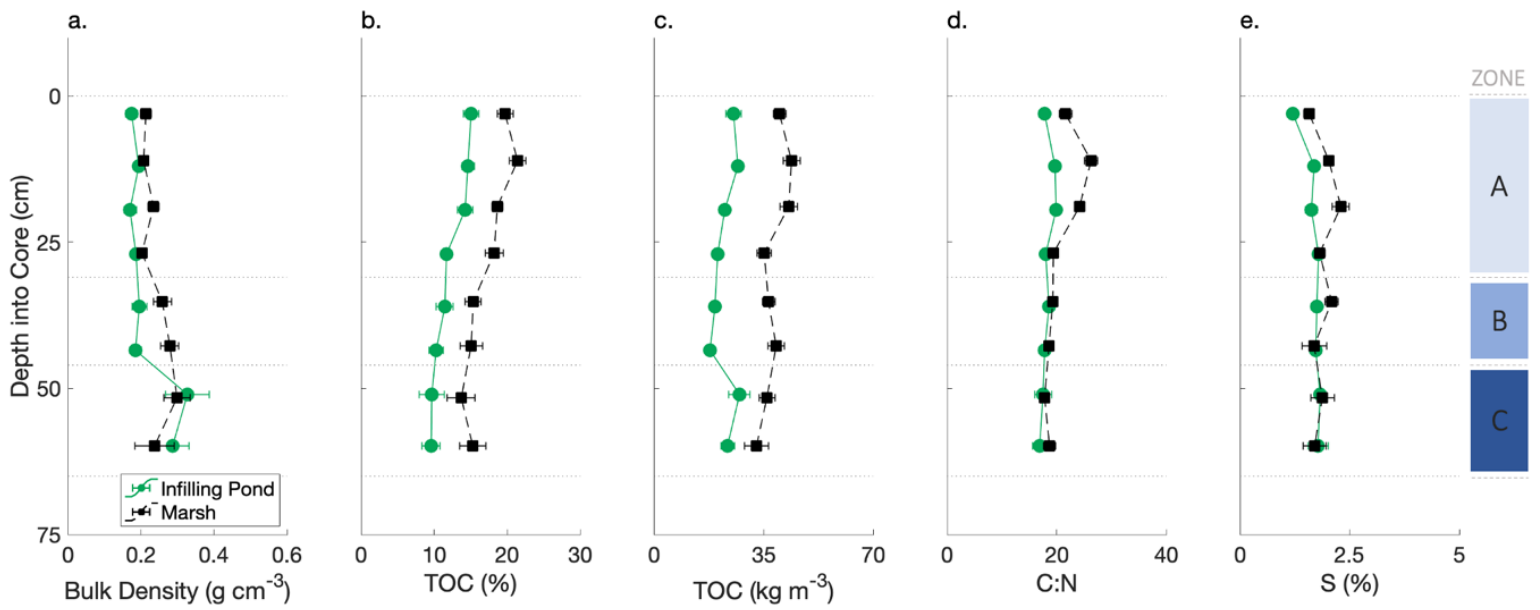

Figure 3: Infilling pond and marsh soil (a) bulk density $\left(\mathrm{g} \mathrm{cm}^{-3}\right)$, (b) total organic carbon (TOC $\%$ and $\mathrm{kg} \mathrm{m}^{-3}$ ) content, (c) $\mathrm{C}: \mathrm{N}$ ratios (molar), and (d) sulfur content (\%) by depth horizon. Data represent mean and SE. See methods for descriptions of depth zones and Table 2 for contrast analyses. 

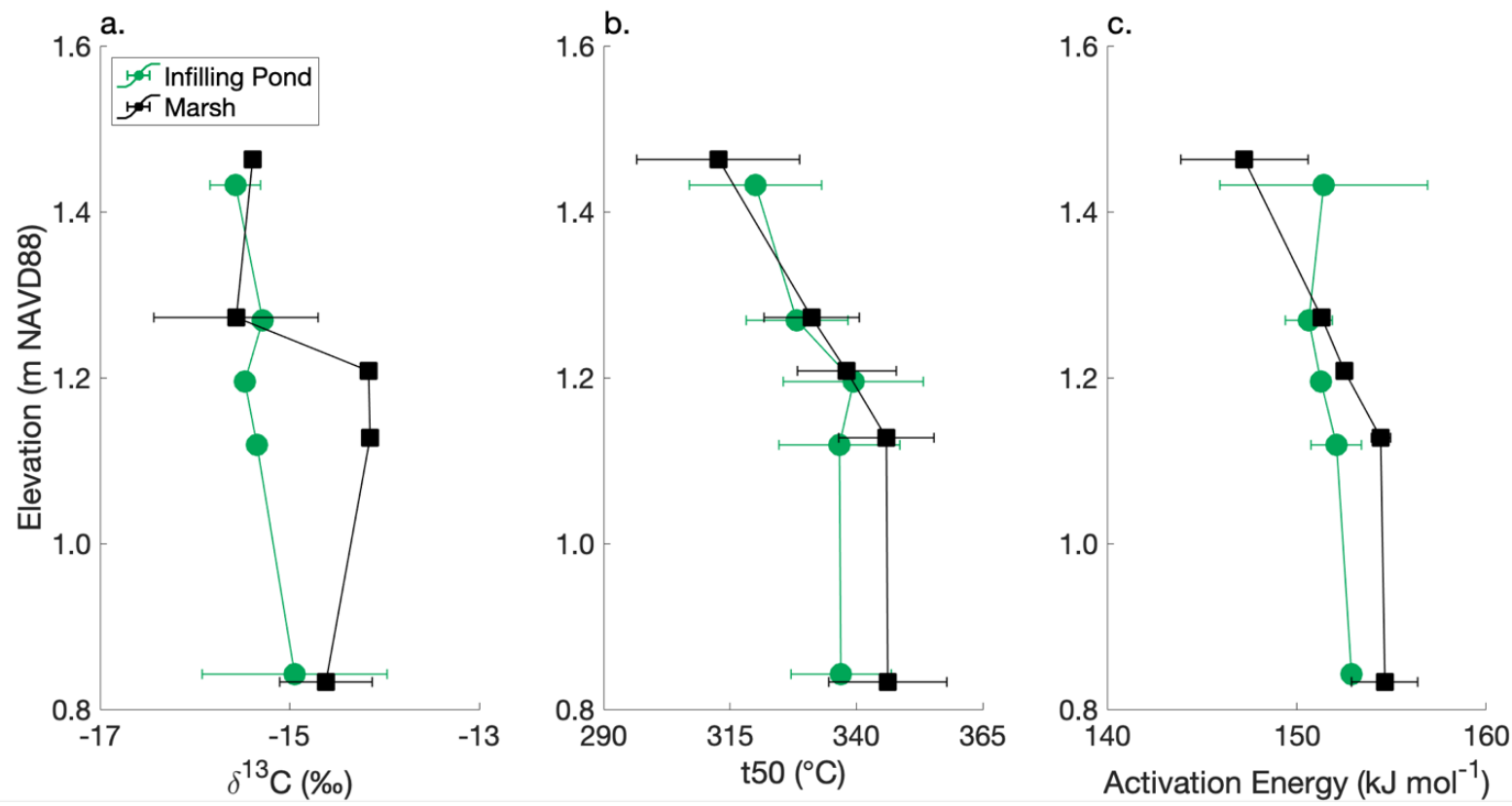

Figure 4: Infilling pond and marsh soil (a) carbon isotopic properties $\left(\delta^{13} \mathrm{C}, \%\right)$ and thermal properties of b) 150 and c) activation energy by elevation. Mean and SE are calculated for years of deposition from 1850-1920 for marsh horizons and the infilling pond horizon paired by elevation. Data represented are mean and associated standard error. 
MARSH

a. 2018 (1.44-1.48m: $-15.4 \pm 0.0 \%$ o)
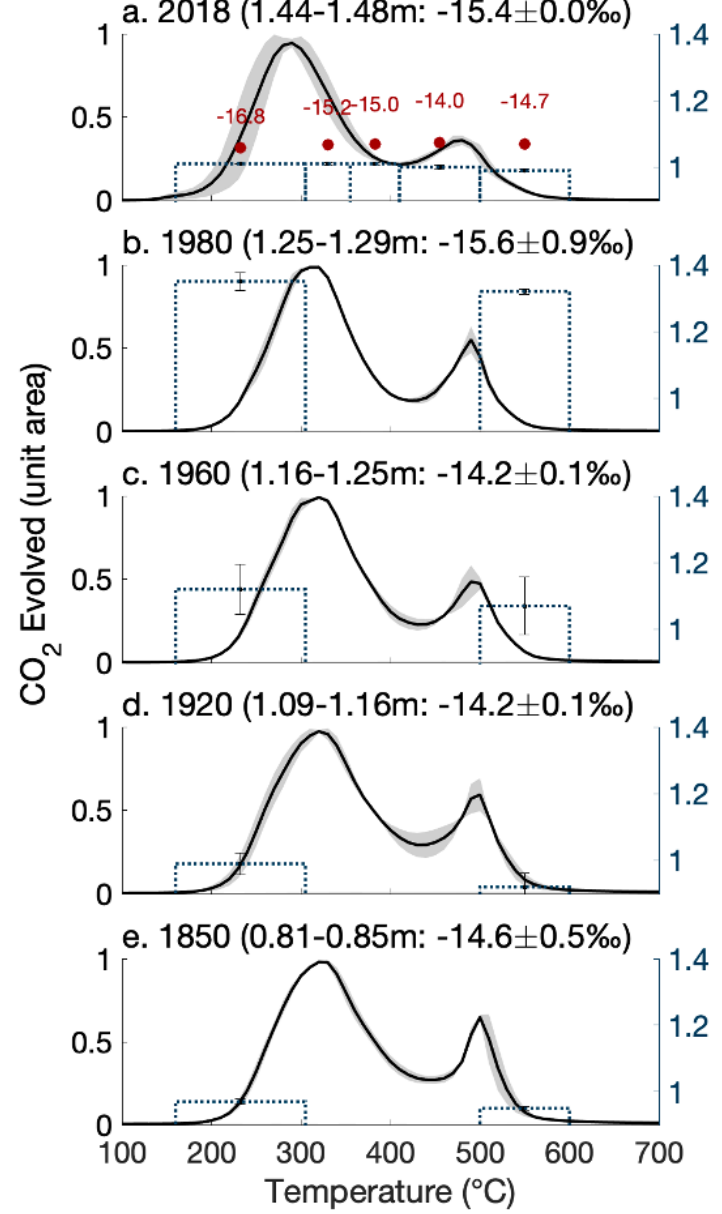

INFILLING POND
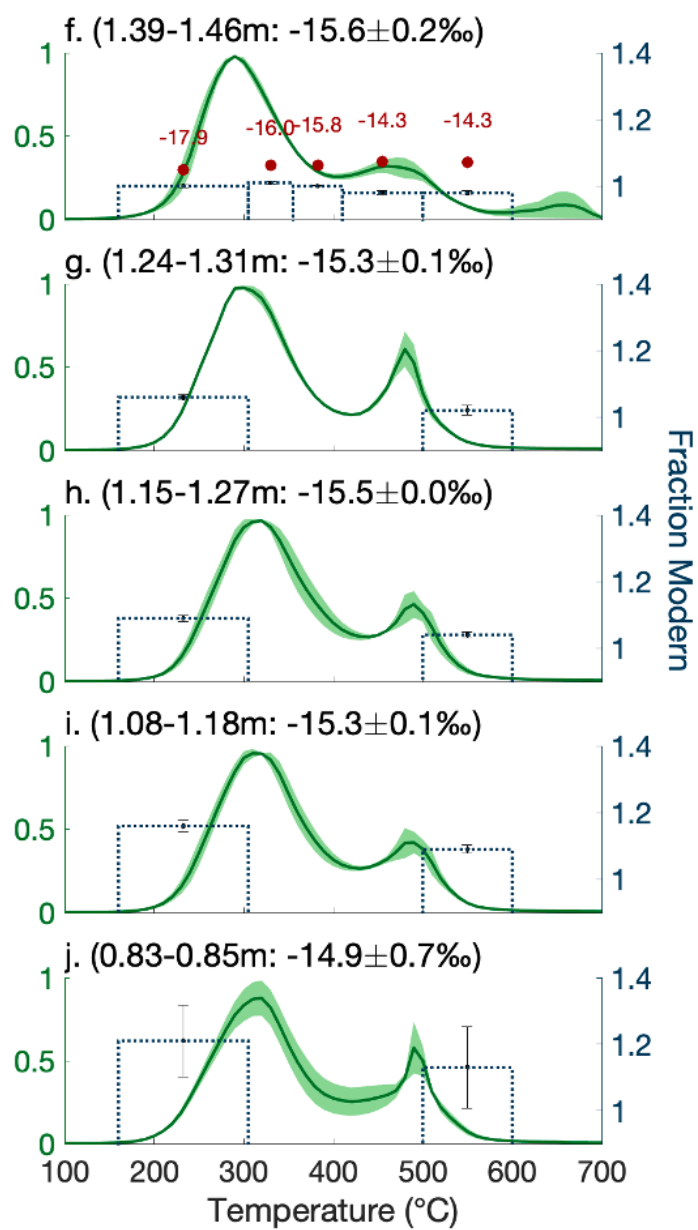

Figure 5: Soil organic carbon thermograms, sources $\left(\delta^{13} \mathrm{C}\right)$, and ages $\left(\mathrm{F}^{14} \mathrm{C}\right)$ of marsh (a-e) and infilling pond $(\mathrm{f}-\mathrm{j})$. Dotted bars are $\mathrm{F}^{14} \mathrm{C}$ values for fractions collected over a temperature interval (bar width) with associated error. The $\delta^{13} \mathrm{C}(\%)$ of $\mathrm{CO}_{2} \mathrm{RPO}$ fractions are indicated with a red dot. Infilling pond and marsh horizons were paired by elevation (NAVD88, m); elevation range and bulk soil $\delta^{13} \mathrm{C}$ are displayed in parentheses. 


\section{SUPPLEMENTAL TABLES AND FIGURES}

Table S1: Multiple linear regression results predicting plant characteristics using an indicator for infilling pond (PondIndicator), distance from creek (Distance from Creek), and platform elevation (Elevation). Coefficients are displayed with number of observations (Observations) and r-squared values. Greyed out values indicate coefficient were not significant ( $p$-value $>0.05$ ).

\begin{tabular}{l|c|c}
\hline VARIABLES & $\begin{array}{c}\text { Biomass } \\
\left(\mathrm{g} \mathrm{cm}^{-2}\right)\end{array}$ & $\begin{array}{c}\text { Plant Height } \\
(\mathrm{cm})\end{array}$ \\
\hline PondIndicator & $\mathbf{3 9 2 . 6}$ & $\mathbf{2 2 . 6 1}$ \\
\hline Distance from Creek & -1.73 & -0.106 \\
\hline Elevation & -530.2 & -17.39 \\
\hline Observations & 18 & 18 \\
\hline R-squared & 0.55 & 0.62 \\
\hline
\end{tabular}


Table S2: Multiple linear regression results predicting bulk soil properties for the (a) infilling pond and (b) adjacent marsh soils using independent variables of each marsh or pond soil core site location (SiteID), depth zones defined as rooting $(0-30 \mathrm{~cm})$, intermediate $(30-45 \mathrm{~cm})$, and deep $(45-60 \mathrm{~cm})$ soil horizons, distance from creek, and distance from ditch. Coefficients are displayed with number of observations (Observations) and r-squared values. Bolded values are significant coefficients ( $\mathrm{p}$-value $<0.05$ ).

\begin{tabular}{|c|c|c|c|c|c|c|}
\hline VARIABLES & $\begin{array}{l}\text { Bulk Density } \\
\log 10\left(\mathrm{~g} \mathrm{~cm}^{-3}\right)\end{array}$ & $\begin{array}{c}\text { Total Organic } \\
\text { Carbon log10(\%) }\end{array}$ & $\begin{array}{c}\text { TOC } \\
\left(\mathrm{kg} \mathrm{m}^{-3}\right)\end{array}$ & $\begin{array}{c}\text { C:N } \\
\log 10 \text { (molar } \\
\text { ratio) }\end{array}$ & $\begin{array}{l}\text { Sulfur } \\
(\%)\end{array}$ & Inorganic (\%) \\
\hline SitelD & -0.008 & 0.006 & 0.331 & 0.003 & 0.016 & -0.00254 \\
\hline Zone & 0.042 & -0.031 & -0.975 & -0.018 & 0.045 & 0.011 \\
\hline Distance from Creek & -0.002 & 0.001 & 0.026 & 0.000 & 0.005 & -0.001 \\
\hline Distance from Ditch & -0.015 & 0.006 & -0.189 & 0.000 & 0.020 & -0.003 \\
\hline Observations & 114 & 114 & 114 & 114 & 103 & 114 \\
\hline R-squared & 0.44 & 0.75 & 0.18 & 0.31 & 0.40 & 0.70 \\
\hline \multicolumn{7}{|l|}{ b. Adjacent Marsh } \\
\hline VARIABLES & $\begin{array}{l}\text { Bulk Density } \\
\log 10\left(\mathrm{~g} \mathrm{~cm}^{-3}\right)\end{array}$ & $\begin{array}{c}\text { Total Organic } \\
\text { Carbon log10(\%) }\end{array}$ & $\begin{array}{c}\text { TOC } \\
\left(\mathrm{kg} \mathrm{m}^{-3}\right)\end{array}$ & $\begin{array}{c}\text { C:N } \\
\log 10 \text { (molar } \\
\text { ratio) }\end{array}$ & $\begin{array}{l}\text { Sulfur } \\
(\%)\end{array}$ & Inorganic (\%) \\
\hline SitelD & 0.022 & -0.003 & 2.325 & 0.005 & 0.457 & 0.000 \\
\hline Zone & 0.023 & -0.045 & -2.312 & -0.025 & 0.000 & 0.028 \\
\hline Distance from Creek & -0.002 & 0.002 & 0.048 & 0.001 & -0.013 & -0.001 \\
\hline Distance from Ditch & 0.003 & 0.000 & 0.572 & 0.002 & 0.033 & -0.002 \\
\hline Observations & 117 & 117 & 117 & 117 & 90 & 117 \\
\hline R-squared & 0.45 & 0.67 & 0.37 & 0.65 & 0.27 & 0.60 \\
\hline
\end{tabular}


Table S3: SOC source $\left(\delta^{13} \mathrm{C}\right)$ and reactivity (t50, activation energy) for the infilling pond and adjacent marsh by elevation (Fig. 4). Data presented are mean and associated standard errors in parentheses.

\begin{tabular}{|c|c|c|}
\hline \multirow[b]{2}{*}{ Elevation } & \multicolumn{2}{|c|}{$\delta^{13} \mathrm{C}($ per mil) } \\
\hline & Infilling Pond & Marsh \\
\hline $1.40-1.46$ & $-15.57(0.27)$ & $-15.39(0.0)$ \\
\hline $1.25-1.31$ & $-15.28(0.08)$ & $-15.57(0.87)$ \\
\hline $1.16-1.27$ & $-15.48(0.03)$ & $-14.17(0.05)$ \\
\hline $1.09-1.18$ & $-15.35(0.07)$ & $-14.15(0.06)$ \\
\hline $0.83-0.85$ & $-14.95(0.97)$ & $-14.62(0.49)$ \\
\hline
\end{tabular}

\begin{tabular}{cc}
\hline \multicolumn{2}{c}{$\mathrm{t50}(\mathrm{C})$} \\
\hline Infilling Pond & Marsh \\
\hline $320(13.1)$ & $312.7(16.1)$ \\
$328.2(10.1)$ & $331.2(9.4)$ \\
$339.4(13.9)$ & $338.1(9.7)$ \\
$336.7(12)$ & $345.9(9.4)$ \\
$337(9.9)$ & $346.2(11.7)$ \\
\hline
\end{tabular}

\begin{tabular}{cc}
\hline \multicolumn{2}{c}{ Activation Energy $\left(\mathrm{kJ} \mathrm{mol}^{-1}\right)$} \\
\hline Infilling Pond & Marsh \\
\hline $151.4(5.5)$ & $147.2(3.4)$ \\
$150.6(1.2)$ & $151.3(0.2)$ \\
$151.3(0.1)$ & $152.5(0.3)$ \\
$152.1(1.3)$ & $154.4(0.5)$ \\
$152.9(0.4)$ & $154.6(1.8)$ \\
\hline
\end{tabular}




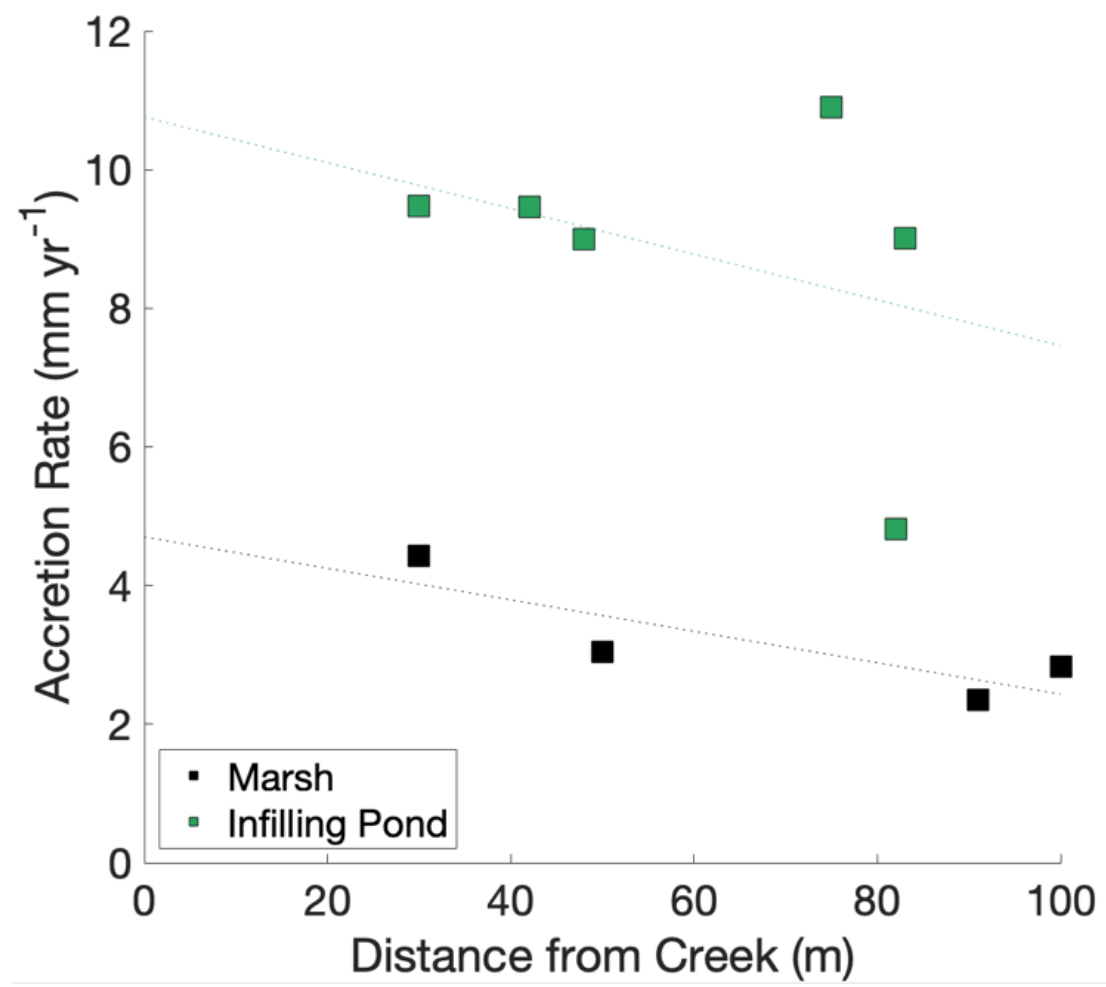

Figure S1: Infilling pond and adjacent marsh CIC accretion rates $\left(\mathrm{mm} \mathrm{yr}^{-1}\right)$ plotted by distance from tidal creek (m). Linear trends were used to test relationships between accretion rate and distance from tidal creek, yet trends were not significant (greyed lines; $\mathrm{p}>0.05$ ). 

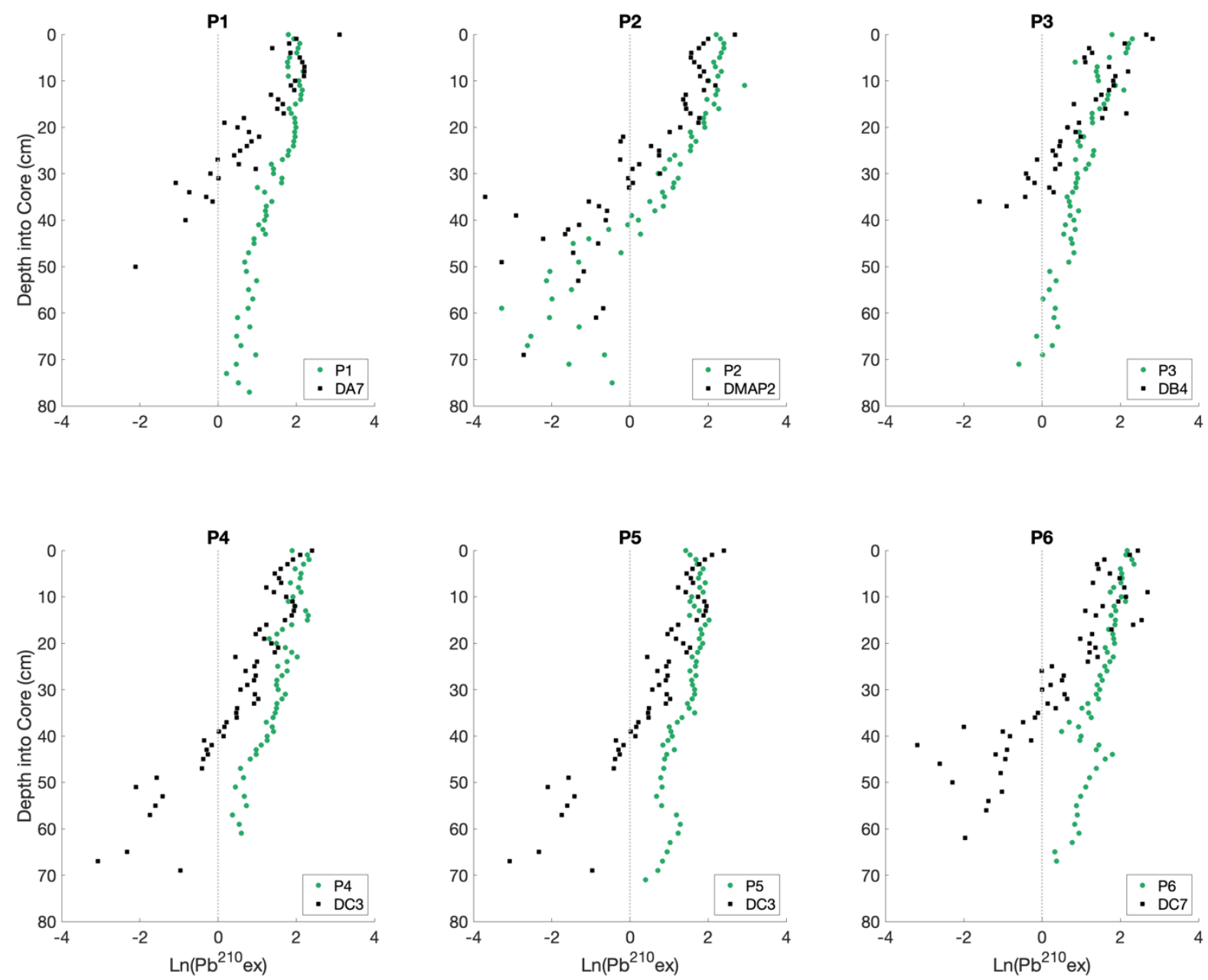

Figure S2: Paired infilling pond (P1 - P6) and adjacent marsh soil excess ${ }^{201} \mathrm{~Pb}\left[\ln \left({ }^{226} \mathrm{Ra}-{ }^{210} \mathrm{~Pb}\right)\right]$ by depth into core $(\mathrm{cm})$. 

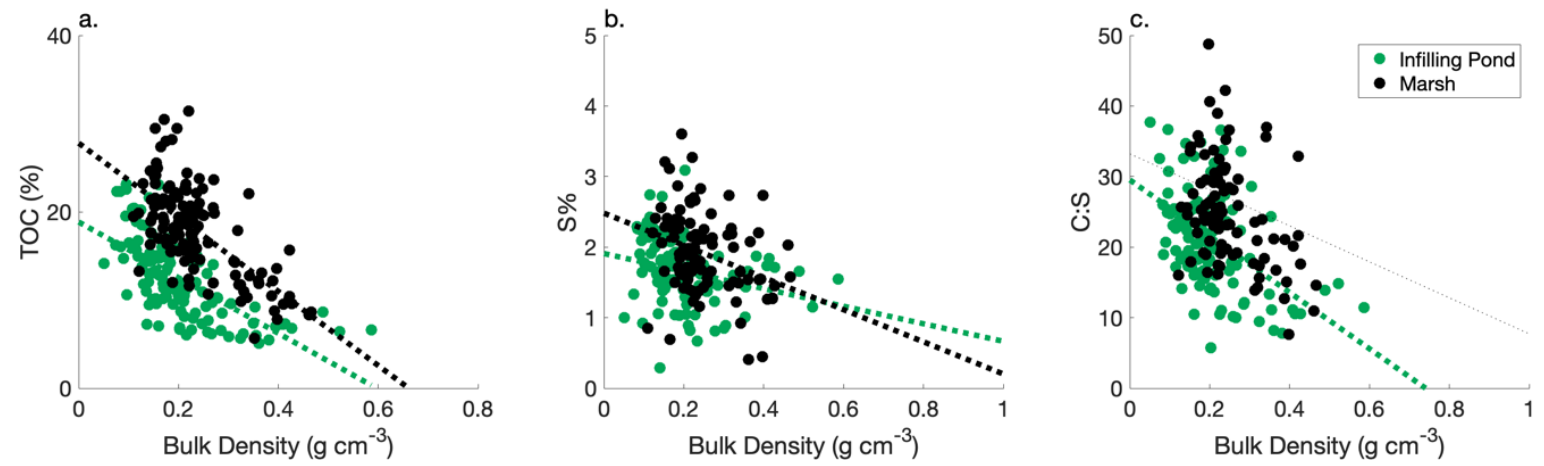

Fig. S3: Infilling pond and marsh soil bulk density $\left(\mathrm{g} \mathrm{cm}^{-3}\right)$ plotted against a) TOC (\%) b) S (\%), and c) $\mathrm{C}: \mathrm{S}$ ratios. Linear trends between bulk soil properties were tested with bolded dashed lines indicating significance $(\mathrm{p}<0.05)$. 


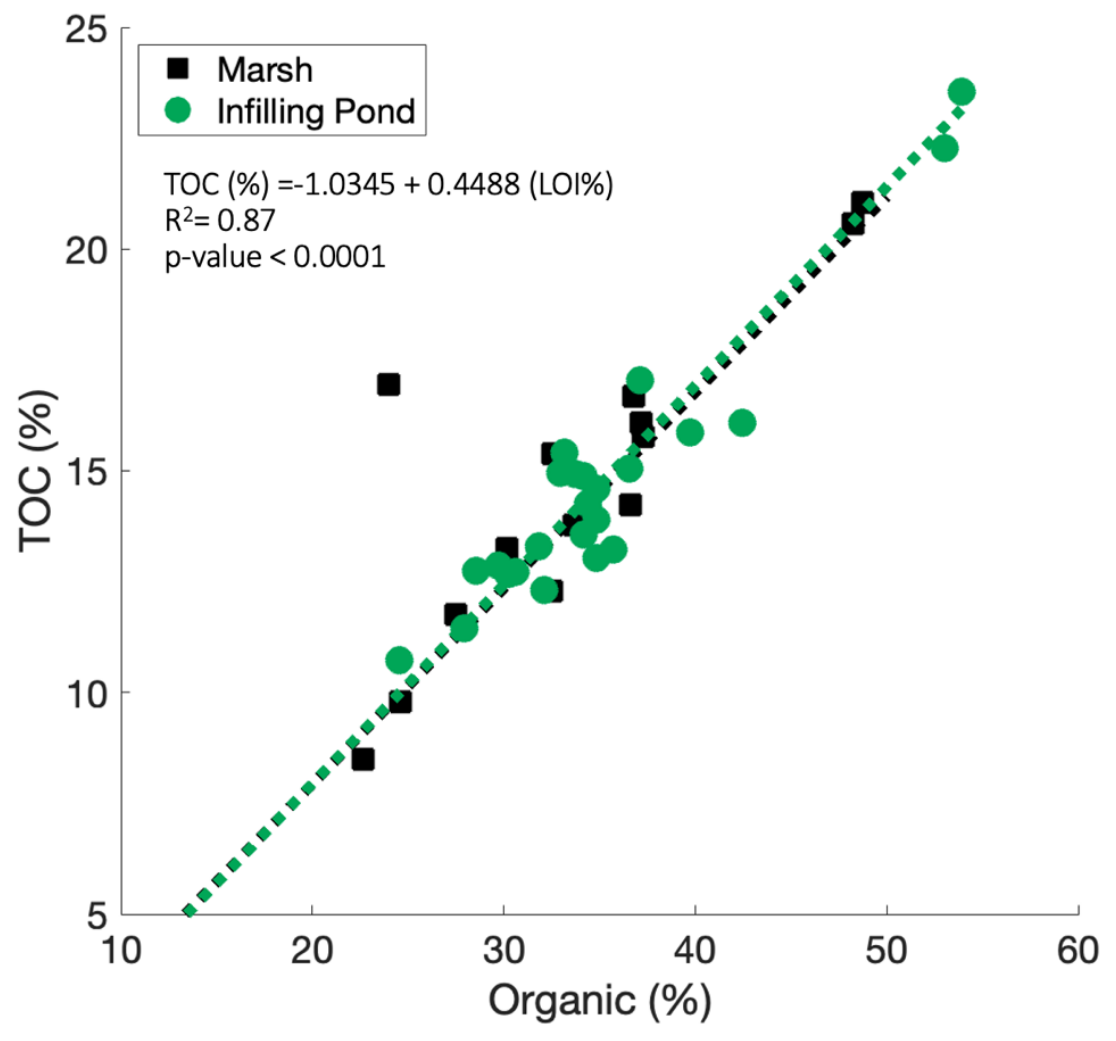

Fig. S4: Infilling pond and marsh organic content (\%) plotted against TOC (\%) from 30cm soil cores to obtain relationships between TOC, organic, and inorganic soil content. Linear trends with bolded dashed lines indicating significance $(\mathrm{p}<0.05)$, alongside linear regression equation, $r-$ squared $\left(\mathrm{R}^{2}\right)$, and $\mathrm{p}$-value. 


\title{
Chapter 5: Impacts of mosquito ditches on salt marsh carbon stocks and future sustainability
}

\begin{abstract}
Salt marshes play an important role in the wellbeing and resilience of coastal communities to global change (e.g., sea-level rise, storms). Yet, the ability of these ecosystems to deliver valuable ecosystem services may be impacted by historical and current resource management decisions that have altered marsh hydrology (e.g., mosquito ditching). We compared long-term soil records and plant characteristics from the ditched $(60 \%)$ and unditched $(40 \%)$ portions of a New England salt marsh system (Great Barnstable Marsh, MA, USA) at differing distance from the main tidal channel $(0-100 \mathrm{~m})$, to understand how natural and altered marsh hydrology can impact current and future marsh ecosystem functioning. Differences in plant characteristics, soil accretion, and soil organic carbon composition and reactivity were minimal at ditched and unditched marsh locations closest to the tidal channel, highlighting the important role of natural marsh hydrology to key ecosystem functions. Within the marsh interior $100 \mathrm{~m}$ away from the tidal channel, decades of ditching coincided with lower elevations $(0.15 \pm 0.04 \mathrm{~m}$ lower $)$ and slower soil accumulation since ditch implementation within the ditched marsh $\left(4.7 \pm 0.17{\left.\mathrm{~mm} \mathrm{yr}^{-1}\right)}^{-1}\right.$ compared to the unditched marsh $\left(5.06 \pm 0.11 \mathrm{~mm} \mathrm{yr}^{-1}\right)$. However, we observed a biogeomorphic response to lower ditched marsh elevations within the tidal frame that dominated current plant characteristics and the long-term soil record within the ditched marsh interior. This was demonstrated by greater plant canopy heights, increased total organic carbon content from recent, local marsh grasses, and a 45\% increase in recent soil accretion rates $(2000-2018 ; 6.52 \pm 0.50 \mathrm{~mm}$

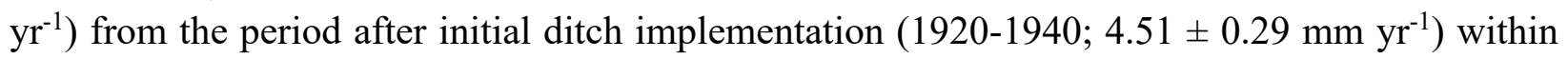
the ditched marsh interior. Incorporating ditches, existing and infilled ponds, and the elevation differences within the marsh interior, we find that the maintenance of mosquito ditches have resulted in an insignificant change in carbon storage ecosystem services after a century of ditching. This must be balanced with the costs of ditch maintenance and potential losses in other ecosystem service values (e.g. recreational bird watching, storm-surge buffering) for accurate cost-benefit analysis and effective management decisions that can optimize both human health aspects and the future health of these valuable ecosystems.
\end{abstract}




\subsection{INTRODUCTION}

Salt marshes have long served human populations due to the delivery of productive ecosystem services (e.g. fisheries, high carbon burial rates), playing an important role in the wellbeing of coastal communities and their resilience to global change (e.g. increased storm intensities and sea-level rise) (Moeller et al., 1996; Gedan et al., 2009; Barbier et al., 2011). Yet, these environments have been heavily altered by human activities (Vitousek et al., 1997; Gedan et al., 2009) such as mosquito ditching (Stearns and MacCreary, 1936; Adamowicz and Roman, 2005). Employed on a large scale in $90 \%$ of Mid-Atlantic and New England salt marshes during the Great Depression, ditching had the dual purpose of providing employment opportunities as well as reducing mosquito populations that breed on standing ponds on the marsh platform (Kennish, 2001; James-Pirri et al., 2009; Riepe, 2010). Yet, management decisions often involve a tradeoff between optimizing one ecosystem service to the detriment of another; the long-term net impacts of ditches on marsh ecosystem functioning (e.g. plant productivity) and delivery of ecosystem services(e.g. carbon storage) remain unclear. After nearly a century of ditching, it is necessary to quantify both the short- and long-term impacts that ditching has on the marsh landscape (e.g. marsh platform elevations, salt marsh ponds) and resulting ecosystem functioning (e.g. soil accumulation, carbon burial) for effective tradeoff analysis and decision-making.

Mosquito ditching is effective in altering marsh hydrology to promote pond infilling on the marsh platform, in part mimicking the role of the tidal channel in natural pond recovery (Portnoy, 1999; Adamowicz and Roman, 2005; Burdick et al., 2020). Typically, permanently inundated ponds can persist for decades until intersecting with a tidal channel and draining which allows for subsequent recovery via recolonization of marsh grasses and rapid vertical soil accretion (Adamowicz and Roman, 2005; Wilson et al, 2014). Marsh hydrology driven in part by the tidal channel plays a key role in salt marsh ecosystem functioning (Fagherazzi et al., 2012, 2013; Kearney and Fagherazzi, 2016; Liu et al., 2020). Dictated by factors such as distance from tidal channel and elevation within the tidal frame, the duration and frequency of marsh platform flooding influences the delivery of inorganic and organic material, nutrient availability, plant species distribution and productivity, and soil redox environment (Redfield, 1972; Nixon, 1980; Sanderson et al., 2001; Fagherazzi et al., 2012). Therefore, the installation of ditches may interact with the tidal channel to impact fundamental marsh ecosystem functions. Considering the importance of hydrology to marsh ecosystem dynamics, it is necessary to explore how the tidal channel and ditches in the salt marsh intermingle to influence the spatial heterogeneity of salt marsh ecosystem functioning (e.g. plant species, elevation, soil accumulation).

Enhancing the drainage of the marsh platform and initiating pond recovery can result in biogeochemical processes that oftentimes act in opposition of one another, making it difficult to predict the net outcome on marsh ecosystem functioning over the timespan since ditch implementation. First, the physical removal of soils during ditch digging represents a reduction in vegetated marsh platform, loss of previously buried carbon, and can increase opportunities for soil erosion at the ditch edge (Roman and Burdick, 2012). Further, increased drainage of the marsh platform and lowering of the water table can lead to compaction of marsh soils as well as more 
oxic conditions that can stimulate decomposition of buried organic matter (Lesser, 1982; Whigham et al., 1982; Portnoy, 1999). In combination, these physical and biogeochemical processes can contribute to the observed 9-20 cm subsidence of ditched marshes (Vincent et al., 2013; Burdick et al., 2020) that may affect whether the marsh can survive future increases in sea-level (Kirwan et al., 2013). Concurrently, more oxic conditions and increased flushing of soils can reduce the buildup of toxic sulfides (King et al., 1982; Giblin and Howarth, 1984) and promote marsh grass growth (Linthurst, 1979; Mendelssohn et al., 1981) leading to increases in soil accumulation and elevation gain. Therefore, understanding the dominating mechanism in these conflicting biogeochemical processes - organic matter decomposition or increased carbon inputs - that are intrinsically linked with elevation can elucidate the changes in marsh ecosystem services and future marsh survival associated with ditching.

A particular concern is how anthropogenic ditching might impact marsh carbon storage. Salt marshes bury a sizable amount of carbon per unit area (18-1,713 $\mathrm{g} \mathrm{C} \mathrm{m}^{-2}$; Ouyang and Lee, 2014) and are ideal systems to assess the management of blue carbon stocks and subsequent costbenefit analysis due to the close proximity with human communities. With the infilling of ponds and potential loss in marsh platform elevation associated with ditching (Adamowicz and Roman, 2005; Burdick et al., 2020), it is unclear whether these processes coincide with changes in plant community composition, the dominant inputs of soil organic carbon, and soil decomposition processes. Further, the timescales at which these processes occur may be important. If rapid elevation loss occurred immediately after ditch installation, the biogeomorphic response to greater flooding at lower elevations may lead to increased plant growth and burial of inorganic and organic material (Morris et al., 2002; Schile et al., 2014). This would allow the marsh platform to recover in elevation and accumulate potentially more fresh, reactive soil organic carbon from primary production. Yet, if long-term decomposition of previously buried organic carbon dominates the soil record over the past century, we would expect consistent losses in elevation and soil carbon over time as well as an accumulation of detrital, less reactive soil organic carbon within the ditched marsh (Bianchi and Canuel, 2011; Luk et al., 2021). Our goal was to gain insight into the potential biogeochemical processes associated with ditching and marsh platform elevation that informs estimates of net ecosystem-wide carbon budgets and overall sustainability.

We compared the ditched and unditched portions of a New England salt marsh system to understand the long-term impacts of mosquito ditching, expanding on previous studies of ditching impacts focused on localized effects within the ditched marsh (Vincent et al., 2013; Burdick et al., 2020). Our objective was to determine how soil characteristics differed across ditched and unditched marsh environments in relation to the tidal channel that may elucidate the impacts of altered and natural marsh hydrology on marsh ecosystem functioning (e.g. pond recovery, elevation maintenance, carbon burial). To this end, we analyzed the soil composition, organic matter sources and reactivity, and accretion rates of soil records within the ditched and unditched marsh at locations near the tidal channel and $100 \mathrm{~m}$ within the marsh interior. We hypothesize that dewatering of the marsh platform led to decomposition-driven long-term elevation loss within the ditched marsh that would be reflected in increased bulk density, slower rates of accretion, 
decreased soil organic carbon content, and accumulation of more detrital, thermally stable, soil organic carbon of ditched marsh soils relative to the unditched marsh. Finally, we posit that despite initiating pond recovery, the ditched marsh would represent decreased carbon storage capacity and loss in marsh ecosystem service values compared to the unditched marsh due to lower elevations, organic carbon content, and the presence of ditches.

\subsection{METHODS}

\subsubsection{Study site}

Great Barnstable Marsh, MA, USA $\left(41.729007^{\circ},-70.376137^{\circ}\right)$ is a macrotidal system (mean tidal range $3 \mathrm{~m}$ ) with an extensive high marsh platform $\left(\sim 10 \mathrm{~km}^{2}\right)$. A portion of this system was historically ditched in the 1930s and the mosquito ditches are currently maintained by the Cape Cod Mosquito Control Project. The ditched (60\%) and unditched (40\%) marsh are collocated in large, adjacent swaths $\left(>1 \mathrm{~km}^{2}\right)$, intersected by natural tidal channels that connect to Cape Cod Bay (Fig. 1). We selected three replicate transects $(0-100 \mathrm{~m})$ that laid perpendicular to the tidal channels in the ditched and unditched marshes. Within each transect we collected $\sim 60 \mathrm{~cm}$ soil cores near the creekbank edge ( 1 - $5 \mathrm{~m}$ away) and $100 \mathrm{~m}$ away from this point toward the marsh interior, which are referred to as the $0 \mathrm{~m}$ and $100 \mathrm{~m}$ soil cores, respectively. Marsh platform elevations were measured using a real time kinematic unit. Sampling was carried out in the Summer - Fall of 2018 .

\subsubsection{Plant characteristics}

Plant community characteristics were determined in $1 \mathrm{~m}^{2}$ quadrats at $25 \mathrm{~m}$ increments along each transect. Percent cover of plant species was visually estimated within the quadrat. Canopy height was determined by measuring the height of the five tallest plants of each species.

\subsubsection{Bulk soil properties}

Soil cores were sectioned into 1-2 cm horizons, with a finer resolution in the upper $45 \mathrm{~cm}$. Soil water content $(\%)$ and bulk density $\left(\mathrm{g} \mathrm{cm}^{-3}\right)$ were determined gravimetrically by drying to constant mass $\left(80^{\circ} \mathrm{C}\right)$. For subsequent elemental analysis, samples at $2 \mathrm{~cm}$ increments were sieved $(1 \mathrm{~mm})$ to remove roots, ball milled and analyzed for total organic carbon [TOC], total nitrogen [TN], and total sulfur [TS]. Samples for TOC and TN analyses were fumed with hydrochloric acid to remove carbonates prior to analysis (Lorrain et al., 2003). We focused on the fine fraction of soils $(<1 \mathrm{~mm})$ to characterize material consistent with the functional definitions of refractory SOC that contribute to long-term elevation gain within the salt marsh (Bruun et al., 2010; Anisfeld and Hill, 2012).

\subsubsection{Soil age models}

Soil accretion rates were constrained through measurements of ${ }^{137} \mathrm{Cs},{ }^{210} \mathrm{~Pb}$, and ${ }^{226} \mathrm{Ra}$ on a planar-type gamma counter (Canberra, Inc. USA; Gonneea et al., 2019). Measured activities of ${ }^{210} \mathrm{~Pb}$ were then processed through rPlum to obtain Bayesian estimates of accretion rate and 
corresponding confidence intervals (Aquino-López et al., 2018). The model was run using measured ${ }^{226} \mathrm{Ra}$ activities as individual estimates of supported ${ }^{210} \mathrm{~Pb}$ within each soil horizon.

\subsubsection{Thermal reactivity and carbon isotope measurements}

The thermal reactivity of soil organic carbon was characterized through ramped pyrolysis oxidation (RPO) at the National Ocean Sciences Accelerator Mass Spectrometry Facility (Woods Hole, MA). In order to capture periods spanning the history of ditching on the marsh platform, we selected soil horizons that were deposited around 1850, 1900, 1920, 1960, and 2018 based on marsh radioisotope age models. Samples of $1 \mathrm{~cm}$ ball milled horizons were homogenized before placing $\sim 20-40 \mathrm{mg}$ within a reactor where temperatures were ramped at $5^{\circ} \mathrm{C} \mathrm{min}^{-1}$ to $1000^{\circ} \mathrm{C}$ (Rosenheim et al., 2008). The evolved carbon dioxide $\left(\mathrm{CO}_{2}\right)$ was measured by a flow-through infrared gas analyzer and thermograms were constructed by plotting concentration versus temperature.

We subsequently analyzed $\mathrm{CO}_{2}$ evolved via $\mathrm{RPO}$ for ${ }^{13} \mathrm{C}\left(\delta^{13} \mathrm{C}\right.$, \%o) and ${ }^{14} \mathrm{C}$ (as $\left.\mathrm{F}^{14} \mathrm{C}\right)$ composition (McNichol et al., 1994b; Reimer et al., 2004). The $\mathrm{CO}_{2}$ fractions were collected over five temperature intervals; there were three low $\left(200-465^{\circ} \mathrm{C}\right)$ and two high $\left(465-650{ }^{\circ} \mathrm{C}\right)$ temperature fractions, based on the evolution of two distinct peaks within the thermogram. The isotopic composition of evolved $\mathrm{CO}_{2}$ was analyzed for all five fractions for the surface horizon (0$2 \mathrm{~cm}$ ) corresponding to the collection year of 2018 while two of the five fractions were analyzed for the deeper horizons. The sample fraction subset was selected to represent $\mathrm{CO}_{2}$ collected at the lowest and highest temperature ranges and reflect SOC age and source endmembers. Bulk soil $\delta^{13} \mathrm{C}$ of the analyzed horizons was measured at Marine Biological Laboratory (Woods Hole, MA) and used for RPO fraction blank correction.

We evaluated SOC thermal reactivity by calculating temperatures at which $50 \%$ of soil organic carbon was pyrolyzed ( $\mathrm{t} 50)$ and thermal activation energies $\left(E a \mathrm{~kJ} \mathrm{~mol}^{-1}\right)$. The thermal activation energy and blank correction were calculated using the Python package rampedpyrox (Hemingway et al., 2017a, 2017b).

\subsubsection{Tidal creek total suspended sediments}

To constrain the role of tidal creek sediments to marsh elevation gain, we measured total suspended sediment in the main tidal creek adjacent to the ditched and unditched marsh transects. Triplicate samples were collected in $1 \mathrm{~L}$ pre-combusted bottles within the tidal creek on flood and ebb tides on four sampling days between June $21^{\text {st }}$ - August $1^{\text {st }}, 2018$. Samples were filtered through glass fiber filters (pre-combusted and weighed; nominal pore size $0.45 \mu \mathrm{m}$ ). Filters were dried to constant mass at $60^{\circ} \mathrm{C}$ and total suspended sediment concentrations were calculated by normalizing sediment mass to volume of tidal creek water filtered.

\subsubsection{Data analysis}

We conducted statistical analyses to detect differences between the ditched and unditched marshes in 3 depth horizons: 0-30 cm (S. alterniflora rooting zone), 30-45 cm (just below the 
rooting zone), and 45-60 cm (deeper horizons). Based on Kolmogorov-Smirnov goodness-of-fit hypothesis tests, four response variables (bulk density, TN (\%), C:N, and TOC (\%)) were logtransformed prior to analyses to meet assumptions of normality. First, we conducted post-hoc contrasts of mixed effect linear models to detect differences between the ditched and unditched and within different depth zones across the entire marsh (near-channel + marsh interior), and at differing distances from the tidal channel (near-channel vs. marsh interior). To detect differences in marsh environments near the tidal channel versus $100 \mathrm{~m}$ within the marsh interior, we conducted post-hoc contrasts of mixed linear models testing differences with distance from tidal channel and different depth zones within the entire marsh (ditched + unditched) and the ditched and unditched marsh, individually. These tests allowed us to identify transitions in bulk soil properties between different marsh environments relative to the tidal channel.

\subsection{RESULTS}

\subsubsection{Marsh elevations and accretion rates}

Marsh elevations were similar closest to the tidal channel near mean higher-high water, but diverged towards the interior with the ditched marsh falling $0.15 \pm 0.04 \mathrm{~m}$ lower than the unditched marsh (Fig. 2, Table 1; NOAA station \#8443970). Ditched marsh elevations decreased ( $0.10 \pm$ $0.06 \mathrm{~m}$ ) and unditched marsh elevations increased $(0.12 \pm 0.05 \mathrm{~m})$ towards the marsh interior (Fig. 2, Table 1). While near-channel accretion rates $\left(4.73 \pm 0.10 \mathrm{~mm} \mathrm{yr}^{-1}\right)$ were similar, mean soil accretion rates in the marsh interior were lower in the ditched $\left(4.70 \pm 0.17 \mathrm{~mm} \mathrm{yr}^{-1}\right)$ compared to the unditched $\left(5.06 \pm 0.11 \mathrm{~mm} \mathrm{yr}^{-1}\right)$ marsh, though both exceeded the sea-level rise rates in Boston Harbor (2.86 $\pm 0.15 \mathrm{~mm} \mathrm{yr}^{-1}$; NOAA station \#8443970) (Fig. 3a).

Time period analysis of accretion rates demonstrated a general increase in accretion rates from the $1920-1940$ to $2000-2018$ that correspond to increases in RSLR $(3.9 \pm 0.86$ to $5.6 \pm 1.5 \mathrm{~mm}$ $\mathrm{yr}^{-1}$; NOAA station \#8443970) (Fig. $3 \mathrm{~b}-\mathrm{c}$ ). Particularly, ditched marsh interior accretion rates increased from $4.51 \pm 0.29 \mathrm{~mm} \mathrm{yr}^{-1}$ to $6.52 \pm 0.50 \mathrm{~mm} \mathrm{yr}^{-1}$, respectively, over this time period (Fig. $3 \mathrm{c})$. The near-channel unditched marsh displayed similar significant increases from $4.56 \pm 0.10$ $\mathrm{mm} \mathrm{yr}^{-1}$ to $6.07 \pm 0.46 \mathrm{~mm} \mathrm{yr}^{-1}$ (Fig. 3b). Overall - since the installation of ditches in the 1920s the ditched marsh interior resides at a lower elevation that coincides with overall lower soil accretion rates when compared to its unditched marsh counterpart, yet contemporary accretion rates appear to have increased since earlier periods.

\subsubsection{Plant characteristics}

Spartina alterniflora was the main grass species in both the ditched and unditched marshes (Fig. 4, Table 1). Plant canopy heights were greatest at the near channel $(0 \mathrm{~m})$ and decreased towards the marsh interior. Further, canopy heights were taller in the ditched marsh, with differences that became more pronounced within the marsh interior (Fig. 4).

\subsubsection{Bulk soil properties}


Ditched marsh soils had higher TOC content $\left(\mathrm{kg} \mathrm{m}^{-3} ; 0-40 \mathrm{~cm}\right)$ and C:N ratios $(0-30 \mathrm{~cm})$, compared to the unditched marsh (Fig. 5, Table 2a). Soil properties at the near-channel sites were largely similar between the unditched and ditched marshes, with the exception of higher TOC content and lower S content in the upper horizons of the ditched marsh (Fig. 5 f, h; Table 2b). There were stronger contrasts between the marsh interiors of ditched and unditched marshes as TOC, sulfur content, and C:N ratios were higher in the ditched marsh (Fig. $5 \mathrm{f}-\mathrm{h}$, Table 2c). Generally, the ditched marsh had greater sulfur contents within the deep soil horizon (C: $45-$ $70 \mathrm{~cm}$; Table 2a), particularly within the ditched interior marsh soil horizons demonstrating greater preservation of sulfides (Table 2c). Consistent enrichments in carbon and sulfur in ditched marsh soils relative to unditched soils were amplified within the ditched marsh interior.

Differences between the ditched and unditched marsh were overshadowed by comparisons of marsh environments near the tidal channel and $100 \mathrm{~m}$ within the marsh interior (Fig. 5e-h, Table 3). Near channel soils tended to have higher bulk densities, lower $\mathrm{C}: \mathrm{N}$ ratios and sulfur content compared to the interior (Table 3a), with much greater differences in the soils compared to ditched versus unditched comparisons (Table 2a). Particularly, the ditched marsh demonstrated significant transitions in all bulk soil properties across all soil horizons (Table 3c). Near channel soils in the ditched marsh had lower TOC content and C:N values compared to the marsh interior soils (Table $3 \mathrm{c}$ ); a trend which was more muted within the unditched marsh (Table 3b). Therefore, ditched marshes appear to have greater marsh soil trends associated with distance from the tidal channel relative to unditched marsh soils.

\subsubsection{SOC thermal reactivity, sources, and age}

Marsh grasses were the main source of SOM to ditched and unditched marshes, as $\delta^{13} \mathrm{C}$ values ranged from -13.4 to - 15.9 \%o (Fig. 6 - 7; Spivak and Ossolinski 2016). Near-channel SOC had lower t50 and Ea values than interior soils in surface horizons (Fig. 6). Below the 1980 horizon (11$17 \mathrm{~cm}$ depth), however, SOC thermal properties were similar in near channel and interior sites of both ditched and unditched marshes (Fig. 6 e-f). Surprisingly, we found few differences in soil thermal properties between ditched and unditched marshes, indicating that distance from the tidal creek had a stronger influence on soil thermal reactivity (Fig. 6).

Soil radiocarbon $\left(\mathrm{F}^{14} \mathrm{C}\right)$ values obtained from $\mathrm{RPO}$ provide additional carbon source and age information (Fig. 7, SI Table 1). As expected, $\mathrm{F}^{14} \mathrm{C}$ values typically decreased from low to high temperature fractions, indicating that less thermally reactive carbon was associated older radiocarbon ages (Fig. 7, SI Table 1). Surface SOC pyrolyzed at $<400{ }^{\circ} \mathrm{C}$ had modern $\mathrm{F}^{14} \mathrm{C}$ values while more thermally stable carbon, representing $46 \pm 1 \%$ and $27 \pm 2 \%$ of the carbon pool in the unditched and ditched surface soils respectively, had $\mathrm{F}^{14} \mathrm{C}$ values $<1$ (Fig. 7, SI Table 1). At the near channel locations, average contributions of old material were similar (24 - 25\%), which became differentiated within the marsh interior for the ditched (16 $\pm 4 \%)$ and unditched $(33 \pm 0 \%)$ marsh (SI Table 1). This increased contribution of thermally stable old marsh carbon in the ditched marsh interior mirrors previously observed increased thermal stability of the bulk SOC (Fig. 6). The 1980 and 1960 horizons, based on ${ }^{210} \mathrm{~Pb}$ age models, demonstrated incorporation of nuclear 
bomb carbon with Fm $>1$ in the low and high temperature fractions. The 1850 and 1920 horizons, deposited prior to ditching, were characterized by Fm values of $0.92-1.00$, similar to the ditched and unditched marsh interior for the low and high temperature fraction. Overall, SOC thermal properties and $\mathrm{F}^{14} \mathrm{C}$ values suggest that ditching did not alter soil carbon reactivity and processes such as redistribution of eroded, old material likely contributes to vertical accretion rates.

\subsubsection{Incorporation of mosquito ditches into the marsh carbon budget}

To understand the change in marsh carbon storage associated with ditching, we calculated carbon stocks within an unditched marsh system with existing ponds and a ditched marsh system with infilled ponds (Table 4). In the first scenario, existing pond volumes were subtracted from the volume of marsh in the upper meter of the soil column. We did this by assuming that $13 \%$ of the Great Barnstable Marsh area was ponded with an average of $0.45 \mathrm{~m}$ pond depths for GBM (Mariotti et al., 2020). In the second scenario where ditching was implemented on the marsh, we removed volumes on the marsh platform associated with ditches and the $0.15 \mathrm{~m}$ elevation difference from the unditched marsh. Ditch length per marsh area $\left(0.03 \mathrm{~m} \mathrm{~m}^{-2}\right)$ was calculated via Google Earth (Phelps et al., in prep) and mean ditch height $(0.77 \mathrm{~m})$ and width $(0.93)$ were measured in the field using a real time kinematic unit. In combination, the volume of total marsh material decreased $(\sim 10 \%)$ due to the implementation of ditches, which was particularly driven by the $\sim 0.15 \mathrm{~m}$ elevation loss of the marsh platform.

We then estimated carbon stocks in each scenario by combining the volume of marsh material and the carbon densities for the unditched marsh $\left(33.4 \pm 0.6 \mathrm{~kg} \mathrm{~m}^{-3}\right)$, ditched marsh (40.6 $\left.\pm 0.9 \mathrm{~kg} \mathrm{~m}^{-3}\right)$, and infilled pond $\left(22.5 \pm 0.6 \mathrm{~kg} \mathrm{~m}^{-3}\right)$ (Fig. $5 \mathrm{~b}$, Table 2, Luk et al., in prep). Infilled pond areas on the ditched marsh were estimated to be $13 \%$ of the total ditched marsh area based on current ponding frequencies on the unditched marsh (Mariotti et al., 2020). This resulted in estimates of carbon stocks per unit area for the unditched $\left(31.45 \pm 0.52 \mathrm{~kg} \mathrm{~m}^{-2}\right)$ and ditched $(31.64$ $\pm 0.43 \mathrm{~kg} \mathrm{~m}^{-2}$ ) marsh that demonstrates an insignificant $1 \%$ increase in carbon stored due to ditching. Therefore, ditching is associated with a $10 \%$ decrease in marsh volumes but compensates with greater soil carbon content and a resulting insignificant change in total carbon stored in the ditched marsh.

\subsection{DISCUSSION}

In this New England salt marsh, decades of anthropogenic ditching have resulted in unique physical landscape features (Fig. 1-2) and distinct plant characteristics and soil composition relative to the unditched marsh in this system (Fig. 4-5, Table 1-2). This underscores the role marsh hydrology plays in salt marsh ecosystem functioning and resilience: enhanced drainage of the salt marsh platform effectively reduces salt marsh pond areas yet results in slower soil accumulation rates and lower marsh elevations since the installation of ditches (Fig. 1 - 3). The ecological plant response to the shift in ditched marsh elevation is consistent with marsh equilibrium models of a relatively healthy marsh ecosystem residing near mean high water and remaining in dynamic equilibrium with elevation and the tidal frame (Morris et al., 2002; Fig. 2, 
Fig 4, Table 1). Particularly within the ditched marsh interior, biogeomorphic responses to lower elevations within the tidal frame included greater plant heights and soil carbon content (Fig. 4-5, Table 2). Overall, the net effect of ditching results in slight increases in carbon storage within the upper $1 \mathrm{~m}$ of GBM, yet corresponds with potential decreased marsh resilience to future sea-level rise due to lower elevations within our study site.

\subsubsection{Factors contributing to subsidence of the ditched marsh}

A century of ditch installation and maintenance achieved the initial goal of reducing pond density but the ditched marsh interior resides at a lower elevation and has slower vertical accretion rates than the adjacent unditched marsh (Fig. $1-3$, Table 1). Studies of the legacy effects of mosquito ditching have focused on the observed subsidence $(9-20 \mathrm{~cm})$ within the ditched marsh that can make salt marshes more vulnerable to flooding with future sea-level rise (Portnoy, 1999; Vincent et al., 2013; Burdick et al., 2020). Here, we observed a similar $15 \pm 4 \mathrm{~cm}$ difference in elevation between the ditched and unditched marsh located $100 \mathrm{~m}$ away from the tidal channel. Decreased soil accretion rates focused within the ditched $\left(4.70 \pm 0.17 \mathrm{~mm} \mathrm{yr}^{-1}\right)$ and unditched marsh interior $\left(5.06 \pm 0.11 \mathrm{~mm} \mathrm{yr}^{-1}\right)$ represent a $7 \%$ decrease in soil accretion rates (Fig. 3a). This is consistent with conceptualizations that attribute elevation loss to decreased soil accretion rates (Roman and Burdick, 2012) and the lowering of the water table (Stearns and MacCreary, 1936) leading to increased aeration and decomposition of long-buried peat (Vincent et al., 2015).

Yet, the differences in soil accretion rates since the implementation of ditches $(\sim 1920)$ only explain $30 \%(\sim 3.5 \mathrm{~cm})$ of the total $15 \mathrm{~cm}$ elevation difference between the ditched and unditched marsh interior (Fig. $2-3$, Table 1). The other $70 \%$ of elevation loss could be explained by additional factors such as increased erosion and slumping at the ditch edges, as well as dewatering and subsequent compaction of soils (Roman and Burdick, 2012; Burdick et al., 2020). Further, ditched and unditched marsh interior soils may have started at differing elevations at the time of ditch implementation. Future exploration of the physical drivers of elevation loss associated with ditching is required; a promising avenue to explore is ditches may mimic the tidal channel in terms of bank slumping and subsequent marsh loss that can accelerate with future sea-level rise (Mariotti et al., 2016). Comparisons of elevation gain within the ditched and adjacent unditched portions of Great Barnstable Marsh provide valuable insight into the multiple biophysical factors that contribute to the observed elevation difference $(\sim 0.15 \mathrm{~m})$ within the ditched marsh interior.

\subsubsection{Biogeomorphic responses to lower elevations in the tidal frame}

Delving into the long-term marsh soil record, comparisons of ditched and unditched marsh soil records spanning nearly a century reveal the nonlinear response to ditch installation and lower elevations on the marsh platform that occur on decadal timescales (Fig. $2-5$, Table 1). As previously observed, multiple processes contributed to the decrease in soil accretion rates and corresponding loss in elevation within the marsh interior after the initial installation of ditches (Terzaghi, 1973, Whigham et al., 1982; Portnoy, 1999; Fig. 3a, Table 1). Currently observed plant characteristics and soil carbon contents within the ditched marsh appear to reflect the dynamic 
biogeomorphic response of marsh grass ecology to elevation within the tidal frame (Fig. 3c - 4, Table 1); marsh platforms that reside at lower elevations within the tidal frame are typically inhabited by taller plant species (e.g. tall form S. alterniflora) coinciding with increased carbon burial and subsequent elevation gain that can act to stabilize the marsh platform (Mendelssohn and Seneca, 1980; Morris et al., 2002; Kirwan and Blum, 2011; Kirwan et al., 2016).

Further, while overall ditched marsh interior accretion rates since the 1920s have been lower than the unditched marsh counterpart (Fig. 3a), inflection points in elevation gain within the ditched marsh interior reveal increases in accretion rates from periods right after ditch installation $\left(1920-1940 \mathrm{~s} ; 4.51 \pm 0.29 \mathrm{~mm} \mathrm{yr}^{-1}\right)$ to contemporary rates of elevation gain $(2000-2018 ; 6.52$ $\pm 0.50 \mathrm{~mm} \mathrm{yr}^{-1}$ ) (Fig. 3c). We observed similar increases in soil accretion rates for the ditched and unditched marsh, reflecting a dynamic response to increasing relative sea-level rise ( $3.9 \pm 0.86$ to $5.6 \pm 1.5 \mathrm{~mm} \mathrm{yr}^{-1}$; NOAA station \#8443970) to maintain elevation within the tidal frame (Fig. 1 and $3 \mathrm{~b}, \mathrm{c})$. In combination, elevation, plant characteristics, and recent accretion rates at GBM demonstrate a resilience within the marsh platform to shifts in elevation associated with ditching.

These biogeomorphic responses may differ for marshes that sit high or low in the intertidal zone; increases in flooding for marshes that reside at a lower elevation relative to the tidal frame can lead to diminished productivity and slower elevation gain, resulting in marsh drowning (Kirwan and Guntenspergen, 2012; Morris et al., 2002). Calculating fractional elevations based on marsh platform elevation (m NAVD88) and local tidal gauge data (NOAA \#84438790) allows comparisons across marsh sites relative to mean sea level (Burns et al., 2021). Currently, GBM resides comfortably within the tidal frame close to mean higher high water (MHHW) (Fig. 2), that may reduce the magnitude of the impacts that anthropogenic ditching has on the marsh platform (Burns et al., 2021). Therefore, further exploration is required to understand how marshes lower in the tidal frame and future increased sea-level rise may exacerbate the impacts that ditching has on marsh survival and subsequent ecosystem delivery.

\subsubsection{The role of the tidal channel and ditches in marsh ecosystem functioning}

The role of the tidal channel to marsh hydrology and platform dynamics are underscored by similar elevations, plant canopy heights, and rates of elevation gain at the near-channel sites regardless of whether the marsh was ditched (Fig. 2-4; Table 1). In contrast, ditching within the marsh interior results in differences in elevation, plant heights, and soil accumulation across the marsh platform (Fig 5e - h, Table 2). The differences associated with the ditched marsh interior mirror the trends we observed with proximity to tidal channel; unditched marsh soils near the tidal channel were characterized with lower elevations, greater canopy heights, and slower rates of elevation gain compared the unditched marsh interior soils (Fig. $2-4$, Table 1). Therefore, ditches appear to mirror the impact of the tidal channel on marsh hydrology (i.e. drainage patterns, tidal inundation period; Morris and Haskin, 1990; Marion, Anthony and Trentesaux, 2009) and play a role in marsh plant ecology and elevation gain within the ditched marsh interior.

Dominating bulk soil composition trends occurred in soils at differing distances from the tidal channel and appeared magnified within the ditched marshes (Fig. 5, Table 2-3). Proximity 
to tidal channel influences factors such as inorganic particle deposition, drainage patterns, soil flushing, flooding frequency and duration that play a role in key marsh ecosystem functions. At close proximity to the tidal channel, greater deposition of high-density inorganic material and increased drainage and flushing of soils (Redfield, 1972; Nixon, 1980; Sanderson et al., 2001; Fagherazzi et al., 2012) would be consistent with the observed greater bulk densities, lower carbon contents and sulfur contents close to the tidal channel (Fig. 5, Table 3). Interestingly, compared to the unditched marsh, the ditched marsh appears to have enhanced differences in soils at differing distances from the tidal channel (Fig. 5, Table 3c), demonstrating a potential interaction between tidal channel influences and lower elevations within the ditched marsh interior. The increase in TOC content within the marsh interior are consistent with decreased contributions of inorganic material from the tidal channel and the greater role of organic matter burial and preservation in contributing to elevation gain. For the ditched marsh interior, greater observed plant heights coincide with greater TOC content and $\mathrm{C}: \mathrm{N}$ ratios which further augment the trend in carbon content with distance from channel compared to the unditched marsh (Fig. 5, Table 1 - 3). Considering sulfur cycling close to the tidal channel, Gardner $(1990,1988)$ found that intrusion of oxygen-rich tidal water through soils could further enhance $\mathrm{FeS}_{2}$ oxidation, in sulfide conversion and export; this would mirror trends of increased soils sulfur preservation towards the marsh interior (Fig. 5, Table 2-3). Lower elevations in the tidal frame within the ditched marsh interior, may result in more anoxic soil environments that correspond with enhanced preservation of both soil sulfur and carbon (Krairapanond et al., 1992; Fig. 2, 5, Table 2). Overall, soil composition heterogeneity associated with distance from the tidal channel and ditching within the marsh interior further underscores the dynamic shifts in ecosystem functioning (e.g. plant characteristics, redox environment, soil carbon content) as a result of natural and altered marsh hydrology.

The ditched and unditched marshes provide valuable insight into the important interactions between marsh environments in close proximity to tidal channels. Ditched and unditched marshes were generally similar to each other in elevation, plant heights, and soil composition in marsh environments closest to the tidal channel demonstrating the importance of natural marsh hydrology to key ecosystem functions (Fig. $2-5$, Table $1-3$ ). Towards the marsh interior we observed greater differences in soils associated with ditching that appear to result from lower elevations corresponding to greater plant heights and increased preservation of carbon and sulfur content within the soils. Thus, evaluating the impacts of ditching requires constraining both unditched and ditched marsh soils with respect to the tidal channel.

\subsubsection{Recycled marsh material contribute to marsh carbon stocks}

Investigation into the source and thermal reactivity of buried soil organic carbon revealed that organic matter is derived from autochthonous marsh material and is characterized by a range of ages and thermal reactivities that vary with depth (Fig. 6-7, SI Table 1). Initially, we hypothesized that lower elevations within the ditched marsh would trap more allochthonous (e.g., terrestrial) organic and inorganic material and that elevation loss driven by dewatering and organic matter decomposition would correspond with increased accumulation of more thermally stable, 
degraded soil organic matter within ditched marsh soils. On the contrary, the sources of the buried organic carbon were marsh grasses across GBM, demonstrating that changes in carbon content within the ditched marsh are not a result of significant increased trapping of allochthonous terrestrial or marine organic matter (Fig. 6 - 7). Further, unditched marsh soils within the marsh interior had greater thermal stability with a greater portion of the bulk soil representing old carbon (Fig. $6-7$ ).

Throughout the marsh, the portion of carbon defined as old $(\mathrm{Fm}<1)$ in the surface horizon $(0-2 \mathrm{~cm})$ ranged from $16-46 \%$ that can impact estimates of new carbon burial within the marsh (Fig. 7; SI Table 1). Processes that contribute to the larger percentage of old, more thermally stable marsh material within the unditched marsh remain unclear but could include increased deposition of old recycled material on the marsh surface that originated from either resuspension of pond material, ditching spoils, or erosion of the marsh creekbank and subsequent redeposition on the marsh platform (Hopkinson et al., 2018). Recycled material from the tidal channel is a possibility based on elevated total suspended solids $\left(57.09 \pm 2.78 \mathrm{mg} \mathrm{L}^{-1}\right)$ in the tidal creek in close proximity to the unditched marsh, compared to that of the ditched marsh $\left(36.30 \pm 2.95 \mathrm{mg} \mathrm{L}^{-1}\right)$. Yet, contributions of old SOC were similar closest to the channel (25\%) and diverged within the ditched and unditched marsh interior (16\% vs. 33\%) (SI Table 1), reflecting additional processes at play. The increased input and preservation of new organic matter resulting from greater plant heights on the ditched marsh could dilute the portion of old carbon that comprises the total buried soil organic carbon (Fig. 4; Fig. 5f; Table 2c). Increased inputs and preservation of fresh marsh material would parallel the increased TOC content, $\mathrm{C}: \mathrm{N}$, and sulfur content characteristics we observed within the ditched marsh interior (Fig. $5 \mathrm{f}$-h, Table 2c). Overall, the contributions of recycled marsh material vary within the unditched and ditched marsh environments whose range can represent a $16-46 \%$ error in carbon stock assessments, further contributing to existing spatial heterogeneity in soil composition associated with ditching.

\subsubsection{Inclusion of resource management strategies in marsh ecosystem service accounting}

Typical assessments of wetland carbon stocks are calculated by measuring soil carbon contents and accumulation rates within a number of sites and extrapolating across the entire upper meter of the marsh system (Chmura et al., 2003; Ouyang and Lee, 2014). Resource managers and scientists encounter additional complexities when establishing estimates of carbon stock changes associated with disturbances to the marsh (e.g. marsh management strategies, global change) that can result in landscape heterogeneity within a single system. By including both existing and infilled ponds, and the elevation differential between the ditch and unditched marsh, we find that ditching is associated with an insignificant change in the carbon stored within the upper meter of the soil column (Table 4). Similar carbon storage estimates associated with ditching is driven by overall greater carbon content associated with ditched marsh soils, compensating for the overall loss of marsh soil volume ( $10 \%$ decrease) due to elevation differences and the presence of ditches. Overall, this provides a framework in which to assess changes in ecosystem functioning (e.g. carbon storage) associated with mosquito ditching across New England marshes that have experienced historical 
ditching. Future exploration is required to understand how ditching impacts marsh ecosystem functioning for marshes that reside lower in the tidal frame and are more susceptible to drowning.

\subsection{CONCLUSION}

Management of coastal wetlands requires accurate tradeoff analysis informed by in-depth assessments of ecosystem functioning when maintaining valuable blue carbon stocks. While ditches are maintained in certain New England marshes, resource managers are becoming increasingly aware that they must balance human health needs with the ecosystem service delivery and survival of the salt marshes they manage. After nearly a century of ditching, we observed that the effects of this resource management strategy were focused within the marsh interior where lower elevations ( $\sim 0.15 \mathrm{~m}$ lower) coincided with a decrease in soil accretion rates $(4.70 \pm 0.17 \mathrm{~mm}$ $\left.\mathrm{yr}^{-1}\right)$ compared to the unditched marsh $\left(5.06 \pm 0.11 \mathrm{~mm} \mathrm{yr}^{-1}\right)$ after ditching was implemented. Overall similarities between the ditched and unditched marsh closest to the tidal channel highlights the important role of natural marsh hydrology in maintaining key marsh ecosystem functions. In response to the change in elevation within the ditched marsh interior, we observed a biogeomorphic response in marsh ecology and soil composition through increased plant heights and carbon contents. Autochthonous marsh material dominated organic matter inputs throughout the marsh system, but the amount of old marsh material deposited at the surface of the marsh varied across ditched (46\%) and unditched (27\%) marsh environments, representing an additional error to carbon stock assessments. Overall, we find that ditching did not significantly change carbon stocks, when ditch features, existing and recovered ponds, and differences in elevation and carbon content were incorporated to carbon accounting for GBM. Further exploration is required to understand how ditching impacts ecosystem functioning and future survival of marshes that may be more susceptible to drowning (e.g. experiencing rapid sea-level rise or reside lower in the tidal frame).

\section{ACKNOWLEDGEMENTS:}

Thanks to Adrian Mann, Jennifer O'Keefe Suttles, and Marshall Otter for help in collecting and processing soil cores. M. Lardie, J. Hemingway, and V. Galy for assisting with RPO and rampedpyrox. Funding support was provided by Woods Hole Sea Grant (NA14OAR4170104) and NOAA (NA14NOS4190145) grants to ACS. 
Table 1: Unditched and ditched marsh elevations, abundance (\% cover), and plant canopy heights $(\mathrm{cm})$ at $0 \mathrm{~m}, 50 \mathrm{~m}$, and $100 \mathrm{~m}$ from the tidal channel as displayed in Fig. 2 and Fig. 4. Values represented are mean and associated SE in parantheses.

\begin{tabular}{|c|c|c|c|c|c|c|}
\hline Distance from Channel & \multicolumn{2}{|c|}{ Om } & \multicolumn{2}{c|}{$50 \mathrm{~m}$} & \multicolumn{2}{c|}{$100 \mathrm{~m}$} \\
\hline & Unditched & Ditched & Unditched & Ditched & Unditched & Ditched \\
\hline Elevation (m NAVD88) & $1.48(0.04)$ & $1.45(0.05)$ & $1.62(0.02)$ & $1.40(0.03)$ & $1.60(0.03)$ & $1.35(0.03)$ \\
\hline S. alterniflora Abundance (\% cover) & $72(17)$ & $12(3)$ & $92(4)$ & $87(8)$ & $85(12)$ & $95(2)$ \\
\hline S. alterniflora Plant Canopy Height (cm) & $61(1)$ & $65(14)$ & $26(1)$ & $35(6)$ & $20(3)$ & $42(2)$ \\
\hline
\end{tabular}


Table 2: Contrast analyses between soil properties (a) of ditched and unditched marshes and locations (b) near the channel or (c) $100 \mathrm{~m}$ towards the interior. Contrast coefficients are for soil zones described in the methods and depicted in Figure 5. Highlighted and bolded coefficients are significant $(p<0.05)$. Contrast coefficients represent the magnitude difference in bulk soil properties between the ditched and unditched marsh (e.g. TOC contents were $10.02 \mathrm{~kg} \mathrm{~m}^{-3}$ greater in the entire ditched marsh compared to the unditched marsh).

\begin{tabular}{|c|c|c|c|c|}
\hline $\begin{array}{l}\text { Contrast: } \\
\text { Ditched vs. Unditched }\end{array}$ & $\begin{array}{l}\text { Bulk Density } \\
\log _{10}\left(\mathrm{~g} \mathrm{~cm}^{-3}\right)\end{array}$ & $\begin{array}{c}\text { TOC } \\
\left(\mathrm{kg} \mathrm{m}^{-3}\right)\end{array}$ & $\begin{array}{c}\mathrm{C}: \mathrm{N} \\
\log _{10}(\text { molar ratio) }\end{array}$ & $\begin{array}{l}S \\
(\%)\end{array}$ \\
\hline \multicolumn{5}{|c|}{ a. Entire marsh: Near-channel + Interior } \\
\hline $\mathrm{A}$ & 0.01 & 10.02 & 0.03 & -0.12 \\
\hline B & 0.07 & 5.56 & 0.02 & -0.34 \\
\hline C & -0.07 & 0.16 & -0.01 & 0.55 \\
\hline \multicolumn{5}{|c|}{ b. Near-channel marsh } \\
\hline$A$ & -0.01 & 6.52 & 0.00 & -0.56 \\
\hline B & -0.01 & -1.06 & -0.02 & -0.24 \\
\hline $\mathrm{C}$ & 0.05 & -2.51 & 0.01 & 0.00 \\
\hline \multicolumn{5}{|l|}{ c. Interior marsh } \\
\hline $\mathrm{A}$ & 0.01 & 14.04 & 0.10 & 0.27 \\
\hline B & 0.13 & 13.24 & -0.02 & 0.02 \\
\hline $\mathrm{C}$ & -0.18 & 2.66 & -0.02 & 1.01 \\
\hline
\end{tabular}


Table 3: Contrast analyses between soil properties (a) of marsh locations near the channel (0m) compared to $100 \mathrm{~m}$ towards the interior and separated by (b) the unditched and (c) unditched marsh. Contrast coefficients are for soil zones described in the methods and depicted in Figure 5. Highlighted and bolded coefficients are significant $(\mathrm{p}<0.05)$. Contrast coefficients represent the magnitude difference in bulk soil properties between the near-channel and interior marsh (e.g. TOC contents were $4.07 \mathrm{~kg} \mathrm{~m}^{-3}$ lower in the near-channel marsh compared to the marsh interior).

\begin{tabular}{|c|c|c|c|c|}
\hline $\begin{array}{l}\text { Contrast: } \\
\text { Near-channel v. Interior }\end{array}$ & $\begin{array}{l}\text { Bulk Density } \\
\log _{10}\left(\mathrm{~g} \mathrm{~cm}^{-3}\right)\end{array}$ & $\begin{array}{c}\text { TOC } \\
\left(\mathrm{kg} \mathrm{m}^{-3}\right)\end{array}$ & $\begin{array}{c}\mathrm{C}: \mathrm{N} \\
\log _{10}(\mathrm{molar} \text { ratio) }\end{array}$ & $\begin{array}{l}\mathrm{S} \\
(\%)\end{array}$ \\
\hline \multicolumn{5}{|c|}{ a. Entire marsh: Unditched + Ditched } \\
\hline $\mathrm{A}$ & 0.32 & -4.07 & -0.11 & -0.84 \\
\hline B & 0.34 & -0.08 & -0.06 & -0.61 \\
\hline $\mathrm{C}$ & 0.32 & -4.40 & -0.09 & -0.88 \\
\hline \multicolumn{5}{|l|}{ b. Unditched } \\
\hline $\mathrm{A}$ & 0.32 & 1.37 & -0.05 & -0.53 \\
\hline B & 0.40 & 8.59 & -0.04 & -0.47 \\
\hline $\mathrm{C}$ & 0.21 & 0.06 & -0.08 & -0.32 \\
\hline \multicolumn{5}{|l|}{ c. Ditched } \\
\hline $\mathrm{A}$ & 0.33 & -6.24 & -0.16 & -1.14 \\
\hline B & 0.29 & -7.42 & -0.08 & -0.78 \\
\hline $\mathrm{C}$ & 0.42 & -8.62 & -0.10 & -1.25 \\
\hline
\end{tabular}


Table 4: Estimates of the Great Barnstable Marsh, MA carbon budget for the following scenarios: 1) natural marsh with $13 \%$ ponded areas and 2 ) ditched marsh with $13 \%$ infilled pond areas, ditches, and lower elevations. This analysis helped elucidate the percent difference (\% Difference) of the carbon stored per unit area (Carbon Stored $\mathrm{kg} \mathrm{m}^{-3}$ ) between the two scenarios.

\begin{tabular}{cccc}
\hline Scenario & Description & Carbon Stored $\left(\mathrm{kg} \mathrm{m}^{-2}\right)$ & $\%$ Difference \\
\hline 1 & Natural marsh w/ ponds & 30.13 & $3 \%$ \\
2 & Ditched marsh w/ infilled ponds & 30.93 & \\
\hline
\end{tabular}




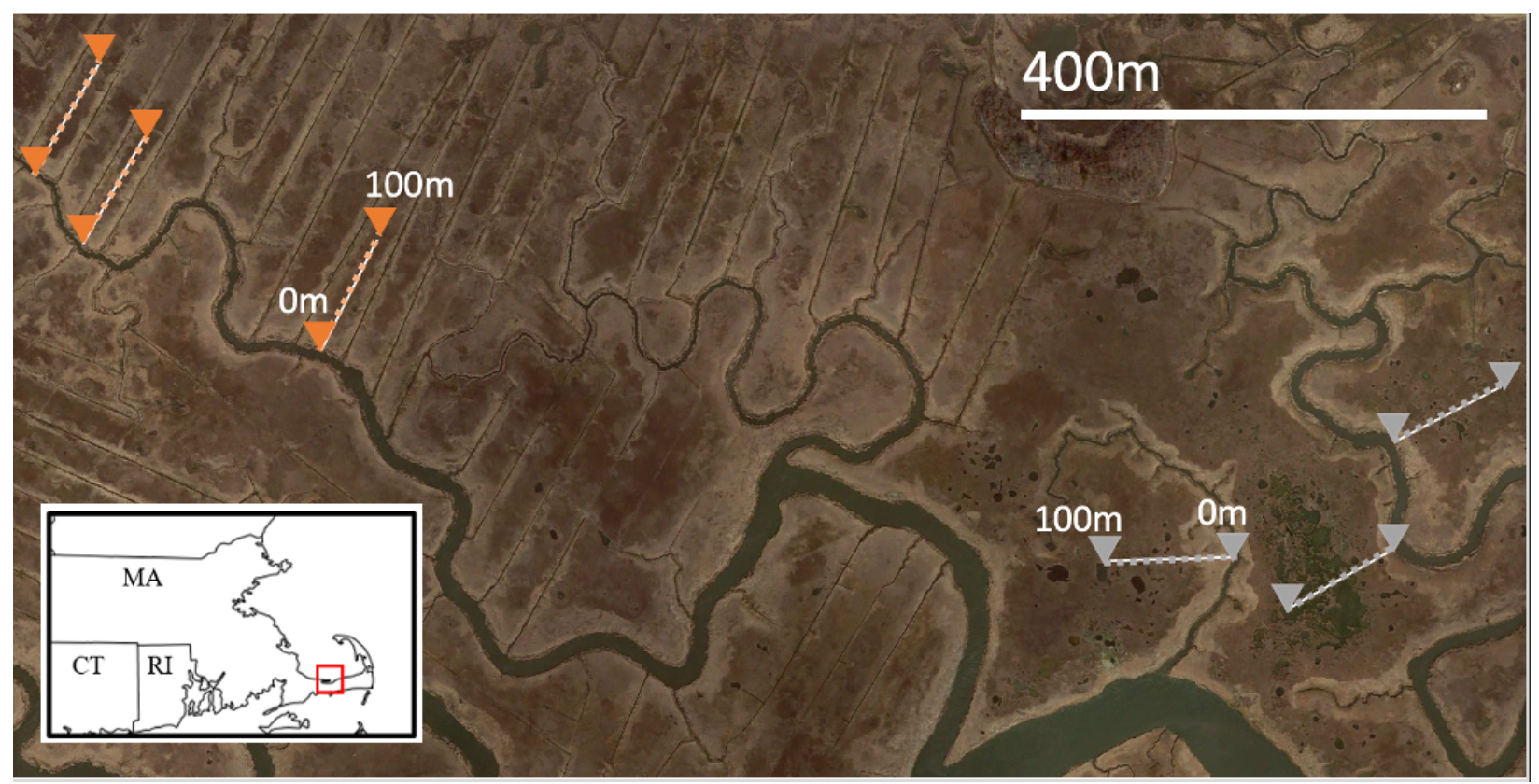

Figure 1: The three $100 \mathrm{~m}$ transects for the ditched (orange) and unditched (grey) marsh in Great Barnstable Marsh (Massachusetts, USA). Triangles indicate the locations of soil core collections at the start $(0 \mathrm{~m}$, near creekbank) and end $(100 \mathrm{~m})$ of the transects. 


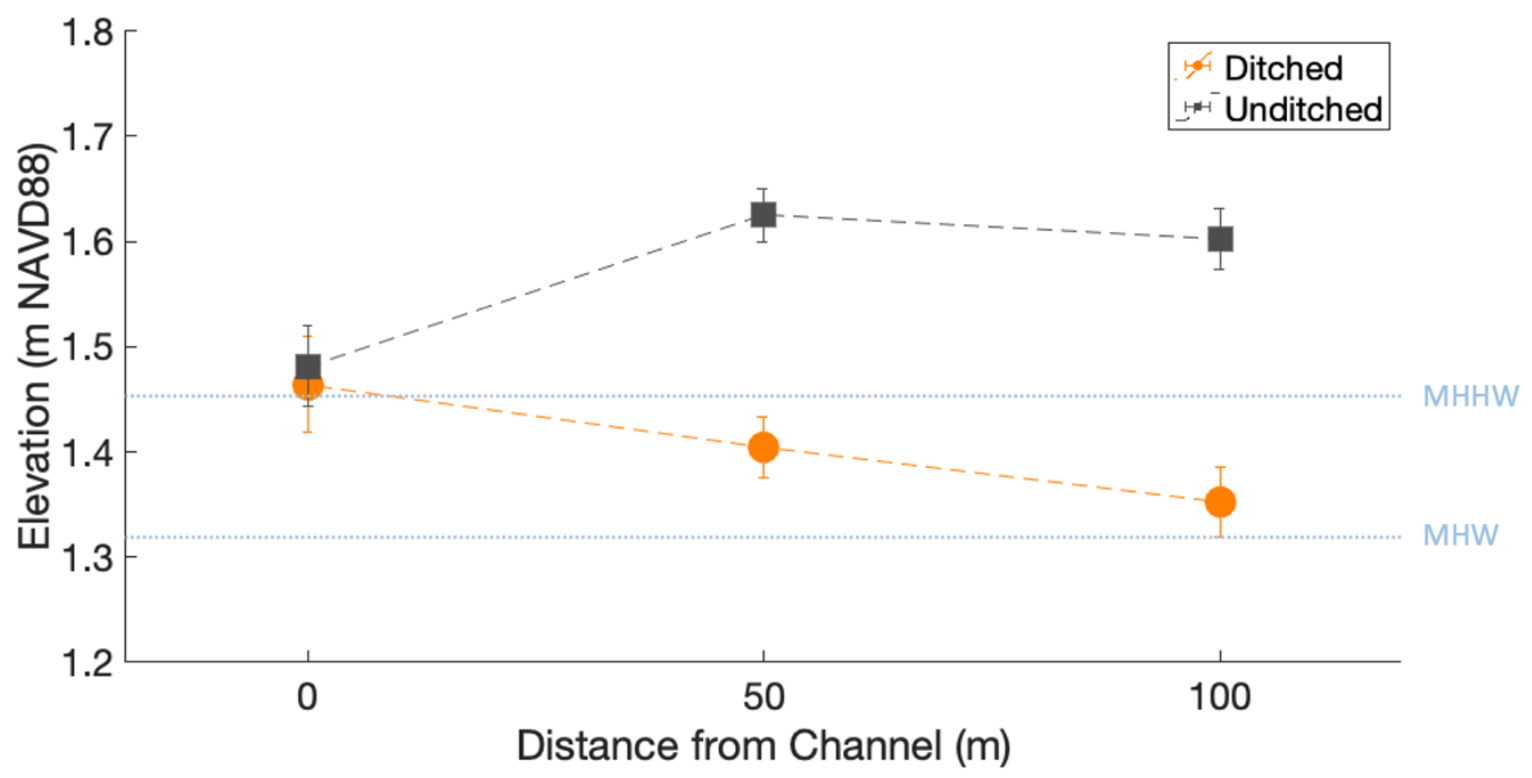

Figure 2: Elevations in the ditched and unditched marshes from the tidal channel edge $(0 \mathrm{~m})$ to the end of the sampling transects $(100 \mathrm{~m})$. Data are mean and associated SE and dashed horizontal lines represent mean higher-high water (MHHW) and mean high water (MHW) (NOAA station \#8443970). See Table 1 for statistics. 

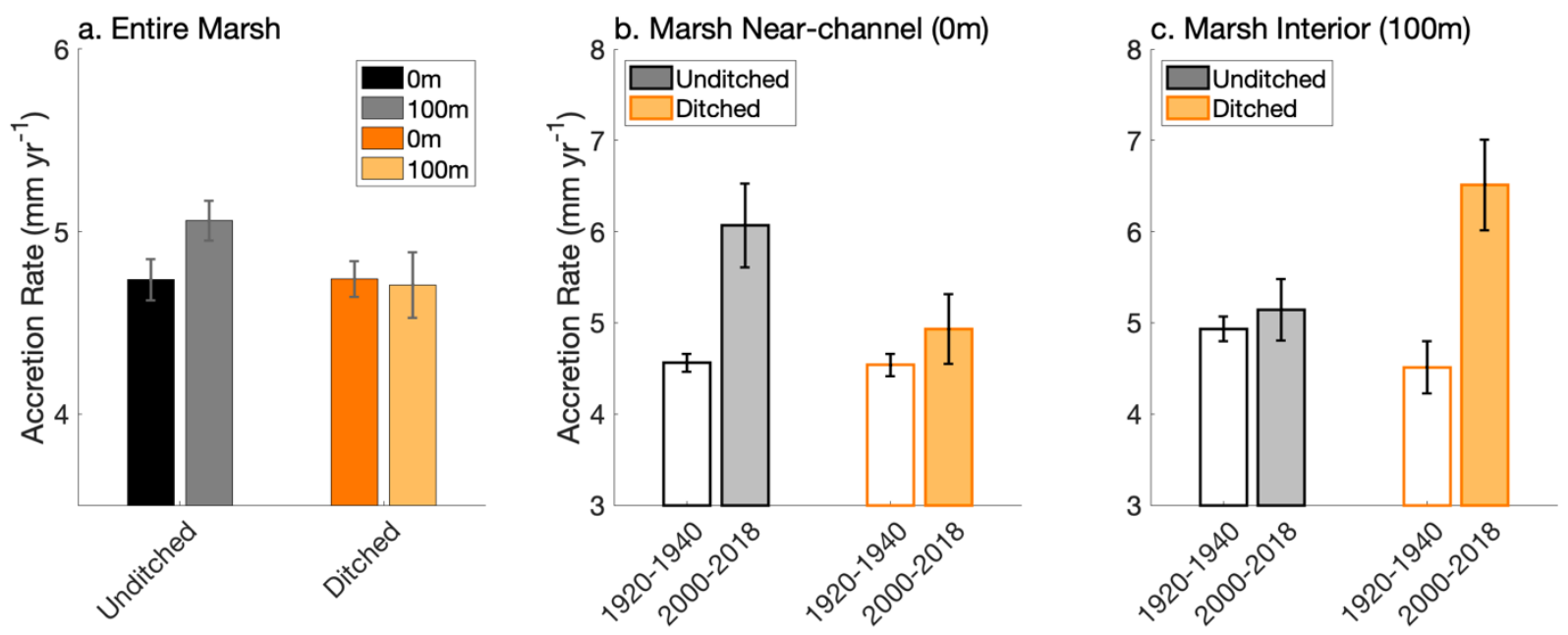

Figure 3: a) Accretion rates $\left(\mathrm{mm} \mathrm{yr}^{-1}\right)$ for the entire unditched and ditched marsh and broken down by the b) near-channel and c) marsh interior for the unditched and ditched marsh over the time periods of 1920-1940 and 2000-2018, demonstrating shifts in accretion rates particularly within the ditched marsh interior. Data displayed are mean and associated SE. 

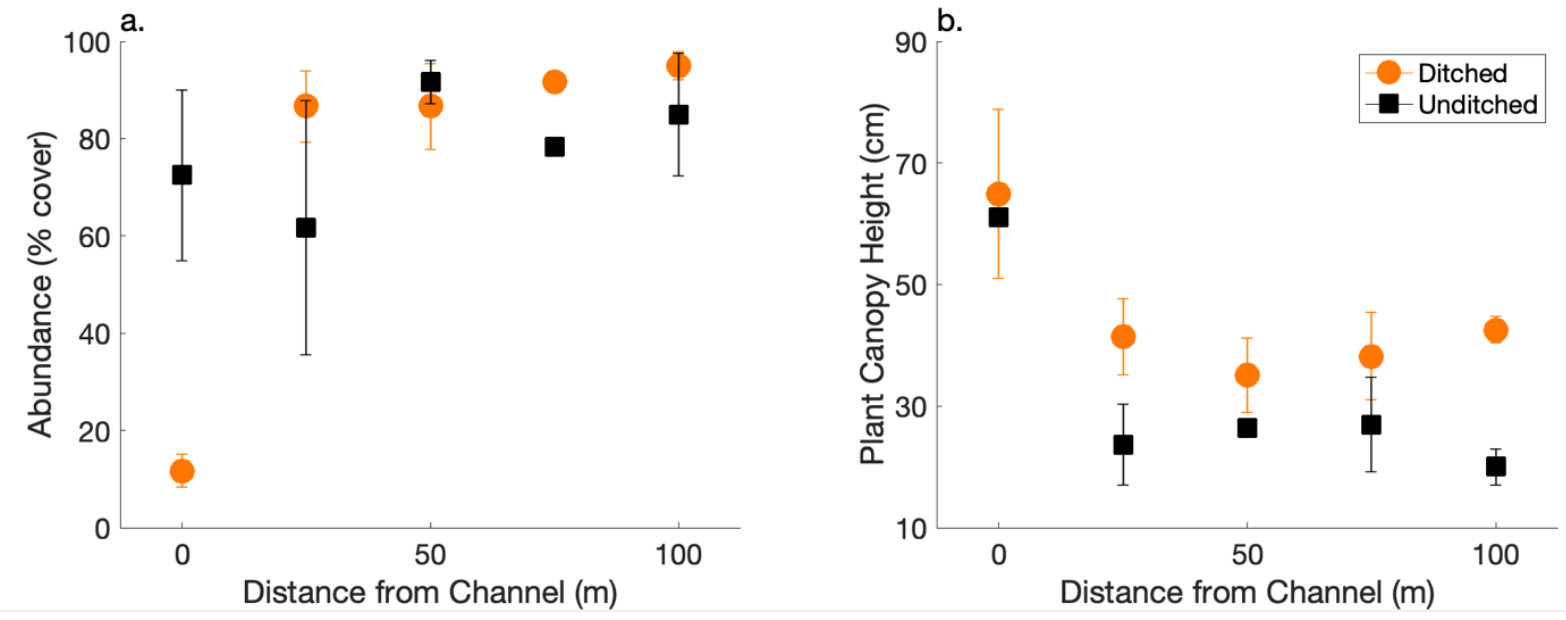

Figure 4: Ditched and unditched S. alterniflora (a) abundance (\% cover) and (b) plant canopy heights $(\mathrm{cm})$ relative to distance from tidal channel $(\mathrm{m})$. Plant canopy heights demonstrate differences with distance from tidal channel and ditching. See Table 1 for statistics. 


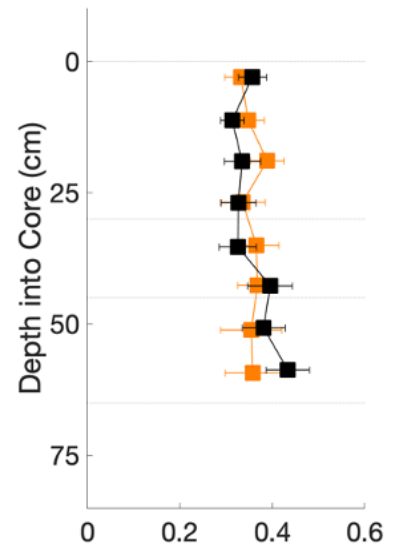

e.

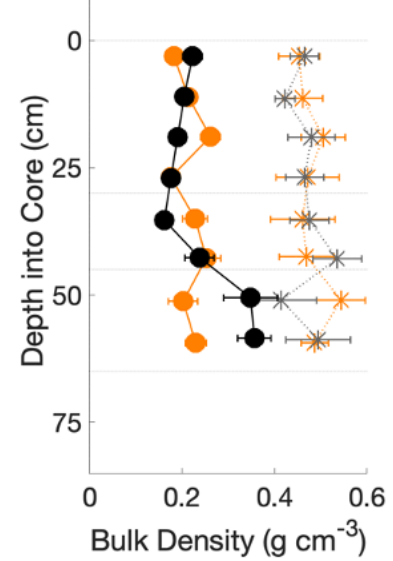

b.

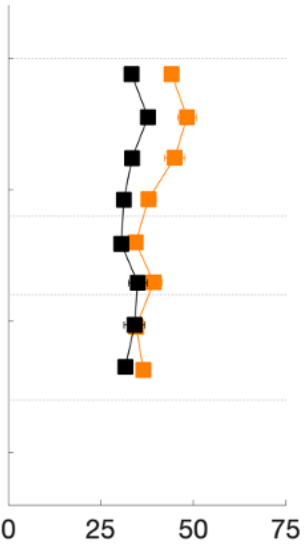

f.

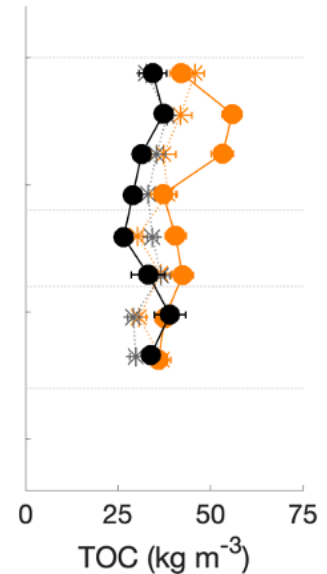

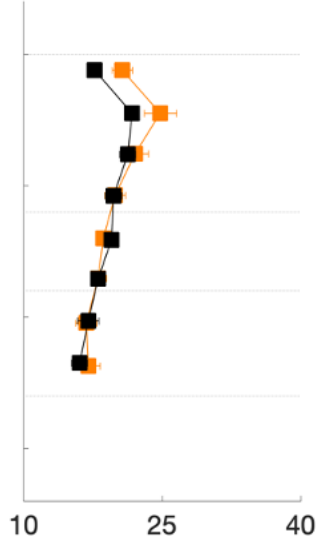

g.

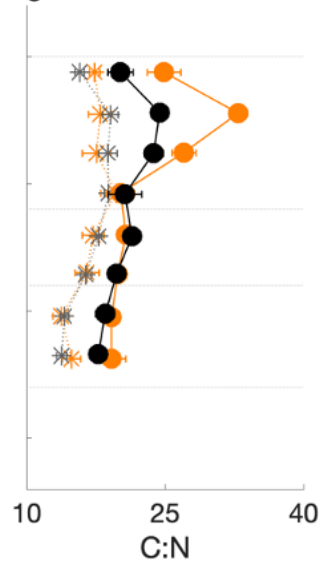

d.

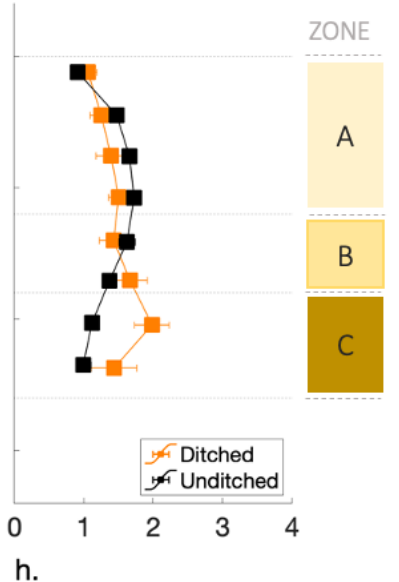

h.

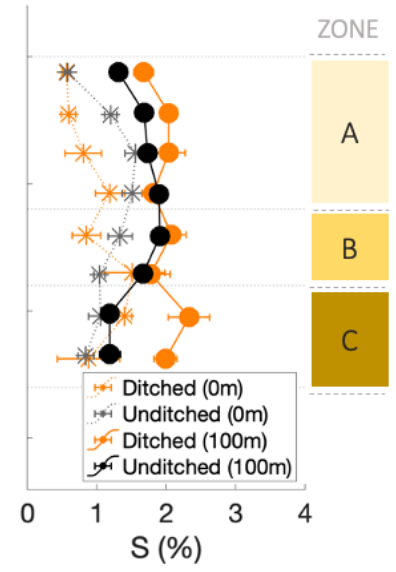

Figure 5: Soil $(\mathrm{a}, \mathrm{e})$ bulk density $\left(\mathrm{g} \mathrm{cm}^{-3}\right),(\mathrm{b}, \mathrm{f})$ total organic carbon $\left(\mathrm{kg} \mathrm{m}^{-3}\right),(\mathrm{c}, \mathrm{g}) \mathrm{C}: \mathrm{N}$ (molar ratio), and $(\mathrm{d}, \mathrm{h})$ sulfur content $(\%)$ in ditched and unditched marshes $(\mathrm{a}-\mathrm{d})$ and by near-channel $(0 \mathrm{~m})$ or interior $(100 \mathrm{~m})(\mathrm{e}-\mathrm{h})$. Data represent mean and SE. See Table 2 - 3 for contrast analyses for zones $\mathrm{A}-\mathrm{C}$ defined in the methods. 

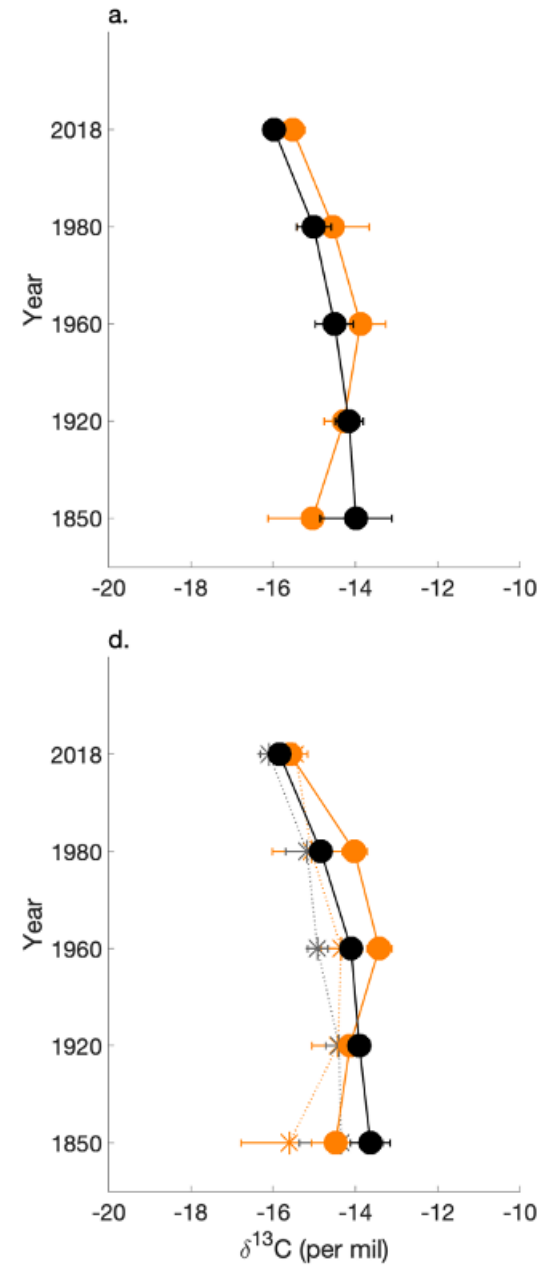

b.

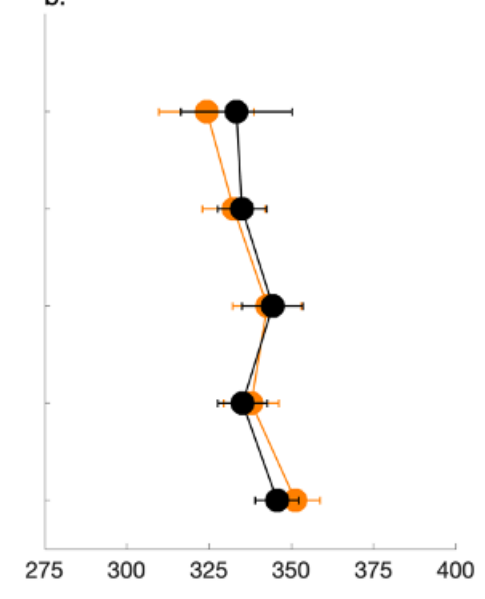

e.

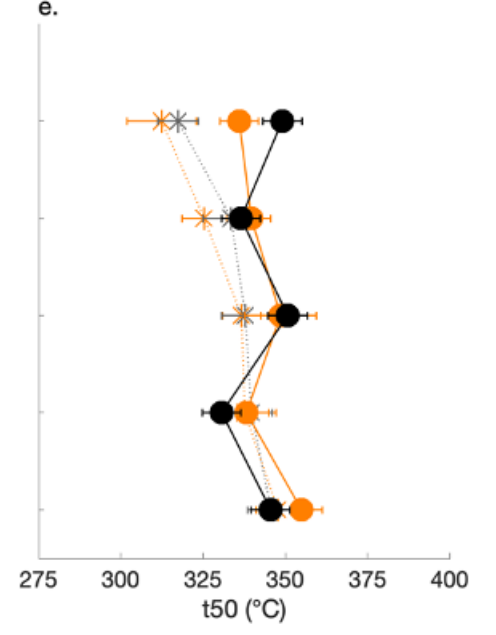

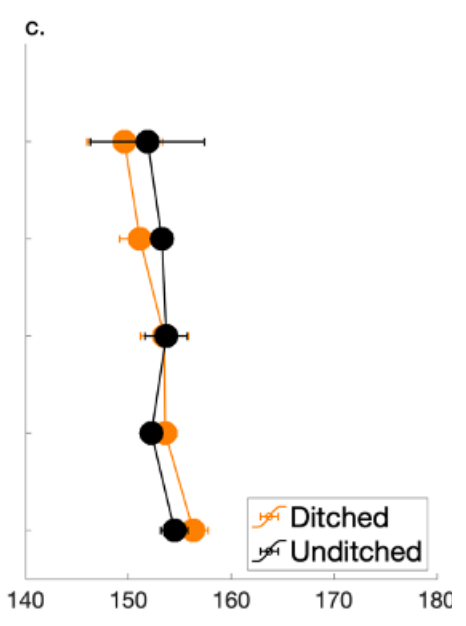

f.

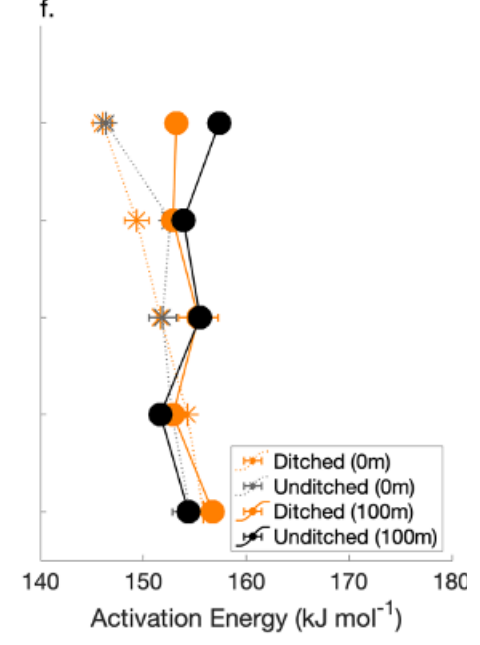

Figure 6: Soil $\delta^{13} \mathrm{C}$ composition (a, d) and thermal properties $\mathrm{t} 50$ (b, e) and activation energy $\left(\mathrm{kJ} \mathrm{mol}^{-1}\right.$; $\left.\mathrm{c}, \mathrm{f}\right)$ by year of deposition estimated from ${ }^{210} \mathrm{~Pb}$ models for the ditched and unditched marshes $(\mathrm{a}-\mathrm{c})$ and by near-channel $(0 \mathrm{~m})$ or interior $(100 \mathrm{~m})(\mathrm{d}-\mathrm{f})$. The mean and SE of $\mathrm{t50}$ and $E a$ are presented based on year of deposition to analyze shifts in soil organic carbon source and reactivity spanning from 1850 to 2018 . 
Unditched

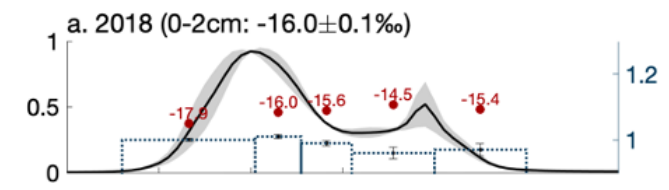

b. 1980 (11-17cm: $-15.0 \pm 0.2 \%$ )
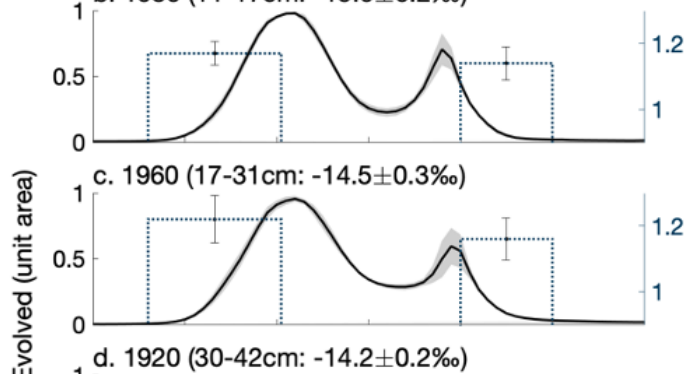

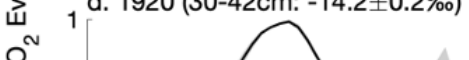

$\mathrm{O}^{\mathrm{N}} 0.5$

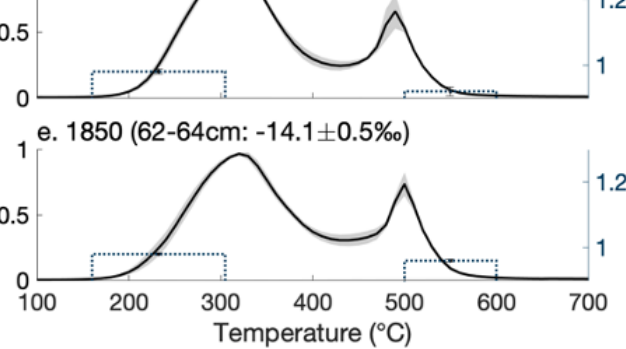

Ditched
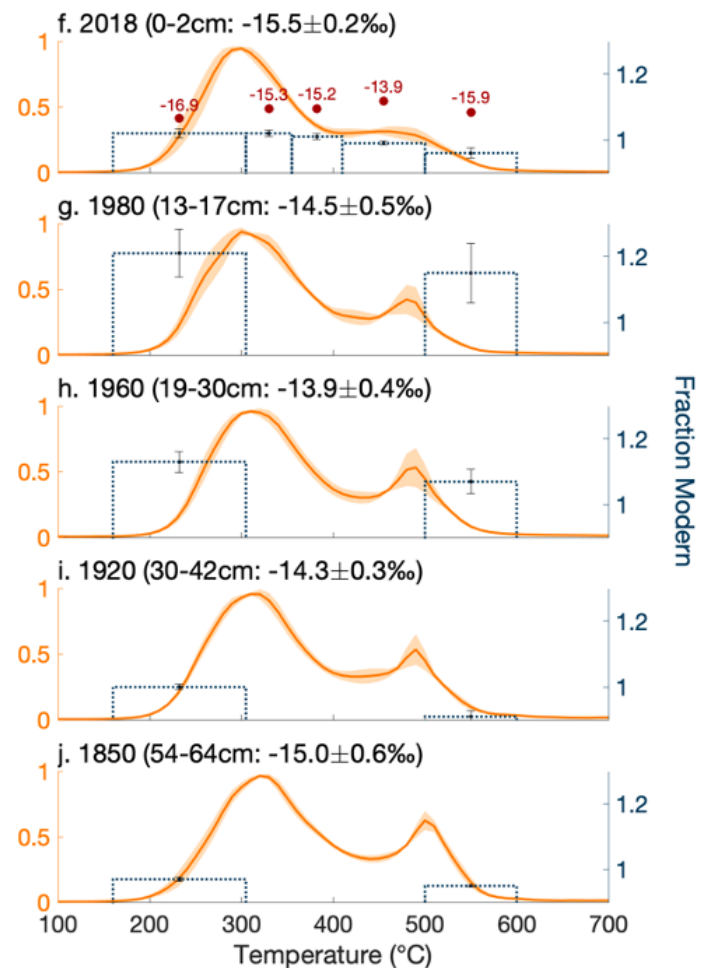

Figure 7: Soil organic carbon thermal properties, sources $\left(\delta^{13} \mathrm{C}\right)$, and ages $\left(\mathrm{F}^{14} \mathrm{C}\right)$ in the unditched (a-e) and ditched marshes (f-j). Dotted bars are $\mathrm{F}^{14} \mathrm{C}$ values for $\mathrm{CO}_{2}$ fractions collected over a temperature interval (bar width) with associated error. Labeled dots represent $\delta^{13} \mathrm{C}$ values of $\mathrm{CO}_{2}$ fractions. Ditched and unditched marsh horizons plotted by year of deposition based on ${ }^{210} \mathrm{~Pb}$ age models; soil depth and bulk soil $\delta^{13} \mathrm{C}$ are in parentheses. 


\section{SUPPLEMENTAL FIGURES}

Table S1: a) Ditched and unditched marsh surface $(0-2 \mathrm{~cm})$ soil Fm values for fractions collected from low to high temperature (F1-F5) and separated by b) near-channel (0m) and c) marsh interior $(100 \mathrm{~m})$ soils. Mean and associated SE of fraction Fm are displayed alongside the average percent carbon evolved within each fraction (\% C) and associated SE (\%C SE). Highlighted rows display fractions with mean values significantly lower than $\mathrm{Fm}<1$ constituting old marsh material. Tables to the right summarizes the percent of old carbon $(\mathrm{Fm}<1)$ and $\mathrm{SE}$ within the surface horizon of the ditched and unditched marsh.

a.

\begin{tabular}{lcccc}
\hline \multicolumn{5}{c}{ ENTIRE DITCHED } \\
Fraction & Fm & Fm SE & $\% C$ & $\%$ C SE \\
\hline F1 & 1.0161 & 0.0129 & $31 \%$ & $3 \%$ \\
F2 & 1.0185 & 0.0094 & $27 \%$ & $1 \%$ \\
F3 & 1.0060 & 0.0087 & $16 \%$ & $1 \%$ \\
F4 & 0.9931 & 0.0054 & $16 \%$ & $1 \%$ \\
F5 & 0.9614 & 0.0158 & $11 \%$ & $3 \%$ \\
\multicolumn{5}{r}{ ENTIRE UNDITCHED } \\
Fraction & Fm & Fm SE & $\% C$ & $\%$ C SE \\
\hline F1 & 1.00 & 0.00 & $29 \%$ & $3 \%$ \\
F2 & 1.01 & 0.01 & $26 \%$ & $0 \%$ \\
F3 & 0.99 & 0.01 & $16 \%$ & $1 \%$ \\
F4 & 0.96 & 0.02 & $18 \%$ & $1 \%$ \\
F5 & 0.97 & 0.02 & $12 \%$ & $3 \%$ \\
\hline
\end{tabular}

b.

\begin{tabular}{|c|c|c|c|c|}
\hline \multicolumn{5}{|c|}{ NEAR CHANNEL DITCHED } \\
\hline Fraction & $\mathrm{Fm}$ & $\mathrm{Fm} \mathrm{SE}$ & $\% \mathrm{C}$ & $\% \mathrm{C} \mathrm{SE}$ \\
\hline F1 & 1.0351 & 0.0138 & $35 \%$ & $3 \%$ \\
\hline F2 & 1.0289 & 0.0173 & $26 \%$ & $1 \%$ \\
\hline F3 & 1.0173 & 0.0104 & $15 \%$ & $0 \%$ \\
\hline F4 & 0.9957 & 0.0035 & $18 \%$ & $1 \%$ \\
\hline F5 & 0.9465 & 0.0306 & $6 \%$ & $0 \%$ \\
\hline \multicolumn{5}{|c|}{ NEAR CHANNEL UNDITCHED } \\
\hline Fraction & $\mathrm{Fm}$ & $\mathrm{Fm} \mathrm{SE}$ & $\% \mathrm{C}$ & $\% \mathrm{CSE}$ \\
\hline F1 & 1.01 & 0.01 & $33 \%$ & $0 \%$ \\
\hline $\mathrm{F} 2$ & 1.00 & 0.01 & $26 \%$ & $0 \%$ \\
\hline F3 & 0.99 & 0.02 & $16 \%$ & $2 \%$ \\
\hline F4 & 0.95 & 0.04 & $18 \%$ & $2 \%$ \\
\hline F5 & 0.94 & 0.02 & $6 \%$ & $0 \%$ \\
\hline
\end{tabular}

C.

\begin{tabular}{lcccc}
\hline \multicolumn{5}{c}{ INTERIOR DITCHED } \\
Fraction & Fm & Fm SE & $\% C$ & $\% C$ SE \\
\hline F1 & 0.9971 & 0.0089 & $26 \%$ & $1 \%$ \\
F2 & 1.0081 & 0.0038 & $27 \%$ & $1 \%$ \\
F3 & 0.9947 & 0.0094 & $17 \%$ & $1 \%$ \\
F4 & 0.9904 & 0.0122 & $14 \%$ & $0 \%$ \\
F5 & 0.9763 & 0.0112 & $16 \%$ & $4 \%$ \\
\multicolumn{5}{r}{} \\
Fraction & INTERIOR UNDITCHED & \\
\hline F1 & 0.9985 & 0.0060 & $24 \%$ & $0 \%$ \\
F2 & 1.0109 & 0.0095 & $26 \%$ & $0 \%$ \\
F3 & 0.9907 & 0.0034 & $15 \%$ & $1 \%$ \\
F4 & 0.9784 & 0.0018 & $18 \%$ & $0 \%$ \\
F5 & 0.9929 & 0.0089 & $17 \%$ & $1 \%$ \\
\hline
\end{tabular}

\begin{tabular}{ccc}
\hline & Percent Carbon Old (\%) & ERROR \\
\hline DITCHED & $27 \%$ & $2 \%$ \\
UNDITCHED & $46 \%$ & $1 \%$ \\
\hline
\end{tabular}

\begin{tabular}{ccc}
\hline & Percent Carbon Old (\%) & ERROR \\
\hline DITCHED & $24 \%$ & $1 \%$ \\
UNDITCHED & $25 \%$ & $1 \%$ \\
\hline
\end{tabular}

\begin{tabular}{ccc}
\hline & Percent Carbon Old (\%) & ERROR \\
\hline DITCHED & $16 \%$ & $4 \%$ \\
UNDITCHED & $33 \%$ & $0 \%$ \\
\hline
\end{tabular}




\title{
Chapter 6: Modeling the effect of water quality on the recreational shellfishing cultural ecosystem service of Buzzards Bay, Massachusetts
}

\begin{abstract}
Estuaries provide significant cultural ecosystem services, including recreation and tourism. Disruptions of estuarine biogeochemical processes resulting from environmental degradation could interrupt the flow of these services, reducing benefits and diminishing the welfare of local communities. This study focused on recreational shellfishing in Buzzards Bay, Massachusetts $\left(41.55^{\circ} \mathrm{N}, 70.80^{\circ} \mathrm{W}\right)$. Relationships among measures of recreational shellfishing, estuarine water quality, and local socioeconomic conditions were tested to understand how the benefits of cultural ecosystem services to local communities might be affected by declining water quality. Transferring estimated economic benefits from an analysis of nearby municipalities, the study finds that increases in Chl $a$ during the 24-year period were associated with losses in recreational shellfishing benefits of $\$ 0.08-0.67$ million. The approach presented here suggests a more broadly applicable framework for assessing the impacts of changes in coastal ecosystem water quality on the welfare of local communities.
\end{abstract}

This chapter was originally published in Marine Pollution Bulletin by Elsevier in 2019 and is under a Creative Commons license.

Luk, S. Y., Hoagland, P., Rheuban, J. E., Costa, J. E., \& Doney, S. C. (2019). Modeling the effect of water quality on the recreational shellfishing cultural ecosystem service of Buzzards Bay, Massachusetts. Marine pollution bulletin, 140, 364-373. 


\subsection{INTRODUCTION}

Despite occupying only $5 \%$ of the global land surface, coastal ecosystems supply a diverse array of ecosystem services, ranging from nursery habitats for key fisheries (a supporting service) to recreation and tourism (cultural services) (MEA, 2005). Environmental degradation adversely affects coastal human populations, which now comprise approximately $60 \%$ of the world's population (Vitousek et al., 1997; Howarth and Marino, 2006; Bricker et al., 2008). Declining water quality, stemming both from nutrient enrichment (leading to eutrophication) and from a changing climate, is of particular concern for coastal environments. With the progression of climate change, it has become critically important to quantify local changes in coastal water quality, its impacts on coastal ecosystems and communities, and any associated changes in human welfare.

\subsubsection{Estuarine water quality}

In many locations around the world, coastal estuaries have experienced increases in coastal populations and rapid development, making them especially susceptible to degradation of water quality. Excessive nutrient loading into coastal waters can lead to eutrophication, a phenomenon in which increased primary production and respiration rates result in declining water quality. Howarth and Marino (2006) estimated that human activity in the United States has led to an average six-fold increase in nutrient fluxes to coastal waters, resulting in the moderate or severe degradation of two-thirds of the nation's coastal waters. Eutrophication is of particular concern for estuarine ecosystems because of impacts that include acute hypoxia (low oxygen), reduced capacity for carbon sequestration, and increased mortality of seagrasses, finfish, and shellfish. These changes in ecosystem functioning ultimately can lead to the loss of ecosystem services and social welfare. In addition, nutrient-impaired water bodies typically are compromised by bacterial pollution that causes closures of commercially or recreationally important shellfish beds. The spatial association of these impairments results from common contributing sources (e.g., stormwater) and because of synergistic effects between nitrogen loading and the survival of indicator bacteria (Campos et al., 2013).

This study focuses on Buzzards Bay, Massachusetts $\left(41.55^{\circ} \mathrm{N}, 70.80^{\circ} \mathrm{W}\right)$, a US National Estuary located on the Southern New England coast composed of a series of river- and groundwater-fed embayments. Buzzards Bay is a shallow estuary (an average depth of $11 \mathrm{~m}$ and an area of $600 \mathrm{~km}^{2}$ ) bordered by 11 municipalities along $500 \mathrm{~km}$ of coastline. As a representative example of a US Northeast coastal estuary, Buzzards Bay is affected by both natural and anthropogenic threats, including storm-surges, sea-level rise, shoreline changes, harmful algal blooms, oil spills, bacterial pollution, and excessive nutrient loading. In accordance with the definitions found in section 303(d) of the US Federal Clean Water Act, due to high levels of nitrogen loading and bacterial pollution, the Massachusetts Department of Environmental Protection (DEP) has listed many of the Buzzards Bay embayments as impaired by elevated levels of both nutrients and bacteria (Massachusetts Department of Environmental Protection, 2016). Since 1992, the Buzzards Bay Coalition (BBC), a local nonprofit group dedicated to the restoration and sustainable use of the Bay, has conducted long-term water quality monitoring to assess the overall health of the bay. Using the BBC's data and other sources, Rheuban et al. (2016) recently 
completed an analysis of long-term trends in Buzzards Bay's water quality, finding a doubling of water column Chl $a$ (phytoplankton biomass) over a 22-year period. Through long-term coastal water monitoring, a deeper understanding of the relationship between water quality and the supply of ecosystem services would better equip policy- and decision-makers with the capacity to design and implement effective strategies that could enhance the overall sustainability of coastal systems (Halpern et al., 2012).

\subsubsection{Linkage between water quality and recreational shellfishing}

Due to the historic importance of fisheries to coastal communities, the study of water quality often has been motivated by its potential economic consequences. Early scientific studies of eutrophication as a threat to marine ecosystems involved trying to understand relationships between occurrences of dense algal blooms and concomitant declines of shellfisheries in Moriches Bay, Long Island, NY (Ryther, 1954). More recently, water quality studies have sought to estimate the economic consequences of changes in water quality (Leggett and Bockstael, 2000). The economic values for some ecosystem services, such as opportunities for nature viewing or recreational fishing trips, can be difficult to quantify because of the absence of markets. By evaluating the goods and services provided by marine coastal ecosystems, it is possible that more credible analyses of the benefits and costs of conserving these services can be undertaken.

In the past, analyses of the effects of water quality measures on cultural ecosystem services, such as recreational shellfishing, have been limited due to the paucity of environmental data (Egan et al., 2009). With the help of groups such as BBC's citizen scientist monitoring program, gaps in the long-term measurement of water quality now are being filled. To begin to understand how recreational shellfishers respond to changes in environmental and socioeconomic conditions, recreational shellfish permit sales were examined in Buzzards Bay during 1992 to 2015 as part of this study.

One common problem arising in water quality studies involves the collinear nature of water quality parameters. Solutions to this problem range from the use of only a subset of water quality parameters to develop aggregate indices of water quality. An example of the former was an application by Liu et al. (2017), who examined changes in the implicit price of coastal housing near Narragansett Bay, Rhode Island, using the concentration of Chl $a$ as an indicator of water quality. As an example of the use of aggregate indices, Ribaudo and Piper (1991) evaluated the impacts of national water quality policies on participation in recreational fishing with a water quality index that examined whether regional total suspended solids, total nitrogen, and total phosphorus concentrations were at concentrations that could impair recreational fishing. More recently, Walsh and Milon (2016) explored how the alternative use of either sole or aggregate nutrient indicators could affect estimates of the potential economic benefits of water quality regulations. These authors found that that an aggregate indicator of water quality helped to explain an observed negative relationship between excess nutrients in the water column and property prices.

In contrast to these earlier efforts, this study employed a partial least squares (PLS) approach to adjust for the near-collinearity of the full array of water quality variables. The PLS 
regression combines characteristics of principal component analysis (PCA) and multiple linear regression by extracting latent variables - linear combinations of the original explanatory variables - that maximize the covariance between the explanatory and response variables (Abdi, 2010). The latent variables then are used in a linear regression for parameter estimation. The number of latent variables used within the regression is user-defined ( $\mathrm{Li}$ et al., 2002), effectively reducing the number of parameters used in the regression. The PLS regression methodology has been used previously in the field of computational chemistry to handle datasets with numerous correlated independent variables that could potentially result in "overfitting" (Wold et al., 2001). Geladi and Kowalski (1986) provide a clear mathematical derivation of the PLS regression methodology. Relying upon a unique and extensive water quality dataset, this study examined how water quality measures, in combination with measures of socioeconomic condition, could be applied to develop estimates of the effects of water quality degradation or improvement. More specifically, using town records of recreational shellfish permit sales, this study tested hypotheses related to the extent to which permit sales correlated with local water quality, shellfish landings, and socioeconomic conditions.

When individuals make decisions about purchasing recreational shellfish permits, they assess the expected net benefits of shellfishing during the year, considering the benefits of this form of leisure and taking into account the relevant costs (such as travel time or fuel costs), availability of shellfish resources, gear purchases, or permit prices. Diminished water quality in the Bay can reduce both the perceived and actual net benefits of recreational shellfishing in several ways. Under the National Shellfish Sanitation Program, regulators close bacteria-impaired shellfish growing areas year-round, seasonally or conditionally based on rainfall amounts. Depending upon their timing and location, these closures can have an important effect on recreational shellfishing because most permit holders do not own boats, and public access to shellfish beds often is limited to certain locations. The total area of shellfish bed closures has increased in some parts of Buzzards Bay and diminished in others during the past thirty years. While bacterial pollution can result in shellfish bed closures, eutrophication can cause changes in the physical appearance of the estuary and lead to declines in shellfish biomass and species composition. Consequently, in this study, indicators of eutrophication, such as $\mathrm{Chl} a$, were hypothesized to be negatively correlated with permit sales.

These examples comprise only some of the pathways where diminished water quality could adversely affect the recreational shellfishing experience and individual decisions to purchase permits in current or subsequent years. Local demographics or economic conditions also may be important in determining recreational demand; population growth and increased disposable income (lower unemployment) could potentially lead to increased recreation. By including water quality indicators, general environmental conditions (e.g., precipitation levels), and socioeconomic characteristics, such a comprehensive modeling technique arguably could explain changes in the value of recreational shellfishing that are applicable more generally to other locations and on a larger geographic scale. This modeling framework can provide opportunities to apply this type of 
water quality analysis to a more expansive set of ecosystem goods and services, rendering economic values that may be tangible even within the global economy.

\subsection{METHODS}

\subsubsection{Water quality monitoring}

In Buzzards Bay, the BBC citizen science sampling program is carried out from late May to early September, with the highest frequency of sampling occurring during the summer months of July and August (Williams and Neill, 2014). The BBC water quality sampling is limited to the summer months because the program design and allocated funding was intended to capture the expected exacerbation of poor water quality conditions occurring during the summer plankton bloom season. During 1992-2015, measurements of nitrate and nitrite $\left(\mathrm{NO}_{3}{ }^{-}+\mathrm{NO}_{2}{ }^{-}\right)$, ammonium $\left(\mathrm{NH}_{4}{ }^{+}\right)$, temperature (T), salinity, dissolved oxygen (DO), Chlorophyll $a$ (Chl $a$ ), particulate organic carbon (POC), dissolved organic nitrogen (DON), particulate organic nitrogen (PON), and phaeopigments were collected from 27 Buzzards Bay embayments. Among these, 14 overlapped with the five towns that had complete shellfish permit data sets during 1992-2015 (Bourne, Falmouth, Marion, Wareham, and Westport; Fig. 1). These data were analyzed both individually and as a group.

\subsubsection{Recreational shellfishing permits}

Massachusetts coastal municipalities manage shellfisheries on the state's tidelands, which generally fall within $6 \mathrm{~km}$ ( $3 \mathrm{nmi})$ of the coast. The individual municipalities allocate shellfishing between commercial and recreational users. In Buzzards Bay, harvesting shellfish either commercially or recreationally requires a permit issued by the relevant municipality (Mass. Gen. Laws chap. 130 sec. 52). Recreational permits are issued annually, and they are priced differentially across residents, nonresidents, and seniors. The date of first issuance of permits varies across towns, but generally, issuance occurs during the calendar year. This study utilized and updated recreational shellfishing permit data compiled by the Buzzards Bay National Estuary Program (BBNEP, 2018). These data contain municipal records of annual recreational and commercial permit sales. Shellfish landings broken down by species also are included (Table 1). Because the data were not fully up to date, municipal shellfish wardens were contacted to bring the series forward, resulting in a comprehensive permit dataset for the five towns, spanning from 1970 to 2015.

\subsubsection{Benefits transfer}

The economic valuation of ecosystem services can be time-consuming and costly, and analysts often rely upon studies conducted at other times and locations, using methods of "benefits transfer" (Plummer, 2009). Benefits transfer involves the application of estimates of the economic value of ecosystem services from prior studies to similar services arising from an unstudied location or time. The methodology of benefits transfer often has been criticized, because transfers can be sensitive to contextual differences across studied and unstudied locations or times. Varying 
environmental and demographic characteristics or spatial and temporal changes in preferences can render benefits transfer problematic and uncertain. Here, an earlier study of the benefits per permit of recreational shellfishing carried out on Cape Cod (Damery and Allen, 2004) was relied upon. Due to proximity, geographic overlaps (e.g., the Cape Cod study included both Bourne and Falmouth, which are two of the five towns in this study), and similarities in coastal environmental conditions, the transfer of economic benefits from values estimated for Cape Cod arguably provide credible estimates of changes in the benefits of recreational shellfishing in Buzzards Bay.

Damery and Allen (2004) developed estimates of both willingness-to-pay (WTP) to purchase unowned shellfishing permits and willingness-to-accept (WTA) compensation for giving up already-purchased permits. Averaging across Cape Cod towns, the estimates (in 2017 US dollars) ranged from a WTP of $\$ 79.25 \pm 12.33$ (all intervals reported in this study comprised $95 \%$ confidence intervals) per permit to a WTA of $\$ 626.75 \pm 19.21$ per permit (Table 2). During the 2002 study period, 16,109 permits were sold on Cape Cod. Applying the range of estimates to the number of permits, the annual total benefits of recreational shellfishing on Cape Cod ranged from \$1.4-10.0 million, implying asset values of \$47-333 million (using a discount rate of 3\%)

\subsubsection{Auxiliary data}

To incorporate other socioeconomic and biophysical drivers that could affect recreational shellfishing, auxiliary data were compiled. Socioeconomic data, including population, unemployment rate, and size of the labor force, were acquired from the Massachusetts Division of Local Services, which collects and distributes demographic and economic data on Massachusetts towns. Tourism data were obtained from the National Park Service, which compiled annual Cape Cod National Seashore (CCNS) visits. Additional data included a measure of mean annual summertime precipitation, calculated from the PRISM Spatial Climate Datasets for the Coterminous United States (PRISM, 2004). This data comprised average monthly precipitation from climatologically aided interpolation models at a resolution of $4 \mathrm{~km}$. Mean annual summertime fecal coliform concentrations in municipal waters across Buzzards Bay were obtained from the Massachusetts Department of Marine Fisheries, which conducts biweekly measurements in recreational shellfishing areas to determine their status with respect to human pathogens or toxins throughout the year.

\subsubsection{Data analysis}

A total of 95 sampling stations across the five towns - Bourne, Falmouth, Marion, Wareham, and Westport - were used for the analysis. The majority of BBC water quality sampling occurs within the summer months, principally July and August, thus limiting our data analysis to that period for the years from 1992 to 2015. To address this data limitation, the relevant months for recreational shellfishing were assumed to have occurred mainly during the summer when weather conditions typically were most favorable. To support this assumption, a survey of recreational shellfishing in Washington's Puget Sound demonstrated that peaks in harvesting activity occurred mainly during the summer months ( $56 \%$ of total harvesters were active) and were 
lower during the winter months (13\% of total harvesters were active) (Anderson and Plummer, 2016). Additionally, it has been observed that summer conditions have led to the exacerbation of poor water quality, resulting in systems that are more prone to hypoxia or anoxia (Moore and Jarvis, 2008; Kemp et al., 2009; Liu et al., 2017). Water quality measurements were averaged to produce mean annual summer (July and August) measurements, and relevant biological indicators such as Chl $a$ were log-transformed prior to averaging due to observed log-normal distributions of the variables (Table 3) (Campbell, 1995).

Linear regression models were developed to characterize decadal trends in water quality and socioeconomic data. Regression models also were developed to quantify relationships between recreational shellfishing permit sales and water quality, shellfish landings, and socioeconomic factors. With respect to the latter relationships, PLS regressions were implemented to mitigate near-collinearities occurring among the water quality variables (Abdi, 2010). The original variables were standardized to have a mean of zero and standard deviation of one (Z-scores) before latent variable construction. For each regression, one latent variable was constructed from a linear combination of the specified predictor variables. This approach addresses the multicollinear nature of the large set of predictor variables by reducing the number of parameters used in the linear regression to a singular latent variable. $95 \%$ confidence intervals and standard errors of the coefficients were obtained through bootstrap re-sampling (Abdi, 2010). Finally, regression coefficients for the original explanatory variables were computed from the estimated ordinary least squares coefficients on the latent variables and the associated weights used to calculate the latent variable. The PLS regression was implemented with the plsRglm R program (Bertrand et al., 2011).

A two-stage modeling approach was carried out. With this approach, water quality was tested to see if it might affect permit sales either directly and/or indirectly by influencing total shellfish landings. Ex ante, it is unclear which way such an indirect effect might work, and any effect might depend upon local ambient environmental conditions. For example, increases in nutrients and primary production might help to grow filter-feeding shellfish stocks, leading to increased landings. Once a eutrophication threshold was reached, however, hypoxic or low $\mathrm{pH}$ conditions could increase the natural mortality of shellfish, leading to a reduction of stocks. Regardless of the direction of the effect, if measures of water quality are not included explicitly in the model, then their effect would be subsumed in the model's error.

$$
\begin{aligned}
\text { Total Shellfish } & =\beta_{1}(\text { Environmental Variables })+\varepsilon_{1} \\
\begin{aligned}
\text { Recreational Permits } \\
\text { Sold Per Capita }
\end{aligned} & \left.\beta_{2} \text { (Predicted Landings }\right)+\beta_{3} \text { (Socioeconomic Variables) } \\
& +\beta_{4}(\text { Environmental Variables })+\varepsilon_{2}
\end{aligned}
$$

In the first stage, shellfish landings were regressed on environmental variables, using a PLS regression (Eq. (1)). Estimated shellfishing landings obtained from the first stage were then incorporated as a predictor variable along with socioeconomic and environmental variables in the second stage, using a PLS regression (Eq. (2)). We utilize predicted shellfish landings to capture the variations in water quality variables that were significantly correlated with shellfish landings 
in the first stage. $\varepsilon 1$ and $\varepsilon 2$ represent the model errors for each stage. This type of model has been applied to analyze the effects of the environment on civil conflicts in Sub-Saharan Africa, where temperature was found to affect conflict both directly and indirectly through agricultural yields (cf., Jun, 2017). In that model, a two-stage approach also was taken, estimating crop yield with environmental variables in the first stage and adding environmental variables as explanatory variables in the second stage.

In the discussion below of the impacts of water quality on recreational permit sales, the Chl $a$ parameter was highlighted due to its large influence within the model relative to the other water quality variables. Additionally, Chl $a$ is not only an important indicator of eutrophication: high concentrations of $\mathrm{Chl} a$ often result in decreased water transparency, potentially affecting perceptions of water quality. Other parameters within the models also were significant, illustrating that there were measurable changes in recreational permit sales associated with variations in those variables as well.

\subsection{RESULTS}

\subsubsection{Summary statistics}

Aggregating the data from the BBC sampling stations into annual summer town-level means allowed for the analysis of water quality patterns on temporal and spatial scales relevant to recreational shellfishing activity in Buzzards Bay. A map of the designated shellfish growing areas overlain with BBC sampling stations (Fig. 1) showed that the water quality measurements were collected from viable recreational shellfishing areas. Table 3 provides descriptive statistics regarding the water quality and socio-economic variables.

\subsubsection{Year trend analysis}

Decadal trends of certain water quality variables, such as temperature, $\mathrm{Chl} a$, salinity, and particulate organic nitrogen $(\mathrm{PON})$, exhibited statistically significant, non-zero values $(\mathrm{p}<0.05)$ across individual towns and all towns taken together (Table 4) (Rheuban et al., 2016). On average, across all towns, temperature increased $0.62 \pm 0.38{ }^{\circ} \mathrm{C}$ per decade. For certain towns, such as Westport, the temperature trend was higher at $1.08 \pm 0.60{ }^{\circ} \mathrm{C}$ per decade. There was a significant positive trend in Chl $a$ across all towns of $0.15 \pm 0.08 \log _{10}\left(\mathrm{Chl} a ; \mathrm{mg} \mathrm{m}^{-3}\right)$ per decade. PON exhibited a similar positive time trend of $0.05 \pm 0.03 \log _{10}(\mathrm{PON} ; \mu \mathrm{M})$ per decade across all towns. Salinity decreased significantly throughout the years across all towns, with a decrease of $0.79 \pm$ $0.73 \mathrm{ppt}$ per decade. Analysis of the relationship between precipitation and salinity illustrated a significant $(\mathrm{p}<0.05)$ negative correlation, an increase of $1 \mathrm{~mm}$ of mean annual summertime precipitation correlated with a decrease in salinity of $0.018 \pm 0.016 \mathrm{ppt}$.

Socioeconomic factors also exhibited distinct spatial and temporal trends (Table 5). Population increased $(\mathrm{p}<0.05)$ by 5,042 $\pm 1,160$ individuals per decade summed across all towns, with increases varying in magnitude across towns. Bourne illustrated the largest population increase of $1448 \pm 288$. There were no significant trends in unemployment rate. Total and per

capita recreational shellfishing permit sales exhibited decreasing time trends on average across all 
towns. On average across all towns, recreational shellfishing permit sales decreased by $437 \pm 241$ permits per decade $(\mathrm{p}<0.05)$, which is $16 \%$ of the average recreational shellfishing permit sales for the five towns. The decreases were significant for towns such as Marion and Wareham where the decrease in permit sales during 1992-2015 was 59\% and $42 \%$ of their average permit sales, respectively.

\subsubsection{Permit sales, shellfish landings, and water quality}

The first stage of the regression analysis demonstrated relationships between Chl $a$ and total shellfish landings (Table 6; Eq. (1)). Within this set of regressions, Chl $a$ was negatively associated with the shellfish landings estimate across all towns, Bourne, Marion, Wareham, and Westport. Within the regression across all towns, the coefficient for $\mathrm{Chl} a$ is the largest relative to the other water quality predictor variables, illustrating a larger change in total shellfish landings associated with variations in $\mathrm{Chl} a$. Additionally, PON and POC were negatively associated with total shellfish landings across all towns taken together, and in Falmouth and Wareham.

The second stage of the regression analysis illustrated that across all towns taken together, as well as in Bourne, Marion, Wareham, and Westport, shellfish landings were positively related to permit sales per capita (Table 7). In contrast, the town of Falmouth had a negative correlation between predicted shellfish landings and permit sales per capita, and an explanation of this difference is broached in the discussion. Chl $a$ was negatively associated with the number of permits sold per capita across all towns and in each of the individual Buzzards Bay towns. CCNS visits was consistently positively correlated with the number of permits sold per capita. Across the Buzzards Bay towns, increases in Chl $a$ during the 24-year period were associated with a decrease in recreational permit sales of $322 \pm 195$ per decade (Table 8 ).

\subsection{DISCUSSION}

The two-stage approach allowed for an exploration of the potential pathways through which water quality might influence permit sales. In particular, water quality was hypothesized to influence shellfish landings, which in turn could influence permit sales. In the model's first stage, water quality measures were found to be significant predictors of total shellfish landings across all towns. Increases in $\mathrm{Chl} a$, a measure of phytoplankton biomass and potential eutrophic conditions, were associated with decreases in shellfish landings. In the second stage, predicted shellfish landings from the first stage, which captured the indirect effect of water quality, in combination with socioeconomic measures and the direct effect of water quality measures were shown to help explain permit sales (Table 7). Low shellfish yields were related to decreases in permit sales in all cases with the notable exception of the Town of Falmouth. One possible explanation for the different result in Falmouth is that recreational shellfish catch is a much smaller percentage of total catch compared to other towns. Additionally, Falmouth has initiated a robust oyster seeding and relay program where the majority of raised shellfish are relayed to areas where only recreational shellfishing is allowed. This type of intervention could potentially cause a deviation from the expected impacts of water quality on the demand for recreational shellfish. Across all towns within 
the study period, increases in Chl $a$ led to an estimated decrease in permit sales of $322 \pm 195$ per decade ( $74 \%$ directly and $26 \%$ indirectly through shellfish landings). The use of predicted shellfish landings from the first stage allowed a teasing apart of the relationship between water quality and permit sales to help characterize the potential that water quality could influence permit sales both directly and indirectly through landings.

\subsubsection{Indirect impacts of water quality on permit sales}

The first stage of the model demonstrated the indirect impact of water quality on permit sales through shellfish landings (Table 6). Increases in phytoplankton biomass in the water column can have mixed effects on shellfish abundance. Habitat degradation as a result of eutrophication can negatively affect shellfish, such as the bay scallop Argopecten irradians, which is a suspension feeder. On the other hand, increases in the quantity and quality of food resources for suspension feeders (as evidenced by higher levels of $\mathrm{Chl} a$ ) also could result in increases in shellfish growth rates (Shriver et al., 2002). The net negative effect of increased mean annual summertime Chl $a$ concentration on both total shellfish landings and permit sales suggests that the habitat degradation effect likely overrides enhanced shellfish growth in Buzzards Bay.

\subsubsection{Direct impacts of water quality on recreational permit sales}

The second stage of the two-stage model illustrated that water quality parameters such as PON, POC, Chl $a$, and salinity have the potential to influence permit sales outside of the predicted shellfish landings variable (Table 7). The biological components of summer water quality, PON, POC, and Chl $a$ were consistently negatively correlated with recreational shellfishing permits per capita (Table 7). These variables can be interpreted as measures of estuarine eutrophication; for example, Chl $a$ comprises phytoplankton biomass, while PON and POC are proxies for either planktonic biomass or detrital matter. In the embayments and nearshore regions of shallow coastal estuaries such as Buzzards Bay, increased phytoplankton biomass is predominantly a result of increased nutrient loading from coastal residences or businesses (septic systems and partially treated wastewater) and agricultural activities (fertilizer), supplying nitrogen and phosphorus species to nitrogen-limited waters (Williamson et al., 2017; Valiela and Costa, 1988). Townaveraged decadal water quality trends demonstrated significant growth in mean annual summertime concentrations of Chl $a$ in Buzzards Bay, $0.15 \pm 0.08 \log _{10}\left(\mathrm{Chl} a ; \mathrm{mg} \mathrm{m}^{-3}\right)$ per decade. This value similar to and within error of the Chl $a$ trend (mean rate of $0.17 \pm 0.09 \log _{10}(\mathrm{Chl} a ; \mathrm{mg}$ $\mathrm{m}^{-3}$ ) per decade) determined on a larger spatial scale across 17 embayments within Buzzards Bay (Rheuban et al., 2016). Eutrophic conditions in coastal waters could be noticeable in a variety of ways, such as through the discoloration of the water column or a decline in shellfish stocks. Based on the results of the second stage, indicators of eutrophication were correlated directly with a decline in recreational shellfish permit sales. Further, this finding is very likely conservative, as the consequences of eutrophication for coastal communities would include not only reduced benefits from shellfishing but also from other coastal recreational activities, such as beachgoing, swimming, or saltwater sportfishing (Keeler et al., 2012). 
The effect of shellfish closures on permit sales was modeled by including precipitation and fecal coliform variables. Regulators close bacterial impaired shellfish growing areas based on rainfall amounts, bacterial contamination, oil spills, and storm events. Local authorities are responsible for openings and closures of shellfish beds, resulting in heterogeneity across towns on conditions that warrant a closure. Interestingly, the precipitation variable was insignificant $(\mathrm{p}>$ 0.05) across all regressions within the second stage. Especially considering the fact that precipitation levels and fecal coliform concentrations lacked significance across the combined Buzzards Bay towns, this suggested that shellfish bed closures played a relatively minor role in driving permit sales over the study period. Rather, the eutrophication indicator $\mathrm{Chl} a$ demonstrated a significant and large impact on permit sales across Buzzards Bay towns.

It is important to reflect on how interactions between nutrient loadings, physical drivers, and a changing climate lead to increases in coastal eutrophication. Freshwater characterized by low salinity, such as groundwater or precipitation runoff, conveys nutrients and bacteria to coastal embayments. This trend is important in the context of the US Northeast, which has experienced both an increase in precipitation levels by $>10 \%$ since the late 1800 s and a $71 \%$ increase in the volume of rainfall within the top $1 \%$ of rainfall events (Horton et al., 2014). Moreover, Williamson et al. (2017) found that, due to summertime warming and altered precipitation patterns, estuarine responses to nitrogen loading may have changed over time, leading to increasing yields of Chl $a$ per unit total nitrogen load during 1992-2013. Importantly, studies have observed inverse correlations between salinity and nutrient concentrations, attributed to the mixing of low-salinity, high-nutrient water masses with high-salinity, low-nutrient water masses (Valiela and Costa, 1988). The degree of mixing of water masses comprising high and low nutrient levels thereby may modulate overall nutrient loading, and this process can be significant for shallow coastal estuaries like Buzzards Bay. The results of the second-stage regressions support this intuition, as permit sales were correlated positively with salinity across all towns and for the individual towns of Falmouth, Marion, Wareham, and Westport.

The modeling approaches carried out here yielded mixed results with respect to the effects of mean annual summertime concentrations of dissolved inorganic species of nitrogen such as $\mathrm{NH}_{4}{ }^{+}$and $\left[\mathrm{NO}_{3}{ }^{-}+\mathrm{NO}_{2}{ }^{-}\right]$in explaining the variability in total shellfish landings and permit sales. The biological components of water quality, PON, POC, Chl $a$, were consistently negatively related to shellfish landings and permit sales. Rheuban et al. (2016) found that the biological component of water quality and dissolved inorganic nitrogen were decoupled in the water column, indicating that excess inorganic nutrients were efficiently take up into biological and detrital reservoirs. This highlights the importance of the local composition of primary producers and the interactions between biophysical drivers (temperature, precipitation) and nutrient loadings that influence the biology within the system, resulting in a change in the delivery of ecosystem services. In a world with a changing climate, it is important to understand the intricate relationships between patterns of anthropogenic nutrient loading and ecological processes.

\subsubsection{Benefits transfer}


To communicate the significance of healthy coastal marine ecosystems to the public, it is critical to characterize how changes in water quality might lead to gains or losses in human welfare. A key aspect of this study was to obtain estimates of changes in the net benefits of recreational shellfishing due to variations in water quality indicators, particularly $\mathrm{Chl} a$. While the full suite of water quality indicators has important implications for ecosystem health, $\mathrm{Chl} a$ is a potentially observable component of water quality that is well documented in its impacts on eutrophication and shellfish mortality. Many water quality indicators, such as salinity or particulate organic nitrogen, can be difficult for people to observe directly within the water column without scientific instrumentation. As the full array of environmental measures becomes more widely publicized and understood, especially through the actions of citizen scientists and the national estuary programs, further efforts to characterize the potential impacts of changes in water quality on human welfare undoubtedly will grow.

The historical positive trends of water-column Chl $a$ in Buzzards Bay are helpful in determining changes in economic values of recreational shellfishing associated with coastal eutrophication and declining water quality over the study period. The water quality trends may not continue into the future, particularly if water quality controls are implemented leading to reduced eutrophication. Across the five Buzzards Bay towns, the results of this study suggest that reducing mean annual summertime concentrations of Chl $a$ could lead to an increase in the cultural ecosystem service benefits from recreational shellfishing. A hypothetical reduction of $0.15 \pm 0.08$ $\log 10\left(\mathrm{Chl} a ; \mathrm{mg} \mathrm{m}^{-3}\right)$ per decade would result in increases in the economic benefits received from recreational shellfishing, ranging from $\$ 25,521$ to $\$ 201,832$ per decade (rows 5 and 6 in Table 8). Annual potential water quality improvements imply asset values ranging from $\$ 0.08 \pm 0.05$ million (WTP) to $\$ 0.67 \pm 0.41$ million (WTA) associated with a hypothetical reduction in Chl $a$ concentrations (calculated at 3\%; rows 7 and 8 in Table 8). Notably, changes in Chl $a$ concentrations are not independent of changes in other water quality parameters, such as PON and POC. The asset value estimates therefore comprise a conservative lower bound on the benefits associated with improvements in water quality conditions. Estimates such as these could help natural resource managers and other stakeholders begin to account for water quality as a supporting ecosystem service, thereby bolstering arguments for improvements.

This study elucidated pathways through which water quality could influence the benefits of recreational shellfishing, and estimated the economic effects associated with changes in water quality measures. While this study focused on the impacts that indicators of eutrophication could have on recreational shellfishing value, there were also other observed significant trends (e.g. increased temperature, decreased salinity) obtained from the comprehensive water quality monitoring program carried out by Buzzards Bay Coalition that could have potential implications for the supply of future ecosystem services from the coastal waters of Buzzards Bay.

\subsection{CONCLUSIONS}

Historically, recreational shellfishing has been a significant cultural ecosystem service provided by Massachusetts bays and estuaries. During the study period, however, both the number 
of shellfish permits sold and shellfish landings have declined in Buzzards Bay. Decisions to purchase recreational shellfish permits depend upon individual perceptions about water quality, seafood safety, and the availability and accessibility of preferred shellfish. Modeling such decisions was beyond the scope of this study. Instead, using a method that extracts information from a large number of collinear environmental measures, diminished water quality was shown to help explain reductions in the capacity of the Buzzards Bay estuary to provide recreation as a cultural ecosystem service. A proxy for apparent pollution $(\mathrm{Chl} a)$ showed the strongest negative relationship with permit sales, and similar relationships also were observed across individual Buzzards Bay towns. Over the 24-year study period, losses of \$0.08-0.67 million in recreational shellfishing benefits were estimated conservatively to be the consequence of declining water quality. The value of goods and services supplied by marine coastal ecosystems can be affected adversely by nutrient over-enrichment and climate changes, and further research quantifying the scales of such losses clearly is warranted.

\section{ACKNOWLEDGEMENTS}

We would like to thank the Buzzards Bay Coalition, the Buzzards Bay National Estuary Program, and the Massachusetts Department of Marine Fisheries for providing data for this analysis. We thank the 1074 citizen volunteers of the Buzzards Bay Coalition who collected the water quality samples and Mark Rasmussen for his leadership in sustaining the Baywatchers Program. Support for this analysis was provided by the John D. and Catherine T. MacArthur Foundation (Grant no. 14-106159-000-CFP), MIT Sea Grant (subaward number 5710004045), the Johnson Endowment of the WHOI Marine Policy Center, and SCD acknowledges support from the University of Virginia. 
Table 1: Summary statistics of annual town averages of total (recreational and commercial) landings of shellfish by species. Displayed statistics are number of observations $(\mathrm{N})$, average value (MEAN), standard deviation (SD), and units (UNITS).

\begin{tabular}{lcccc}
\hline Variables & N & MEAN & SD & UNITS \\
\hline Quahog & 84 & 188 & 149 & Tons \\
Little neck clams & 39 & 88 & 129 & Tons \\
Soft shell clams & 86 & 41 & 51 & Tons \\
Oysters & 94 & 9 & 11 & Tons \\
Bay scallops & 88 & 5 & 20 & Tons \\
Surf clams & 58 & 5 & 13 & Tons \\
Conch & 53 & 3 & 6 & Tons \\
\hline
\end{tabular}


Table 2: Willingness-to-pay (WTP) and willingness-to-accept (WTA) total value estimates (2017 USD) for Cape Cod towns from Damery and Allen (2004). Total value estimates for each town are the sum of permit revenues and consumer surplus estimates from survey estimates of willingness-to-pay (WTP) and willingness-to-accept (WTA). Average value per permit across towns was calculated for each approach. Standard errors are reported for average value per permit.

\begin{tabular}{|c|c|c|c|c|c|c|}
\hline \multicolumn{7}{|c|}{ Willingness to Pay Total Value Estimates } \\
\hline Year & Town & Permit Revenue & Consumer Surplus Estimate & Total Value & Permits Issued & Unit Value Permits \\
\hline 2017 & Barnstable & $\$ 50,707$ & $\$ 91,621$ & $\$ 142,328$ & 1,955 & $\$ 73$ \\
\hline 2017 & Bourne & $\$ 103,390$ & $\$ 155,006$ & $\$ 258,396$ & 2,310 & $\$ 112$ \\
\hline 2017 & Brewster & $\$ 14,863$ & $\$ 32,301$ & $\$ 47,164$ & 689 & $\$ 68$ \\
\hline 2017 & Chatham & $\$ 128,879$ & $\$ 178,047$ & $\$ 306,926$ & 2,775 & $\$ 111$ \\
\hline 2017 & Dennis & $\$ 12,218$ & $\$ 29,675$ & $\$ 41,892$ & 676 & $\$ 62$ \\
\hline 2017 & Eastham & $\$ 39,164$ & $\$ 72,375$ & $\$ 111,539$ & 1,532 & $\$ 73$ \\
\hline 2017 & Falmouth & $\$ 50,035$ & $\$ 91,841$ & $\$ 141,876$ & 1,951 & $\$ 73$ \\
\hline 2017 & Harwich & $\$ 7,000$ & $\$ 20,849$ & $\$ 27,849$ & 466 & $\$ 60$ \\
\hline 2017 & Mashpee & $\$ 14,551$ & $\$ 30,032$ & $\$ 44,582$ & 688 & $\$ 65$ \\
\hline 2017 & Orleans & $\$ 45,628$ & $\$ 61,931$ & $\$ 107,559$ & 984 & $\$ 109$ \\
\hline 2017 & Provincetown & $\$ 1,731$ & $\$ 6,742$ & $\$ 8,474$ & 162 & $\$ 52$ \\
\hline 2017 & Truro & $\$ 2,505$ & $\$ 7,890$ & $\$ 10,395$ & 169 & $\$ 62$ \\
\hline 2017 & Wellfleet & $\$ 33,107$ & $\$ 51,230$ & $\$ 84,337$ & 684 & $\$ 123$ \\
\hline 2017 & Yarmouth & $\$ 22,325$ & $\$ 49,573$ & $\$ 71,898$ & 1,068 & $\$ 67$ \\
\hline
\end{tabular}

\begin{tabular}{|lc|}
\hline Summary Table \\
\hline Cape Cod Total Value & $\$ 1,405,215$ \\
\hline Average Value Per Permit & $\$ 79.25 \pm 6.29$ \\
\hline
\end{tabular}

Willingness To Accept Total Value Estimates

\begin{tabular}{|c|c|c|c|c|c|c|}
\hline Year & Town & Permit Revenue & Consumer Surplus Estimate & Total Value & Permits Issued & Unit Value Permits \\
\hline 2017 & Barnstable & $\$ 50,707$ & $\$ 1,239,641$ & $\$ 1,290,348$ & 1,955 & $\$ 660$ \\
\hline 2017 & Bourne & $\$ 103,390$ & $\$ 1,406,997$ & $\$ 1,510,386$ & 2,310 & $\$ 654$ \\
\hline 2017 & Brewster & $\$ 14,863$ & $\$ 422,696$ & $\$ 437,559$ & 689 & $\$ 635$ \\
\hline 2017 & Chatham & $\$ 128,879$ & $\$ 1,418,073$ & $\$ 1,546,951$ & 2,775 & $\$ 557$ \\
\hline 2017 & Dennis & $\$ 12,218$ & $\$ 427,427$ & $\$ 439,645$ & 676 & $\$ 650$ \\
\hline 2017 & Eastham & $\$ 39,164$ & $\$ 904,141$ & $\$ 943,305$ & 1,532 & $\$ 616$ \\
\hline 2017 & Falmouth & $\$ 50,035$ & $\$ 1,195,248$ & $\$ 1,245,282$ & 1,951 & $\$ 638$ \\
\hline 2017 & Harwich & $\$ 7,000$ & $\$ 281,283$ & $\$ 288,284$ & 466 & $\$ 619$ \\
\hline 2017 & Mashpee & $\$ 14,551$ & $\$ 436,905$ & $\$ 451,455$ & 688 & $\$ 656$ \\
\hline 2017 & Orleans & $\$ 45,628$ & $\$ 487,090$ & $\$ 532,718$ & 984 & $\$ 541$ \\
\hline 2017 & Provincetown & $\$ 1,731$ & $\$ 101,909$ & $\$ 103,641$ & 162 & $\$ 640$ \\
\hline 2017 & Truro & $\$ 2,505$ & $\$ 100,125$ & $\$ 102,630$ & 169 & $\$ 607$ \\
\hline 2017 & Wellfleet & $\$ 33,107$ & $\$ 406,885$ & $\$ 439,993$ & 684 & $\$ 643$ \\
\hline 2017 & Yarmouth & $\$ 22,325$ & $\$ 679,579$ & $\$ 701,904$ & 1,068 & $\$ 657$ \\
\hline
\end{tabular}


Table 3: Summary statistics of town averages for variables used for regression analysis. Displayed statistics are number of observations $(\mathrm{N})$, average value (MEAN), standard deviation (SD), and the units of the variable (UNITS). Cape Cod National Seashore visits is a 1992-2015 dataset that is not town specific.

\begin{tabular}{|c|c|c|c|c|}
\hline Variables & $\mathrm{N}$ & MEAN & SD & UNITS \\
\hline Recreational shellfish permits & 120 & 1341 & 658 & Permits \\
\hline Recreational shellfish permits per capita & 120 & 0.08 & 0.03 & Permits per capita \\
\hline Recreational shellfish landings & 94 & 56 & 66 & Tons \\
\hline Commercial shellfish landings & 95 & 176 & 171 & Tons \\
\hline Total shellfish landings & 94 & 235 & 192 & Tons \\
\hline Population & 120 & 18,266 & 8775 & People \\
\hline Unemployment rate & 120 & 6.52 & 2.66 & $\%$ \\
\hline Cape Cod National Seashore visits & 24 & $4,582,000$ & 362,304 & People \\
\hline Fecal coliform & 119 & 8.61 & 5.73 & $\mathrm{cfu} / 100 \mathrm{~mL}$ \\
\hline Precipitation & 120 & 88.79 & 33.21 & $\mathrm{~mm}$ \\
\hline PON & 119 & 0.98 & 0.10 & $\log _{10}(\mu \mathrm{M})$ \\
\hline POC & 119 & 1.85 & 0.16 & $\log _{10}(\mu \mathrm{M})$ \\
\hline Chlorophyll $a$ & 119 & 0.66 & 0.21 & $\log _{10}\left(\mathrm{mg} \mathrm{m}^{-3}\right)$ \\
\hline Temperature & 120 & 23.26 & 1.05 & ${ }^{\circ} \mathrm{C}$ \\
\hline $\mathrm{PO}_{4}{ }^{3-}$ & 119 & -0.17 & 0.15 & $\log _{10}(\mu \mathrm{M})$ \\
\hline $\mathrm{NH}_{4}^{+}$ & 119 & -0.01 & 0.24 & $\log _{10}(\mu \mathrm{M})$ \\
\hline $\mathrm{NO}_{3}^{-}+\mathrm{NO}_{2}^{-}$ & 119 & -0.43 & 0.34 & $\log _{10}(\mu \mathrm{M})$ \\
\hline $\mathrm{O}_{2}$ saturation & 120 & 0.85 & 0.07 & $\%$ \\
\hline DON & 119 & 1.32 & 0.13 & $\log _{10}(\mu \mathrm{M})$ \\
\hline Salinity & 120 & 28.01 & 2.31 & ppt \\
\hline
\end{tabular}


Table 4: Linear regression analysis to illustrate decadal time trends of annual mean summer water quality across all towns and individual towns. Slopes of linear regressions are expressed as units per decade. Standard errors (SE), p-values, $\mathrm{R}^{2}$ values, and observations (n) are reported. Bolded coefficients are significant at the $5 \%$ level.

\begin{tabular}{|c|c|c|c|c|c|}
\hline \multirow[b]{2}{*}{ Town } & \multicolumn{5}{|c|}{ Temperature $\left({ }^{\circ} \mathrm{C}\right)$} \\
\hline & slope & SE & $\mathrm{p}$-value & $r^{2}$ & $\mathrm{n}$ \\
\hline All Towns & 0.62 & 0.19 & $<<0.01$ & 0.32 & 24 \\
\hline Bourne & 0.36 & 0.25 & 0.17 & 0.09 & 24 \\
\hline Falmouth & 0.65 & 0.20 & $<<0.01$ & 0.32 & 24 \\
\hline Marion & 0.12 & 0.30 & 0.69 & 0.01 & 24 \\
\hline Wareham & 0.90 & 0.19 & $<<0.01$ & 0.51 & 24 \\
\hline \multirow[t]{2}{*}{ Westport } & 1.08 & 0.31 & $<<0.01$ & 0.36 & 24 \\
\hline & \multicolumn{5}{|c|}{ Salinity (ppt) } \\
\hline Town & slope & $\mathrm{SE}$ & $\mathrm{p}$-value & $r^{2}$ & $\mathrm{n}$ \\
\hline All Towns & -0.79 & 0.37 & 0.05 & 0.17 & 24 \\
\hline Bourne & -0.11 & 0.32 & 0.74 & 0.01 & 24 \\
\hline Falmouth & -0.28 & 0.30 & 0.36 & 0.04 & 24 \\
\hline Marion & -1.17 & 0.41 & 0.01 & 0.28 & 24 \\
\hline Wareham & -1.21 & 0.47 & 0.02 & 0.23 & 24 \\
\hline Westport & -1.16 & 0.72 & 0.12 & 0.11 & 24 \\
\hline
\end{tabular}

\begin{tabular}{|c|c|c|c|c|c|}
\hline \multirow[b]{2}{*}{ Town } & \multicolumn{5}{|c|}{$\log _{10}\left(\mathrm{Chl} a\left(\mathrm{mg} \mathrm{m}^{-3}\right)\right)$} \\
\hline & slope & SE & p-value & $r^{2}$ & $n$ \\
\hline All Towns & 0.15 & 0.04 & $<<0.01$ & 0.40 & 24 \\
\hline Bourne & 0.16 & 0.04 & $<<0.01$ & 0.38 & 24 \\
\hline Falmouth & 0.18 & 0.04 & $<<0.01$ & 0.54 & 24 \\
\hline Marion & 0.08 & 0.05 & 0.16 & 0.09 & 23 \\
\hline Wareham & 0.15 & 0.04 & $<<0.01$ & 0.38 & 24 \\
\hline \multirow[t]{2}{*}{ Westport } & 0.14 & 0.05 & 0.01 & 0.29 & 24 \\
\hline & \multicolumn{5}{|c|}{$\left.\log _{10} P O N(\mu M)\right)$} \\
\hline Town & slope & SE & $\mathrm{p}$-value & $r^{2}$ & $\mathrm{n}$ \\
\hline All Towns & 0.05 & 0.02 & 0.01 & 0.29 & 24 \\
\hline Bourne & 0.03 & 0.02 & 0.08 & 0.13 & 24 \\
\hline Falmouth & 0.07 & 0.02 & $<<0.01$ & 0.39 & 24 \\
\hline Marion & 0.04 & 0.03 & 0.13 & 0.10 & 23 \\
\hline Wareham & 0.06 & 0.02 & $<<0.01$ & 0.39 & 24 \\
\hline Westport & 0.02 & 0.02 & 0.32 & 0.05 & 24 \\
\hline
\end{tabular}


Table 5: Linear regression analysis to illustrate decadal trends in socioeconomic variables used in the analysis. Slopes of linear regressions are expressed as units per decade. Standard errors (SE), $\mathrm{p}$-values, $\mathrm{R}^{2}$ values, and observations (n) are reported. Bolded coefficients are significant at the $5 \%$ level.

\begin{tabular}{|c|c|c|c|c|c|}
\hline \multirow[b]{2}{*}{ Town } & \multicolumn{5}{|c|}{ Population (People) } \\
\hline & slope & SE & p-value & $r^{2}$ & $\mathrm{n}$ \\
\hline All Towns & 5,042 & 592 & $\ll<0.01$ & 0.77 & 24 \\
\hline Bourne & 1,448 & 147 & $<<0.01$ & 0.82 & 24 \\
\hline Falmouth & 1,184 & 434 & 0.01 & 0.25 & 24 \\
\hline Marion & 73 & 57 & 0.21 & 0.07 & 24 \\
\hline Wareham & 1,409 & 81 & $<<0.01$ & 0.93 & 24 \\
\hline Westport & 928 & 48 & $<<0.01$ & 0.95 & 24 \\
\hline
\end{tabular}

\begin{tabular}{|c|c|c|c|c|c|}
\hline \multirow[b]{2}{*}{ Town } & \multicolumn{5}{|c|}{ Recreational Shellfish Permits (Number of Permits) } \\
\hline & slope & SE & p-value & $r^{2}$ & $\mathrm{n}$ \\
\hline All Towns & -437 & 123 & $<<0.01$ & 0.36 & 24 \\
\hline Bourne & 29 & 83 & 0.73 & 0.01 & 24 \\
\hline Falmouth & -16 & 55 & 0.77 & 0.00 & 24 \\
\hline Marion & -124 & 22 & $<<0.01$ & 0.60 & 24 \\
\hline Wareham & -256 & 59 & $<<0.01$ & 0.46 & 24 \\
\hline Westport & -70 & 18 & $<<0.01$ & 0.42 & 24 \\
\hline
\end{tabular}


Table 6: Estimated parameters with standard errors (in parentheses) for the first stage PLS regression, comprising environmental variables. Displayed in the columns are regressions using data for all five towns ("All Towns") and for each town individually. Coefficients at $10 \%$ and 5\% significance level are indicated by * and **, respectively.

\begin{tabular}{|c|c|c|c|c|c|c|}
\hline \multirow[t]{2}{*}{ Independent variables } & \multicolumn{6}{|c|}{ Dependent variable: total shellfish landings } \\
\hline & All Towns & Bourne & Falmouth & Marion & Wareham & Westport \\
\hline \multirow[t]{2}{*}{ Fecal coliform } & 0.048 & 0.049 & 0.136 & $-0.277^{* *}$ & $0.089^{*}$ & 0.069 \\
\hline & $(0.046)$ & $(0.073)$ & $(0.148)$ & $(0.064)$ & $(0.051)$ & $(0.114)$ \\
\hline \multirow[t]{2}{*}{ Precipitation } & 0.005 & -0.023 & -0.043 & -0.051 & 0.025 & 0.076 \\
\hline & $(0.042)$ & $(0.069)$ & $(0.092)$ & $(0.085)$ & $(0.061)$ & $(0.094)$ \\
\hline \multirow[t]{2}{*}{ PON } & $-0.088^{* *}$ & -0.068 & $-0.563^{* * *}$ & 0.018 & $-0.227^{* *}$ & -0.028 \\
\hline & $(0.036)$ & $(0.055)$ & $(0.094)$ & $(0.096)$ & $(0.039)$ & (0.104) \\
\hline \multirow[t]{2}{*}{ POC } & $-0.080^{*}$ & -0.034 & $-0.680^{* *}$ & 0.126 & $-0.283^{* *}$ & -0.008 \\
\hline & $(0.048)$ & $(0.080)$ & $(0.092)$ & $(0.106)$ & $(0.039)$ & $(0.106)$ \\
\hline \multirow[t]{2}{*}{ Chl $a$} & $-0.155^{* *}$ & $-0.157^{* *}$ & 0.036 & $-0.239 * *$ & $-0.191 * *$ & $-0.226^{* *}$ \\
\hline & $(0.037)$ & $(0.078)$ & $(0.081)$ & $(0.084)$ & $(0.046)$ & $(0.106)$ \\
\hline \multirow[t]{2}{*}{ Temperature } & 0.001 & $-0.101^{*}$ & 0.070 & $0.240^{* *}$ & $-0.136^{* *}$ & $0.230^{*}$ \\
\hline & $(0.061)$ & $(0.058)$ & $(0.120)$ & $(0.093)$ & $(0.042)$ & $(0.133)$ \\
\hline \multirow[t]{2}{*}{$\mathrm{PO}_{4}{ }^{3-}$} & $0.101^{* *}$ & $0.108^{*}$ & 0.000 & 0.121 & 0.057 & $0.223^{* *}$ \\
\hline & $(0.043)$ & $(0.060)$ & $(0.129)$ & $(0.086)$ & $(0.053)$ & $(0.093)$ \\
\hline \multirow[t]{2}{*}{$\mathrm{NH}_{4}^{+}$} & 0.028 & 0.052 & $-0.383^{* *}$ & -0.033 & $0.163^{* *}$ & 0.098 \\
\hline & $(0.040)$ & $(0.060)$ & $(0.100)$ & $(0.082)$ & $(0.042)$ & $(0.079)$ \\
\hline \multirow[t]{2}{*}{$\mathrm{NO}_{3}{ }^{-}+\mathrm{NO}_{2}{ }^{-}$} & 0.055 & 0.089 & 0.091 & -0.099 & 0.088 & 0.100 \\
\hline & $(0.048)$ & $(0.067)$ & $(0.105)$ & $(0.110)$ & $(0.057)$ & $(0.092)$ \\
\hline \multirow[t]{2}{*}{$\mathrm{O}_{2}$ saturation } & -0.029 & 0.051 & 0.136 & $0.114^{*}$ & $-0.138^{* *}$ & $-0.317^{* *}$ \\
\hline & $(0.055)$ & $(0.089)$ & $(0.104)$ & $(0.068)$ & $(0.065)$ & $(0.109)$ \\
\hline \multirow[t]{2}{*}{ DON } & $-0.083^{* *}$ & -0.069 & 0.047 & $-0.234^{* *}$ & -0.053 & $-0.157^{* *}$ \\
\hline & $(0.042)$ & $(0.071)$ & $(0.113)$ & $(0.082)$ & $(0.062)$ & $(0.064)$ \\
\hline \multirow[t]{2}{*}{ Salinity } & 0.068 & 0.024 & $-0.241^{* *}$ & $0.292^{\star *}$ & 0.070 & $0.187^{* *}$ \\
\hline & $(0.057)$ & $(0.083)$ & $(0.104)$ & $(0.078)$ & $(0.079)$ & $(0.078)$ \\
\hline Observations & 93 & 23 & 18 & 15 & 17 & 20 \\
\hline $\mathrm{R}^{2}$ & 0.16 & 0.25 & 0.62 & 0.65 & 0.60 & 0.57 \\
\hline RMSE & 0.90 & 0.85 & 0.60 & 0.59 & 0.61 & 0.64 \\
\hline
\end{tabular}


Table 7: Table of coefficients with standard errors (in parentheses) for the second stage PLS regressions, comprising predicted shellfish landings from the first stage, socioeconomic variables, and environmental variables as predictors. Coefficients at $10 \%$ and $5 \%$ significance levels are indicated with $*$ and $* *$, respectively.

\begin{tabular}{|c|c|c|c|c|c|c|}
\hline \multirow[t]{2}{*}{ Independent variables } & \multicolumn{6}{|c|}{ Dependent variable: permits sold per capita } \\
\hline & All Towns & Bourne & Falmouth & Marion & Wareham & Westport \\
\hline \multirow[t]{2}{*}{ Predicted landing } & $0.270^{* \star}$ & $0.160^{* *}$ & $-0.089^{* *}$ & $0.191^{* *}$ & $0.132^{* *}$ & $0.106^{* *}$ \\
\hline & $(0.013)$ & $(0.044)$ & $(0.043)$ & $(0.062)$ & $(0.014)$ & $(0.053)$ \\
\hline \multirow[t]{2}{*}{ Unemployment rate } & 0.040 & -0.051 & $0.258^{* *}$ & $0.131^{*}$ & -0.007 & -0.086 \\
\hline & $(0.032)$ & $(0.072)$ & $(0.043)$ & $(0.073)$ & $(0.039)$ & $(0.088)$ \\
\hline \multirow[t]{2}{*}{ CCNS visits } & $0.144^{* *}$ & 0.003 & $0.224^{* *}$ & $0.271^{* *}$ & $0.094^{\star *}$ & $0.240^{* *}$ \\
\hline & $(0.033)$ & $(0.111)$ & $(0.050)$ & $(0.049)$ & $(0.023)$ & $(0.061)$ \\
\hline \multirow[t]{2}{*}{ Fecal coliform } & 0.026 & -0.008 & -0.072 & -0.084 & $0.096^{\text {** }}$ & $0.146^{\text {** }}$ \\
\hline & $(0.028)$ & $(0.095)$ & $(0.051)$ & $(0.062)$ & $(0.032)$ & $(0.055)$ \\
\hline \multirow[t]{2}{*}{ Precipitation } & -0.027 & -0.033 & 0.107 & -0.064 & -0.050 & -0.098 \\
\hline & $(0.035)$ & $(0.078)$ & $(0.087)$ & $(0.050)$ & $(0.048)$ & $(0.063)$ \\
\hline \multirow[t]{2}{*}{ PON } & $-0.052^{* *}$ & $-0.095^{\star}$ & 0.049 & $-0.128^{* *}$ & $-0.097^{* *}$ & 0.032 \\
\hline & $(0.020)$ & $(0.056)$ & $(0.046)$ & $(0.059)$ & $(0.022)$ & $(0.068)$ \\
\hline \multirow[t]{2}{*}{ POC } & $-0.060^{* *}$ & -0.070 & 0.051 & -0.114 & $-0.091^{* *}$ & -0.071 \\
\hline & $(0.023)$ & $(0.047)$ & $(0.055)$ & $(0.073)$ & $(0.023)$ & $(0.092)$ \\
\hline \multirow[t]{2}{*}{ Chl $a$} & $-0.121^{* *}$ & $-0.112^{\star *}$ & $-0.151^{*}$ & $-0.154^{* *}$ & $-0.108^{* *}$ & $-0.131^{* *}$ \\
\hline & $(0.023)$ & $(0.054)$ & $(0.080)$ & $(0.063)$ & $(0.032)$ & $(0.051)$ \\
\hline \multirow[t]{2}{*}{ Temperature } & -0.048 & -0.035 & -0.029 & $0.158^{*}$ & $-0.103^{* *}$ & $-0.178^{* *}$ \\
\hline & $(0.038)$ & $(0.086)$ & $(0.090)$ & $(0.088)$ & $(0.044)$ & $(0.073)$ \\
\hline \multirow[t]{2}{*}{$\mathrm{PO}_{4}{ }^{3-}$} & $0.061^{* *}$ & 0.036 & $0.147^{\text {** }}$ & 0.078 & 0.032 & 0.057 \\
\hline & $(0.023)$ & $(0.074)$ & $(0.037)$ & $(0.061)$ & $(0.037)$ & $(0.059)$ \\
\hline \multirow[t]{2}{*}{$\mathrm{NH}_{4}{ }^{+}$} & 0.047 & 0.110 & 0.069 & -0.004 & $0.100^{* *}$ & -0.096 \\
\hline & $(0.029)$ & $(0.126)$ & $(0.043)$ & $(0.067)$ & $(0.030)$ & $(0.080)$ \\
\hline \multirow[t]{2}{*}{$\mathrm{NO}_{3}{ }^{-}+\mathrm{NO}_{2}{ }^{-}$} & -0.002 & 0.023 & -0.119 & 0.003 & $0.056^{*}$ & -0.023 \\
\hline & $(0.033)$ & $(0.082)$ & $(0.082)$ & $(0.070)$ & $(0.034)$ & $(0.075)$ \\
\hline \multirow[t]{2}{*}{$\mathrm{O}_{2}$ saturation } & -0.011 & 0.004 & $0.229 * *$ & -0.073 & $-0.074^{* *}$ & -0.104 \\
\hline & $(0.034)$ & $(0.077)$ & $(0.047)$ & $(0.091)$ & $(0.033)$ & $(0.086)$ \\
\hline \multirow[t]{2}{*}{ DON } & 0.036 & 0.061 & -0.051 & 0.051 & 0.072 & 0.028 \\
\hline & $(0.036)$ & $(0.117)$ & $(0.050)$ & $(0.076)$ & $(0.047)$ & $(0.090)$ \\
\hline \multirow[t]{2}{*}{ Salinity } & 0.120 ** & 0.014 & $0.175^{* *}$ & $0.179 * *$ & $0.114^{* *}$ & $0.177^{* *}$ \\
\hline & $(0.030)$ & $(0.069)$ & $(0.053)$ & $(0.044)$ & $(0.041)$ & $(0.058)$ \\
\hline Observations & 118 & 24 & 24 & 22 & 24 & 24 \\
\hline $\mathrm{R}^{2}$ & 0.25 & 0.15 & 0.80 & 0.59 & 0.56 & 0.48 \\
\hline RMSE & 0.85 & 0.90 & 0.44 & 0.65 & 0.65 & 0.70 \\
\hline
\end{tabular}


Table 8: Calculation of total asset values with associated standard errors from the two stage regression approach. The first row depicts obtained PLSR coefficients that have units of standard deviation change in permits sold per capita per one standard deviation change in Chl $a$ (SD Permit Per Capita/SD Chl $a$ ). The second row (Permits/ Chl $a$ ) is the change in permits associated with a $1 \%$ change in $\mathrm{Chl} a$ concentrations ( $\mathrm{mg} \mathrm{m}^{-3}$ ). The third row (Permits/Decade) is the change in permits sold per decade, associated with Chl $a$ trends from 1992 to 2015. The fourth and fifth rows are the WTP and WTA value estimates by applying the $\$ 79.25$ and $\$ 626.75$ total value per permit estimates to the change in permits sold per decade. The sixth and seventh rows indicate asset values obtained by dividing the associated change in economic value (\$ WTP or \$ WTA) per year by 0.03 (discounted at $3 \%$ ).

\begin{tabular}{|c|c|c|c|c|c|}
\hline & All Town & Bourne & Marion & Wareham & Westport \\
\hline SD Permits Per Capita/SD Chl $a$ & $-0.16 \pm 0.03$ & $-0.14 \pm 0.06$ & $-0.20 \pm 0.07$ & $-0.13 \pm 0.03$ & $-0.15 \pm 0.05$ \\
\hline Permits/Chl $a$ & $-2091 \pm 326$ & $-205 \pm 84$ & $-133 \pm 45$ & $-267 \pm 65$ & $-91 \pm 31$ \\
\hline Permits/Decade & $-322 \pm 99$ & $-33 \pm 16$ & $-11 \pm 8$ & $-39 \pm 14$ & $-13 \pm 6$ \\
\hline \$ WTP/Decade & $-25,521 \pm 8128$ & $-2644 \pm 1312$ & $-834 \pm 639$ & $-3086 \pm 1158$ & $-1033 \pm 504$ \\
\hline \$ WTA/Decade & $-201,832 \pm 62,332$ & $-20,910 \pm 10,245$ & $-6599 \pm 5029$ & $-24,407 \pm 8960$ & $-8173 \pm 3932$ \\
\hline \$ Asset Value (WTP) & $-85,070 \pm 27,093$ & $-8813 \pm 4372$ & $-2781 \pm 2131$ & $-10,287 \pm 3860$ & $-3445 \pm 1679$ \\
\hline \$ Asset Value (WTA) & $-672,774 \pm 207,775$ & $-69,700 \pm 34,150$ & $-21,998 \pm 16,764$ & $-81,357 \pm 29,866$ & $-27,242 \pm 13,108$ \\
\hline
\end{tabular}




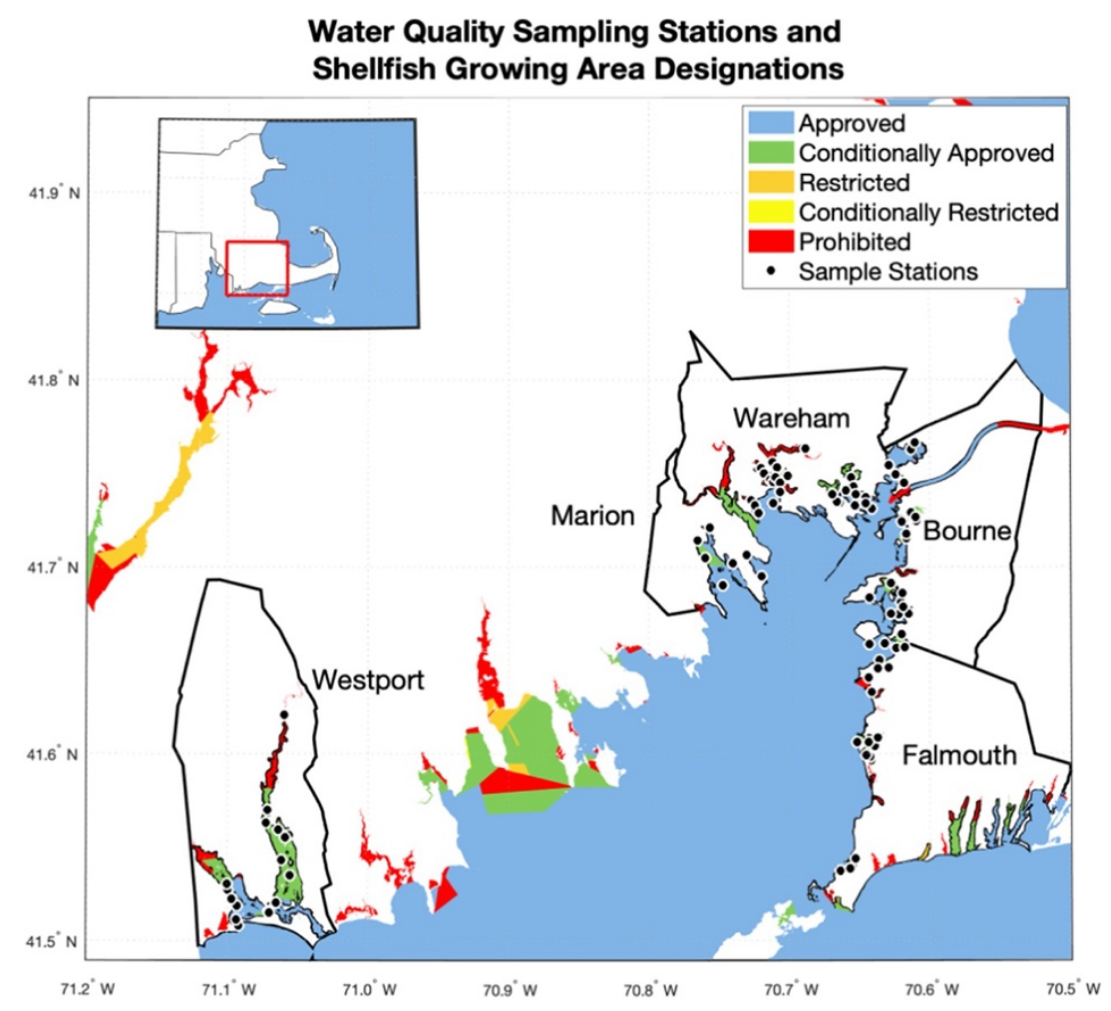

Fig. 1. Map of Buzzards Bay, MA towns and the Buzzards Bay Coalition water quality sampling stations used in the analysis overlain by designated shellfish growing areas. 


\section{Chapter 7: Conclusions}

This thesis provides an assessment of coastal ecosystem biogeochemical processes alongside socioeconomic trends to reveal linkages in ecosystem service benefits and promote the future survival of these valuable ecosystems. I captured the response and recovery from disturbances within these environments through the analysis of long-term marsh soil records and high spatial-resolution water quality monitoring efforts. Coastal ecosystems are heterogeneous environments based on the exploration of existing and infilling ponds (Ch $2-4)$, ditched and unditched marshes (Ch 5), and watershed-specific estuarine water quality trends (Ch 6) that deliver unique types and rates of ecosystem services. This can make characterizations of ecosystem services more elusive, particularly in the context of increased disturbances to ecosystem functioning in a future of global change (Portnoy, 1999; Pendleton et al., 2012; Spivak et al., 2019).

In Chapter 2, natural salt marsh carbon storage was characterized with a range of soil organic carbon (SOC) pools that are cycled along a continuum of turnover times. Overlaid metrics of carbon reactivity, source, and age described multiple processes contributing to soil development and heterogeneity in long-term SOC burial: new production, erosion and redeposition, and microbial reworking. Disturbances in the form of ponding on the marsh platform, that accelerate decomposition, result in shifts in the reactivity and composition of marsh SOC. Broader application of these geochemical approaches has the potential to enhance understanding of preservation under different environmental settings and inform marsh ecosystem evolution models and service valuation.

Chapter 3 expanded on the impacts of ponding on the marsh platform and revealed that the effects of ponding do not significantly propagate throughout the marsh platform. Instead, pond expansion processes result in shifts in pond soil carbon sources and the loss and redistribution of long-buried carbon within the marsh carbon budget. During pond deepening, erosion and decomposition contribute in nearly equal parts to soil carbon loss and alter surficial pond soil carbon dynamics. Further, incorporation of ponds in salt marsh carbon budgets for our study site can lead to a 7\% decrease in carbon stocks. Combined with the social cost of carbon ( $\$ 176$ per ton of carbon; Ricke et al., 2018), this would lead to an error in around \$4.1 million USD in carbon storage ecosystem services for GBM. Therefore, constraining the influence of natural gradients within the salt marsh landscape on the vertical and lateral distribution of marsh soil properties as well as processes that contribute to pond development can help refine marsh soil carbon budgets and ecosystem services.

At the other end of the pond life-cycle, Chapter 4 explores the nature of pond recovery on the marsh platform and whether this results in a zero-sum game in terms of changes in marsh carbon storage services associated with pond expansion and recovery. Catalyzed by mosquito ditching in the 1920s, pond recovery within Great Barnstable Marsh, MA has resulted in a virtually indistinguishable vegetated marsh landscape. Ponds that previously existed in the 1920 s have now nearly recovered in elevation to the surrounding marsh platform through drainage, revegetation, and rapid soil accumulation $\left(4.8-10.9 \mathrm{~mm} \mathrm{yr}^{-1}\right)$. Yet, infilled pond environments continue to contribute to soil heterogeneity within the marsh environment. Thus, incorporating the full pond 
life cycle into estimates of salt marsh carbon budgets and turnover will be key to informing ditch management decisions and refining marsh carbon budgets.

In Chapter 5, incorporation of pond features from $\mathrm{Ch} 2-4$ informed resource management trade-off analysis in the marsh carbon budget in Great Barnstable Marsh, MA. Considering the presence of ditches, recovered and existing ponds, the elevation differences within the marsh interior, we find that the maintenance of mosquito ditches have not significantly impacted carbon storage services after a century of ditching. Through balancing the costs of ditch maintenance and potential losses in other ecosystem service values (e.g. recreational bird watching, storm-surge buffering), accurate cost-benefit analysis can aid effective management decisions that optimize both human health aspects and the future health of these valuable ecosystems. Through the close collaboration between resource managers and scientists, this analysis informed an end-user decision support tool to help resource managers make decisions that balance human wellbeing and long-term marsh sustainability.

Moving from intertidal coastal marsh ecosystems to estuarine ecosystems, Chapter 6 explores the use of long-term water quality monitoring and socioeconomic records to demonstrate the relationship between water quality degradation and losses in cultural ecosystem service benefits within different towns of Buzzards Bay, MA. Diminished water quality coincided with reductions in the capacity of the Buzzards Bay estuary to provide recreation as a cultural ecosystem service, valued at \$0.08-0.67 million in recreational shellfishing benefits. Thus, the value of estuarine ecosystem goods and services can be affected adversely by anthropogenic disturbance and global change.

A summary table of the work explored within each thesis chapter is provided to highlight how disturbances to marsh ecosystem functioning consequently impact potential coastal ecosystem services (provisioning, regulating, cultural, and supporting) (Table 1). Direct impacts (bolded) of disturbances to coastal ecosystem services include changes in coastal carbon storage, science and education opportunities, mosquito habitats, and recreational fishing. For Chapter $2-$ 5 , an additional area of research includes future exploration of how natural and anthropogenic disturbances impact marsh ecosystem functioning within rapidly submerging environments. The New England marsh systems within this thesis are relatively healthy when compared to marshes located in Blackwater River, Maryland (S_chepers_et_al.2 2017) and Mississippi River Delta Plain, Louisiana (Penland, 2002). With increasing global change, marsh ecosystems may reflect currently submerging marsh environments. In terms of ecosystem service valuation associated with natural and anthropogenic disturbances, further research is required to determine how to translate changes in marsh landscape features (e.g. ponds, ditches, platform elevations) to alterations in nutrient uptake, storm-surge protection, and recreational ecosystem service values. Finally, analysis of the temporal and spatial heterogeneity of coastal ecosystem functioning and services demonstrates the need for future expansion of biogeochemical datasets that can constrain the variability within these valuable ecosystems that directly impact coastal communities. 
Overall, this thesis highlights the importance of predicting coastal ecosystem biogeochemical functioning in the context of natural and anthropogenic disturbance that will be key for refining their continued roles in ecosystem service delivery and predicting future survival. Coastal salt marsh soil organic carbon burial and preservation - a vital component to marsh survival - is biogeochemically complex and spatially heterogeneous revealing a range of ecosystem service delivery rates for current and future climate scenarios. Further, elucidating pathways in which water quality could impact recreational shellfishing activity and cultural ecosystem service benefits received by coastal communities can bolster arguments for coastal ecosystem rehabilitation and protection by resource managers and stakeholders. Future work will involve expanding spatiotemporal datasets within coastal ecosystems to further clarify relationships between ecosystem functioning and additional ecosystem service values that may still not be realized by scientists and the general public. The approach presented here suggests a more broadly applicable framework that utilizes long-term environmental and socioeconomic records to assess the disturbance-driven changes in coastal ecosystem functioning and service delivery to human populations. 


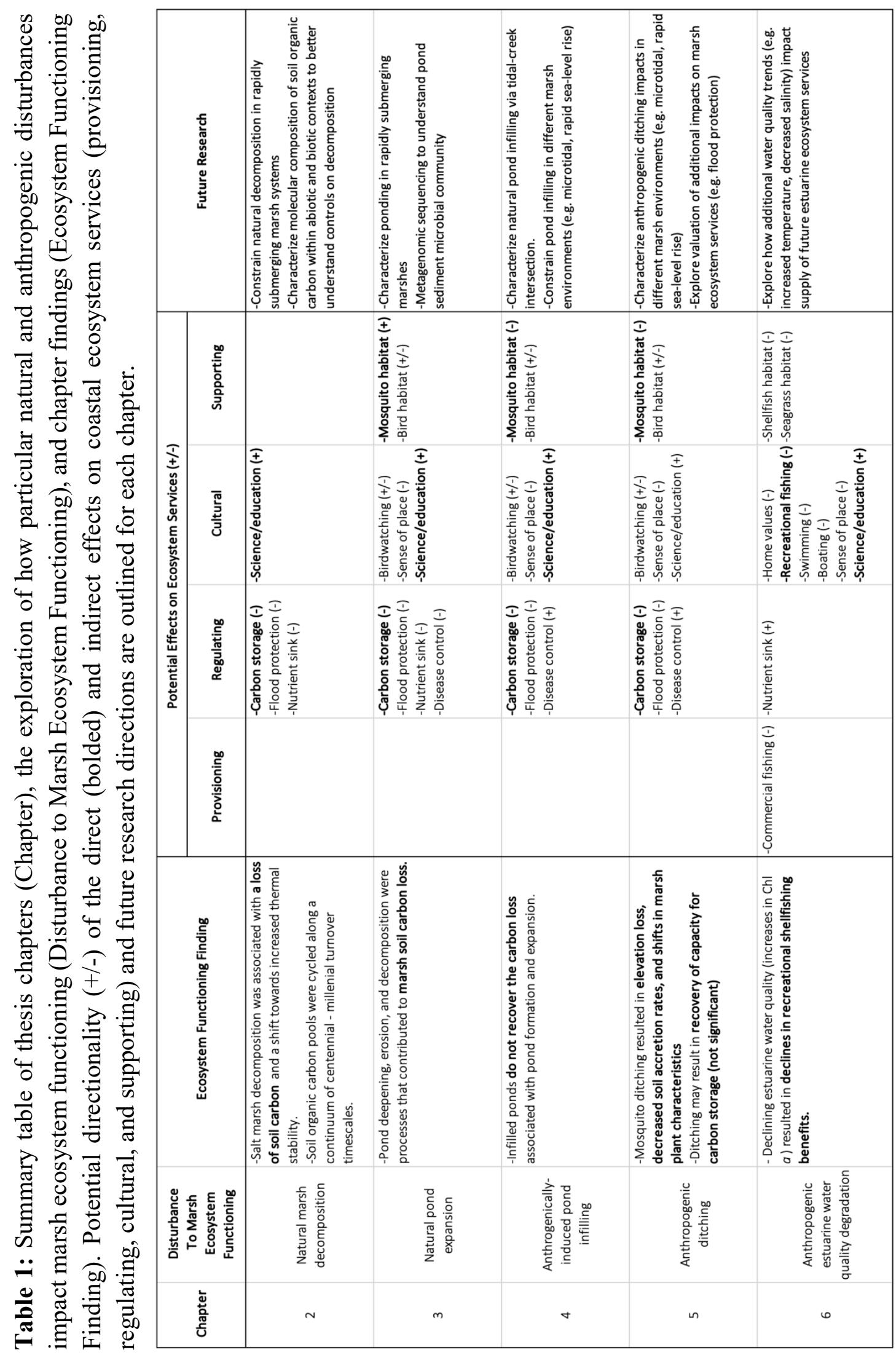




\section{REFERENCES}

Abdi, H., 2010. Partial least squares regression and projection on latent structure regression (PLS Regression). Wiley Interdiscip. Rev. Comput. Stat. 2 (1), 97-106.

Adamowicz, S.C. and Roman, C.T. (2005) 'New England salt marsh pools: A quantitative analysis of geomorphic and geographic features', Wetlands, 25(2), pp. 279-288. doi:10.1672/4.

Allen, J. (2000) 'Morphodynamics of Holocene salt marshes: a review sketch from the Atlantic and Southern North Sea coasts of Europe', Quaternary Science Reviews, 19(12), pp. 1155-1231. doi:10.1016/S0277-3791(99)00034-7.

Anderson, L.E., Plummer, M., 2016. Puget Sound Recreational Shellfishing Survey: Methodology and Results. US Dept. Commer.https://doi.org/10.7289/V5/TM-NWFSC-132. NOAA Tech. Memo. NMFS-NWFSC-132.

Anisfeld, S.C. and Hill, T.D. (2012) 'Fertilization Effects on Elevation Change and Belowground Carbon Balance in a Long Island Sound Tidal Marsh', Estuaries and Coasts, 35(1), pp. 201-211. doi:10.1007/s12237-011-9440-4.

Appleby, P.G. and Oldfield, F. (1978) 'The calculation of lead-210 dates assuming a constant rate of supply of unsupported $210 \mathrm{~Pb}$ to the sediment', CATENA, 5(1), pp. 1-8. doi:10.1016/S0341-8162(78)80002-2.

Aquino-López, M.A., Blaauw, M., Christen, J.A. and Sanderson, N.K. (2018) 'Bayesian Analysis of 210Pb Dating', Journal of Agricultural, Biological and Environmental Statistics, 23(3), pp. 317-333. doi:10.1007/s13253-018-0328-7.

Barbier, E.B. (2015) 'Valuing the storm protection service of estuarine and coastal ecosystems', Ecosystem Services, 11, pp. 32-38. doi:10.1016/j.ecoser.2014.06.010.

Barbier, E.B., Hacker, S.D., Kennedy, C., Koch, E.W., Stier, A.C. and Silliman, B.R. (2011) 'The value of estuarine and coastal ecosystem services', Ecological Monographs, 81(2), pp. 169-193. doi:10.1890/10-1510.1.

Benner, R., Fogel, M.L., Sprague, E.K. and Hodson, R.E. (1987) 'Depletion of 13C in lignin and its implications for stable carbon isotope studies', Nature, 329(6141), pp. 708-710. doi:10.1038/329708a0.

Bertrand, F., Meyer, N., Maumy-Bertrand, M., 2011. plsRglm Partial Least Squares Regression for Generalized Linear Models. R Package Version 0.7-6. http://www. cran.robject.org/package= plsRglm/.

Bianchi, T.S. (2011) 'The role of terrestrially derived organic carbon in the coastal ocean: A changing paradigm and the priming effect', Proceedings of the National Academy of Sciences, 108(49), pp. 19473-19481. doi:10.1073/pnas.1017982108.

Bianchi, T.S. and Canuel, E.A. (2011) Chemical Biomarkers in Aquatic Ecosystems: Princeton University Press. doi:10.1515/9781400839100.

Bricker, S.B., Longstaff, B., Dennison, W., Jones, A., Boicourt, K., Wicks, C., Woerner, J.,2008. Effects of nutrient enrichment in the nation's estuaries: a decade of change. Harmful Algae $8(1), 21-32$.

Bricker-Urso, S., Nixon, S.W., Cochran, J.K., Hirschberg, D.J. and Hunt, C. (1989) 'Accretion Rates and Sediment Accumulation in Rhode Island Salt Marshes', Estuaries, 12(4), p. 300. doi:10.2307/1351908. 
Bruun, S., Ågren, G.I., Christensen, B.T. and Jensen, L.S. (2010) 'Measuring and modeling continuous quality distributions of soil organic matter', Biogeosciences, 7(1), pp. 27-41. doi:10.5194/bg-7-27-2010.

Bulseco, A. N., Giblin, A. E., Tucker, J., Murphy, A. E., Sanderman, J., Hiller-Bittrolff, K., (2019). Nitrate addition stimulates microbial decomposition of organic matter in salt marsh sediments. Global Change Biology, 25(10), 3224-3241. https://doi.org/10.1111/gcb.14726

Bulseco, A.N., Vineis, J.H., Murphy, A.E., Spivak, A.C., Giblin, A.E., Tucker, J. and Bowen, J.L. (2020) 'Metagenomics coupled with biogeochemical rates measurements provide evidence that nitrate addition stimulates respiration in salt marsh sediments', Limnology and Oceanography, 65(S1), pp. S321-S339. doi:10.1002/lno.11326.

Burdick, D.M., Moore, G.E., Adamowicz, S.C., Wilson, G.M. and Peter, C.R. (2020) 'Mitigating the Legacy Effects of Ditching in a New England Salt Marsh', Estuaries and Coasts, 43(7), pp. 1672-1679. doi:10.1007/s12237-019-00656-5.

Burns, C.J., Alber, M. and Alexander, C.R. (2021) 'Historical Changes in the Vegetated Area of Salt Marshes', Estuaries and Coasts, 44(1), pp. 162-177. doi:10.1007/s12237-02000781-6.

Buzzards Bay National Estuary Program, 2018. Available at. http://buzzardsbay.org (verified 21 Jan. 2018).

Caçador, I., Duarte, B., Marques, J.C. and Sleimi, N. (2016) 'Carbon Mitigation', in Halophytes for Food Security in Dry Lands. Elsevier, pp. 83-110. doi:10.1016/B978-0-12-8018545.00006-6.

Callaway, J.C., DeLaune, R.D. and Jr., W.H.P. (1997) 'Sediment Accretion Rates from Four Coastal Wetlands along the Gulf of Mexico', Journal of Coastal Research, 13(1), pp. $181-191$.

Campbell, J.W., 1995. The lognormal distribution as a model for bio-optical variability in the sea. J. Geophys. Res. Oceans 100 (C7), 13237-13254.

Campos, C.J., Kershaw, S.R., Lee, R.J., 2013. Environmental influences on faecal indicator organisms in coastal waters and their accumulation in bivalve shellfish. Estuar. Coasts 36 (4), 834-853.

Canuel, E.A., Freeman, K.H. and Wakeham, S.G. (1997) 'Isotopic compositions of lipid biomarker compounds in estuarine plants and surface sediments', Limnology and Oceanography, 42(7), pp. 1570-1583. doi:10.4319/lo.1997.42.7.1570.

Canuel, E.A. and Martens, C.S. (1993) 'Seasonal variations in the sources and alteration of organic matter associated with recently-deposited sediments', Organic Geochemistry, 20(5), pp. 563-577. doi:10.1016/0146-6380(93)90024-6.

Canuel, E.A. and Martens, C.S. (1996) 'Reactivity of recently deposited organic matter: Degradation of lipid compounds near the sediment-water interface', Geochimica et Cosmochimica Acta, 60(10), pp. 1793-1806. doi:10.1016/0016-7037(96)00045-2.

Cavatorta, J.R., Johnston, M., Hopkinson, C. and Valentine, V. (2003) 'Patterns of Sedimentation in a Salt Marsh-Dominated Estuary', The Biological Bulletin, 205(2), pp. 239-241. doi:10.2307/1543274.

Chambers, L.G., Steinmuller, H.E. and Breithaupt, J.L. (2019) 'Toward a mechanistic understanding of "peat collapse" and its potential contribution to coastal wetland loss', Ecology, 100(7). doi:10.1002/ecy.2720.

Childers, D.L., Day, J.W. and Mckellar, H.N. (2000) 'Twenty More Years of Marsh and Estuarine Flux Studies: Revisiting Nixon (1980)', in Weinstein, M.P. and Kreeger, D.A. 
(eds) Concepts and Controversies in Tidal Marsh Ecology. Dordrecht: Springer

Netherlands, pp. 391-423. doi:10.1007/0-306-47534-0_18.

Chmura, G.L., Anisfeld, S.C., Cahoon, D.R. and Lynch, J.C. (2003) 'Global carbon sequestration in tidal, saline wetland soils', Global Biogeochemical Cycles, 17(4), p. n/a-n/a. doi:10.1029/2002GB001917.

Choi, Y. and Wang, Y. (2004) 'Dynamics of carbon sequestration in a coastal wetland using radiocarbon measurements', Global Biogeochemical Cycles, 18(4). doi:10.1029/2004GB002261.

Costanza, R., d'Arge, R., de Groot, R., Farber, S., Grasso, M., Hannon, B., Limburg, K., Naeem, S., O’Neill, R., Paruelo, J., Raskin, R., Sutton, P. and van den Belt, M. (1997) 'The value of the world's ecosystem', Nature, 387(6630), pp. 253-260.

Cristina, R. A., Flores, J. B., Cardenas, V., Salazar, S. O. R., \& Cervantes, L. D. (2018). Bacillus amyloliquefaciens as a plant growth promoting bacteria with the interaction with of grass salt Distichlis palmeri (Vasey) under field conditions, in desert of Sonora, Mexico. Journal of Plant Science and Phytopathology, 2, 59-67. https://doi.org/10.29328/journal.jpsp.1001021

Damery, D.T., Allen, P.G., 2004. An economic valuation of recreational shellfishing on Cape Cod. In: University of Massachusetts Resource Economics Working Paper No. 2004-10, (Available at SSRN: https://ssrn.com/abstract $=615582$ or https://doi.org/ 10.2139/ssrn.615582).

Day, J.W., Kemp, G.P., Reed, D.J., Cahoon, D.R., Boumans, R.M., Suhayda, J.M. and Gambrell, R. (2011) 'Vegetation death and rapid loss of surface elevation in two contrasting Mississippi delta salt marshes: The role of sedimentation, autocompaction and sea-level rise', Ecological Engineering, 37(2), pp. 229-240. doi:10.1016/j.ecoleng.2010.11.021.

Day, J.W., Rybczyk, J., Scarton, F., Rismondo, A., Are, D. and Cecconi, G. (1999) 'Soil Accretionary Dynamics, Sea-Level Rise and the Survival of Wetlands in Venice Lagoon: A Field and Modelling Approach', Estuarine, Coastal and Shelf Science, 49(5), pp. 607628. doi:10.1006/ecss.1999.0522.

Dean, W.E. (1974) 'Determination of carbonate and organic matter in calcareous sediments and sedimentary rocks by loss on ignition; comparison with other methods', Journal of Sedimentary Research, 44(1), pp. 242-248. doi:10.1306/74D729D2-2B21-11D78648000102C1865D.

Deegan, L. and Garritt, R. (1997) 'Evidence for spatial variability in estuarine food webs', Marine Ecology Progress Series, 147, pp. 31-47. doi:10.3354/meps 147031.

DeLaune, R.D., Nyman, J.A. and Jr., W.H.P. (1994) 'Peat Collapse, Ponding and Wetland Loss in a Rapidly Submerging Coastal Marsh', Journal of Coastal Research, 10(4), pp. 10211030.

Egan, K.J., Herriges, J.A., Kling, C.L., Downing, J.A., 2009. Valuing water quality as a function of water quality measures. Am. J. Agric. Econ. 91 (1), 106-123.

Eglinton, G. and Hamilton, R.J. (1967) 'Leaf Epicuticular Waxes', Science, 156(3780), pp. 1322-1335.

Engelhart, S. E., Horton, B. P., Douglas, B. C., Peltier, W. R., \& Törnqvist, T. E. (2009). Spatial variability of late Holocene and 20th century sea-level rise along the Atlantic coast of the United States. Geology, 37(12), 1115-1118. https://doi.org/10.1130/G30360A.1 
Fagherazzi, S., Kirwan, M.L., Mudd, S.M., Guntenspergen, G.R., Temmerman, S., D’Alpaos, A., van de Koppel, J., Rybczyk, J.M., Reyes, E., Craft, C. and Clough, J. (2012) 'Numerical models of salt marsh evolution: Ecological, geomorphic, and climatic factors', Reviews of Geophysics, 50(1), p. RG1002. doi:10.1029/2011RG000359.

Fagherazzi, S., Wiberg, P.L., Temmerman, S., Struyf, E., Zhao, Y. and Raymond, P.A. (2013) 'Fluxes of water, sediments, and biogeochemical compounds in salt marshes', Ecological Processes, 2(1), p. 3. doi:10.1186/2192-1709-2-3.

Fleurence, J., Gutbier, G., Mabeau, S. and Leray, C. (1994) 'Fatty acids from 11 marine macroalgae of the French Brittany coast', Journal of Applied Phycology, 6(5-6), pp. 527532. doi:10.1007/BF02182406.

Fontaine, S., Barot, S., Barré, P., Bdioui, N., Mary, B., \& Rumpel, C. (2007). Stability of organic carbon in deep soil layers controlled by fresh carbon supply. Nature, 450(7167), 277-280. https://doi.org/10.1038/nature06275

Friedrichs, C.T. and Perry, J.E. (2001) 'Tidal Salt Marsh Morphodynamics: A Synthesis', Journal of Coastal Research, pp. 7-37.

Ganju, N.K., Defne, Z. and Fagherazzi, S. (2020) 'Are Elevation and Open-Water Conversion of Salt Marshes Connected?', Geophysical Research Letters, 47(3), p. e2019GL086703. doi:10.1029/2019GL086703.

Ganju, N.K., Defne, Z., Kirwan, M.L., Fagherazzi, S., D’Alpaos, A. and Carniello, L. (2017) 'Spatially integrative metrics reveal hidden vulnerability of microtidal salt marshes', Nature Communications, 8(1), p. 14156. doi:10.1038/ncomms14156.

Gardner, L.R. (1990) 'Simulation of the Diagenesis of Carbon, Sulfur, and Dissolved Oxygen in Salt Marsh Sediments’, Ecological Monographs, 60(1), pp. 91-111. doi:10.2307/1943027.

Gedan, K.B., Kirwan, M.L., Wolanski, E., Barbier, E.B. and Silliman, B.R. (2011) 'The present and future role of coastal wetland vegetation in protecting shorelines: answering recent challenges to the paradigm', Climatic Change, 106(1), pp. 7-29. doi:10.1007/s10584010-0003-7.

Gedan, K.B., Silliman, B.R. and Bertness, M.D. (2009) 'Centuries of Human-Driven Change in Salt Marsh Ecosystems’, Annual Review of Marine Science, 1(1), pp. 117-141. doi:10.1146/annurev.marine.010908.163930.

Geladi, P., Kowalski, B.R., 1986. Partial least-squares regression: a tutorial. Anal. Chim. Acta 185, $1-17$.

Giblin, A.E. and Howarth, R.W. (1984) 'Porewater evidence for a dynamic sedimentary iron cycle in salt marshes1', Limnology and Oceanography, 29(1), pp. 47-63. doi:10.4319/1o.1984.29.1.0047.

Gleixner, G., Poirier, N., Bol, R., \& Balesdent, J. (2002). Molecular dynamics of organic matter in a cultivated soil. Organic Geochemistry, 33(3), 357-366. https://doi.org/10.1016/S01466380(01)00166-8

Goñi, M.A. and Thomas, K.A. (2000) 'Sources and Transformations of Organic Matter in Surface Soils and Sediments from a Tidal Estuary (North Inlet, South Carolina, USA)', Estuaries, 23(4), p. 548. doi:10.2307/1353145.

Gonneea, M. E., Maio, C. V., Kroeger, K. D., Hawkes, A. D., Mora, J., Sullivan, R., et al. (2019). Salt marsh ecosystem restructuring enhances elevation resilience and carbon storage during accelerating relative sea-level rise. Estuarine, Coastal and Shelf Science, 217, 56-68. https://doi.org/10.1016/j.ecss.2018.11.003 
Haddad, R. I., \& Martens, C. S. (1987). Biogeochemical cycling in an organic-rich coastal marine basin: 9. Sources and accumulation rates of vascular plant-derived organic material. Geochimica et Cosmochimica Acta, 51(11), 2991-3001. https://doi. org/10.1016/00167037(87)90372-3

Halpern, B.S., Longo, C., Hardy, D., McLeod, K.L., Samhouri, J.F., Katona, S.K., ... Rosenberg, A.A., 2012. An index to assess the health and benefits of the global ocean. Nature 488 (7413), 615-620.

Hedges, J.I. and Stern, J.H. (1984) 'Carbon and nitrogen determinations of carbonate-containing solids1', Limnology and Oceanography, 29(3), pp. 657-663. doi:10.4319/1o.1984.29.3.0657.

Hemingway, J. D., Galy, V. V., Gagnon, A. R., Grant, K. E., Rosengard, S. Z., Soulet, G., et al. (2017a). Assessing the blank carbon contribution, isotope mass balance, and kinetic isotope fractionation of the ramped pyrolysis/oxidation instrument at nosams. Radiocarbon, 59(1), 179-193. https://doi.org/10.1017/RDC.2017.3

Hemingway, J. D., Rothman, D. H., Rosengard, S. Z., \& Galy, V. V. (2017b). Technical note: An inverse method to relate organic carbon reactivity to isotope composition from serial oxidation. Biogeosciences, 14(22), 5099-5114. https://doi.org/10.5194/bg-14-5099-2017

Hemminga, M. A., Kok, C. J., \& De Munck, W. (1988). Decomposition of Spartina anglica roots and rhizomes in a salt marsh of the Westerschelde Estuary. Marine Ecology Progress Series, 48, 175-184.

Hopkinson, C.S., Morris, J.T., Fagherazzi, S., Wollheim, W.M. and Raymond, P.A. (2018) 'Lateral Marsh Edge Erosion as a Source of Sediments for Vertical Marsh Accretion', Journal of Geophysical Research: Biogeosciences, 123(8), pp. 2444-2465. doi:10.1029/2017JG004358.

Horton, R., Yohe, G., Easterling, W., Kates, R., Ruth, M., Sussman, E., ... Lipschultz, F., 2014. Ch. 16: Northeast. Climate Change Impacts in the United States: The Third National Climate Assessment. pp. 371-395.

Howarth, R.W. (1984) 'The ecological significance of sulfur in the energy dynamics of salt marsh and coastal marine sediments', Biogeochemistry, 1(1), pp. 5-27. doi:10.1007/BF02181118.

Howarth, R.W., Marino, R., 2006. Nitrogen as the limiting nutrient for eutrophication in coastal marine ecosystems: evolving views over three decades. Limnol. Oceanogr. 51 (1part2), 364-376.

James-Pirri, M.-J., Ginsberg, H.S., Erwin, R.M. and Taylor, J. (2009) 'Effects of Open Marsh Water Management on Numbers of Larval Salt Marsh Mosquitoes', Journal of Medical Entomology, 46(6), pp. 1392-1399. doi:10.1603/033.046.0620.

Janik, L. J., Skjemstad, J. O., Shepherd, K. D., \& Spouncer, L. R. (2007). The prediction of soil carbon fractions using mid-infrared-partial least square analysis. Australian Journal of Soil Research, 45(2), 73-81. https://doi.org/10.1071/SR06083

Johnston, M. E., Cavatorta, J. R., Hopkinson, C. S., \& Valentine, V. (2003). Importance of metabolism in the development of salt marsh ponds. The Biological Bulletin, 205(2), 248249. https://doi.org/10.2307/1543278

Jovanovic, Z., Pedersen, M., Larsen, M., Kristensen, E. and Glud, R. (2015) 'Rhizosphere O2 dynamics in young Zostera marina and Ruppia maritima', Marine Ecology Progress Series, 518, pp. 95-105. doi:10.3354/meps 11041. 
Jun, T., 2017. Temperature, maize yield, and civil conflicts in sub-Saharan Africa. Clim. Chang. $142(1-2), 183-197$.

Kaneda, T. (1991) 'Iso- and anteiso-fatty acids in bacteria: biosynthesis, function, and taxonomic significance.', Microbiological Reviews, 55(2), pp. 288-302.

Kantrud, H.A. (1991) Wigeongrass (Ruppia Maritima L.): A Literature Review. United States Department of the Interior, Fish and Wildlife Service.

Kearney, W.S. and Fagherazzi, S. (2016) 'Salt marsh vegetation promotes efficient tidal channel networks', Nature Communications, 7(1), p. 12287. doi:10.1038/ncomms12287.

Keeler, B.L., Polasky, S., Brauman, K.A., Johnson, K.A., Finlay, J.C., O'Neill, A., Kovacs, K., Dalzell, B., 2012. Linking water quality and well-being for improved assessment and valuation of ecosystem services. Proc. Natl. Acad. Sci. 201215991.

Kemp, W.M., Testa, J.M., Conley, D.J., Gilbert, D., Hagy, J.D., 2009. Temporal responses of coastal hypoxia to nutrient loading and physical controls. Biogeosciences 6 (12), 29853008.

Kennish, M.J. (2001) 'Coastal Salt Marsh Systems in the U.S.: A Review of Anthropogenic Impacts', Journal of Coastal Research, 17(3), pp. 731-748.

King, G.M., Klug, M.J., Wiegert, R.G. and Chalmers, A.G. (1982) 'Relation of Soil Water Movement and Sulfide Concentration to Spartina alterniflora Production in a Georgia Salt Marsh', Science, 218(4567), pp. 61-63.

Kirwan, M.L. and Blum, L.K. (2011) 'Enhanced decomposition offsets enhanced productivity and soil carbon accumulation in coastal wetlands responding to climate change', Biogeosciences, 8(4), pp. 987-993. doi:10.5194/bg-8-987-2011.

Kirwan, M.L. and Guntenspergen, G.R. (2010) 'Influence of tidal range on the stability of coastal marshland', Journal of Geophysical Research: Earth Surface, 115(F2). doi:10.1029/2009JF001400.

Kirwan, M.L., Langley, J.A., Guntenspergen, G.R. and Megonigal, J.P. (2013) 'The impact of sea-level rise on organic matter decay rates in Chesapeake Bay brackish tidal marshes', Biogeosciences, 10(3), pp. 1869-1876. doi:10.5194/bg-10-1869-2013.

Kirwan, M.L. and Mudd, S.M. (2012) 'Response of salt-marsh carbon accumulation to climate change', Nature, 489(7417), pp. 550-553. doi:10.1038/nature11440.

Kirwan, M.L., Murray, A.B. and Boyd, W.S. (2008) 'Temporary vegetation disturbance as an explanation for permanent loss of tidal wetlands', Geophysical Research Letters, 35(5), p. L05403. doi:10.1029/2007GL032681.

Kirwan, M.L., Murray, A.B., Donnelly, J.P. and Corbett, D.R. (2011) 'Rapid wetland expansion during European settlement and its implication for marsh survival under modern sediment delivery rates', Geology, 39(5), pp. 507-510. doi:10.1130/G31789.1.

Kirwan, M.L., Temmerman, S., Skeehan, E.E., Guntenspergen, G.R. and Fagherazzi, S. (2016) 'Overestimation of marsh vulnerability to sea level rise', Nature Climate Change, 6(3), pp. 253-260. doi:10.1038/nclimate2909.

Kuzyakov, Y., Friedel, J.K. and Stahr, K. (2000) 'Review of mechanisms and quanti ${ }^{\circledR}$ cation of priming e ects', Soil Biology, p. 14.

Leggett, C.G., Bockstael, N.E., 2000. Evidence of the effects of water quality on residential land prices. J. Environ. Econ. Manag. 39 (2), 121-144.

Lehmann, J., Hansel, C.M., Kaiser, C., Kleber, M., Maher, K., Manzoni, S., Nunan, N., Reichstein, M., Schimel, J.P., Torn, M.S., Wieder, W.R. and Kögel-Knabner, I. (2020) 
'Persistence of soil organic carbon caused by functional complexity', Nature Geoscience, 13(8), pp. 529-534. doi:10.1038/s41561-020-0612-3.

Lesser, C.R. (1982) 'A Study of the Effects of Three Mosquito Control Marsh Management Techniques on Selected Parameters of the Ecology of a Chesapeake Bay Tidewater Marsh in Maryland', Maryland Department of Natural Resources, Coastal Zone Unit [Preprint].

Li, B., Morris, J., Martin, E.B., 2002. Model selection for partial least squares regression. Chemom. Intell. Lab. Syst. 64 (1), 79-89.

Linthurst, R.A. (1979) 'The Effect of Aeration on the Growth of Spartina alterniflora Loisel.', American Journal of Botany, 66(6), pp. 685-691. doi:10.2307/2442413.

Liu, Z., Fagherazzi, S., She, X., Ma, X., Xie, C. and Cui, B. (2020) 'Efficient tidal channel networks alleviate the drought-induced die-off of salt marshes: Implications for coastal restoration and management', Science of The Total Environment, 749, p. 141493. doi:10.1016/j.scitotenv.2020.141493.

Liu, T., Opaluch, J.J., Uchida, E., 2017. The impact of water quality in Narragansett Bay on housing prices. Water Resour. Res. 53 (8), 6454-6471. https://doi.org/10.1002/ 2016WR019606.

Lorrain, A., Savoye, N., Chauvaud, L., Paulet, Y.-M. and Naulet, N. (2003) 'Decarbonation and preservation method for the analysis of organic $\mathrm{C}$ and $\mathrm{N}$ contents and stable isotope ratios of low-carbonated suspended particulate material', Analytica Chimica Acta, 491(2), pp. 125-133. doi:10.1016/S0003-2670(03)00815-8.

Luk, S.Y., Todd-Brown, K., Eagle, M., McNichol, A.P., Sanderman, J., Gosselin, K. and Spivak, A.C. (2021) 'Soil Organic Carbon Development and Turnover in Natural and Disturbed Salt Marsh Environments', Geophysical Research Letters, 48(2). doi:10.1029/2020GL090287.

Luk, S. Y., Spivak, A. C., Eagle, M. J., \& O'Keefe-Suttles, J. A. (2020). Collection, analysis, and age-dating of sediment cores from a salt marsh platform and ponds in, Rowley, Massachusetts, in 2014-15: U.S. Geological Survey data release. https://doi.org/10.5066/P9HIOWKT

Luther, G.W. and Church, T.M. (1988) 'Seasonal cycling of sulfur and iron in porewaters of a Delaware salt marsh', Marine Chemistry, 23(3-4), pp. 295-309. doi:10.1016/03044203(88)90100-4.

Manzoni, S., Katul, G. G., \& Porporato, A. (2009). Analysis of soil carbon transit times and age distributions using network theories. Journal of Geophysical Research, 114, G04025. https://doi.org/10.1029/2009JG001070

Marani, M., D’Alpaos, A., Lanzoni, S., Carniello, L. and Rinaldo, A. (2007) 'Biologicallycontrolled multiple equilibria of tidal landforms and the fate of the Venice lagoon', Geophysical Research Letters, 34(11). doi:10.1029/2007GL030178.

Marani, M., D’Alpaos, A., Lanzoni, S., Carniello, L. and Rinaldo, A. (2010) 'The importance of being coupled: Stable states and catastrophic shifts in tidal biomorphodynamics', Journal of Geophysical Research, 115(F4), p. F04004. doi:10.1029/2009JF001600.

Marion, C., Anthony, E.J. and Trentesaux, A. (2009) 'Short-term ( $\leq 2$ yrs) estuarine mudflat and saltmarsh sedimentation: High-resolution data from ultrasonic altimetery, rod surfaceelevation table, and filter traps', Estuarine, Coastal and Shelf Science, 83(4), pp. 475484. doi:10.1016/j.ecss.2009.03.039. 
Mariotti, G. (2016) 'Revisiting salt marsh resilience to sea level rise: Are ponds responsible for permanent land loss?: SALT MARSH PONDS', Journal of Geophysical Research: Earth Surface, 121(7), pp. 1391-1407. doi:10.1002/2016JF003900.

Mariotti, G. and Fagherazzi, S. (2013) 'Critical width of tidal flats triggers marsh collapse in the absence of sea-level rise', Proceedings of the National Academy of Sciences, 110(14), pp. 5353-5356. doi:10.1073/pnas.1219600110.

Mariotti, G., Kearney, W.S. and Fagherazzi, S. (2016) 'Soil creep in salt marshes', Geology, 44(6), pp. 459-462. doi:10.1130/G37708.1.

Mariotti, G., Spivak, A.C., Luk, S.Y., Ceccherini, G., Tyrrell, M. and Gonneea, M.E. (2020) 'Modeling the spatial dynamics of marsh ponds in New England salt marshes', Geomorphology, 365, p. 107262. doi:10.1016/j.geomorph.2020.107262.

Massachusetts Department of Environmental Protection, 2016. Massachusetts Year 2016 Integrated List of Waters.

Mccaffrey, R.J. and Thomson, J. (1980) 'A Record of the Accumulation of Sediment and Trace Metals in A Connecticut Salt Marsh', in Advances in Geophysics. Elsevier, pp. 165-236. doi:10.1016/S0065-2687(08)60066-7.

McNichol, A. P., Osborne, E. A., Gagnon, A. R., Fry, B., \& Jones, G. A. (1994). TIC, TOC, DIC, DOC, PIC, POC-Unique aspects in the preparation of oceanographic samples for ${ }^{14} \mathrm{C}$ AMS. Nuclear Instruments and Methods in Physics Research Section B: Beam Interactions with Materials and Atoms, 92(1-4), 162-165. https://doi.org/10.1016/0168583X(94)95998-6

Meade, R.H. (1982) 'Sources, Sinks, and Storage of River Sediment in the Atlantic Drainage of the United States', The Journal of Geology, 90(3), pp. 235-252.

Mendelssohn, I.A., McKee, K.L. and Patrick, W.H. (1981) 'Oxygen Deficiency in Spartina alterniflora Roots: Metabolic Adaptation to Anoxia', Science, 214(4519), pp. 439-441.

Mendelssohn, I.A. and Seneca, E.D. (1980) 'The influence of soil drainage on the growth of salt marsh cordgrass Spartina alterniflora in North Carolina', Estuarine and Coastal Marine Science, 11(1), pp. 27-40. doi:10.1016/S0302-3524(80)80027-2.

Millette, T.L., Argow, B.A., Marcano, E., Hayward, C., Hopkinson, C.S. and Valentine, V. (2010) 'Salt Marsh Geomorphological Analyses via Integration of Multitemporal Multispectral Remote Sensing with LIDAR and GIS', Journal of Coastal Research, 265, pp. 809-816. doi:10.2112/JCOASTRES-D-09-00101.1.

Millenium Ecosystem Assessment (MEA), 2005. Ecosystems and Human Wellbeing: Synthesis. Island Press, Washington, DC Last accessed on May 3, 2018 at: https:// www.millenniumassessment.org/en/index.html.

Mitchener, H. and Torfs, H. (1996) 'Erosion of mud/sand mixtures', Coastal Engineering, 29(12), pp. 1-25. doi:10.1016/S0378-3839(96)00002-6.

Moeller, I., Spencert, T. and French, J.R. (1996) 'Wind Wave Attenuation over Saltmarsh Surfaces: Preliminary Results from Norfolk, England', Journal of Coastal Research, 12(4), pp. 1009-1016.

Moffett, K., Nardin, W., Silvestri, S., Wang, C. and Temmerman, S. (2015) 'Multiple Stable States and Catastrophic Shifts in Coastal Wetlands: Progress, Challenges, and Opportunities in Validating Theory Using Remote Sensing and Other Methods', Remote Sensing, 7(8), pp. 10184-10226. doi:10.3390/rs70810184. 
Moore, K.A., Jarvis, J.C., 2008. Environmental factors affecting recent summertime eelgrass diebacks in the lower Chesapeake Bay: implications for long-term persistence. J. Coast. Res. 135-147.

Morris, J.T., Barber, D.C., Callaway, J.C., Chambers, R., Hagen, S.C., Hopkinson, C.S., Johnson, B.J., Megonigal, P., Neubauer, S.C., Troxler, T. and Wigand, C. (2016) 'Contributions of organic and inorganic matter to sediment volume and accretion in tidal wetlands at steady state', Earth's Future, 4(4), pp. 110-121. doi:10.1002/2015EF000334.

Morris, J.T. and Haskin, B. (1990) 'A 5-yr Record of Aerial Primary Production and Stand Characteristics of Spartina Alterniflora', Ecology, 71(6), pp. 2209-2217. doi:10.2307/1938633.

Morris, J. T., \& Bowden, W. B. (1986). A mechanistic, numerical model of sedimentation, mineralization, and decomposition for marsh sediments. Soil Science Society of America Journal, 50(1), 96-105. https://doi.org/10.2136/sssaj1986.03615995005000010019x

Morris, J.T., Sundareshwar, P.V., Nietch, C.T., Kjerfve, B. and Cahoon, D.R. (2002) 'RESPONSES OF COASTAL WETLANDS TO RISING SEA LEVEL', Ecology, 83(10), pp. 2869-2877. doi:10.1890/0012-9658(2002)083[2869:ROCWTR]2.0.CO;2.

Mudd, S.M., Howell, S.M. and Morris, J.T. (2009) 'Impact of dynamic feedbacks between sedimentation, sea-level rise, and biomass production on near-surface marsh stratigraphy and carbon accumulation', Estuarine, Coastal and Shelf Science, 82(3), pp. 377-389. doi:10.1016/j.ecss.2009.01.028.

Nixon, S.W. (1980) 'Between Coastal Marshes and Coastal Waters - A Review of Twenty Years of Speculation and Research on the Role of Salt Marshes in Estuarine Productivity and Water Chemistry', in Hamilton, P. and Macdonald, K.B. (eds) Estuarine and Wetland Processes: With Emphasis on Modeling. Boston, MA: Springer US (Marine Science), pp. 437-525. doi:10.1007/978-1-4757-5177-2_20.

Nyman, J.A., Walters, R.J., Delaune, R.D. and Patrick, W.H. (2006) 'Marsh vertical accretion via vegetative growth', Estuarine, Coastal and Shelf Science, 69(3-4), pp. 370-380. doi:10.1016/j.ecss.2006.05.041.

Ortiz, A. C., Roy, S., \& Edmonds, D. A. (2017). Land loss by pond expansion on the Mississippi river delta plain. Geophysical Research Letters, 44, 3635-3642. https://doi.org/10.1002/2017GL073079

Ouyang, X. and Lee, S.Y. (2014) 'Updated estimates of carbon accumulation rates in coastal marsh sediments', Biogeosciences, 11(18), pp. 5057-5071. doi:10.5194/bg-11-50572014.

Peltier, W. R., Argus, D. F., \& Drummond, R. (2015). Space geodesy constrains ice age terminal deglaciation: The global ICE-6G_C (VM5a) model. Journal of Geophysical Research: Solid Earth, 120, 450-487. https://doi.org/10.1002/2014JB011176

Pendleton, L., Donato, D.C., Murray, B.C., Crooks, S., Jenkins, W.A., Sifleet, S., Craft, C., Fourqurean, J.W., Kauffman, J.B., Marbà, N., Megonigal, P., Pidgeon, E., Herr, D., Gordon, D. and Baldera, A. (2012) 'Estimating Global "Blue Carbon” Emissions from Conversion and Degradation of Vegetated Coastal Ecosystems', PLoS ONE. Edited by S. Thrush, 7(9), p. e43542. doi:10.1371/journal.pone.0043542.

Penland, S. (2002) 'Geologic Classification of Coastal Land Loss between 1932 and 1990 in the Mississippi River Delta Plain, Southeastern Louisiana', 52, pp. 799-807. 
Pennings, S. C., Wiçski, K., \& Mahadevan, A. (2009). Rapid headward erosion of marsh creeks in response to relative sea level rise. Geophysical Research Letters, 36, L03602. https://doi.org/10.1029/2008GL036000

Pennington, W., Cambray, R. S., Eakins, J. D., \& Harkness, D. D. (1976). Radionuclide dating of the recent sediments of Blelham Tarn. Freshwater Biology, 6(4), 317-331. https://doi.org/10.1111/j.1365-2427.1976.tb01617.x

Peterson, B.J. and Howarth, R.W. (1987) 'Sulfur, carbon, and nitrogen isotopes used to trace organic matter flow in the salt-marsh estuaries of Sapelo Island, Georgia1', Limnology and Oceanography, 32(6), pp. 1195-1213. doi:10.4319/lo.1987.32.6.1195.

Pethick, J.S. (1981) 'Long-term accretion rates on tidal salt marshes', Journal of Sedimentary Research, 51(2), pp. 571-577. doi:10.1306/212F7CDE-2B24-11D7$8648000102 \mathrm{C} 1865 \mathrm{D}$.

Plante, A.F., Fernández, J.M., Haddix, M.L., Steinweg, J.M. and Conant, R.T. (2011) 'Biological, chemical and thermal indices of soil organic matter stability in four grassland soils', Soil Biology and Biochemistry, 43(5), pp. 1051-1058. doi:10.1016/j.soilbio.2011.01.024.

Plummer, M.L., 2009. Assessing benefit transfer for the valuation of ecosystem services. Front. Ecol. Environ. 7 (1), 38-45.

Portnoy, J.W. (1999) 'Salt Marsh Diking and Restoration: Biogeochemical Implications of Altered Wetland Hydrology', Environmental Management, 24(1), pp. 111-120. doi:10.1007/s002679900219.

PRISM Climate Group, Oregon State University, 2004. http://prism.oregonstate.edu (created 4 Feb 2004).

Redfield, A.C. (1972) 'Development of a New England Salt Marsh', Ecological Monographs, 42(2), pp. 201-237. doi:10.2307/1942263.

Reed, D.J., Spencer, T., Murray, A.L., French, J.R. and Leonard, L. (1999) 'Marsh surface sediment deposition and the role of tidal creeks: Implications for created and managed coastal marshes', Journal of Coastal Conservation, 5(1), pp. 81-90. doi:10.1007/BF02802742.

Reimer, P. J., Brown, T. A., \& Reimer, R. W. (2004). Discussion: Reporting and calibration of post-bomb $\quad{ }^{14} \mathrm{C} \quad$ data. Radiocarbon, $46(3), \quad 1299-1304$. https://doi.org/10.1017/S0033822200033154

Rheuban, J.E., Williamson, S., Costa, J.E., Glover, D.M., Jakuba, R.W., McCorkle, D.C., Neill, C., Williams, T., Doney, S.C., 2016. Spatial and temporal trends in summertime climate and water quality indicators in the coastal embayments of Buzzards Bay, Massachusetts. Biogeosciences 13 (1), 253.

Ribaudo, M.O., Piper, S.L., 1991. Estimating changes in recreational fishing participation from national water quality policies. Water Resour. Res. 27 (7), 1757-1763.

Ricke, K., Drouet, L., Caldeira, K. and Tavoni, M. (2018) 'Country-level social cost of carbon', Nature Climate Change, 8(10), pp. 895-900. doi:10.1038/s41558-018-0282-y.

Riepe, D. (2010) 'Open Marsh Water Management: Impacts on Tidal Wetlands', Memoirs of the Torrey Botanical Society, 26, pp. 80-101.

Roman, C.T. and Burdick, D.M. (2012) Tidal marsh restoration: a synthesis of science and practice. Washington: Island Press.

Rosenheim, B.E., Day, M.B., Domack, E., Schrum, H., Benthien, A. and Hayes, J.M. (2008)

'Antarctic sediment chronology by programmed-temperature pyrolysis: Methodology and 
data treatment: PYROLYSIS OF ANTARCTIC SEDIMENTS', Geochemistry, Geophysics, Geosystems, 9(4), p. n/a-n/a. doi:10.1029/2007GC001816.

Ryther, J.H., 1954. The ecology of phytoplankton blooms in Moriches Bay and Great South Bay, Long Island, New York. Biol. Bull. 106 (2), 198-209.

Sanderman, J. and Grandy, A.S. (2019) Ramped thermal analysis for isolating biologically meaningful soil organic matter fractions with distinct residence times. preprint. Soils and biogeochemical cycling. doi:10.5194/soil-2019-44.

Sanderson, E.W., Foin, T.C. and Ustin, S.L. (2001) 'A simple empirical model of salt marsh plant spatial distributions with respect to a tidal channel network', Ecological Modelling, 139(2-3), pp. 293-307. doi:10.1016/S0304-3800(01)00253-8.

Schepers, L., Kirwan, M., Guntenspergen, G. and Temmerman, S. (2017) 'Spatio-temporal development of vegetation die-off in a submerging coastal marsh: Spatio-temporal marsh die-off', Limnology and Oceanography, 62(1), pp. 137-150. doi:10.1002/lno.10381.

Schile, L.M., Callaway, J.C., Morris, J.T., Stralberg, D., Parker, V.T. and Kelly, M. (2014) 'Modeling Tidal Marsh Distribution with Sea-Level Rise: Evaluating the Role of Vegetation, Sediment, and Upland Habitat in Marsh Resiliency', PLoS ONE. Edited by J. Cebrian, 9(2), p. e88760. doi:10.1371/journal.pone.0088760.

Schuerch, M., Rapaglia, J., Liebetrau, V., Vafeidis, A. and Reise, K. (2012) 'Salt Marsh Accretion and Storm Tide Variation: an Example from a Barrier Island in the North Sea', Estuaries and Coasts, 35(2), pp. 486-500. doi:10.1007/s12237-011-9461-z.

Sessions, A.L. (2006) 'Seasonal changes in D/H fractionation accompanying lipid biosynthesis in Spartina alterniflora', Geochimica et Cosmochimica Acta, 70(9), pp. 2153-2162. doi:10.1016/j.gca.2006.02.003.

Shepard, C.C., Crain, C.M. and Beck, M.W. (2011) 'The Protective Role of Coastal Marshes: A Systematic Review and Meta-analysis', PLoS ONE. Edited by J. Clifton, 6(11), p. e27374. doi:10.1371/journal.pone.0027374.

Shriver, A.C., Carmichael, R.H., Valiela, I., 2002. Growth, condition, reproductive potential, and mortality of bay scallops, Argopecten irradians, in response to eutrophic driven changes in food resources. J. Exp. Mar. Biol. Ecol. 279 (1), 21-40.

Sollins, P., Swanston, C., Kleber, M., Filley, T., Kramer, M., Crow, S., et al. (2006). Organic C and $\mathrm{N}$ stabilization in a forest soil: Evidence from sequential density fractionation. Soil Biology and Biochemistry, 38(11), 3313-3324. https://doi.org/10.1016/j.soilbio.2006.04.014

Spivak, A. and Ossolinski, J. (2016) 'Limited effects of nutrient enrichment on bacterial carbon sources in salt marsh tidal creek sediments', Marine Ecology Progress Series, 544, pp. 107-130. doi:10.3354/meps11587.

Spivak, A.C. (2015) 'Benthic biogeochemical responses to changing estuary trophic state and nutrient availability: A paired field and mesocosm experiment approach: Trophic history alters benthic processes', Limnology and Oceanography, 60(1), pp. 3-21. doi:10.1002/lno.10001.

Spivak, A.C., Denmark, A., Gosselin, K.M. and Sylva, S.P. (2020) 'Salt Marsh Pond Biogeochemistry Changes Hourly-to-Yearly but Does Not Scale With Dimensions or Geospatial Position', Journal of Geophysical Research: Biogeosciences, 125(10). doi:10.1029/2020JG005664.

Spivak, A.C., Gosselin, K., Howard, E., Mariotti, G., Forbrich, I., Stanley, R. and Sylva, S.P. (2017) 'Shallow ponds are heterogeneous habitats within a temperate salt marsh 
ecosystem', Journal of Geophysical Research: Biogeosciences, 122(6), pp. 1371-1384. doi:10.1002/2017JG003780.

Spivak, A.C., Gosselin, K.M. and Sylva, S.P. (2018) 'Shallow ponds are biogeochemically distinct habitats in salt marsh ecosystems', Limnology and Oceanography, 63(4), pp. 1622-1642. doi:10.1002/lno.10797.

Spivak, A.C., Sanderman, J., Bowen, J.L., Canuel, E.A. and Hopkinson, C.S. (2019) 'Globalchange controls on soil-carbon accumulation and loss in coastal vegetated ecosystems', Nature Geoscience, 12(9), pp. 685-692. doi:10.1038/s41561-019-0435-2.

Stearns, L.A. and MacCreary, D. (1936) 'Mosquito work in Delaware during 1933', Proc. N.J. Mosq. Exterm. Comm., 22, pp. 128-136.

Tobias, C. and Neubauer, S.C. (2019) 'Salt Marsh Biogeochemistry-An Overview', in Coastal Wetlands. Elsevier, pp. 539-596. doi:10.1016/B978-0-444-63893-9.00016-2.

Torn, M.S., Swanston, C.W., Castanha, C. and Trumbore, S.E. (2009) 'Storage and Turnover of Organic Matter in Soil', in Senesi, N., Xing, B., and Huang, P.M. (eds) BiophysicoChemical Processes Involving Natural Nonliving Organic Matter in Environmental Systems. Hoboken, NJ, USA: John Wiley \& Sons, Inc., pp. 219-272. doi:10.1002/9780470494950.ch6.

Trumbore, S. (2009) 'Radiocarbon and Soil Carbon Dynamics', Annual Review of Earth and Planetary Sciences, 37(1), pp. 47-66. doi:10.1146/annurev.earth.36.031207.124300.

Trumbore, S.E. (1997) 'Potential responses of soil organic carbon to global environmental change', Proceedings of the National Academy of Sciences, 94(16), pp. 8284-8291. doi:10.1073/pnas.94.16.8284.

Turner, R.E., Swenson, E.M. and Milan, C.S. (2002) 'Organic and Inorganic Contributions to Vertical Accretion in Salt Marsh Sediments', in Weinstein, M.P. and Kreeger, D.A. (eds) Concepts and Controversies in Tidal Marsh Ecology. Dordrecht: Kluwer Academic Publishers, pp. 583-595. doi:10.1007/0-306-47534-0_27.

Valiela, I., Costa, J.E., 1988. Eutrophication of Buttermilk Bay, a Cape Cod coastal embayment: concentrations of nutrients and watershed nutrient budgets. Environ. Manag. 12 (4), 539553.

Van Allen, R., Schreiner, K.M., Guntenspergen, G. and Carlin, J. (2021) 'Changes in organic carbon source and storage with sea level rise-induced transgression in a Chesapeake Bay marsh', Estuarine, Coastal and Shelf Science, 261, p. 107550. doi:10.1016/j.ecss.2021.107550.

Vincent, R.E., Burdick, D.M. and Dionne, M. (2013) 'Ditching and Ditch-Plugging in New England Salt Marshes: Effects on Hydrology, Elevation, and Soil Characteristics', Estuaries and Coasts, 36(3), pp. 610-625. doi:10.1007/s12237-012-9583-y.

Vincent, R.E., Dionne, M., Burdick, D.M. and Hobbie, E.A. (2015) 'Fish Productivity and Trophic Transfer in Created and Naturally Occurring Salt Marsh Habitat', Estuaries and Coasts, 38(4), pp. 1233-1250. doi:10.1007/s12237-015-9969-8.

Viso, A.-C. and Marty, J.-C. (1993) 'Fatty acids from 28 marine microalgae', Phytochemistry, 34(6), pp. 1521-1533. doi:10.1016/S0031-9422(00)90839-2.

Vitousek, P.M., Mooney, H.A., Lubchenco, J. and Melillo, J.M. (1997) 'Human Domination of Earth's Ecosystems', Science, 277(5325), pp. 494-499.

Volkman, J.K., Jeffrey, S.W., Nichols, P.D., Rogers, G.I. and Garland, C.D. (1989) 'Fatty acid and lipid composition of 10 species of microalgae used in mariculture', Journal of 
Experimental Marine Biology and Ecology, 128(3), pp. 219-240. doi:10.1016/00220981(89)90029-4.

Volkman, J.K., Johns, R.B., Gillan, F.T., Perry, G.J. and Bavor, H.J. (1980) 'Microbial lipids of an intertidal sediment-I. Fatty acids and hydrocarbons', Geochimica et Cosmochimica Acta, 44(8), pp. 1133-1143. doi:10.1016/0016-7037(80)90067-8.

Walling, D.E. and Quine, T.A. (1994) 'Use of fallout radionuclide measurements in soil erosion investigations', Proceedings of an international symposium held in Vienna, pp. 17-21.

Walsh, P.J., Milon, J.W., 2016. Nutrient standards, water quality indicators, and economic benefits from water quality regulations. Environ. Resour. Econ. 64 (4), 643-661.

Wang, C. and Temmerman, S. (2013) 'Does biogeomorphic feedback lead to abrupt shifts between alternative landscape states?: An empirical study on intertidal flats and marshes: SHIFTS BETWEEN INTERTIDAL FLAT AND MARSH', Journal of Geophysical Research: Earth Surface, 118(1), pp. 229-240. doi:10.1029/2012JF002474.

Wang, X.-C., Chen, R.F. and Berry, A. (2003) 'Sources and preservation of organic matter in Plum Island salt marsh sediments (MA, USA): long-chain n-alkanes and stable carbon isotope compositions', Estuarine, Coastal and Shelf Science, 58(4), pp. 917-928. doi:10.1016/j.ecss.2003.07.006.

Watson, E.B., Wigand, C., Davey, E.W., Andrews, H.M., Bishop, J. and Raposa, K.B. (2017) 'Wetland Loss Patterns and Inundation-Productivity Relationships Prognosticate Widespread Salt Marsh Loss for Southern New England', Estuaries and Coasts, 40(3), pp. 662-681. doi:10.1007/s12237-016-0069-1.

Weston, N. B. (2014). Declining sediments and rising seas: An unfortunate convergence for tidal wetlands. Estuaries and Coasts, 37(1), 1-23. https://doi.org/10.1007/s12237-013-9654-8

Whigham, D.F., O’Neill, J.P. and McWethy, M. (1982) 'Effect of Thre Marsh Management Techqniues on the Ecology of Irregularly Flooded Chesapeake Bay Wetlans', p. 309.

Wiberg, P.L. and Sherwood, C.R. (2008) 'Calculating wave-generated bottom orbital velocities from surface-wave parameters', Computers \& Geosciences, 34(10), pp. 1243-1262. doi:10.1016/j.cageo.2008.02.010.

Williams, E.K. and Rosenheim, B.E. (2015) 'What happens to soil organic carbon as coastal marsh ecosystems change in response to increasing salinity? An exploration using ramped pyrolysis', Geochemistry, Geophysics, Geosystems, 16(7), pp. 2322-2335. doi:10.1002/2015GC005839.

Williams, T., Neill, C., 2014. Buzzards Bay Coalition Citizens' Water Quality Monitoring Program, "Baywatchers", 5 Year Quality Assurance Project Plan.

Williamson, S.C., Rheuban, J.E., Costa, J.E., Glover, D.M., Doney, S.C., 2017. Assessing the impact of local and regional influences on nitrogen loads to Buzzards Bay, MA. Front. Mar. Sci. 3, 279.

Wilson, B.J., Servais, S., Charles, S.P., Davis, S.E., Gaiser, E.E., Kominoski, J.S., Richards, J.H. and Troxler, T.G. (2018) 'Declines in Plant Productivity Drive Carbon Loss from Brackish Coastal Wetland Mesocosms Exposed to Saltwater Intrusion', Estuaries and Coasts, 41(8), pp. 2147-2158. doi:10.1007/s12237-018-0438-z.

Wilson, C.A., Hughes, Z.J., FitzGerald, D.M., Hopkinson, C.S., Valentine, V. and Kolker, A.S. (2014a) 'Saltmarsh pool and tidal creek morphodynamics: Dynamic equilibrium of northern latitude saltmarshes?', Geomorphology, 213, pp. 99-115.

doi:10.1016/j.geomorph.2014.01.002. 
Wilson, C.A., Hughes, Z.J., FitzGerald, D.M., Hopkinson, C.S., Valentine, V. and Kolker, A.S. (2014b) 'Saltmarsh pool and tidal creek morphodynamics: Dynamic equilibrium of northern latitude saltmarshes?', Geomorphology, 213, pp. 99-115.

doi:10.1016/j.geomorph.2014.01.002.

Wilson, K.R., Kelley, J.T., Croitoru, A., Dionne, M., Belknap, D.F. and Steneck, R. (2009) 'Stratigraphic and Ecophysical Characterizations of Salt Pools: Dynamic Landforms of the Webhannet Salt Marsh, Wells, ME, USA', Estuaries and Coasts, 32(5), pp. 855-870. doi:10.1007/s 12237-009-9203-7.

Wilson, K.R., Kelley, J.T., Tanner, B.R. and Belknap, D.F. (2010) 'Probing the Origins and Stratigraphic Signature of Salt Pools from North-Temperate Marshes in Maine, U.S.A', Journal of Coastal Research, 26, pp. 1007-1026. doi:10.2112/JCOASTRES-D-1000007.1.

Wold, S., Sjöström, M., Eriksson, L., 2001. PLS-regression: a basic tool of chemometrics. Chemom. Intell. Lab. Syst. 58 (2), 109-130.

Young, I. and Verhagan, L. (1996) 'The growth of fetch limited waves in water of finite depth. Part 1: Total energy and peak frequency', Coastal Engineering, 27, pp. 47-78. doi:10.1016/S0378-3839(96)00006-3. 